\title{
The renin-angiotensin system in the hypertensive kidney
}

Citation for published version (APA):

van Twist, D. (2016). The renin-angiotensin system in the hypertensive kidney: clinical studies in patients with essential hypertension, fibromuscular dysplasia, and the atherosclerotic renal artery stenosis . [Doctoral Thesis, Maastricht University]. https://doi.org/10.26481/dis.20160629dt

Document status and date:

Published: 01/01/2016

DOI:

$10.26481 /$ dis.20160629dt

Document Version:

Publisher's PDF, also known as Version of record

\section{Please check the document version of this publication:}

- A submitted manuscript is the version of the article upon submission and before peer-review. There can be important differences between the submitted version and the official published version of record.

People interested in the research are advised to contact the author for the final version of the publication, or visit the DOI to the publisher's website.

- The final author version and the galley proof are versions of the publication after peer review.

- The final published version features the final layout of the paper including the volume, issue and page numbers.

Link to publication

\footnotetext{
General rights rights.

- You may freely distribute the URL identifying the publication in the public portal. please follow below link for the End User Agreement:

www.umlib.nl/taverne-license

Take down policy

If you believe that this document breaches copyright please contact us at:

repository@maastrichtuniversity.nl

providing details and we will investigate your claim.
}

Copyright and moral rights for the publications made accessible in the public portal are retained by the authors and/or other copyright owners and it is a condition of accessing publications that users recognise and abide by the legal requirements associated with these

- Users may download and print one copy of any publication from the public portal for the purpose of private study or research.

- You may not further distribute the material or use it for any profit-making activity or commercial gain

If the publication is distributed under the terms of Article $25 \mathrm{fa}$ of the Dutch Copyright Act, indicated by the "Taverne" license above, 
The renin-angiotensin system in the hypertensive kidney

Clinical studies in patients with essential hypertension, fibromuscular dysplasia, and atherosclerotic renal artery stenosis 
(C) 2016, Daan van Twist, Echt.

No part of this book may be reproduced or transmitted in any form or by any means, without prior permission in writing by the author, or when appropriate, by the publishers of the publications.

Layout: Tiny Wouters.

Cover picture: Arthimedes/Shutterstock.

Production: Ipskamp Drukkers B.V..

ISBN: 978-94-028-0191-0

Printing and distribution of this thesis was financially supported by Amgen B.V., Astellas Pharma B.V., and Pfizer B.V.. 


\section{The renin-angiotensin system in the hypertensive kidney}

Clinical studies in patients with essential hypertension, fibromuscular dysplasia, and atherosclerotic renal artery stenosis

\section{PROEFSCHRIFT}

ter verkrijging van de graad van doctor aan de Universiteit Maastricht, op gezag van de Rector Magnificus, Prof. dr. L.L.G. Soete

volgens het besluit van het College van Decanen,

in het openbaar te verdedigen op woensdag 29 juni 2016, om 14.00 uur.

door

Daniël Johanna Leonardus van Twist 
Promotores:

Prof. dr. P.W. de Leeuw

Prof. dr. A.A. Kroon

\section{Copromotor:}

Dr. A.J.H.M. Houben

\section{Beoordelingscommissie:}

Prof. dr. T. Unger (voorzitter)

Prof. dr. A.H.J. Danser, Erasmus Universiteit, Rotterdam

Prof. dr. A. Persu, Université Catholique de Louvain, Brussel, België

Dr. L.J. Schurgers

Prof. dr. J.E. Wildberger 


\section{Contents}

$\begin{array}{lll}\text { Chapter } 1 & \text { Introduction and outline of this thesis } & 7\end{array}$

Chapter 2 Angiotensin-(1-7) induced renal vasodilation in hypertensive $\quad 17$

humans is attenuated by low sodium intake and

angiotensin II co-infusion

Chapter 3 Angiotensin-(1-7)-induced renal vasodilation is reduced in

human kidneys with renal artery stenosis

Chapter 4 Angiotensin-(1-7) as a strategy in the treatment

of hypertension?

Chapter 5 Acute eprosartan-induced intrarenal vasodilation in hypertensive humans is not influenced by dietary sodium intake or angiotensin II co-infusion

Chapter 6 Renal hemodynamics and renin-angiotensin system activity in humans with multifocal renal artery fibromuscular dysplasia

Chapter 7 Pathophysiological differences between multifocal fibromuscular dysplasia and atherosclerotic renal artery stenosis

Chapter 8 General discussion

Summary

Nederlandstalige samenvatting

Valorization addendum

Dankwoord

Curriculum vitae

List of publications 

Chapter 1

Introduction and outline of this thesis 


\section{Introduction and outline of this thesis}

Hypertension, currently affecting more than 1 billion people worldwide, ${ }^{1,2}$ is the most important risk factor for the development of cardiovascular diseases. ${ }^{3}$ These diseases, such as myocardial infarction and stroke, are still the leading cause of death worldwide. ${ }^{4}$ Therefore, hypertension is the main individual risk factor for death and burden of disease. ${ }^{5}$ Unfortunately, the global incidence of hypertension is rising, ${ }^{1}$ which will probably lead to an even higher incidence of cardiovascular diseases over the coming years. Although it has been known for decades that mortality and incidence of cardiovascular diseases can be reduced by lowering blood pressure with antihypertensive drugs, ${ }^{6,7}$ appropriate treatment of hypertension apparently continues to be difficult as blood pressure remains above goal in more than $50 \%$ of the patients with hypertension. ${ }^{8,9}$ Therefore, research on pathophysiological mechanisms in the regulation of blood pressure and development of new therapeutic strategies is still of great importance.

\section{The renin-angiotensin system}

One of the most important systems in the regulation of blood pressure and tissue blood flow is the renin-angiotensin system. This system, a complex endocrine cascade that was already discovered in $1898,{ }^{10}$ is nowadays considered the main target in the treatment of hypertension and prevention of cardiovascular disease. ${ }^{11}$ The kidney is the key activator and effector of the renin-angiotensin system. In short, the macula densa in the renal arterioles proximal to the glomerulus detects changes in arterial blood pressure and distal tubular sodium delivery. In case of decreased blood pressure or decreased sodium delivery the juxtaglomerular cells release an enzyme: renin. ${ }^{12}$ Renin cleaves the peptide angiotensinogen into the 10 amino-acid peptide angiotensin I, which on its turn is cleaved into the eight amino-acid peptide angiotensin II (Ang II) by angiotensin-converting enzyme (ACE). Ang II is the effector of this cascade and stimulates the angiotensin-type 1-receptor $\left(A T_{1} R\right)$, which results in vasoconstriction, sodium retention, and, eventually, an increase in blood pressure (Figure 1.1, left panel). In this way the renin-angiotensin system maintains the blood pressure at a stable level in case of an acute event such as dehydration or bleeding. Hereby it prevents insufficient perfusion of vital organs which could cause tissue damage or organ failure. However, in case of unnecessary long-term activation (i.e. in the absence of dehydration or bleeding), the renin-angiotensin system induces several adverse effects: stimulation of the $A T_{1} R$ by Ang II induces hypertension, endothelial dysfunction, inflammation, fibrosis, and chronic kidney failure. Therefore, current pharmacotherapeutic strategies targeting the renin-angiotensin system are based on inhibition of the production of Ang II (such as ACE-inhibitors and direct renin inhibitors) or preventing stimulation of the $A T_{1} R$ by $A n g$ II ( $A T_{1} R$ blockers). ${ }^{13}$ 
Figure 1.1 The renin angiotensin system.

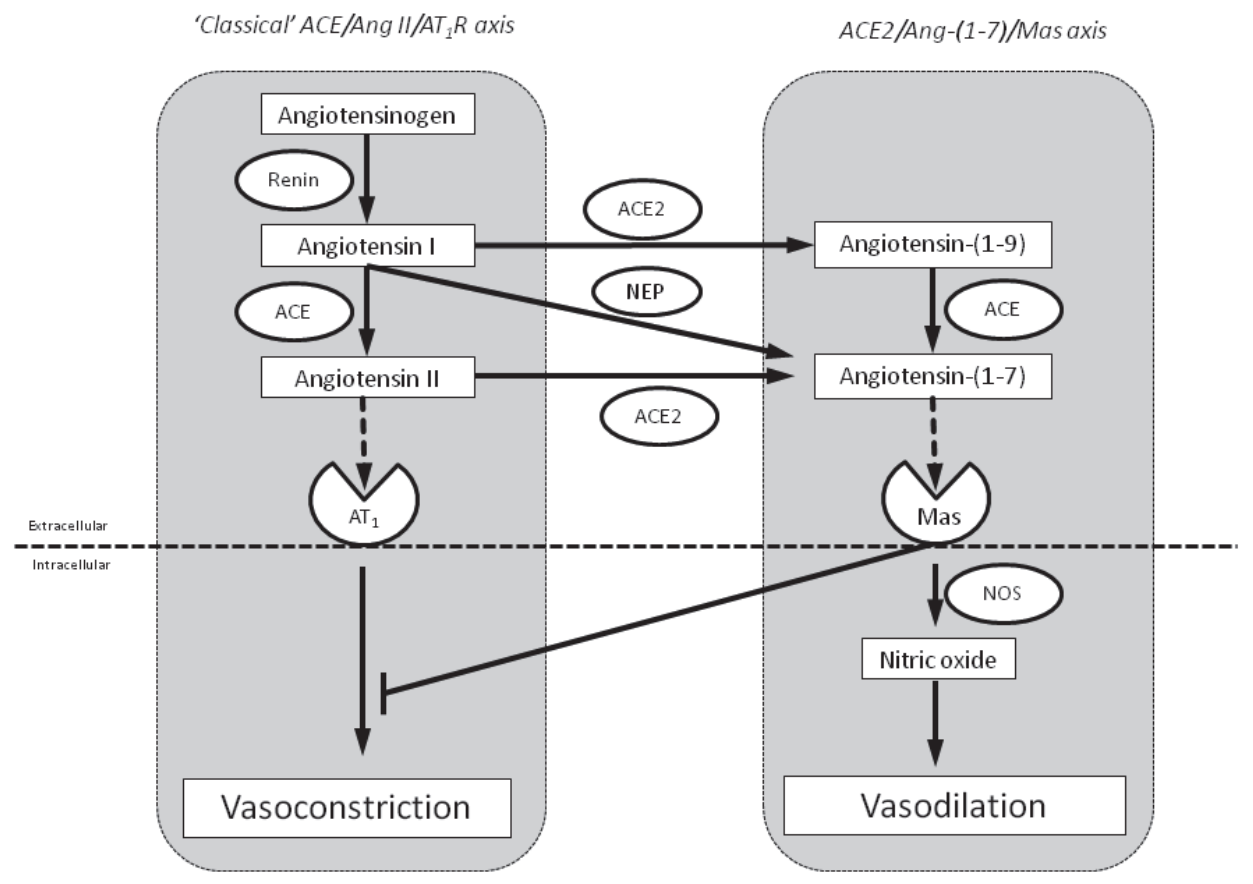

Simplified overview of the renin-angiotensin system with the classical ACE/Ang II/AT $R$ axis on the left side and the ACE2/Ang-(1-7)/MasR on the right side. ACE indicates angiotensin converting enzyme; ACE2, angiotensin converting enzyme 2 ; NEP, neutral endopeptidase and neprilysin; $A T_{1} R$, angiotensin II type-1 receptor; NOS, nitric oxide synthase.

\section{Angiotensin-(1-7)}

Over the past decade more and more studies showed that the renin-angiotensin system is far more complex than the 'classical' $A C E / A n g ~ I I / A T_{1} R$ axis. Several enzymes have been discovered that degrade Ang I and Ang II into other angiotensins. ${ }^{14}$ One of these angiotensins is angiotensin-(1-7) [Ang-(1-7)], a seven-amino acid peptide that is present in the plasma in levels comparable to those of Ang $\mathrm{II} .{ }^{15} \mathrm{It}$ is closely related to the classical ACE/Ang II/AT ${ }_{1} R$ axis as the enzymes producing Ang-(1-7) use other angiotensins as its substrate (Figure 1). ACE-homologue ACE2 is the most important enzyme and produces Ang-(1-7) by cleaving the C-terminal phenylalanine residue from Ang II. ${ }^{14}$ Ang-(1-7) is also produced out of Ang I and Ang-(1-9) by other enzymes, but these pathways are of less importance. Ang-(1-7) stimulates its own receptor: the Masreceptor. ${ }^{16}$ Several studies demonstrated that Mas-receptor stimulation by Ang-(1-7) results in potent vasodilation, ${ }^{16,17,18}$ which suggests that Ang-(1-7) could become a 
future target in the treatment of hypertension and prevention of cardiovascular disease. Unfortunately the available data on the effects of Ang-(1-7) are limited to studies using animal models or human forearm vasculature, ${ }^{17,18}$ without knowledge on the effects in clinically more important vascular beds such as the kidney.

\section{Renovascular hypertension}

Renovascular hypertension is, next to low blood pressure and low sodium intake, another typical cause of renin-angiotensin system activation. The underlying mechanisms in renovascular hypertension have been extensively studied in animal models. ${ }^{19}$ In the so-called two-kidney-one-clip animal model, a clip is placed around the renal artery, thereby decreasing renal blood flow and blood pressure in the distal part of the vessel. Similar to conditions such as dehydration or bleeding this fall in pressure is detected by the juxtaglomerular apparatus. As a result renin secretion increases, inducing vasoconstriction and sodium retention, which finally leads to hypertension. Such model differs considerably from the situation in humans, in whom renovascular abnormalities almost always develop slowly (instead of acute as in the two-kidney-one-clip animal model) and very often occur bilateral.

In humans, renovascular hypertension is most often caused by atherosclerotic renal artery stenosis (Figure 1.2), which generally occurs in older patients who already have atherosclerosis in other vascular beds (e.g. peripheral vascular disease or coronary artery disease) and is associated with the classical risk factors for atherosclerosis such as smoking, dyslipidemia, and hyperglycemia. ${ }^{20}$ In the presence of a chronic atherosclerotic renal artery stenosis, several changes in the renal microvasculature distal to the renal artery stenosis occur, resulting in fibrosis and loss of function. ${ }^{20}$ Over the past years, several studies have evaluated the effects of restoring the patency of renal arteries, either by balloon angioplasty or surgical intervention. Although tremendous effects were observed in two-kidney-one clip animal models, large human studies were rather disappointing: revascularization appeared not to be superior to treatment with antihypertensive drugs with regard to blood pressure lowering effect and long-term preservation of kidney function, ${ }^{21-23}$ presumably as a result of the abovementioned microvascular changes. 


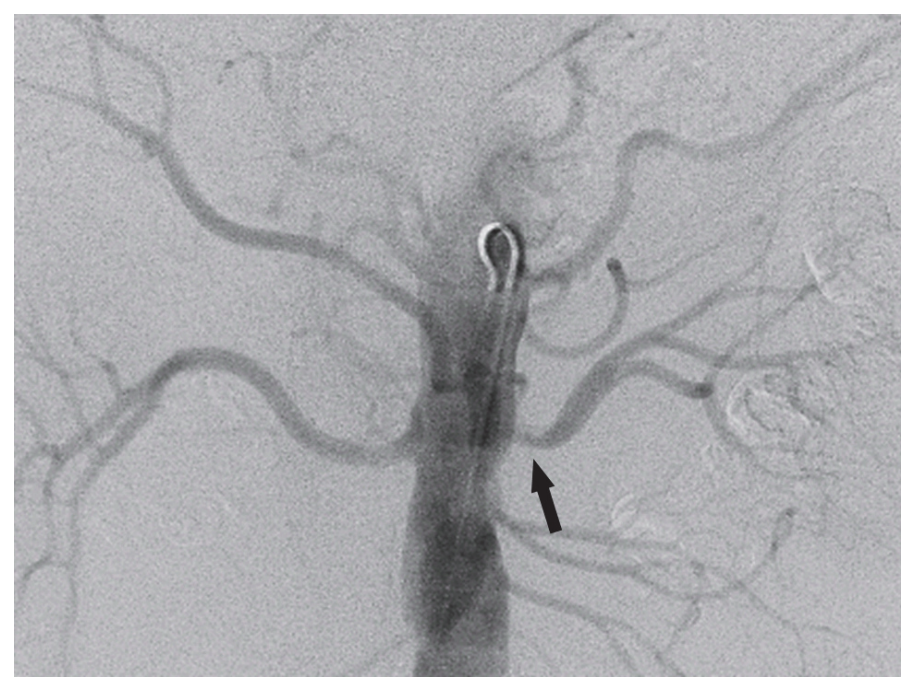

Angiographic image of left-sided atherosclerotic renal artery stenosis (arrow). A catheter is positioned in the abdominal aorta. Note the typical post-stenotic dilation and the atherosclerotic changes in the abdominal aorta.

\section{Fibromuscular dysplasia}

The second most common cause of renovascular hypertension is fibromuscular dysplasia. This disease can lead to hypertension at young age and is defined as an idiopathic, segmental, non-atherosclerotic, non-inflammatory disease of the musculature of arterial walls, leading to stenosis of small and medium-sized arteries. ${ }^{24}$ The most common form is the multifocal type, which is characterized by a typical "string-of-beads" appearance (Figure 1.3) and is caused by thickening of the medial layer of the arterial wall. In contrast to atherosclerotic renal artery stenosis, fibromuscular dysplasia is known for its fairly good blood pressure response to revascularization: balloon angioplasty or surgical revascularization of the renal artery results in a substantial decrease in blood pressure (with a stable or lower number of antihypertensive drugs) in the majority of patients with fibromuscular dysplasia. ${ }^{25}$ Thus far, it is assumed that the mechanisms that lead to hypertension in patients with renal artery fibromuscular dysplasia are similar to those in animal models and humans with atherosclerotic renal artery stenosis. However, hardly any studies evaluated the reninangiotensin system and the renal microvasculature in kidneys with fibromuscular dysplasia. 


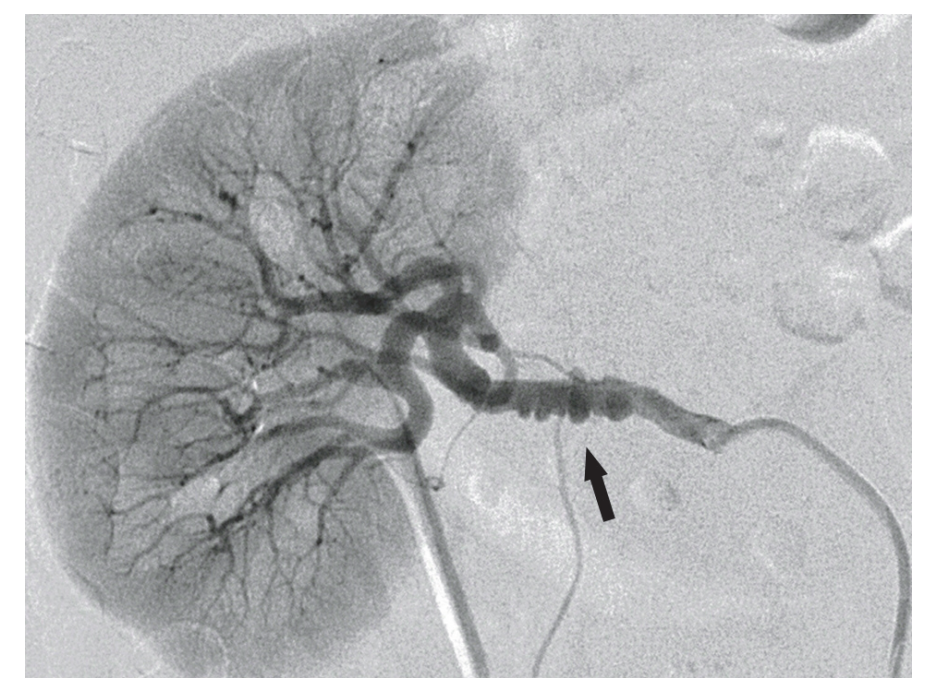

Typical angiographic image of multifocal fibromuscular dysplasia of the right kidney. A catheter is positioned in the renal artery. Note the typical string-of-beads appearance of the renal artery (arrow).

\section{Outline of this thesis}

In this thesis we aimed to answer several questions with regard to several new and older concepts on the renin-angiotensin system and the kidney in patients with hypertension.

As previously mentioned, human studies in clinically important vascular beds on Ang(1-7) are lacking. Therefore, in Chapter 2, we evaluated the effects of Ang-(1-7) on renal blood flow in kidneys of humans with essential hypertension. We hypothesized that Ang-(1-7) would increase renal blood flow in hypertensive humans as well. In addition, we questioned whether renin-angiotensin system activation has any influence on the effect of Ang-(1-7). For that reason, various states of reninangiotensin system activation were imposed by restriction of dietary sodium intake (inducing endogenous renin-angiotensin system activation) and/or co-infusion of Ang II (increasing Ang II availability).

In Chapter 3 we evaluated the effect of Ang-(1-7) on renal blood flow in kidneys with atherosclerotic renal artery stenosis. As the renin-angiotensin system is activated in the presence of atherosclerotic renal artery stenosis, we hypothesized that the effect of Ang-(1-7) would be decreased in those kidneys. Additionally, as renin-angiotensin system activity may differ between the stenotic and non-stenotic kidney in case of unilateral renal artery stenosis, we tested whether the effects of Ang-(1-7) differ 
between the affected and non-affected kidney in patients with unilateral renal artery stenosis.

In Chapter 4 we evaluated the potential of using the ACE2/Ang-(1-7)/Mas-axis as a therapeutic target. Based on several promising results in animal studies, this axis could be a future target for the treatment of hypertension and chronic kidney disease. Several potential drug therapies (all under development) are discussed here.

Given the influence of sodium intake and Ang II co-infusion on the vasodilatory effects of Ang-(1-7) (Chapter 2), we questioned in Chapter 5 whether variations in reninangiotensin system-activity would also influence the vasodilatory effect of intrarenal $\mathrm{AT}_{1} \mathrm{R}$-blockade. As endogenous production of Ang $\mathrm{II}$ is higher during renin-angiotensin system activation, we hypothesized that the effect of $A T_{1} R$-blockade would be greater in patients receiving a low sodium diet and that Ang II co-infusion would attenuate the effect of $A T_{1} R$-blockade. Therefore, we infused $A T_{1} R$-blocker eprosartan in kidneys of patients with essential hypertension. Again, we imposed various states of reninangiotensin system activation by varying sodium intake and/or co-infusion of Ang II.

In Chapter 6 we evaluated the renin-angiotensin system and renal microvasculature in kidneys with fibromuscular dysplasia. Given the relatively good results of revascularization in fibromuscular dysplasia, we hypothesized that renal microvascular function is preserved in kidneys with fibromuscular dysplasia. We also hypothesized that the renin-angiotensin system is relatively intact in these kidneys. To evaluate this, we studied the effects of either blockade or stimulation of the ACE/Ang II/AT ${ }_{1} \mathrm{R}$ axis or the ACE2/Ang-(1-7)/MasR axis in kidneys with fibromuscular dysplasia and compared it to the effects in patients with essential hypertension.

In Chapter $\mathbf{7}$ we evaluated whether the involved pathophysiological mechanisms in hypertension due to fibromuscular dysplasia are similar to those in atherosclerotic renal artery stenosis. As several differences between fibromuscular dysplasia and atherosclerotic renal artery stenosis have been demonstrated previously (patients with fibromuscular dysplasia are generally younger, less exposed to classical cardiovascular risk factors such as smoking or hypercholesterolemia, and, most importantly, the blood pressure response to revascularization is substantially better in fibromuscular dysplasia) we hypothesized that the involved mechanisms are different. To answer this question we evaluated differences in renal blood flow, renin secretion, and the relationship with blood pressure between patients with fibromuscular dysplasia and patients with atherosclerotic renal artery stenosis. 


\section{References}

1. Kearney PM, Whelton M, Reynolds K, Muntner P, Whelton PK, He J. Global burden of hypertension: Analysis of worldwide data. Lancet. 2005;365:217-223

2. Go AS, Mozaffarian D, Roger VL, Benjamin EJ, Berry JD, Blaha MJ, Dai S, Ford ES, Fox CS, Franco S, Fullerton HJ, Gillespie C, Hailpern SM, Heit JA, Howard VJ, Huffman MD, Judd SE, Kissela BM, Kittner SJ, Lackland DT, Lichtman JH, Lisabeth LD, Mackey RH, Magid DJ, Marcus GM, Marelli A, Matchar DB, McGuire DK, Mohler ER, 3rd, Moy CS, Mussolino ME, Neumar RW, Nichol G, Pandey DK, Paynter NP, Reeves MJ, Sorlie PD, Stein J, Towfighi A, Turan TN, Virani SS, Wong ND, Woo D, Turner MB. Heart disease and stroke statistics--2014 update: A report from the american heart association. Circulation. 2014;129:e28-e292

3. Allen N, Berry JD, Ning H, Van Horn L, Dyer A, Lloyd-Jones DM. Impact of blood pressure and blood pressure change during middle age on the remaining lifetime risk for cardiovascular disease: The cardiovascular lifetime risk pooling project. Circulation. 2012;125:37-44

4. Lozano R, Naghavi M, Foreman K, Lim S, Shibuya K, et al. Global and regional mortality from 235 causes of death for 20 age groups in 1990 and 2010: A systematic analysis for the global burden of disease study 2010. Lancet. 2012;380:2095-2128

5. Ezzati M, Riboli E. Behavioral and dietary risk factors for noncommunicable diseases. $N$ Engl J Med. 2013;369:954-964

6. Effects of treatment on morbidity in hypertension. Results in patients with diastolic blood pressures averaging 115 through $129 \mathrm{~mm}$ hg. JAMA. 1967;202:1028-1034

7. van Vark LC, Bertrand M, Akkerhuis KM, Brugts JJ, Fox K, Mourad JJ, Boersma E. Angiotensinconverting enzyme inhibitors reduce mortality in hypertension: A meta-analysis of randomized clinical trials of renin-angiotensin-aldosterone system inhibitors involving 158,998 patients. Eur Heart J. 2012;33:2088-2097

8. Banegas JR, Lopez-Garcia E, Dallongeville J, Guallar E, Halcox JP, Borghi C, Masso-Gonzalez EL, Jimenez FJ, Perk J, Steg PG, De Backer G, Rodriguez-Artalejo F. Achievement of treatment goals for primary prevention of cardiovascular disease in clinical practice across europe: The eurika study. Eur Heart $J$. 2011;32:2143-2152

9. Prugger C, Keil U, Wellmann J, de Bacquer D, de Backer G, Ambrosio GB, Reiner Z, Gaita D, Wood D, Kotseva K, Heidrich J, Group EIS. Blood pressure control and knowledge of target blood pressure in coronary patients across europe: Results from the euroaspire iii survey. J Hypertens. 2011;29:16411648

10. Tigerstedt R, Bergman P. Niere und kreislauf. Skand Arch Physiol. 1898;8:223-271

11. Mancia G, Fagard R, Narkiewicz K, Redon J, Zanchetti A, Bohm M, Christiaens T, Cifkova R, De Backer G, Dominiczak A, Galderisi M, Grobbee DE, Jaarsma T, Kirchhof P, Kjeldsen SE, Laurent S, Manolis AJ, Nilsson PM, Ruilope LM, Schmieder RE, Sirnes PA, Sleight P, Viigimaa M, Waeber B, Zannad F. 2013 esh/esc guidelines for the management of arterial hypertension: The task force for the management of arterial hypertension of the european society of hypertension (esh) and of the european society of cardiology (esc). J Hypertens. 2013;31:1281-1357

12. Castrop H, Hocherl K, Kurtz A, Schweda F, Todorov V, Wagner C. Physiology of kidney renin. Physiol Rev. 2010;90:607-673

13. Robles NR, Cerezo I, Hernandez-Gallego R. Renin-angiotensin system blocking drugs. J Cardiovasc Pharmacol Ther. 2014;19:14-33

14. Velez JC, lerardi JL, Bland AM, Morinelli TA, Arthur JM, Raymond JR, Janech MG. Enzymatic processing of angiotensin peptides by human glomerular endothelial cells. Am J Physiol Renal Physiol. 2012;302:F1583-1594

15. Joyner J, Neves LA, Granger JP, Alexander BT, Merrill DC, Chappell MC, Ferrario CM, Davis WP, Brosnihan KB. Temporal-spatial expression of ang-(1-7) and angiotensin-converting enzyme 2 in the kidney of normal and hypertensive pregnant rats. Am J Physiol Regul Integr Comp Physiol. 2007;293:R169-177

16. Ferreira AJ, Santos RA, Bradford CN, Mecca AP, Sumners C, Katovich MJ, Raizada MK. Therapeutic implications of the vasoprotective axis of the renin-angiotensin system in cardiovascular diseases. Hypertension. 2010;55:207-213 
17. Sasaki S, Higashi Y, Nakagawa K, Matsuura H, Kajiyama G, Oshima T. Effects of angiotensin-(1-7) on forearm circulation in normotensive subjects and patients with essential hypertension. Hypertension. 2001;38:90-94

18. van der Wouden EA, Ochodnicky P, van Dokkum RP, Roks AJ, Deelman LE, de Zeeuw D, Henning RH. The role of angiotensin(1-7) in renal vasculature of the rat. J Hypertens. 2006;24:1971-1978

19. Ploth DW. Angiotensin-dependent renal mechanisms in two-kidney, one-clip renal vascular hypertension. Am J Physiol. 1983;245:F131-141

20. Textor SC, Lerman L. Renovascular hypertension and ischemic nephropathy. Am J Hypertens. 2010;23:1159-1169

21. Cooper CJ, Murphy TP, Cutlip DE, Jamerson K, Henrich W, Reid DM, Cohen DJ, Matsumoto AH, Steffes M, Jaff MR, Prince MR, Lewis EF, Tuttle KR, Shapiro Jl, Rundback JH, Massaro JM, D'Agostino RB, Sr., Dworkin LD, Investigators $C$. Stenting and medical therapy for atherosclerotic renal-artery stenosis. $N$ Engl J Med. 2014;370:13-22

22. Riaz IB, Husnain M, Riaz H, Asawaeer M, Bilal J, Pandit A, Shetty R, Lee KS. Meta-analysis of revascularization versus medical therapy for atherosclerotic renal artery stenosis. Am J Cardiol. 2014;114:1116-1123

23. Wheatley K, Ives N, Gray R, Kalra PA, Moss JG, Baigent C, Carr S, Chalmers N, Eadington D, Hamilton G, Lipkin G, Nicholson A, Scoble J. Revascularization versus medical therapy for renal-artery stenosis. $N$ Engl J Med. 2009;361:1953-1962

24. Persu A, Giavarini A, Touze E, Januszewicz A, Sapoval M, Azizi M, Barral X, Jeunemaitre X, Morganti A, Plouin PF, de Leeuw P, Hypertension ESHWG, the K. European consensus on the diagnosis and management of fibromuscular dysplasia. J Hypertens. 2014;32:1367-1378

25. Trinquart L, Mounier-Vehier C, Sapoval M, Gagnon N, Plouin PF. Efficacy of revascularization for renal artery stenosis caused by fibromuscular dysplasia: A systematic review and meta-analysis. Hypertension. 2010;56:525-532 


\section{Chapter 2}

\section{Angiotensin-(1-7) induced renal vasodilation in hypertensive humans is attenuated by low sodium intake and angiotensin II co-infusion}

Daan J.L. van Twist, Alfons J.H.M. Houben, Michiel W. de Haan, Guy J.M. Mostard, Abraham A. Kroon, and Peter W. de Leeuw

Hypertension 2013;51:789-93 


\section{Abstract}

Current evidence suggests that angiotensin-(1-7) plays an important role in the regulation of tissue blood flow. This evidence, however, is restricted to studies in animals and human forearm. Therefore, we studied the effects of intrarenal angiotensin-(1-7) infusion on renal blood flow in hypertensive humans. To assess the influence of renin-angiotensin-system activity, sodium intake was varied and co-infusion with angiotensin II was performed in a subgroup. In 57 hypertensive patients who were scheduled for renal angiography, renal blood flow was measured $\left({ }^{133}\right.$ Xenon washout method) before and during intrarenal infusion of angiotensin-(1-7) (three incremental doses: $0.27,0.9$, and $2.7 \mathrm{ng} / \mathrm{kg} / \mathrm{min}$ ). Patients were randomized into low or high sodium intake. These two groups of patients received angiotensin-(1-7), with or without intrarenal co-infusion of angiotensin 11 ( $0.3 \mathrm{ng} / \mathrm{kg} / \mathrm{min})$.

Angiotensin-(1-7) infusion resulted in intrarenal vasodilation in patients adhering to a sodiumrich diet. This vasodilatory effect of Ang-(1-7) was clearly attenuated by low-sodium intake, angiotensin II co-infusion or both. Regression analyses showed that the prevailing renin concentration was the only independent predictor of angiotensin-(1-7) induced renal vasodilation. In conclusion, angiotensin-(1-7) induces renal vasodilation in hypertensive humans, but the effect of Ang-(1-7) is clearly attenuated by low sodium intake and/or co-infusion of angiotensin II. This supports the hypothesis that angiotensin-(1-7) induced renal vasodilation depends upon the degree of renin-angiotensin-system activation. 


\section{Introduction}

Angiotensin-(1-7) (Ang-(1-7)) is a vasoactive peptide which plays an important role in the regulation of tissue blood flow. ${ }^{1}$ It is closely linked to the classical reninangiotensin-system (RAS) since the enzymes producing Ang-(1-7) use angiotensin I and angiotensin II (Ang II) as its substrate. Available data, limited to studies using animal models and human forearm vasculature, predominantly demonstrate a vasodilatory effect of Ang-(1-7). ${ }^{2,3}$ Human data on the effect of Ang-(1-7) in clinically important vascular beds such as that of the kidney are lacking. ${ }^{4}$ As the kidney and RAS-activation play a key role in blood pressure regulation and the development of hypertension, studying the intrarenal flow-effects of Ang-(1-7) in hypertensive patients may lead to new insights in the pathophysiology of hypertension. We hypothesized that, in correspondence to the data currently available, Ang-(1-7) increases renal blood flow in hypertensive humans. For that reason we studied the effect of intrarenal Ang-(1-7) infusion on renal blood flow in hypertensive patients. In order to assess the influence of the RAS, various states of RAS-stimulation were simulated by restriction of dietary sodium intake (inducing endogenous RAS-activation) and/or co-infusion of Ang II (increasing Ang II availability).

\section{Methods}

\section{Participants and protocol}

This study was performed in 85 hypertensive outpatients (all whites) who were angiographically evaluated for the presence of renovascular abnormalities. Inclusion criteria were difficult-to-treat hypertension (mostly blood pressure remaining above goal in spite of the use of at least three full-dose antihypertensive drugs) and/or clinical suspicion on renovascular abnormalities based on clinical clues (e.g. the presence of an abdominal bruit, peripheral vascular disease, or a rise in serum creatinine following treatment with a RAS-inhibitor). Patients previously diagnosed with renovascular abnormalities or other secondary causes of hypertension were excluded. Three weeks before to the angiography all antihypertensive medication was discontinued to avoid interference with the experiments. Patients in whom interruption of the medication was not possible because of a high risk for acute cardiovascular events (a recent cardiovascular event or (expected) blood pressure higher than $180 / 110 \mathrm{mmHg}$ ) were excluded from the study. Patients were randomly allocated to adhere to either a sodium-restricted diet ( $<55 \mathrm{mmol}$ sodium/24 hours) or a sodium-rich diet (>200 mmol sodium/24 hours) during the week preceding the study. The day preceding the angiography study, patients underwent a non-invasive 24-hour ambulatory blood pressure measurement (using SpaceLabs ambulatory blood pressure monitor type 90207 or $90217-b$ ) and collected a 24-hour urine specimen to measure 
urinary sodium excretion to monitor dietary compliance. All patients gave written informed consent and the study was approved by the Medical Ethics Committee of the Maastricht University Medical Centre.

\section{Experimental procedures}

Patients were admitted to our ward one day prior to the angiography. After an overnight fast, the aorta and both renal veins were cannulated via the femoral route. Blood samples were drawn from the aorta and both renal veins. Subsequently, mean renal blood flow (MRBF) was measured using the ${ }^{133}$ Xenon washout technique, as described previously. ${ }^{5}$ In short, after infusion of a bolus of ${ }^{133}$ Xenon directly into the renal artery, ${ }^{133}$ Xenon washout curves were recorded using an extracorporeal scintillation counter. After subtraction of background radiation, the disappearance of ${ }^{133}$ Xenon from the kidney was analyzed mathematically using either a two-phase or one-phase exponential decay model, depending on the best fit. From this model we calculated MRBF (expressed as $\mathrm{ml} / 100 \mathrm{~g}$ kidney/min). In our hands, ${ }^{133}$ Xenon washout technique has a coefficient of variation of $8 \%$ for repeated measurements. Intrarenal placebo infusions have no measurable effects on MRBF. ${ }^{5}$

After obtaining baseline data, infusion studies were started (see below). For reasons of standardization, we performed all infusion studies in the right kidney. During each MRBF measurement, heart rate and blood pressure (intra-arterially) were measured continuously.

After the renal blood flow measurements, we performed subtraction angiography of the renal arteries. All radiographic films were reviewed by two independent and experienced radiologists. No contrast agents were administered before the flow measurements had been completed.

\section{Infusion studies}

Patients were randomly allocated to one of the two infusion studies:

\section{Study 1: Infusion of Ang-(1-7) ( $n=45)$}

We infused Ang-(1-7) into the renal artery in three incremental doses $(0.27,0.9$, and $2.7 \mathrm{ng} / \mathrm{kg} / \mathrm{min}$, respectively) for 5 minutes each. After each dose MRBF was measured as described above.

\section{Study 2: Pre-constriction with Ang II, combined with infusion of Ang-(1-7) ( $n=40)$}

Ang II was infused into the renal artery at a continuous rate of $0.3 \mathrm{ng} / \mathrm{kg} / \mathrm{min}$. After five minutes MRBF was measured. Thereafter, similar to study 1, we infused three incremental doses of Ang-(1-7) (0.27, 0.9 and $2.7 \mathrm{ng} / \mathrm{kg} / \mathrm{min})$ into the renal artery, 
additionally to the continuous infusion of Ang II. Again, MRBF was measured after each dose of Ang-(1-7).

Doses of Ang-(1-7) were derived from studies using animal models and human forearm vasculature demonstrating a local vasodilatory response without systemic effects. ${ }^{3,6}$ We conducted a pilot study in 6 patients with the aforementioned doses. As a clear dose-response relationship was found, we used these doses in all study patients.

\section{Analyses}

Each of the two study groups was divided into two subgroups according to their prescribed dietary sodium intake: a high sodium group and a low sodium group (abbreviated as HS- and LS-group in study 1 and as HS-Ang II- and LS-Ang II-group in study 2). As we aimed to study the effects of Ang-(1-7) in essentially hypertensive patients, patients with atherosclerotic renal artery stenosis (ARAS, defined as a reduction of the luminal diameter of $50 \%$ or more) or fibromuscular dysplasia (FMD) were excluded from the present analyses. Since these patients could only be excluded after the renal angiography (thus after randomization and the flow measurements), study groups in the present analyses are of unequal size. Based on the normal variability in renal blood flow, ${ }^{5}$ we considered a change in MRBF by $15 \%$ or more to be significant. In order to demonstrate such a difference at the $5 \%$ level with a power of $80 \%$, at least eight patients were needed in each group. As mentioned before, patients with renal artery abnormalities could only be excluded after finishing the study protocol, therefore a larger group of patients was studied to provide sufficient power. In order to decrease the influence of intra-individual variation in response to the various doses of Ang-(1-7) we calculated mean and maximal change in MRBF (defined as the patient's average and respectively highest MRBF during infusion of the three doses of Ang-(1-7) minus baseline MRBF). For the patients in the second study protocol (pre-constriction by infusion of Ang II), MRBF during Ang II infusion was used as the baseline MRBF in these formulas. Arterial active plasma renin concentrations were measured using an immunoradiometric assay. ${ }^{7}$ Glomerular filtration rate (eGFR) was estimated using the Chronic Kidney Disease Epidemiology Collaboration (CKD-EPI) formula. ${ }^{8}$

For the statistical analyses we used Graphpad (Graphpad Software Inc., version 5.01, San Diego, California, USA) and SPSS software (SPSS Inc., version 17.0, Chicago, Illinois, USA). Within-group comparisons (expressed as mean \pm S.E.M.; all data were distributed normally) were evaluated using paired t-test or one-way repeatedmeasures ANOVA with Dunnett's post-hoc test. For between-group comparisons we used one-way ANOVA or Student's t-test in case of normally distributed data and Kruskal-Wallis test in case of non-normally distributed data (expressed as medians with interquartile ranges). The chi square test was used in case of categorical data. We applied regression analyses to study the determinants of the change in MRBF during 
Ang-(1-7) infusion (only in the data of study 1, to avoid distortion of the results by Ang II co-infusion). Correlations were tested using Pearson's R. A p-value of $<0.05$ was considered statistically significant.

\section{Results}

\section{Patient characteristics}

Eighty-five patients were studied, of whom 28 were excluded because of renovascular abnormalities ( 19 had ARAS, 8 had FMD, and one had a combination of both ARAS and FMD). Fifty-seven essential hypertensive patients were eligible for inclusion, 32 in study 1 , and 25 in study 2 . As mentioned before, study groups were of unequal size as patients with renovascular abnormalities could only be excluded after the renal angiography and the flow measurements. Baseline characteristics are listed in Table 2.1. No statistically significant differences were found between the study groups, except for 24 hour urinary sodium excretion which was, as expected, lower in the low sodium groups ( $p<0.001$, vs. HS and HS-Ang II group). The demographic data of the excluded patients did not significantly differ from the total group (Table 2.1).

Table 2.1 Baseline characteristics of the study patients.

\begin{tabular}{lccccc}
\hline & High sodium & Low sodium & $\begin{array}{c}\text { High sodium } \\
\text { + Ang II }\end{array}$ & $\begin{array}{c}\text { Low sodium } \\
\text { + Ang II }\end{array}$ & $\begin{array}{c}\text { Excluded } \\
\text { patients }\end{array}$ \\
\hline $\mathrm{n}$ & 14 & 18 & 11 & 14 & 28 \\
Gender (male/female) & $8 / 6$ & $12 / 6$ & $9 / 2$ & $6 / 8$ & $12 / 16$ \\
Age (years) & $54.0 \pm 2.6$ & $58.0 \pm 2.9$ & $54.0 \pm 3.3$ & $50.9 \pm 3.4$ & $56.4 \pm 2.6$ \\
Body mass index (kg/m ${ }^{2}$ ) & $28.9 \pm 1.3$ & $28.1 \pm 3.0$ & $29.5 \pm 1.5$ & $27.5 \pm 0.8$ & $25.8 \pm 0.8$ \\
24h systolic blood pressure (mmHg) & $166 \pm 7$ & $162 \pm 5$ & $163 \pm 5$ & $158 \pm 7$ & $160 \pm 8$ \\
24h diastolic blood pressure (mmHg) & $96 \pm 5$ & $94 \pm 3$ & $95 \pm 4$ & $97 \pm 2$ & $91 \pm 4$ \\
eGFR (ml/min/1.73m ${ }^{2}$ ) & $76 \pm 6$ & $81 \pm 4$ & $82 \pm 3$ & $83 \pm 6$ & $76 \pm 4$ \\
Urinary sodium excretion & $204 \pm 25$ & $64 \pm 10 *$ & $249 \pm 31$ & $100 \pm 17 *$ & $128 \pm 15$ \\
(mmol/24h) & & & & & \\
\hline
\end{tabular}

No statistically significant differences were found between the study groups, except for urinary sodium excretion which was lower in the low sodium groups ( ${ }^{*} p<0.001$ for LS vs. HS, and LS-Ang II vs. HS-Ang II). Values expressed as mean \pm S.E.M. eGFR indicates estimated glomerular filtration rate using CKD-EPI formula; ${ }^{8}$ Ang II, angiotensin II; LS, low sodium; HS, high sodium.

\section{Flow studies}

Results of the flow studies are presented in Figure 2.1 and Table 2.2. Infusion of Ang(1-7) resulted in a clear dose-response relationship in the HS group, but not in the LS group ( $p=N S$; Figure 2.1). In the second study group, Ang II infusion resulted in a fall in MRBF ( $p<0.001$ vs. baseline). Infusion of the various doses of Ang-(1-7) combined with continuous Ang II infusion did not result in a clear dose-effect relationship in the LS-Ang II group ( $p=N S$ ). In the HS-Ang II group however, a small but statistically 
significant change in MRBF during infusion of Ang-(1-7) was found (Figure 2.1). As shown in Table 2.2, Ang-(1-7) induced renal vasodilation in all groups, since maximal MRBF was higher than baseline in each group $(p<0.001)$. In addition, maximal change in MRBF was significantly higher in the HS group as compared to the LS-Ang II group (group with 'double' Ang II stimulation, $p=0.035$ for between group comparison; Table 2.2). Although maximal MRBF was higher than baseline in each group, a significant change in mean MRBF was found in the HS and HS-Ang II group only ( $p=0.002$ and 0.005 respectively for mean MRBF vs. baseline; Figure 2.2), and not in the LS and LS-Ang II group (similar to the trends demonstrated in Figure 2.1). In the second study group the infused doses of Ang-(1-7) could only partially counteract the Ang II induced decrease in MRBF ( $p<0.001$ vs. baseline before Ang II co-infusion). Blood pressure and heart rate did not change during any of the infusions, indicating that no systemic effects of either Ang-(1-7) or Ang II, or the combination of both occurred (data not shown).

Figure 2.1 MRBF for incremental doses of Ang-(1-7) infusion.
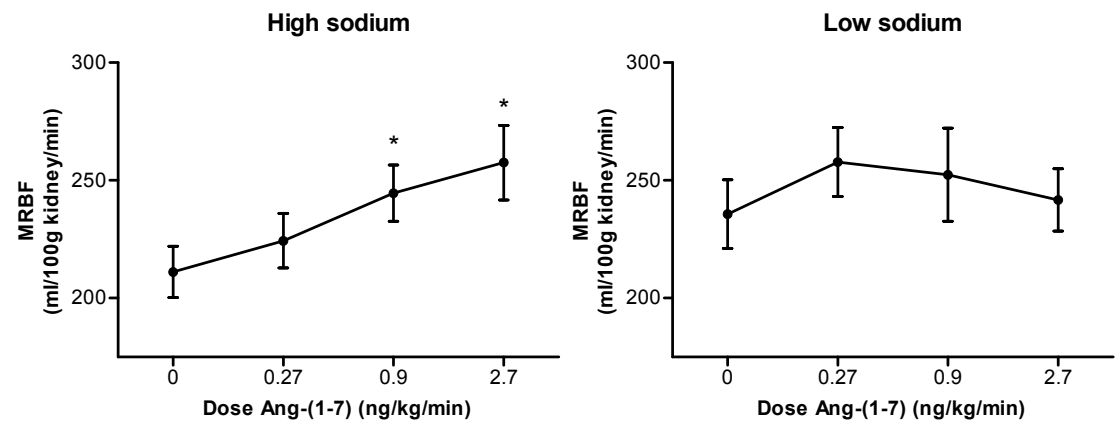

High sodium - Ang II

Low sodium - Ang II
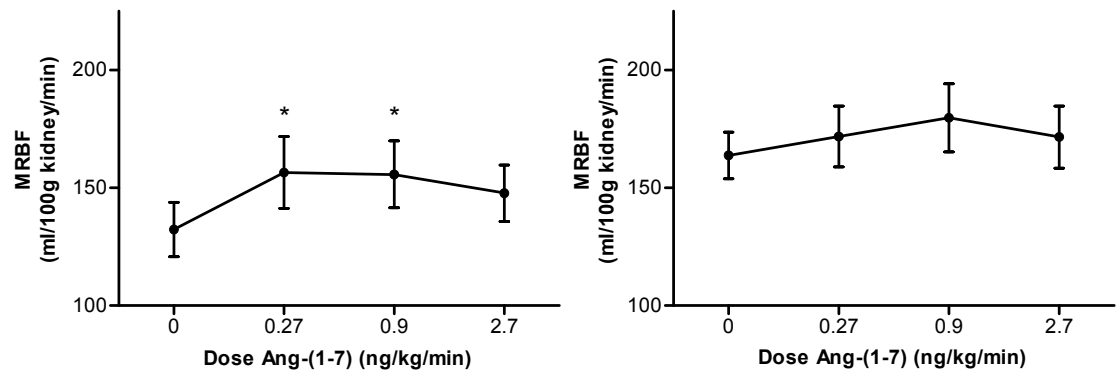

Data presented as mean and S.E.M. and divided into four groups according to sodium intake and presence or absence of continuous Ang II infusion ( $0.3 \mathrm{ng} / \mathrm{kg} / \mathrm{min}) .{ }^{*} \mathrm{p}<0.05$ vs. baseline (repeated-measures ANOVA with Dunnett's post-hoc test). Ang-(1-7) indicates angiotensin-(1-7); Ang II, angiotensin II; MRBF, mean renal blood flow. 
Table 2.2 Results of the renal blood flow measurements.

\begin{tabular}{lcccc}
\hline & High sodium & Low sodium & $\begin{array}{c}\text { High sodium } \\
\text { - Ang II }\end{array}$ & $\begin{array}{c}\text { Low sodium } \\
\text { - Ang II }\end{array}$ \\
\hline $\begin{array}{l}\text { Baseline MRBF } \\
\text { (ml/100g kidney/min) }\end{array}$ & $211 \pm 11$ & $236 \pm 15$ & $224 \pm 25$ & $251 \pm 15$ \\
$\begin{array}{l}\text { Baseline MRBF with Ang II } \\
\text { infusion (ml/100g kidney/min) }\end{array}$ & - & - & $132 \pm 12^{\ddagger}$ & $164 \pm 10^{\ddagger}$ \\
$\begin{array}{l}\text { Maximal Ang-(1-7) induced change } \\
\text { in MRBF (ml/100g kidney/min) }\end{array}$ & $64 \pm 12^{*}$ II & $37 \pm 12^{*}$ & $36 \pm 7^{\dagger \S}$ & $29 \pm 10^{\S}$ \\
$\begin{array}{l}\text { Active plasma renin concentration (mU/l) } \\
\text { 9 }\end{array}$ & $9.6(5.7-19.9)$ & $16.3(11.3-21.3)$ & $10.3(8.4-23.8)$ & $19.7(12.6-41.5)$ \\
\hline
\end{tabular}

All measurements were performed in the right kidney. Data expressed as mean \pm S.E.M. or median (IQ range). ${ }^{*} p<0.001$ for increase in MRBF by Ang-(1-7) vs. baseline; ${ }^{\dagger} p<0.001$ for increase in MRBF by Ang-(1-7) vs. baseline with Ang II; $\neq p<0.001$ for decrease in MRBF by Ang II vs. baseline; $\S p<0.001$ for maximal MRBF vs. baseline before Ang II co-infusion; || p=0.035 vs. low-sodium Ang II group; ๆ $p=0.056$ for between group comparison of renin concentrations. Ang II indicates angiotensin II; Ang-(1-7), angiotensin-(1-7); MRBF, mean renal blood flow.

Figure 2.2 Mean change in MRBF during Ang-(1-7) infusion.

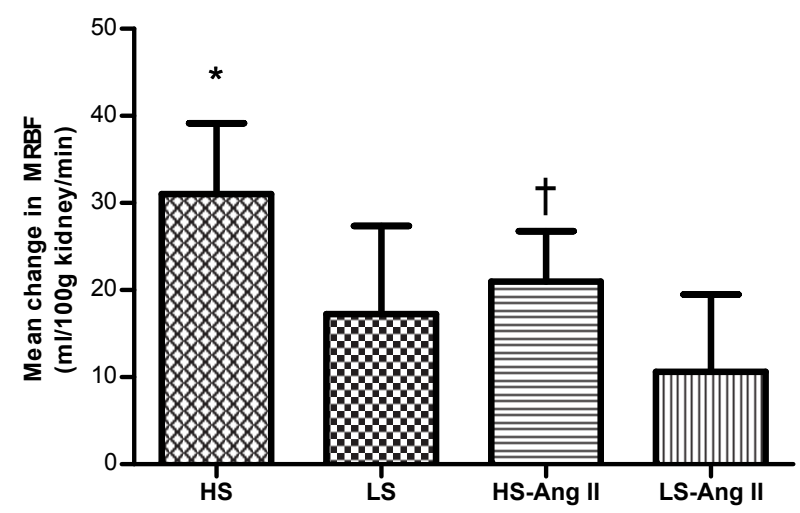

Mean change in MRBF during infusion of Ang-(1-7) for each group, calculated as the average of the three MRBF values measured after infusion of the three doses of Ang-(1-7) minus baseline MRBF. Data expressed as mean and S.E.M.. * $p=0.002$ vs. baseline MRBF; $+p=0.005$ vs. baseline MRBF. $p=N S$ for between group comparison. Ang II indicates angiotensin II; Ang-(1-7), angiotensin-(1-7); HS, high sodium; LS, low sodium; MRBF, mean renal blood flow.

\section{Determinants of Ang-(1-7) effect}

Mean change in MRBF during Ang-(1-7) infusion correlated inversely with renin levels (Pearsons $\mathrm{R}-0.457 ; \mathrm{p}=0.010$ ). A step-wise regression analysis showed that the active plasma renin concentration was the only independent determinant of mean change in MRBF (Beta $-0.551, p=0.010$ ). No relation was found with age, body mass index, gender, $24 \mathrm{~h}$ urinary sodium excretion, eGFR, or $24 \mathrm{~h}$ blood pressure. 


\section{Discussion}

The present study demonstrates that intrarenal Ang-(1-7) infusion induces renal vasodilation in essentially hypertensive humans. Co-infusion of Ang $\mathrm{II}$, stimulation of RAS by a sodium-restricted diet, or both, clearly attenuates this effect.

Previous research on this subject is limited. Animal studies reported an increase in renal blood flow in response to Ang-(1-7) infusion (using doses comparable to this study). ${ }^{6,9}$ This effect is thought to be the result of Mas-receptor (Ang-(1-7)'s target receptor) stimulation, which induces endothelial nitric oxide (NO) release and inhibition of intracellular Ang II / $\mathrm{AT}_{1}$ receptor (type-1 Ang II receptor) signalling, both resulting in vasodilation. ${ }^{4}$ Other animal studies using higher doses of Ang-(1-7) reported a minor vasoconstrictor effect, ${ }^{10,11}$ probably as a result of weak $\mathrm{AT}_{1}$ receptor stimulation by high doses of Ang-(1-7). ${ }^{12}$ Human data on Ang-(1-7) flow effects are limited to studies in the forearm. Results of those studies are not uniform. This may be caused by a dose-response effect with an increased in blood flow with low/normal doses of Ang-(1-7), ${ }^{3}$ but a decrease in blood flow higher doses. ${ }^{13}$

In the present study the Ang-(1-7) induced flow-response was clearly affected by RAS activation following sodium restriction. Whereas the Ang-(1-7) induced vasodilatory effect was only marginally significant in the sodium restricted groups (a significant response was found after selection of the maximal change in MRBF, but no significant effect was found for the mean change in MRBF), a clear dose-response effect of Ang(1-7) was found in patients with a sodium-rich diet (suppressing endogenous RAS activity). In combination with the regression analysis which demonstrated that renin was the only independent determinant of Ang-(1-7)-induced vasodilation, these findings support the previously suggested hypothesis ${ }^{14}$ that RAS activation (due to low sodium intake) results in a diminished effect of Ang-(1-7). These findings are in agreement with in vitro studies using rat aortas, that showed that Ang-(1-7) induces vasodilation in rats with normal or high sodium diet, but not in sodium depleted rats. ${ }^{15}$ Three possible mechanisms could explain this phenomenon: First, a low sodium state results in high endogenous Ang-(1-7) levels as RAS is activated. ${ }^{16,17}$ Possibly, the Ang-(1-7)-induced vasodilatory effect is already on its maximum, so that additional Ang-(1-7) infusion would hardly be able to produce an additional effect. Previous research showing that blocking of Ang-(1-7) only exerts a hemodynamic effect in sodium-depleted rats but not in sodium-repleted rats supports this hypothesis. ${ }^{18,19}$ Second, a low sodium state may decrease Ang-(1-7) effects by Mas-receptor desensitization, as continuous stimulation by high Ang 1-7 levels leads to Mas-receptor

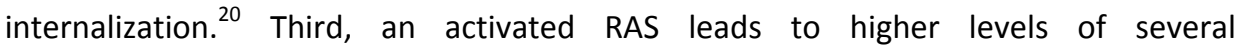
vasoconstrictor peptides such as Ang $\mathrm{II}^{16,17}$ which may reverse the Ang-(1-7) effect. Presumably, each of the-proposed mechanisms contributes to this phenomenon to some extent.

The present study also shows that the Ang-(1-7) induced flow-response was diminished in patients with Ang II infusion compared to those without, indicating that 
Ang II decreases the effects of Ang-(1-7). Conversely, we also demonstrated that Ang-(1-7) is able to at least partially counteract the vasoconstrictor effect of Ang II in human renal circulation, as MRBF during combined infusion of Ang-(1-7) and Ang II was higher than with infusion of Ang II alone (HS-Ang II group). This finding is in line with previous studies in human forearm and rat renal arteries. ${ }^{2,13}$ The combination of both exogenous Ang II infusion and endogenous RAS activation (a 'double' Ang II stimulation in the LS-Ang II group) almost completely blocked the Ang-(1-7) induced increase in renal blood flow as compared to the effect in patients without any Ang II/RASstimulation (HS-group without Ang II co-infusion). Again, one can discuss on the pathophysiological mechanisms involved: either diminished vasodilatory effects of Ang-(1-7) and/or increased vasoconstriction mediated by Ang II (see above). Further research is required to unravel the exact pathway. Nevertheless, we may conclude that in the human hypertensive kidney there is a delicate balance between vasoconstrictor peptides such as Ang II on one side and vasodilator peptides such as Ang-(1-7) on the other. This balance appears to be influenced by dietary sodium intake.

The present study is limited by the fact that we were not able to perform a cross-over study (i.e. studying the same patient during both a high and low sodium diet), as this would require a second invasive procedure with additional risks for the patients. Therefore, we do not have information on the individual changes in response to the shift in sodium intake. Also, because of the relatively small number of included patients we cannot definitively rule out the possibility that the outcomes were influenced by small (not statistically significant) differences in patient characteristics such as age and eGFR. However, the fact that no correlations were found between the outcome and any of these characteristics reduces the risk of such bias. Furthermore, this study was performed in a highly selected population of difficult-to-treat hypertensive subjects who were off medication, which limits extrapolation of the results to the general hypertensive population.

\section{Perspectives}

The present study demonstrates that intrarenal infusion of exogenous Ang-(1-7) induces renal vasodilation and partially counteracts Ang II induced vasoconstriction in hypertensive humans. Both endogenous (low dietary sodium intake) and exogenous (Ang II co-infusion) RAS stimulation clearly attenuate Ang-(1-7) induced vasodilation, indicating that the effects of Ang-(1-7) depend upon the degree of RAS activation. The vasodilatory effects of Ang-(1-7) could provide an interesting pathway for new pharmacological interventions in hypertension and the prevention of chronic kidney disease. 


\section{References}

1. Ferreira AJ, Santos RA, Bradford CN, Mecca AP, Sumners C, Katovich MJ, Raizada MK. Therapeutic implications of the vasoprotective axis of the renin-angiotensin system in cardiovascular diseases. Hypertension. 2010;55:207-213

2. van der Wouden EA, Ochodnicky P, van Dokkum RP, Roks AJ, Deelman LE, de Zeeuw D, Henning RH. The role of angiotensin(1-7) in renal vasculature of the rat. J Hypertens. 2006;24:1971-1978

3. Sasaki S, Higashi Y, Nakagawa K, Matsuura H, Kajiyama G, Oshima T. Effects of angiotensin-(1-7) on forearm circulation in normotensive subjects and patients with essential hypertension. Hypertension. 2001;38:90-94

4. Fraga-Silva RA, Ferreira AJ, Dos Santos RA. Opportunities for targeting the angiotensin-converting enzyme 2/angiotensin-(1-7)/mas receptor pathway in hypertension. Curr Hypertens Rep. 2013;15: 31-38

5. Wierema TK, Houben AJ, Kroon AA, Koster D, van der Zander K, van Engelshoven JM, de Leeuw PW. Nitric oxide dependence of renal blood flow in patients with renal artery stenosis. J Am Soc Nephrol. 2001;12:1836-1843

6. Sampaio WO, Nascimento AA, Santos RA. Systemic and regional hemodynamic effects of angiotensin(1-7) in rats. Am J Physiol Heart Circ Physiol. 2003;284:H1985-1994

7. Deinum J, Derkx FH, Schalekamp MA. Improved immunoradiometric assay for plasma renin. Clin Chem. 1999;45:847-854

8. Levey AS, Stevens LA, Schmid CH, Zhang YL, Castro AF, 3rd, Feldman HI, Kusek JW, Eggers P, Van Lente $\mathrm{F}$, Greene T, Coresh J. A new equation to estimate glomerular filtration rate. Ann Intern Med. 2009; 150:604-612

9. Ren Y, Garvin JL, Carretero OA. Vasodilator action of angiotensin-(1-7) on isolated rabbit afferent arterioles. Hypertension. 2002;39:799-802

10. Heller J, Kramer HJ, Maly J, Cervenka L, Horacek V. Effect of intrarenal infusion of angiotensin-(1-7) in the dog. Kidney Blood Press Res. 2000;23:89-94

11. Handa RK, Ferrario CM, Strandhoy JW. Renal actions of angiotensin-(1-7): In vivo and in vitro studies. Am J Physiol. 1996;270:F141-147

12. Santos RA, Ferreira AJ, Pinheiro SV, Sampaio WO, Touyz R, Campagnole-Santos MJ. Angiotensin-(1-7) and its receptor as a potential targets for new cardiovascular drugs. Expert Opin Investig Drugs. 2005; 14:1019-1031

13. Ueda S, Masumori-Maemoto S, Ashino K, Nagahara T, Gotoh E, Umemura S, Ishii M. Angiotensin-(1-7) attenuates vasoconstriction evoked by angiotensin ii but not by noradrenaline in man. Hypertension. 2000;35:998-1001

14. Ferrario CM, Chappell MC, Tallant EA, Brosnihan KB, Diz DI. Counterregulatory actions of angiotensin(1-7). Hypertension. 1997;30:535-541

15. Roks AJ, Nijholt J, van Buiten A, van Gilst WH, de Zeeuw D, Henning RH. Low sodium diet inhibits the local counter-regulator effect of angiotensin-(1-7) on angiotensin ii. J Hypertens. 2004;22:2355-2361

16. Kocks MJ, Lely AT, Boomsma F, de Jong PE, Navis G. Sodium status and angiotensin-converting enzyme inhibition: Effects on plasma angiotensin-(1-7) in healthy man. J Hypertens. 2005;23:597-602

17. Nakamura S, Averill DB, Chappell MC, Diz DI, Brosnihan KB, Ferrario CM. Angiotensin receptors contribute to blood pressure homeostasis in salt-depleted shr. Am J Physiol Regul Integr Comp Physiol. 2003;284:R164-173

18. Burgelova M, Kramer HJ, Teplan V, Thumova M, Cervenka L. Effects of angiotensin-(1-7) blockade on renal function in rats with enhanced intrarenal ang ii activity. Kidney Int. 2005;67:1453-1461

19. Iyer SN, Averill DB, Chappell MC, Yamada K, Allred AJ, Ferrario CM. Contribution of angiotensin-(1-7) to blood pressure regulation in salt-depleted hypertensive rats. Hypertension. 2000;36:417-422

20. Gironacci MM, Adamo HP, Corradi G, Santos RA, Ortiz P, Carretero OA. Angiotensin (1-7) induces mas receptor internalization. Hypertension. 2011;58:176-181 


\section{Chapter 3}

\section{Angiotensin-(1-7)-induced renal vasodilation is}

reduced in human kidneys with renal artery stenosis

Daan J.L. van Twist, Alfons J.H.M. Houben, Michiel W. de Haan, Guy J.M. Mostard, Peter W. de Leeuw, and Abraham A. Kroon

J Hypertension 2014, 32:2428-2432 


\section{Abstract}

Angiotensin-(1-7) modulates renal blood flow in humans with essential hypertension by inducing vasodilation and counterbalancing angiotensin II-induced vasoconstriction. Little is known, however, about the effects of angiotensin-(1-7) in kidneys with atherosclerotic renal artery stenosis. We previously demonstrated that the effect of angiotensin-(1-7) is reduced in patients with increased activity of the renin-angiotensin-system. As the renin-angiotensin-system is also activated in kidneys with renal artery stenosis, we hypothesized that the vasodilatory effect of angiotensin-(1-7) is also reduced in such kidneys. Therefore, we selectively measured mean renal blood flow $\left({ }^{133}\right.$ Xenon washout method) before and during local infusion of angiotensin-(1-7) $(0.27,0.9$, and $2.7 \mathrm{ng} / \mathrm{kg} / \mathrm{min})$ in hypertensive patients who were angiographically evaluated for the presence of renovascular abnormalities. Data were analyzed in three groups: stenotic kidneys, non-stenotic kidneys with renal artery stenosis of the contralateral kidney (contralateral stenotic kidneys), or essentially hypertensive controls without renovascular abnormalities (matched for urinary sodium excretion). Angiotensin-(1-7) infusion resulted in an increase in renal blood flow in matched controls. In stenotic kidneys however, the effect of angiotensin-(1-7) was significantly reduced as compared to controls. The angiotensin-(1-7) effect in contralateral stenotic kidneys was comparable to controls. In conclusion, angiotensin-(1-7) -induced vasodilation is reduced in stenotic kidneys, but not in contralateral stenotic kidneys. This suggests that the altered blood flow regulation in kidneys with atherosclerotic renal artery stenosis is a local phenomenon and not related to generalized atherosclerotic burden. Probably, renin-angiotensin system activation, bioavailability of nitric oxide, and structural changes in the stenotic kidney play a role in this phenomenon. 


\section{Introduction}

Angiotensin-(1-7) (Ang-(1-7)) is a vasoactive peptide that induces intrarenal vasodilation and counterbalances the vasoconstrictor effects of angiotensin II (Ang II) in humans with essential hypertension. ${ }^{1}$ Less is known, however, about the effects of Ang-(1-7) in kidneys with atherosclerotic renal artery stenosis (ARAS). Several experimental studies support the notion that Ang-(1-7) plays an important role in renal blood flow regulation in case of ARAS. Studies mimicking unilateral renal artery stenosis using 2-kidney, 1-clip Goldblatt hypertensive animals (2K1C) demonstrated that clipping of one of the renal arteries leads to a significant increase in renal Ang-(1-7) levels. ${ }^{2}$ Blockade of the Ang-(1-7)-pathway in these animals results in a significant decrease in renal blood flow and increase in blood pressure. ${ }^{2-4}$ Previously, we demonstrated that the intrarenal vasodilatory effect of Ang-(1-7) is reduced in patients with increased activity of the renin-angiotensin system (RAS) due to a low salt diet and/or Ang II co-infusion. ${ }^{1}$ As the RAS is also activated in kidneys with ARAS, ${ }^{5}$ we hypothesized that the vasodilatory effect of Ang-(1-7) is also reduced in such kidneys. Therefore, we studied the effects of intrarenal Ang-(1-7) infusion in patients with ARAS. Since renal blood flow regulation, RAS activation, and the response to vasoactive agents may differ between the stenotic and the non-stenotic kidney in case of unilateral ARAS, ${ }^{6}$ we also studied the effects of Ang-(1-7) in non-stenotic kidneys in the presence of ARAS of the contralateral kidney.

\section{Methods}

\section{Patients and protocol}

The present study was performed in 85 consecutive outpatients with hypertension (all Caucasian) who were angiographically evaluated for the presence of renovascular abnormalities. Inclusion criteria were difficult-to-treat hypertension (e.g. blood pressure remaining above goal in spite of the use of three full-dose antihypertensive drugs) and/or clinical suspicion of renovascular abnormalities (e.g. presence of peripheral vascular disease or an abdominal bruit, or a decrease in renal function following treatment with a renin-angiotensin system inhibitor). Patients with other secondary causes of hypertension or those in whom renovascular abnormalities had been previously diagnosed were excluded from the study. All patients gave written informed consent and the study was approved by the Medical Ethics Committee of the Maastricht University Medical Centre.

All patients underwent renal angiography according to the following standard study protocol. Patients discontinued all antihypertensive medication three weeks before the angiographic study, in order to avoid interference with the experiments. We excluded patients with a recent ( $<6$ months) cardiovascular event or (expected) blood 
pressure $>180 / 110 \mathrm{mmHg}$ because of a high risk for acute cardiovascular events. The day preceding the angiography study, patients were admitted to our ward, underwent a 24 hour blood pressure measurement (using Spacelabs ambulatory blood pressure monitor type 90207 or $90217-b)$, and collected a 24 hour urine specimen for sodium excretion measurements in order to determine dietary sodium intake.

After an overnight fast, patients underwent selective catheterization of the aorta, where blood samples were drawn. Then we measured mean renal blood flow (MRBF, expressed as $\mathrm{ml} / 100 \mathrm{~g}$ kidney/min) using the ${ }^{133}$ Xenon washout technique as previously described. ${ }^{6}$ In summary, ${ }^{133}$ Xenon is infused directly into the renal artery and the washout of ${ }^{133}$ Xenon is recorded using an extracorporeal scintillation counter. After subtraction of the background radiation the washout of ${ }^{133}$ Xenon from the kidney is analyzed mathematically using an exponential decay model. From that model MRBF is calculated. In our hospital, ${ }^{133}$ Xenon washout technique has a variation coefficient of $8 \%$ for repeated measurements and infusion of placebo ( $0.9 \%$ saline) has no measurable effects on MRBF. ${ }^{6}$ During the procedure, heart rate and blood pressure (intra-arterially) were monitored continuously.

\section{Infusion studies}

After obtaining baseline data, we started infusion studies using Ang-(1-7) (Bachem, Germany). We performed all infusion studies in the right kidney only as Ang-(1-7) infusion in one kidney might induce systemic effects that could distort the subsequent measurements in the other kidney. We infused Ang-(1-7) into the right renal artery in three incremental doses $(0.27,0.9$, and $2.7 \mathrm{ng} / \mathrm{kg} / \mathrm{min}$, respectively) for 5 minutes each. After each dose, we measured MRBF of the right kidney as described above. Doses were derived from a study in patients with essential hypertension that we previously reported. ${ }^{1}$

\section{Angiography}

Following the flow measurements, we performed diagnostic subtraction angiography of the renal arteries. No contrast material was administered prior to completion of the infusion studies. Angiographic images of the abdominal aorta and renal arteries were obtained in anterior-posterior and two oblique views with injection of $25 \mathrm{ml}$ of iopromide (Ultravist 300, Bayer HealthCare, Berlin, Germany) through a 4 French Universal Flush catheter (Cordis Europe, Johnson \& Johnson, Waterloo, Belgium) positioned at the level of the renal arteries. Selective renal angiography was performed in the majority of cases with injection of $12 \mathrm{ml}$ iopromide through a 5 French end-hole Cobra-2 or Simmons-2 catheter (Cordis Europe, Johnson \& Johnson, Waterloo, Belgium). After the procedure, angiographic films were analyzed by two independent, experienced radiologists who were unaware of the results of the blood flow measurements. The patients were classified as having either no renal artery abnormalities, ARAS (uni- or bilateral, defined as a reduction of the luminal diameter 
of $50 \%$ or more), or fibromuscular dysplasia (FMD), depending upon the presence or absence of visible abnormalities in the renal artery. In case of disagreement on renal artery abnormalities, a third radiologists' opinion was decisive.

\section{Calculations and analyses}

Data were analysed at the kidney level, split up into three groups:

1) Stenotic kidneys: Kidneys with ARAS of the right kidney or bilateral ARAS (i.e. ARAS of the kidney in which Ang-(1-7) was infused).

2) Contralateral stenotic kidneys: Kidneys without renovascular abnormalities, but in the presence of ARAS of the contralateral kidney (i.e. unilateral ARAS of the left kidney, Ang-(1-7) was infused into the normal right kidney).

3) Matched controls: Kidneys of patients with essential hypertension without renovascular abnormalities. These patients were included as controls in a casecontrol ratio of 1:2. Since dietary sodium intake modifies the renal flow effects of Ang-(1-7), ${ }^{1}$ controls were matched for dietary sodium intake on the basis of $24 \mathrm{~h}$ urinary sodium excretion, a marker for dietary sodium intake ${ }^{7}$.

Patients with FMD (uni- or bilateral) were excluded from the study. Glomerular filtration rate (eGFR) was estimated using the Chronic Kidney Disease Epidemiology Collaboration (CKD-EPI) formula. ${ }^{8}$ The active plasma renin concentration (APRC) was measured in blood samples obtained from the aorta using an immunoradiometric assay. ${ }^{9}$ Change in MRBF per dose was calculated as MRBF during Ang-(1-7) infusion minus baseline MRBF. We defined maximal change in MRBF as the largest increase in MRBF vs. baseline in response to any of the three doses of Ang-(1-7) per individual kidney. Graphpad (Graphpad Software Inc., version 5.01, San Diego, California, USA) and SPSS (SPSS Inc., version 17.0, Chicago, Illinois, USA) were used for the statistical analyses. We used T-tests (paired and unpaired) for normally distributed data (expressed as mean \pm S.E.M.) and Mann-Whitney $U$ test in case of non-normally distributed data (expressed as medians and interquartile range). Chi square test was used to assess categorical data. Dose response curves were analyzed using mixed model ANOVA. We performed uni- en multivariate regression analyses to evaluate correlation between patient characteristics and the effects of Ang-(1-7). ANCOVA was used to adjust for pre-existing differences in patient characteristics. A p-value of $<0.05$ was considered statistically significant.

\section{Results}

\section{Patient characteristics}

In total, twenty-eight patients (out of 85) were diagnosed with renovascular abnormalities: Twelve with right-sided ARAS (among whom four had bilateral ARAS), 
further referred to as stenotic kidneys, and seven with unilateral left-sided ARAS, further referred to as contralateral stenotic kidneys. Nine patients were diagnosed with FMD (including one with FMD of the right renal artery and ARAS of the left renal artery) and were excluded. Baseline characteristics did not differ significantly between the groups, except for body mass index which was lower in the contralateral stenosis group as compared to matched controls ( $p=0.035$; Table 3.1). A non-statistically significant trend towards lower MRBF and higher renin levels in patients with ARAS as compared to controls was observed.

Table 3.1 Baseline characteristics of the study patients.

\begin{tabular}{lccc}
\hline Baseline characteristic & Stenotic kidneys & $\begin{array}{c}\text { Contralateral } \\
\text { stenotic kidneys }\end{array}$ & Matched controls \\
\hline $\mathrm{n}$ & 12 & 7 & 38 \\
Gender (male/female) & $5 / 7$ & $6 / 1$ & $24 / 14$ \\
Age (years) & $60.9 \pm 1.6$ & $59.5 \pm 3.7$ & $56.1 \pm 1.8$ \\
Body mass index $\left(\mathrm{kg} / \mathrm{m}^{2}\right.$ ) & $26.6 \pm 1.6$ & $25.2 \pm 1.3^{*}$ & $28.9 \pm 0.7$ \\
24h mean arterial pressure (mmHg) & $120 \pm 3$ & $124 \pm 7$ & $120 \pm 3$ \\
eGFR (ml/min/1.73m ${ }^{2}$ ) & $69 \pm 7$ & $72 \pm 9$ & $79 \pm 3$ \\
Urinary sodium excretion (mmol/24h) & $157 \pm 25$ & $105 \pm 29$ & $139 \pm 14$ \\
Active plasma renin concentration (mU/l) & $18.0(7.8-30.9)$ & $26.9(10.6-30.9)$ & $11.9(8.6-22.4)$ \\
Baseline MRBF (ml/100g kidney/min) & $185 \pm 21$ & $187 \pm 21$ & $215 \pm 8$ \\
\hline
\end{tabular}

No statistically significant differences were found between the groups, except for body mass index which was significantly lower in the contralateral stenotic kidney group as compared to matched controls $\left({ }^{*} \mathrm{p}=0.035\right)$. Values expressed as mean \pm S.E.M. or median (interquartile range). eGFR indicates estimated glomerular filtration rate using CKD-EPI formula; ${ }^{8}$ Ang II, angiotensin II; MRBF, mean renal blood flow of the right kidney.

\section{Flow studies}

Figure 3.1 demonstrates the changes in MRBF for incremental doses of Ang-(1-7). In stenotic kidneys, no significant increase in MRBF compared to baseline was observed. A significant increase in MRBF compared to baseline was found in matched controls $(F=4.154, p=0.016)$ and in contralateral stenotic kidneys $(F=5.296, p=0.009)$. In contralateral stenotic kidneys, the vasodilatory effect was somewhat reduced for the highest dose of Ang-(1-7). The dose response curve in stenotic kidneys significantly differed from the dose response curve in contralateral stenotic kidneys ( $F=2.836$, $p=0.048)$, but not from matched controls $(F=0.882, p=N S)$. No statistically significant differences in dose response effect were found between contralateral stenotic kidneys and matched controls.

A similar pattern was found for maximal changes in MRBF in response to Ang-(1-7): Maximal change was significantly reduced in stenotic kidneys as compared to matched controls and contralateral stenotic kidneys $(p=0.008$ and $p=0.030$ respectively, Figure 3.2). In contralateral stenotic kidneys the maximal effect of Ang-(1-7) was comparable to matched controls. 
No statistically significant differences in Ang-(1-7) effect were found between men and women, and no statistically significant correlations were found between renin levels, age, body mass index, $24 \mathrm{~h}$ urinary sodium excretion, eGFR, or $24 \mathrm{~h}$ blood pressure and change in MRBF in response to infusion of any dose of Ang-(1-7). No significant correlations were found between hormonal status (i.e. pre- or postmenopausal status) or use of hormone replacement therapy and the effect of Ang-(1-7) on MRBF (data not shown). Adjustment for body mass index and other patient characteristics in the ANCOVA model did not significantly alter the results. Blood pressure and heart rate did not significantly change during any of the infusions, indicating that no systemic effects of Ang-(1-7) occurred. None of the study participants had to be excluded from the study because of high blood pressure and no acute cardiovascular events (such as cerebrovascular accident or myocardial infarction) were reported during the study period.

Figure 3.1 Change in MRBF for incremental doses of Ang-(1-7) infusion.

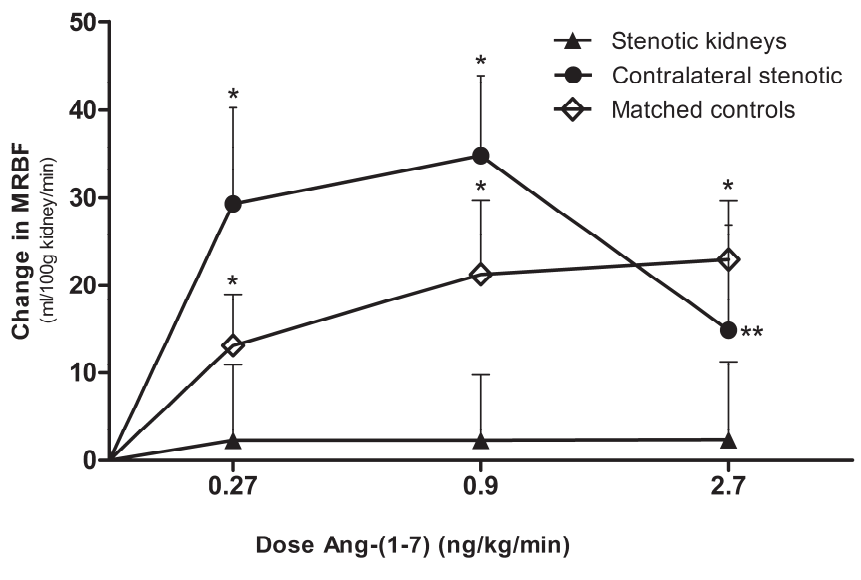

Change in MRBF vs. baseline for incremental doses of intrarenal Ang-(1-7) infusion in stenotic kidneys vs. matched and vs. contralateral stenotic kidneys. A significant increase in MRBF compared to baseline was found in matched controls $(F=4.154, p=0.016)$ and in contralateral stenotic kidneys $(F=5.296, p=0.009)$, but not in stenotic kidneys. The dose-response curve in stenotic kidneys significantly differed from contralateral stenotic kidneys ( ${ }^{* *} \mathrm{~F}=2.836, \mathrm{p}=0.048$ ), but not from matched controls ( $\mathrm{F}=0.882, \mathrm{p}=\mathrm{NS}$ ). No statistically significant differences in dose response effect were found between contralateral stenotic kidneys and matched controls. ${ }^{*} p<0.05$ vs. baseline per dose of Ang-(1-7). Ang-(1-7) indicates angiotensin-(1-7); MRBF, mean renal blood flow. 
Figure 3.2 Maximal effect of Ang-(1-7) on renal blood flow.

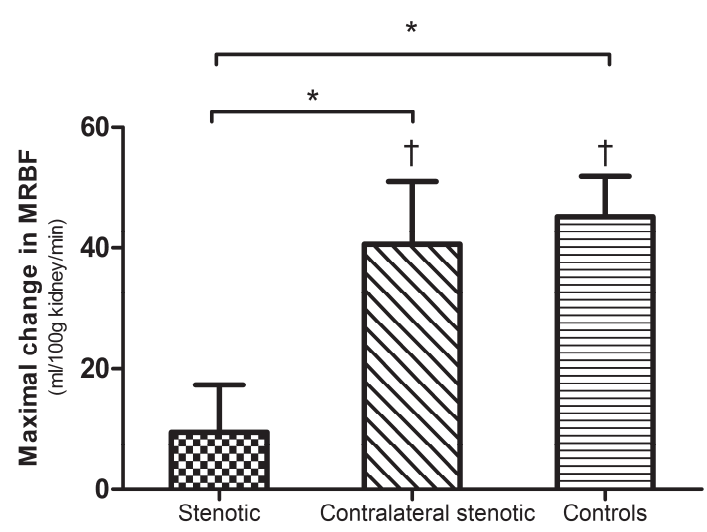

Maximal change in MRBF (defined as the largest increase in MRBF vs. baseline in response to any of the three doses of Ang-(1-7)) in stenotic kidneys, contralateral stenotic kidneys, and matched controls. ${ }^{*} p<0.05$ for stenotic kidneys vs. contralateral stenotic kidneys and stenotic kidneys vs. matched controls $(p=0.030$ and $p=0.008$ respectively). $+p<0.05$ for change in MRBF vs. baseline $(p=0.008$ for contralateral stenotic kidneys and $p<0.001$ for matched controls). Data expressed as mean and S.E.M.. MRBF indicates mean renal blood flow; Ang-(1-7), angiotensin-(1-7).

\section{Discussion}

In the present study we demonstrated that the vasodilatory effect of Ang-(1-7) is reduced in kidneys with ARAS, as compared to an essentially hypertensive control group without renovascular abnormalities (off medication and matched for dietary sodium intake). In agreement with our previously reported study, a dose-response effect of Ang-(1-7) was found in matched controls. ${ }^{1}$ In stenotic kidneys however, the vasodilatory effect of Ang-(1-7) was significantly reduced.

Thus far, available data on the effect of Ang-(1-7) on renal blood flow in stenotic kidneys were scarce. A study in hypertensive children with renal artery stenosis demonstrated that levels of Ang-(1-7) are elevated in these patients, and that surgical treatment of the stenosis results in a substantial decrease in Ang-(1-7) levels. ${ }^{10}$ A similar phenomenon was observed in $2 \mathrm{~K} 1 \mathrm{C}$ animal models. ${ }^{2}$ Moreover, blockade of the Ang-(1-7) pathway in such animals results in a significant decrease in renal blood flow, ${ }^{3,4}$ suggesting a role for Ang-(1-7) in the preservation of blood flow in stenotic kidneys.

Interestingly, in contralateral stenotic kidneys, the effect of Ang-(1-7) was comparable to hypertensive controls, although the vasodilatory effect of Ang-(1-7) was somewhat attenuated at the highest dose. Probably this is the result of weak type-1 Ang II receptor $\left(A T_{1}\right)$ stimulation by higher levels of Ang-(1-7). ${ }^{1}$ Our observation that the 
effect of intrarenal Ang-(1-7) infusion is reduced in stenotic kidneys, but not in the non-stenotic kidney in patients with unilateral ARAS, suggests that it is unlikely to be related to generalized atherosclerotic burden or any other systemic mechanism (such as systemic RAS activation), as this would have led to a diminished effect of Ang-(1-7) in the contralateral, non-stenotic kidney as well. It is also unlikely that the reduced effect of Ang-(1-7) in the stenotic kidney was the result of decreased delivery of Ang-(1-7) due to the stenosis itself, as MRBF was not significantly reduced in these kidneys. Moreover, we previously demonstrated that adenosine (with a half-life comparable to Ang-(1-7)) does induce vasodilation in kidneys with ARAS, ${ }^{12}$ indicating that our observation is specific for Ang-(1-7) and cannot be generalized to all vasodilating agents. Influence of gender and hormonal status on the intrarenal flow effects of Ang-(1-7), as previously demonstrated in animal models, ${ }^{13}$ was not observed.

Although the present study was not designed to investigate the pathophysiological mechanisms involved, various possibilities exist to explain our observations: (I) increased RAS-activation in the stenotic kidney, (II) decreased bioavailability of nitric oxide in the stenotic kidney, and (III) structural changes in the stenotic kidney:

First, renin-angiotensin system (RAS) activation in stenotic kidneys leads to a diminished effect of Ang-(1-7). As previously demonstrated, RAS activation in the stenotic kidney ${ }^{5,6}$ leads to higher intrarenal levels of Ang-(1-7) and Ang II. 4,5 Probably, the maximal vasodilatory effect of Ang-(1-7) has already been reached in these kidneys, due to saturation and desensitization of the available Mas-receptors (Ang-(1-7)'s target receptor). ${ }^{14}$ The addition of more Ang-(1-7) only creates a surplus of Ang-(1-7), but not an additional effect. Moreover, increased levels of Ang II will induce a powerful vasoconstrictory effect that is more difficult to counteract. As the balance between vasoconstriction and vasodilation is turned to Ang Il-induced vasoconstriction, infusion of relatively small doses of Ang-(1-7) on top of the already high endogenous levels of Ang II and Ang-(1-7) will probably not be sufficient to turn the balance over to vasodilation. We previously demonstrated a comparable phenomenon when RAS was activated due to a low salt diet. ${ }^{1}$ In addition, in that study we found that the vasodilatory effect of Ang-(1-7) was independently determined by the renin levels. These findings support the hypothesis that it is RAS activation that attenuates the vasodilatory response to Ang-(1-7) in stenotic kidneys. However, the observation that Ang-(1-7) is able to induce vasodilation in contralateral non-stenotic kidneys, suggests that it is local and not systemic RAS activity that determines the response to Ang-(1-7), as systemic RAS activation would have reduced the Ang-(1-7) effect in the contralateral non-stenotic kidney as well.

Second, decreased bioavailability of nitric oxide in the stenotic kidney will lead to decreased effects of Ang-(1-7). We previously demonstrated that nitric oxide bioavailability is decreased in stenotic kidneys of hypertensive humans with unilateral ARAS. ${ }^{6}$ Considering that the Mas-receptor exerts its vasodilatory action by nitric oxide release (nitric oxide release increases in response to Ang-(1-7) and Ang-(1-7) induced 
vasodilation is impaired by nitric oxide blockers ${ }^{15-17}$ ), reduced bioavailability of nitric oxide in the stenotic kidney restricts Ang-(1-7) induced vasodilation. Interestingly, our aforementioned study and studies in 2K1C animal models also demonstrated that nitric oxide availability is increased in the contralateral, non-stenotic kidney. ${ }^{6,18}$ This could explain the vasodilatory effect of Ang-(1-7) in the contralateral kidney as observed in the present study.

Third, structural damage in the stenotic kidney will decrease its ability to respond to vasodilating agents. Renal artery stenosis induces structural changes such as glomerulosclerosis, interstitial fibrosis, and interstitial atrophy. As this results in a blunted response to vasodilating agents such as acetylcholine and nitroprusside, ${ }^{19,20}$ it is likely that these changes also play a role in the diminished vasodilatory effects of Ang-(1-7). However, as other vasodilating agents are able to induce vasodilation in stenotic kidneys (e.g. adenosine ${ }^{12}$ ), structural changes cannot explain the entire reduction in Ang-(1-7) effect.

The present study was limited by a relatively small number of patients. Hence, we cannot rule out that the outcomes were influenced by small differences in baseline characteristics that were unnoticed. However, as adjustment for these characteristics (including body mass index) did not alter the results, no correlations between the outcome and any of these characteristics were found, we consider the risk of such bias to be low. Moreover, despite the relatively small number of patients, we found marked differences in Ang-(1-7) effect between the groups, making a type 2 error unlikely.

In conclusion, the present study demonstrates that Ang-(1-7) induced vasodilation is attenuated in kidneys with ARAS. The effect of Ang-(1-7) in contralateral stenotic kidneys is comparable to that in hypertensive controls, suggesting that the reduced effect of Ang-(1-7) in kidneys with ARAS is a local phenomenon and is not related to generalized atherosclerotic burden. Probably, activation of RAS, bioavailability of nitric oxide, and structural changes in the stenotic kidney play a role in this phenomenon. Besides contributing to further understanding of renal blood flow regulation in stenotic kidneys, these findings suggest that future therapeutic strategies targeting the Masreceptor (i.e. drugs increasing local Ang-(1-7) availability or Mas-receptor agonists) might be less effective in kidneys with renal artery stenosis. 


\section{References}

1. van Twist DJ, Houben AJ, de Haan MW, Mostard GJ, Kroon AA, de Leeuw PW. Angiotensin-(1-7)induced renal vasodilation in hypertensive humans is attenuated by low sodium intake and angiotensin ii co-infusion. Hypertension. 2013;62:789-793

2. Rakusan D, Burgelova M, Vaneckova I, Vanourkova Z, Huskova Z, Skaroupkova P, Mrazova I, Opocensky M, Kramer HJ, Netuka I, Maly J, Alenina N, Bader M, Santos RA, Cervenka L. Knockout of angiotensin 17 receptor mas worsens the course of two-kidney, one-clip goldblatt hypertension: Roles of nitric oxide deficiency and enhanced vascular responsiveness to angiotensin ii. Kidney Blood Press Res. 2010; 33:476-488

3. Burgelova M, Kramer HJ, Teplan V, Thumova M, Cervenka L. Effects of angiotensin-(1-7) blockade on renal function in rats with enhanced intrarenal ang ii activity. Kidney Int. 2005;67:1453-1461

4. Burgelova M, Vanourkova Z, Thumova M, Dvorak P, Opocensky M, Kramer HJ, Zelizko M, Maly J, Bader $M$, Cervenka L. Impairment of the angiotensin-converting enzyme 2-angiotensin-(1-7)-mas axis contributes to the acceleration of two-kidney, one-clip goldblatt hypertension. $J$ Hypertens. 2009;27: 1988-2000

5. Webb DJ, Cumming AM, Adams FC, Hodsman GP, Leckie BJ, Lever AF, Morton JJ, Murray GD, Robertson Jl. Changes in active and inactive renin and in angiotensin ii across the kidney in essential hypertension and renal artery stenosis. J Hypertens. 1984;2:605-614

6. Wierema TK, Houben AJ, Kroon AA, Koster D, van der Zander K, van Engelshoven JM, de Leeuw PW. Nitric oxide dependence of renal blood flow in patients with renal artery stenosis. J Am Soc Nephrol. 2001;12:1836-1843

7. Kesteloot $\mathrm{H}$, Joossens JV. The relationship between dietary intake and urinary excretion of sodium, potassium, calcium and magnesium: Belgian interuniversity research on nutrition and health. $J$ Hum Hypertens. 1990;4:527-533

8. Levey AS, Stevens LA, Schmid CH, Zhang YL, Castro AF, 3rd, Feldman HI, Kusek JW, Eggers P, Van Lente $\mathrm{F}$, Greene T, Coresh J. A new equation to estimate glomerular filtration rate. Ann Intern Med. 2009;150:604-612

9. Deinum J, Derkx FH, Schalekamp MA. Improved immunoradiometric assay for plasma renin. Clin Chem. 1999;45:847-854

10. Simoes ESAC, Diniz JS, Regueira Filho A, Santos RA. The renin angiotensin system in childhood hypertension: Selective increase of angiotensin-(1-7) in essential hypertension. J Pediatr. 2004;145: 93-98

11. Santos RA, Ferreira AJ, Pinheiro SV, Sampaio WO, Touyz R, Campagnole-Santos MJ. Angiotensin-(1-7) and its receptor as a potential targets for new cardiovascular drugs. Expert Opin Investig Drugs. 2005; 14:1019-1031

12. Wierema TK, Postma CT, Houben AJ, Kroon AA, Thien T, Smits P, de Leeuw PW. Adenosine-induced renal vasodilatation is prolonged in renal artery stenosis. J Hypertens. 1998;16:2109-2112

13. Chappell MC, Marshall AC, Alzayadneh EM, Shaltout HA, Diz DI. Update on the angiotensin converting enzyme 2-angiotensin (1-7)-mas receptor axis: Fetal programing, sex differences, and intracellular pathways. Front Endocrinol (Lausanne). 2014;4:201

14. Gironacci MM, Adamo HP, Corradi G, Santos RA, Ortiz P, Carretero OA. Angiotensin (1-7) induces mas receptor internalization. Hypertension. 2011;58:176-181

15. Heitsch H, Brovkovych S, Malinski T, Wiemer G. Angiotensin-(1-7)-stimulated nitric oxide and superoxide release from endothelial cells. Hypertension. 2001;37:72-76

16. Dharmani M, Mustafa MR, Achike FI, Sim MK. Effects of angiotensin 1-7 on the actions of angiotensin ii in the renal and mesenteric vasculature of hypertensive and streptozotocin-induced diabetic rats. Eur $J$ Pharmacol. 2007; 561:144-150

17. Nakamoto H, Ferrario CM, Fuller SB, Robaczewski DL, Winicov E, Dean RH. Angiotensin-(1-7) and nitric oxide interaction in renovascular hypertension. Hypertension. 1995;25:796-802

18. Bosse HM, Bachmann S. Immunohistochemically detected protein nitration indicates sites of renal nitric oxide release in goldblatt hypertension. Hypertension. 1997;30:948-952 
19. Favreau F, Zhu XY, Krier JD, Lin J, Warner L, Textor SC, Lerman LO. Revascularization of swine renal artery stenosis improves renal function but not the changes in vascular structure. Kidney Int. 2010; 78:1110-1118

20. Chade AR, Rodriguez-Porcel M, Grande JP, Krier JD, Lerman A, Romero JC, Napoli C, Lerman LO. Distinct renal injury in early atherosclerosis and renovascular disease. Circulation. 2002;106:1165-1171 


\section{Chapter 4}

\section{Angiotensin-(1-7) as a strategy in the treatment of hypertension?}

Daan J.L. van Twist, Abraham A. Kroon, Peter W. de Leeuw Curr Opin Nephrol Hypertens 2014, 23:480-486 


\section{Abstract}

\section{Purpose of review}

The renin-angiotensin system plays an important role in cardiovascular disease via the production of angiotensin II (Ang II). Over the past decades however, more and more evidence has accumulated suggesting an important role for another angiotensin: Angiotensin-(1-7) [Ang-(1-7)]. In this review we discuss the recent findings on the effects of Ang-(1-7) and the ACE2/Ang-(1-7)/Mas axis on the cardiovascular system.

\section{Recent findings}

Recent studies demonstrated that Ang-(1-7) exerts a vasodilatory and antiproliferative effect via stimulation of the Mas receptor and inhibition of the effects of angiotensin-type 1 receptor $\left(A T_{1} R\right)$ stimulation by Ang II. This results in a dynamic equilibrium between Ang-(1-7) and Ang II. Various animal studies demonstrated that Ang-(1-7) has beneficial effects on blood pressure, kidney function, and the prevention of cardiovascular disease. Although targeting the ACE2/Ang-(1-7)/Mas axis has been difficult so far, several new therapeutic strategies are being developed. Promising results of these new strategies on blood pressure and cardiovascular disease were demonstrated in animal studies.

\section{Summary}

The beneficial effects of the ACE2/Ang-(1-7)/Mas axis have been widely demonstrated in animal studies and provide a promising basis for further development of drugs targeting this axis of the renin-angiotensin system. Further research in humans, however, is necessary to make a serious step forward. 


\section{Introduction}

The renin-angiotensin system (RAS) is an endocrine cascade that nowadays is considered the key target in treatment of hypertension and prevention of cardiovascular disease. ${ }^{1}$ In the classical point of view, renin activates an enzymatic cascade, eventually resulting in the production of an eight-amino-acid peptide: angiotensin II (Ang II). ${ }^{2}$ By stimulation of the angiotensin-type 1 receptor $\left(A T_{1} R\right)$, Ang II induces many adverse cardiovascular effects such as decreased tissue blood flow, hypertension, sodium retention, endothelial dysfunction, and fibrosis. Therefore, current pharmacotherapeutic strategies targeting the RAS are based on inhibition of the production of Ang II (such as angiotensin-converting-enzyme (ACE) inhibitors and direct renin inhibitors) or blockade of the $A T_{1} R$ (ARBs). ${ }^{2}$

Over the past decades however, more and more evidence has accumulated suggesting an important role for another angiotensin: Angiotensin-(1-7). This 7-amino-acid peptide is produced out of other angiotensins by removal of the terminal amino acid(s) by several enzymes (see Figure 4.1). ${ }^{3,4}$ The most important pathway is the cleavage of phenylalanine from the Ang II-molecule by an homolog of ACE, ACE2. ${ }^{5}$ Next to this process, several other pathways lead to the production of Ang-(1-7), i.e. breakdown of Ang I by ACE2 and neutral endopeptidase (NEP) into the biologically active angiotensin(1-9), which on its turn is cleaved into Ang-(1-7) by ACE. In addition Ang-(1-7) is produced directly out of Ang I by several endopeptidases in the vascular wall. ${ }^{3}$ Ang-(1-7) is further degraded into angiotensin-(1-5) or angiotensin-(1-4), who are probably biologically ineffective.

Ang-(1-7) exerts its effect by stimulation of the G-protein coupled Mas receptor. ${ }^{4}$ Activation of the Mas receptor on the endothelial cell induces the PI3K/Akt (phosphatidylinositosol 3-kinases / Akt) pathway, eventually leading to activation of endothelial nitric oxide synthase (eNOS) (Figure 4.1). The subsequent release of nitric oxide (NO) induces relaxation of the vascular smooth muscle cell and vasodilation. Besides the release of NO, stimulation of the Mas receptor counter-regulates the effects of Ang II by inhibiting the intracellular pathways such as ERK (extracellular signal-regulated kinases) $1 / 2$ and $c$-Src that are induced by $A_{1} R$ stimulation. ${ }^{4}$ The effects of Ang-(1-7) are therefore ambiguous: Induction of NO-mediated vasodilation on the one hand, and inhibiting the vasoconstrictor effects of Ang II on the other. In this way Ang-(1-7) is able to counterbalance the effects of Ang II, resulting in a dynamic equilibrium between levels of Ang-(1-7) and Ang II. Hence, shifting this balance towards Ang-(1-7) results in vasodilation, whereas a balance turned toward Ang II induces vasoconstriction. ${ }^{6}$ 
Figure 4.1 Overview of the renin-angiotensin system.

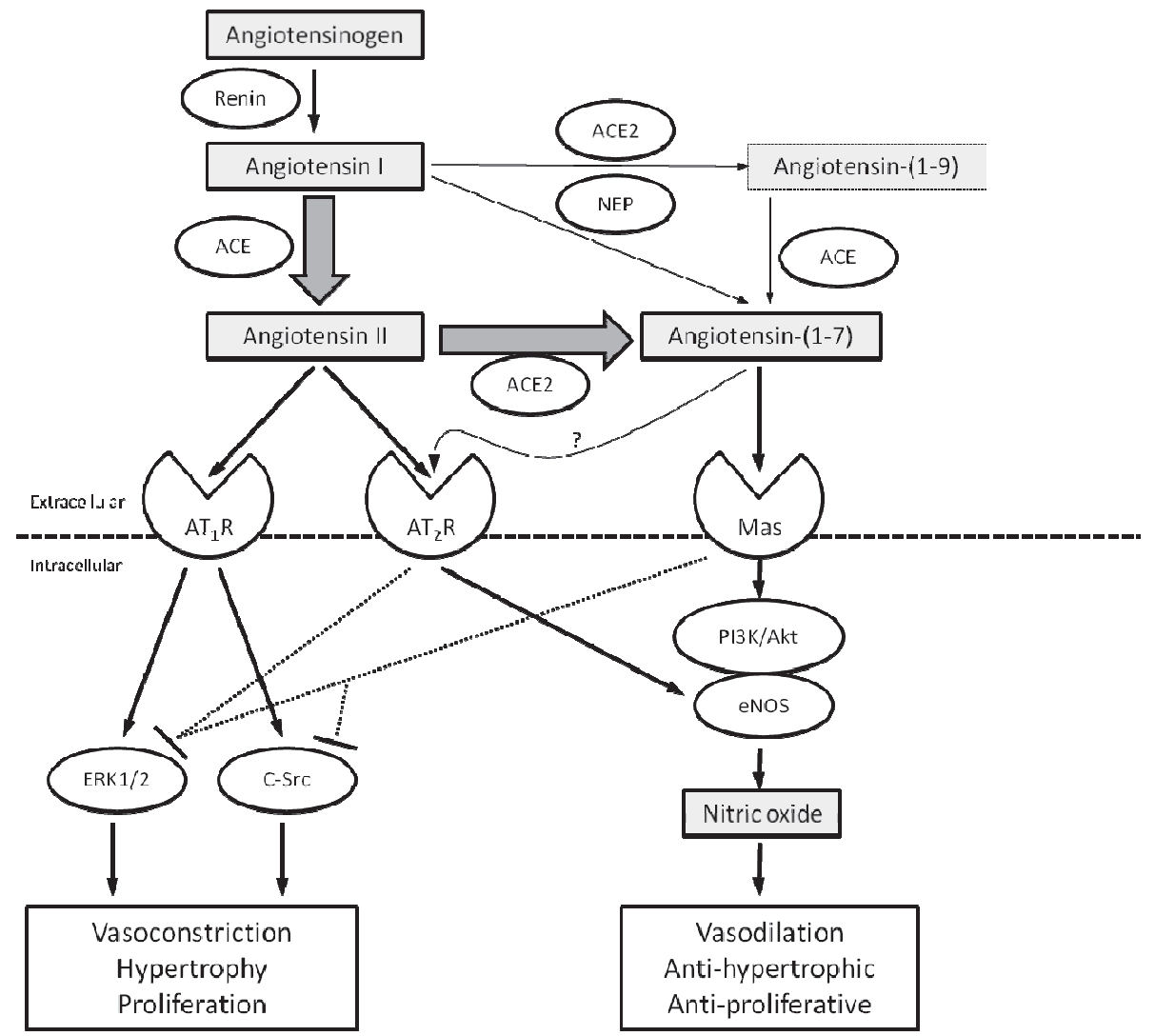

Schematic overview of the enzymatic cascade of the RAS and the most important intracellular signaling pathways. ACE indicates angiotensin converting enzyme; ACE2 angiotensin converting enzyme 2; $A T_{1} R$, angiotensin-type 1 receptor; $A T_{2} R$, angiotensin-type 2 receptor; eNOS, endothelial nitric oxide synthase; NEP, neutral endopeptidases; PI3K, phosphatidylinositosol 3-kinases; ERK 1/2, extracellular signal-regulated kinases $1 / 2$.

\section{Ang-(1-7) and cardiovascular regulation}

The cardiovascular effects of the ACE2/Ang-(1-7)/Mas axis have been widely studied in animal models. Several studies using ACE2 knockout animals demonstrated the importance of this axis in blood pressure homeostasis, as knocking out ACE2 increased blood pressure due to a reduction in Ang-(1-7) levels. ${ }^{7}$ Ang-(1-7) exerts its effects on blood pressure in three important organ systems: the vascular system, the kidney, and the brain. 
As previous reviewed elsewhere, ${ }^{8}$ Ang-(1-7) induces vasodilation and thus an increase in blood flow and a fall in blood pressure. Some studies, using higher doses of Ang-(1-7) reported a minor vasoconstrictor effect, ${ }^{9,10}$ probably as a result of weak $A T_{1} R$ stimulation by higher doses of Ang-(1-7). Despite a large amount of animal studies, very little human studies on the vascular effects of Ang-(1-7) have been performed. Until recently, human data on Ang-(1-7) flow effects were limited to a handful of studies in the forearm circulation. ${ }^{11,12}$ Results of those studies are not uniform. Probably, a dose-response effect (similar to the aforementioned animal studies) plays a role, since low dose Ang-(1-7)-infusion resulted in vasodilation ${ }^{12}$ and higher doses resulted in vasoconstriction. ${ }^{11}$ Recently, we studied the effects of Ang-(1-7) in a clinically more important vascular bed: the human kidney. ${ }^{6}$ In this study, intrarenal infusion of three incremental doses of Ang-(1-7) led to a dose-dependent increase in renal blood flow in hypertensive patients on a high sodium diet. This effect, however, was clearly attenuated in patients on a sodium-restricted diet and in patients who underwent co-infusion of Ang II. Probably, the activated RAS leads to higher levels of Ang II, which reverses the Ang-(1-7) effect. The role of RAS activity was supported by the finding that the vasodilatory effect of Ang-(1-7) inversely correlated with renin levels. ${ }^{6}$ Furthermore, the endogenous RAS activation induced by low sodium intake results in higher levels of Ang-(1-7), which in turn results in saturation and desensitization of the available Mas receptors. ${ }^{13}$ This seems to attenuate the effect of additional Ang-(1-7) infusion.

Next to its direct effect on the vascular tone, Ang-(1-7) exerts several effects on intrarenal sodium and water transport. ${ }^{14}$ Animal studies demonstrated that intrarenal infusion of Ang-(1-7) increases water and sodium excretion, probably due to inhibition of sodium reabsorption in the proximal tubule. ${ }^{15}$ This effect, however, also appears to be dependent to dietary sodium intake. Infusion of Ang-(1-7) in animals on a lowsodium diet resulted in higher rates of glomerular filtration, diuresis, and urinary sodium excretion as compared to animals on a high sodium diet. As renin levels (and subsequently levels of Ang-(1-7) and Ang II) were also significantly lower in this group, the difference in effect in response to variation in sodium intake might be explained by intrarenal RAS activity, although the exact mechanism is still to be unraveled. ${ }^{15}$

Besides its direct effect on blood vessels and the kidney, the ACE2/Ang-(1-7)/Mas axis plays a key role in central blood pressure regulation. As recently reviewed, ${ }^{16}$ several animal studies demonstrated an antihypertensive effect of intracerebral ACE2/Ang-(1-7)/Mas stimulation, probably as a result of alterations in vasopressin and catecholamine release, but also due to modulation of sympathetic nerve and baroreflex activity. ${ }^{16,17}$ 


\section{Ang-(1-7) and target organ damage}

In addition to its effects on blood pressure and blood flow, Ang-(1-7) exerts several other beneficial effects in cardiovascular diseases. For example, several animal studies demonstrated that blockade of the ACE2/Ang-(1-7)/Mas axis results in cardiac injury, in particular increased inflammation, fibrosis, and apoptotic responses. ${ }^{18,19}$ Together with the fact that ACE2 activity in humans is associated with better left ventricular function and improved outcomes in case of acute heart failure, ${ }^{20,21}$ these findings indicate that ACE2/Ang-(1-7)/Mas stimulation could play a beneficial role in cardiac remodeling and the treatment of heart failure.

Several studies demonstrated that the ACE2/Ang-(1-7)/Mas axis also plays an important role in the development and stabilization of atherosclerotic plaques. ${ }^{22} \mathrm{~A}$ recent study in human carotid plaques found that the Mas receptor (but not the $A T_{1} R$ ) is upregulated in stable plaques of asymptomatic patients as compared to patients who had an ischemic stroke, ${ }^{23}$ suggesting a stabilizing effect of Ang-(1-7) on these plaques. Studies using ACE2- or Mas-knockout models demonstrated that ACE2- or Mas-deficiency induces atherosclerosis and neointimal formation by vascular smooth muscle cell proliferation, accumulation of macrophages, oxidative stress, and increased expression of vascular inflammation-related genes. ${ }^{24,25}$ Indeed, treatment with Ang-(1-7) in animals with atherosclerosis leads to plaque stabilization due to an increase in collagen content and a decrease in neutrophil infiltration and matrixmetallo-proteinases. ${ }^{23,26}$ Interestingly, this beneficial effect is also observed in Mas knock-out mice. ${ }^{27}$ Although the effect was somewhat attenuated as compared to that in wild-type mice, these findings indicate that Ang-(1-7) also influences vascular remodeling via pathways other than the Mas receptor. Probably, Ang-(1-7) stimulation of the angiotensin type- 2 receptor $\left(A T_{2} R\right)$ plays a role in this phenomenon, as the effect of Ang-(1-7) was less marked in $\mathrm{AT}_{2} \mathrm{R}$ knockout mice. ${ }^{27}$

Studies using animal models of acute or chronic kidney injury due to hypertension, diabetes, glomerulonephritis, or acute ischemia, found that treatment with Ang-(1-7) protects the kidney, prevents glomerulosclerosis and diminishes inflammation and apoptosis. ${ }^{28-31}$ However, some studies found the exact opposite, namely that Ang-(1-7) may increase kidney injury. ${ }^{14}$ These differences in outcome may be related to variations in local RAS activation, stimulation of other signaling pathways, and differences in renal Ang-(1-7) availability due to differences in Ang-(1-7) dose and administration route. ${ }^{14}$ Therefore, further research is needed to explore the exact role for Ang-(1-7) in the kidney. Furthermore, recent studies demonstrated beneficial effects of ACE2/Ang-(1-7)/Mas stimulation on insulin sensitivity, ${ }^{32,33}$ probably because Ang-(1-7) and insulin share a common intracellular signaling pathway. ${ }^{34}$ Ang-(1-7) also improves endothelial function, as recently demonstrated in obese animals and porcine coronary arteries. $^{35,36}$ In animal models of myocardial infarction, stimulation of the 
Mas receptor limits infarct size, improves cardiac function, and attenuates cardiac remodeling. ${ }^{37,38}$ Likewise, in cerebral hemorrhage or ischemic stroke, Ang-(1-7) infusion reduced neurologic damage and inflammatory responses, and improved survival. $^{16,39}$

In summary, stimulation of the ACE2/Ang-(1-7)/Mas axis in animal models induces several beneficial effects with regard to the cardiovascular diseases, both in the preclinical stage (i.e. endothelial function, insulin resistance, and development of atherosclerosis) and the course of target organ damage (i.e. myocardial ischemia, stroke, and chronic kidney disease), indicating that the ACE2/Ang-(1-7)/Mas axis is an interesting target in the prevention of cardiovascular disease.

\section{Targeting the ACE2/Ang-(1-7)/Mas axis}

Given the favorable effects of Ang-(1-7) in the aforementioned experimental studies, the ACE2/Ang-(1-7)/Mas axis may be an interesting target in the treatment of hypertension and cardiovascular disease. Up till recently, targeting the Mas receptor has been difficult as the plasma half-life of Ang-(1-7) is only 10-15 seconds and orally administered Ang-(1-7) is degraded in the gastro-intestinal tract. Therefore other strategies have been investigated.

The first strategy involves synthetic Mas-agonists, which have been extensively studied in animal models. AVE 0991 is the first (non-peptide) selective and competitive agonist of the Mas-receptor, exerting effects comparable to Ang-(1-7) (Figure 4.2). Recent studies in hypertensive animals demonstrated that AVE 0991 is able to induce vasodilation and reduce blood pressure, ${ }^{40,41}$ especially in combination with a direct renin inhibitor. ${ }^{42}$ In animal models mimicking acute and chronic kidney injury, administration of AVE 0991 reduced tissue injury and renal inflammation leading to improved renal function and a reduction in proteinuria. ${ }^{31,43}$ Recent studies using the more recently developed Mas-agonists CGEN-856 demonstrated that this peptide is not only able to induce NO-dependent vasodilation and a reduction in blood pressure, but also attenuates myocardial infarction injury and cardiac remodeling. ${ }^{38}$

Other strategies in targeting the Mas receptor involve compounds that protect orally ingested Ang-(1-7) from degradation by enzymes in the digestive tract. One such formulation is an inclusion compound consisting of hydroxyl-propyl-beta-cyclodextrin and Ang-(1-7). Cyclodextrin is degraded by bacteria in the distal portions of the digestive tract, which allows uptake of Ang-(1-7) in the colon. In animal models this results in a sustained increase in Ang-(1-7) serum levels, inducing several beneficial effects such as reductions in blood pressure, cholesterol levels, insulin resistance, 
hepatic steatosis, diabetic nephropathy, and inflammation in atherosclerotic plaques. $^{23,32,44-46}$

Another proposed strategy is enhancing the endogenous production of Ang-(1-7) via stimulation of the ACE2 enzyme by small molecule ACE2 activators such as diminazene and XNT (1-[[2-(dimetilamino)etil]amino]-4-(hidroximetil)-7-[[(4-metilfenil)sulfonil]oxi]$9 \mathrm{H}$-xantona-9). ${ }^{47}$ Although beneficial effects similar to Ang-(1-7) administration were observed (such as vasodilation, blood pressure reduction, and improved endothelial and cardiac function), ${ }^{47-49}$ a recent study demonstrated that both substances do not

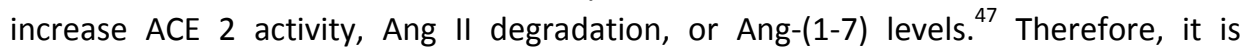
uncertain whether the beneficial effects of XNT and diminazene are actually exerted by ACE2 activation or by an as yet unknown other mechanism.

Figure 4.2 Drugs targeting the renin-angiotensin system.

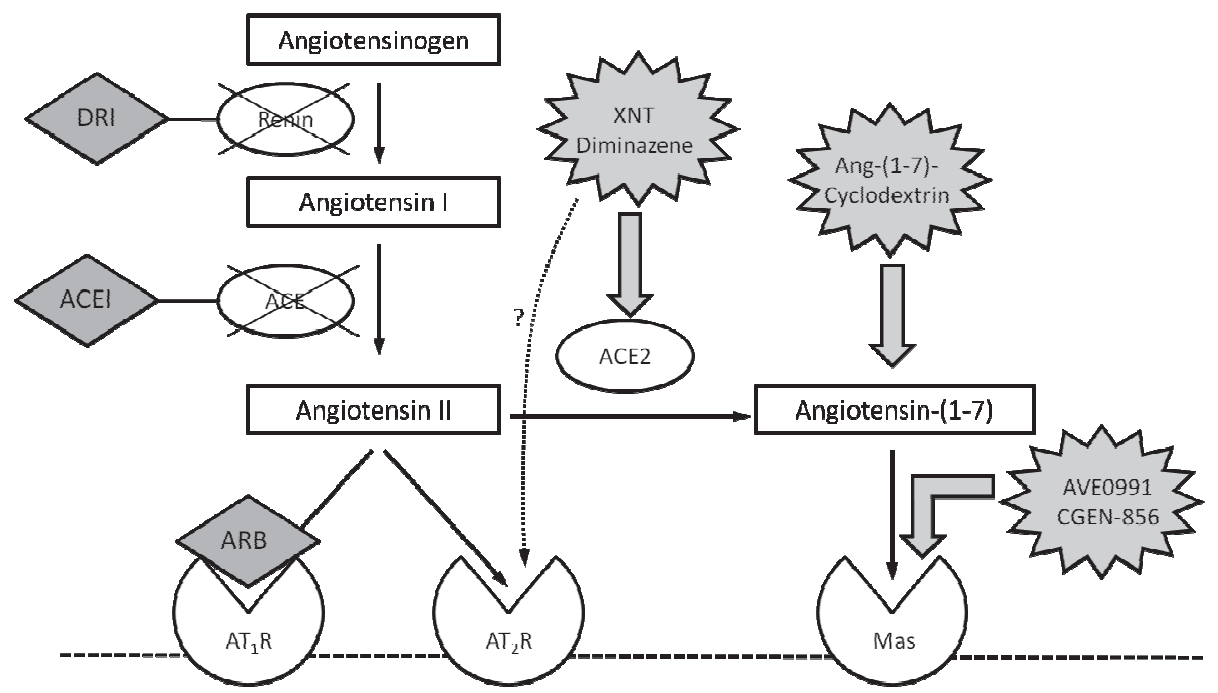

Points of action for currently available drugs blocking the ACE/Angiotensin II/AT ${ }_{1} \mathrm{R}$ axis (diamonds) and potential drugs (still under development) stimulating the ACE2/Ang-(1-7)/Mas axis (stars). XNT and diminazene activate ACE2 (increasing the production of Ang-(1-7), but probably also exert actions via the $A T_{2} R$. Ang-(1-7)-cyclodextrin is an inclusion compound, allowing oral administration of angiotensin-(1-7) by protecting it from early degradation in the digestive tract. AVE0991 and CGEN-856 are both synthetic Mas agonists. ACE indicates angiotensin converting enzyme; ACE2 angiotensin converting enzyme 2; ACEI, $A C E$ inhibitor; Ang-(1-7), angiotensin-(1-7); $A R B$, angiotensin receptor blocker; $A T_{1} R$, angiotensin-type 1 receptor; $A T_{2} R$, angiotensin-type 2 receptor; $D R I$, direct renin inhibitor (i.e. aliskiren); XNT, 1-[[2-(dimetilamino)etil]amino]-4-(hidroximetil)-7-[[(4-metilfenil)sulfonil]oxi]-9H-xantona-9. 


\section{Future directions and limitations}

Over the past decade, major progress has been made in the understanding of the ACE2/Ang-(1-7)/Mas axis and in the development of new drugs targeting this axis. Several issues however, could prevent these drugs from becoming widely used in clinical practice.

First, almost all studies mentioned in this review were performed in animal models. Although we recently confirmed that Ang-(1-7) is able to induce vasodilation in hypertensive patients, ${ }^{6}$ it is still unknown whether other beneficial effects (especially long-term effects) of Ang-(1-7) occur in humans. It is even conceivable that Ang-(1-7) induces adverse effects, similar to what has been seen in previous animal studies. ${ }^{14}$ Therefore, further research is needed to provide more information on the effects of Ang-(1-7) in humans.

Second, various lifestyle factors and co-morbidities could attenuate the effects of Ang-(1-7). As we recently demonstrated, ${ }^{6}$ variations in sodium intake and subsequent variations in RAS activity seriously impair the vasodilatory effects of Ang-(1-7). Research in animal models also found that variations in sodium intake affect Ang-(1-7) induced changes in glomerular filtration and urinary sodium excretion. ${ }^{15}$

Third, although probably unintentionally, several successful and widely used therapeutic strategies such as ACE inhibitors and ARBs, at least partly exert their effect via the ACE2/Ang-(1-7)/Mas axis. The fact that ACE inhibitors and ARBs significantly increase systemic levels of Ang-(1-7) ${ }^{50}$ and that concomitant blockade of ACE2/Ang-(1-7)/Mas axis substantially attenuates their beneficial effects ${ }^{7,27}$ indicates that the ACE2/Ang-(1-7)/Mas axis is crucial for the action of these drugs. Several animal studies demonstrated that drugs targeting the ACE2/Ang-(1-7)/Mas axis have similar effects as the widely used ARBs and ACE inhibitors. ${ }^{27,31}$ Therefore, the question is whether future drugs targeting the ACE2/Ang-(1-7)/Mas axis really contribute to the currently available drugs over and above the currently available agents with which we can block the RAS. Theoretically, the ideal treatment consists of one drug which blocks the classical $A C E / A n g \quad \| / A T_{1} R$ axis and another one that stimulates the ACE2/Ang-(1-7)/Mas axis. This completely shifts the balance between both axis towards the ACE2/Ang-(1-7)/Mas axis and has proven to be beneficial in animal models. ${ }^{28,42}$ However, it remains to been seen whether this is also the case in clinical practice.

\section{Conclusion}

The beneficial effects of the ACE2/Ang-(1-7)/Mas axis have been widely demonstrated in animal studies and provide a strong and promising basis for further development of the ACE2/Ang-(1-7)/Mas axis as a target in the treatment of hypertension and prevention of cardiovascular disease. However, although tremendous efforts have 
been made in studying the effects and developing drugs that stimulate the ACE2/Ang-(1-7)/Mas axis, studies in humans are still scarce. In our opinion, it is time to make a serious step forward by performing more studies in humans with hypertension or other cardiovascular diseases. 


\section{References}

1. Mancia G, Fagard R, Narkiewicz K, Redon J, Zanchetti A, Bohm M, Christiaens T, Cifkova R, De Backer G, Dominiczak A, Galderisi $M$, Grobbee DE, Jaarsma T, Kirchhof $P$, Kjeldsen SE, Laurent S, Manolis AJ, Nilsson PM, Ruilope LM, Schmieder RE, Sirnes PA, Sleight P, Viigimaa M, Waeber B, Zannad F. 2013 esh/esc guidelines for the management of arterial hypertension: The task force for the management of arterial hypertension of the european society of hypertension (esh) and of the european society of cardiology (esc). J Hypertens. 2013;31:1281-1357

2. Robles NR, Cerezo I, Hernandez-Gallego R. Renin-angiotensin system blocking drugs. J Cardiovasc Pharmacol Ther. 2014;19:14-33

3. Velez JC, lerardi JL, Bland AM, Morinelli TA, Arthur JM, Raymond JR, Janech MG. Enzymatic processing of angiotensin peptides by human glomerular endothelial cells. Am J Physiol Renal Physiol. 2012;302:F1583-1594

4. Verano-Braga T, Schwammle V, Sylvester M, Passos-Silva DG, Peluso AA, Etelvino GM, Santos RA, Roepstorff P. Time-resolved quantitative phosphoproteomics: New insights into angiotensin-(1-7) signaling networks in human endothelial cells. J Proteome Res. 2012;11:3370-3381

5. Vickers C, Hales P, Kaushik V, Dick L, Gavin J, Tang J, Godbout K, Parsons T, Baronas E, Hsieh F, Acton S, Patane M, Nichols A, Tummino P. Hydrolysis of biological peptides by human angiotensin-converting enzyme-related carboxypeptidase. J Biol Chem. 2002;277:14838-14843

6. van Twist DJ, Houben AJ, de Haan MW, Mostard GJ, Kroon AA, de Leeuw PW. Angiotensin-(1-7)induced renal vasodilation in hypertensive humans is attenuated by low sodium intake and angiotensin ii co-infusion. Hypertension. 2013;62:789-793

7. Tikellis C, Bernardi S, Burns WC. Angiotensin-converting enzyme 2 is a key modulator of the reninangiotensin system in cardiovascular and renal disease. Curr Opin Nephrol Hypertens. 2011;20:62-68

8. Schindler C, Bramlage P, Kirch W, Ferrario CM. Role of the vasodilator peptide angiotensin-(1-7) in cardiovascular drug therapy. Vasc Health Risk Manag. 2007;3:125-137

9. Heller J, Kramer HJ, Maly J, Cervenka L, Horacek V. Effect of intrarenal infusion of angiotensin-(1-7) in the dog. Kidney Blood Press Res. 2000;23:89-94

10. Handa RK, Ferrario CM, Strandhoy JW. Renal actions of angiotensin-(1-7): In vivo and in vitro studies. Am J Physiol. 1996;270:F141-147

11. Ueda S, Masumori-Maemoto S, Ashino K, Nagahara T, Gotoh E, Umemura S, Ishii M. Angiotensin-(1-7) attenuates vasoconstriction evoked by angiotensin ii but not by noradrenaline in man. Hypertension. 2000;35:998-1001

12. Sasaki S, Higashi Y, Nakagawa K, Matsuura H, Kajiyama G, Oshima T. Effects of angiotensin-(1-7) on forearm circulation in normotensive subjects and patients with essential hypertension. Hypertension. 2001;38:90-94

13. Gironacci MM, Adamo HP, Corradi G, Santos RA, Ortiz P, Carretero OA. Angiotensin (1-7) induces mas receptor internalization. Hypertension. 2011;58:176-181

14. Zimmerman D, Burns KD. Angiotensin-(1-7) in kidney disease: A review of the controversies. Clin Sci (Lond). 2012;123:333-346

15. O'Neill J, Corbett A, Johns EJ. Dietary sodium intake modulates renal excretory responses to intrarenal angiotensin (1-7) administration in anesthetized rats. Am J Physiol Regul Integr Comp Physiol. 2013;304:R260-266

16. Jiang T, Gao L, Lu J, Zhang YD. Ace2-ang-(1-7)-mas axis in brain: A potential target for prevention and treatment of ischemic stroke. Curr Neuropharmacol. 2013;11:209-217

17. Li P, Sun HJ, Cui BP, Zhou YB, Han Y. Angiotensin-(1-7) in the rostral ventrolateral medulla modulates enhanced cardiac sympathetic afferent reflex and sympathetic activation in renovascular hypertensive rats. Hypertension. 2013;61:820-827

18. Meng W, Zhao W, Zhao T, Liu C, Chen Y, Liu H, Sun Y. Autocrine and paracrine function of angiotensin 1-7 in tissue repair during hypertension. Am J Hypertens. 2014

19. Song B, Zhang ZZ, Zhong JC, Yu XY, Oudit GY, Jin HY, Lu L, Xu YL, Kassiri Z, Shen WF, Gao PJ, Zhu DL. Loss of angiotensin-converting enzyme 2 exacerbates myocardial injury via activation of the ctgf-fractalkine signaling pathway. Circ J. 2013;77:2997-3006 
20. Hao PP, Chen YG, Liu YP, Zhang MX, Yang JM, Gao F, Zhang Y, Zhang C. Association of plasma angiotensin-(1-7) level and left ventricular function in patients with type 2 diabetes mellitus. PLoS One. 2013;8:e62788

21. Shao Z, Shrestha K, Borowski AG, Kennedy DJ, Epelman S, Thomas JD, Tang WH. Increasing serum soluble angiotensin-converting enzyme 2 activity after intensive medical therapy is associated with better prognosis in acute decompensated heart failure. J Card Fail. 2013;19:605-610

22. Wang Y, Tikellis C, Thomas MC, Golledge J. Angiotensin converting enzyme 2 and atherosclerosis. Atherosclerosis. 2013;226:3-8

23. Fraga-Silva RA, Savergnini SQ, Montecucco F, Nencioni A, Caffa I, Soncini D, Costa-Fraga FP, De Sousa FB, Sinisterra RD, Capettini LA, Lenglet S, Galan K, Pelli G, Bertolotto M, Pende A, Spinella G, Pane B, Dallegri F, Palombo D, Mach F, Stergiopulos N, Santos RA, da Silva RF. Treatment with angiotensin-(17) reduces inflammation in carotid atherosclerotic plaques. Thromb Haemost. 2014;111

24. Sui YB, Chang JR, Chen WJ, Zhao L, Zhang BH, Yu YR, Tang CS, Yin XH, Qi YF. Angiotensin-(1-7) inhibits vascular calcification in rats. Peptides. 2013;42:25-34

25. Sahara M, Ikutomi M, Morita T, Minami Y, Nakajima T, Hirata Y, Nagai R, Sata M. Deletion of angiotensin-converting enzyme 2 promotes the development of atherosclerosis and arterial neointima formation. Cardiovasc Res. 2014;101:236-246

26. Yang JM, Dong $M$, Meng X, Zhao YX, Yang XY, Liu XL, Hao PP, Li JJ, Wang XP, Zhang K, Gao F, Zhao XQ, Zhang $\mathrm{MX}$, Zhang $\mathrm{Y}$, Zhang $\mathrm{C}$. Angiotensin-(1-7) dose-dependently inhibits atherosclerotic lesion formation and enhances plaque stability by targeting vascular cells. Arterioscler Thromb Vasc Biol. 2013;33:1978-1985

27. Ohshima K, Mogi M, Nakaoka H, Iwanami J, Min LJ, Kanno H, Tsukuda K, Chisaka T, Bai HY, Wang XL, Ogimoto A, Higaki J, Horiuchi M. Possible role of angiotensin-converting enzyme 2 and activation of angiotensin ii type 2 receptor by angiotensin-(1-7) in improvement of vascular remodeling by angiotensin ii type 1 receptor blockade. Hypertension. 2014;63:e53-59

28. Xu C, Ding W, Zhang M, Gu Y. Protective effects of angiotensin-(1-7) administrated with an angiotensin-receptor blocker in a rat model of chronic kidney disease. Nephrology (Carlton). 2013;18:761-769

29. Giani JF, Burghi V, Veiras LC, Tomat A, Munoz MC, Cao G, Turyn D, Toblli JE, Dominici FP. Angiotensin(1-7) attenuates diabetic nephropathy in zucker diabetic fatty rats. Am J Physiol Renal Physiol. 2012;302:F1606-1615

30. Fang F, Liu GC, Zhou X, Yang S, Reich HN, Williams V, Hu A, Pan J, Konvalinka A, Oudit GY, Scholey JW, John R. Loss of ace2 exacerbates murine renal ischemia-reperfusion injury. PLoS One. 2013;8:e71433

31. Silveira KD, Barroso LC, Vieira AT, Cisalpino D, Lima CX, Bader M, Arantes RM, Dos Santos RA, Simoes ESAC, Teixeira MM. Beneficial effects of the activation of the angiotensin-(1-7) mas receptor in a murine model of adriamycin-induced nephropathy. PLoS One. 2013;8:e66082

32. Santos SH, Giani JF, Burghi V, Miquet JG, Qadri F, Braga JF, Todiras M, Kotnik K, Alenina N, Dominici FP, Santos RA, Bader M. Oral administration of angiotensin-(1-7) ameliorates type 2 diabetes in rats. $J \mathrm{Mol}$ Med (Berl). 2014;92:255-265

33. Echeverria-Rodriguez O, Del Valle-Mondragon L, Hong E. Angiotensin 1-7 improves insulin sensitivity by increasing skeletal muscle glucose uptake in vivo. Peptides. 2014;51:26-30

34. Dominici FP, Burghi V, Munoz MC, Giani JF. Modulation of the action of insulin by angiotensin-(1-7). Clin Sci (Lond). 2014;126:613-630

35. Beyer AM, Guo DF, Rahmouni K. Prolonged treatment with angiotensin 1-7 improves endothelial function in diet-induced obesity. J Hypertens. 2013;31:730-738

36. Raffai G, Khang G, Vanhoutte PM. Angiotensin-(1-7) augments endothelium-dependent relaxations of porcine coronary arteries to bradykinin by inhibiting ace1. J Cardiovasc Pharmacol. 2014

37. Marques FD, Melo MB, Souza LE, Irigoyen MC, Sinisterra RD, de Sousa FB, Savergnini SQ, Braga VB, Ferreira AJ, Santos RA. Beneficial effects of long-term administration of an oral formulation of angiotensin-(1-7) in infarcted rats. Int J Hypertens. 2012;2012:795452

38. Savergnini SQ, lanzer D, Carvalho MB, Ferreira AJ, Silva GA, Marques FD, Peluso AA, Beiman M, Cojocaru G, Cohen Y, Almeida AP, Rotman G, Santos RA. The novel mas agonist, cgen-856s, attenuates isoproterenol-induced cardiac remodeling and myocardial infarction injury in rats. PLoS One. 2013; 8:e57757 
39. Regenhardt RW, Mecca AP, Desland F, Ritucci-Chinni PF, Ludin JA, Greenstein D, Banuelos C, Bizon JL, Reinhard MK, Sumners C. Centrally administered angiotensin-(1-7) increases the survival of stroke prone spontaneously hypertensive rats. Exp Physiol. 2014;99:442-453

40. Cunha TM, Lima WG, Silva ME, Souza Santos RA, Campagnole-Santos MJ, Alzamora AC. The nonpeptide ang-(1-7) mimic ave 0991 attenuates cardiac remodeling and improves baroreflex sensitivity in renovascular hypertensive rats. Life Sci. 2013;92:266-275

41. Souza AP, Sobrinho DB, Almeida JF, Alves GM, Macedo LM, Porto JE, Vencio EF, Colugnati DB, Santos RA, Ferreira AJ, Mendes EP, Castro $\mathrm{CH}$. Angiotensin ii type 1 receptor blockade restores angiotensin(1-7)-induced coronary vasodilation in hypertrophic rat hearts. Clin Sci (Lond). 2013;125:449-459

42. Singh Y, Singh K, Sharma PL. Effect of combination of renin inhibitor and mas-receptor agonist in docasalt-induced hypertension in rats. Mol Cell Biochem. 2013;373:189-194

43. Barroso LC, Silveira KD, Lima CX, Borges V, Bader M, Rachid M, Santos RA, Souza DG, Simoes ESAC, Teixeira MM. Renoprotective effects of ave0991, a nonpeptide mas receptor agonist, in experimental acute renal injury. Int J Hypertens. 2012;2012:808726

44. Bertagnolli M, Casali KR, De Sousa FB, Rigatto K, Becker L, Santos SH, Dias LD, Pinto G, Dartora DR, Schaan BD, Milan RD, Irigoyen MC, Santos RA. An orally active angiotensin-(1-7) inclusion compound and exercise training produce similar cardiovascular effects in spontaneously hypertensive rats. Peptides. 2013;51C:65-73

45. Feltenberger JD, Andrade JM, Paraiso A, Barros LO, Filho AB, Sinisterra RD, Sousa FB, Guimaraes AL, de Paula AM, Campagnole-Santos MJ, Qureshi M, dos Santos RA, Santos SH. Oral formulation of angiotensin-(1-7) improves lipid metabolism and prevents high-fat diet-induced hepatic steatosis and inflammation in mice. Hypertension. 2013;62:324-330

46. Santos CF, Santos SH, Ferreira AV, Botion LM, Santos RA, Campagnole-Santos MJ. Association of an oral formulation of angiotensin-(1-7) with atenolol improves lipid metabolism in hypertensive rats. Peptides. 2013;43:155-159

47. Haber PK, Ye M, Wysocki J, Maier C, Haque SK, Batlle D. Angiotensin-converting enzyme 2independent action of presumed angiotensin-converting enzyme 2 activators: Studies in vivo, ex vivo, and in vitro. Hypertension. 2014;63:774-782

48. Fraga-Silva RA, Costa-Fraga FP, Murca TM, Moraes PL, Martins Lima A, Lautner RQ, Castro CH, Soares CM, Borges CL, Nadu AP, Oliveira ML, Shenoy V, Katovich MJ, Santos RA, Raizada MK, Ferreira AJ. Angiotensin-converting enzyme 2 activation improves endothelial function. Hypertension. 2013;61: 1233-1238

49. Qi Y, Zhang J, Cole-Jeffrey CT, Shenoy V, Espejo A, Hanna M, Song C, Pepine CJ, Katovich MJ, Raizada MK. Diminazene aceturate enhances angiotensin-converting enzyme 2 activity and attenuates ischemia-induced cardiac pathophysiology. Hypertension. 2013;62:746-752

50. Moniwa N, Varagic J, Ahmad S, VonCannon JL, Simington SW, Wang H, Groban L, Brosnihan KB, Nagata S, Kato J, Kitamura K, Gomez RA, Lopez ML, Ferrario CM. Hemodynamic and hormonal changes to dual renin-angiotensin system inhibition in experimental hypertension. Hypertension. 2013;61:417-424 


\section{Chapter 5}

Acute eprosartan-induced intrarenal vasodilation in hypertensive humans is not influenced by dietary sodium intake or angiotensin II co-infusion

Daan J.L. van Twist, Alfons J.H.M. Houben, Peter W. de Leeuw, Abraham A. Kroon $J$ Hypertension 2016; in press 


\section{Abstract}

Angiotensin II is thought to play an important role in the development of hypertension. Nevertheless, knowledge on the angiotensin II type-1-receptors ( $\left.A T_{1} R s\right)$ in the hypertensive kidney and the influence of sodium intake and renin-angiotensin system activity on intrarenal $A T_{1} R$ blockade is scarce. To improve our understanding of renal $A T_{1} R s$ in hypertensive patients we studied the effects of acute, local administration of $A T_{1} R$-blocker eprosartan in kidneys of patients with essential hypertension (off medication). In 73 hypertensive patients who were scheduled for diagnostic renal angiography, we measured renal blood flow $\left({ }^{133}\right.$ Xenon washout method) before and during intrarenal infusion of two incremental doses of eprosartan ( 3 and 10 $\mu \mathrm{g} / \mathrm{kg} / \mathrm{min}$ for 15 minutes per dose). We hypothesized that the vasodilatory effects of eprosartan would be increased by stimulation of the renin-angiotensin system secondary to low sodium intake and would be reduced during angiotensin II co-infusion. Therefore, we allocated the patients to either a high or a low sodium diet and co-infused angiotensin II (1 ng/ $/ \mathrm{kg} / \mathrm{min})$ in a subgroup. Eprosartan infusion resulted in intrarenal vasodilation in all groups. No differences in the magnitude of this effect were found between the groups. No correlation was found between 24 hour urinary sodium excretion (a proxy for dietary sodium intake) and the effect of eprosartan. In conclusion, eprosartan-induced vasodilation is not influenced by sodium intake and/or co-infusion of angiotensin II. These rather unexpected findings could be explained by differences between circulating and tissue angiotensin II levels, variations in $\mathrm{AT}_{1} \mathrm{R}$ expression, and/or stimulation of other vasodilatory pathways. 


\section{Introduction}

The renin-angiotensin system (RAS) plays an important role in renal blood flow regulation. The main vasoconstrictor within the RAS is angiotensin II (Ang II), which induces vasoconstriction via stimulation of the angiotensin II type-1-receptor $\left(A T_{1} R\right)$. Although Ang II is thought to play an important role in the development of hypertension, knowledge on local $\mathrm{AT}_{1} \mathrm{Rs}$ in the hypertensive kidney is scarce. In animal studies, acute blockade of the $\mathrm{AT}_{1} \mathrm{R}$ induces intrarenal vasodilation. ${ }^{1,2}$ Human studies on this topic, however, are limited to studies using oral $A T_{1} R$-blockers, which induced a renal vasodilatory effect in some studies, ${ }^{3-6}$ but had no effect in others. ${ }^{7-11}$ The effects of acute, local administration of $\mathrm{AT}_{1} \mathrm{R}$-blockers (without allowing the body to activate several adaptation mechanisms) on renal perfusion have not been evaluated in hypertensive humans yet. To improve our understanding of the renal $A T_{1} R s$ in hypertensive patients, we infused the competitive $A T_{1} R$ antagonist eprosartan in the kidneys of essentially hypertensive patients (off-medication) under various states of RAS stimulation. As we previously demonstrated that the acute vasodilatory effects of angiotensin-(1-7) [Ang-(1-7)] are attenuated by RAS activation secondary to low sodium intake and/or angiotensin II (Ang II) co-infusion, ${ }^{12}$ we questioned whether low sodium intake and/or Ang II co-infusion would also influence the effect of intrarenal $\mathrm{AT}_{1} \mathrm{R}$ blockade. We hypothesized that the effect of eprosartan would be greater in patients receiving a low sodium diet, as the endogenous Ang II production is higher during RAS activation. ${ }^{13}$ We further hypothesized that the effects of eprosartan would be smaller during co-infusion of high-dose Ang II due to competitive antagonism, as more $\mathrm{AT}_{1} \mathrm{Rs}$ would then be occupied by the agonist.

\section{Methods}

\section{Patients}

We performed this study in 101 outpatients (all Caucasian) with hypertension who were referred for angiographic evaluation on suspicion of renovascular abnormalities. In general, these patients were referred because of difficult-to-treat hypertension and/or clinical clues that suggested renovascular abnormalities (e.g. a rise in serum creatinine following treatment with an angiotensin II-type I-receptor blocker or angiotensin-converting-enzyme inhibitor, an abdominal bruit, or peripheral vascular disease). As discontinuation of the antihypertensive drugs was part of the study protocol, we excluded patients in whom we expected blood pressure to rise above $180 / 110 \mathrm{mmHg}$ without antihypertensive medication as well as patients who had a cardiovascular event within 6 months prior to this study. Moreover, we excluded patients who previously underwent a renovascular intervention (e.g. surgery or balloon angioplasty with or without stent placement), patients with other secondary 
causes of hypertension, patients with a contracted kidney, and patients with only one kidney (either acquired or congenital).

\section{Protocol}

Three weeks before the angiography all antihypertensive medication was discontinued to avoid interference with the experiments. Patients were then randomly allocated to either a sodium-rich diet ( $>200 \mathrm{mmol}$ sodium/24 hours) or a sodium-restricted diet ( $<55 \mathrm{mmol}$ sodium/24 hours) during the week preceding the study. The day before the angiography the patients were admitted to our ward, collected a 24-hour urine specimen (to measure urinary sodium excretion for monitoring compliance to the prescribed sodium diet), and underwent a non-invasive 24-hour ambulatory blood pressure measurement (using Spacelabs ambulatory blood pressure monitor type 90207 or 90217-b). This study was approved by the Medical Ethics Committee of the Maastricht University Medical Centre and all patients gave written informed consent for the study.

After an overnight fast we cannulated the renal arteries via the femoral route without the use of iodinated contrast agents. Blood samples were obtained from the aorta and both renal veins for determination of renin levels. Then we measured renal blood flow using the ${ }^{133}$ Xenon washout technique as previously described. ${ }^{14}$ In summary, a bolus of ${ }^{133}$ Xenon is infused directly into the renal artery. The washout of ${ }^{133}$ Xenon is measured using an extracorporeal scintillation counter placed at the kidney level. After subtraction of background radiation we calculated mean renal blood flow (MRBF, expressed as $\mathrm{ml} / 100 \mathrm{~g}$ kidney/min) using either a one- or two phase exponential decay model (depending on which one fitted best). In our hands, the ${ }^{133}$ Xenon washout technique has a coefficient of variation of $8 \%$ for repeated measurements and intrarenal placebo infusions have no measurable effects on MRBF. ${ }^{14}$

After obtaining baseline data, we infused eprosartan (Solvay Pharma B.V., Weesp, the Netherlands) into the renal artery in two incremental (cumulative) doses (3 and $10 \mu \mathrm{g} / \mathrm{kg} / \mathrm{min}$, dissolved in $5 \%$ glucose solution) for 15 minutes per dose. In a subgroup we continuously co-infused Ang II (Bachem, Weil am Rhein, Germany) at a rate of $1 \mathrm{ng} / \mathrm{kg} / \mathrm{min}$ in parallel with the infusion of the abovementioned doses of eprosartan. After each dose, MRBF was measured as described above. For reasons of standardization the infusions of eprosartan and/or Ang II were always performed in the right kidney. The doses of eprosartan were derived from a previous study ${ }^{15}$ and were based on a pilot study that we conducted in 6 patients. We chose the doses that resulted in an increase in renal blood flow without systemic effects on blood pressure and/or heart-rate. We infused a relatively high dose of Ang II (without inducing systemic effects) as compared to previous studies ${ }^{12}$ in order to achieve maximal stimulation of the $A T_{1} R$.

After completion of the flow measurements we performed subtraction angiography of the renal arteries. No contrast materials were administered prior to completion of the 
flow studies. We obtained angiographic images of the abdominal aorta and renal arteries in anterior-posterior and two oblique views with injection of $25 \mathrm{ml}$ of iopromide (Ultravist 300, Bayer HealthCare, Berlin, Germany) through a 4 French Universal Flush catheter (Cordis Europe, Johnson \& Johnson, Waterloo, Belgium) positioned at the level of the renal arteries. Selective renal angiography was performed as well with injection of $12 \mathrm{ml}$ iopromide through a 5 French end-hole Cobra-2 or Simmons-2 catheter (Cordis Europe, Johnson \& Johnson, Waterloo, Belgium). After the procedure, angiographic films were analyzed by two independent, experienced radiologists who were unaware of the results of the flow studies. Renal angiograms were classified as showing no renovascular abnormalities, atherosclerotic renal artery stenosis (ARAS, defined as a reduction of the luminal diameter of $50 \%$ or more) or fibromuscular dysplasia (FMD). During the procedure, heart rate and blood pressure (intra-arterially) were monitored continuously.

\section{Analyses}

The study population was divided into four subgroups according to sodium diet (high or low sodium intake) and the presence or absence of Ang II co-infusion. Only patients without renovascular abnormalities were included in the present analyses as we aimed to study the effects of eprosartan in patients with essential hypertension. Therefore, the study groups were of unequal size, as patients with ARAS or FMD could only be excluded after the renal angiography (thus after randomization and after performing the measurements). We considered a change in MRBF by $15 \%$ or more to be significant (based on the normal variability in renal blood flow). In order to demonstrate such a difference at the $5 \%$ level with a power of $80 \%$ we needed at least 8 patients in each group. We studied a larger group of patients to provide sufficient power as we could only exclude the patients with ARAS or FMD after finishing the study protocol.

In order to reduce the influence of intra-individual variation on the effect of the different doses of eprosartan, we used the maximal change in MRBF (defined as the highest MRBF during infusion of the two doses of eprosartan minus baseline MRBF) in several comparisons. Glomerular filtration rate (eGFR) was estimated using the Chronic Kidney Disease Epidemiology Collaboration (CKD-EPI) formula. ${ }^{16}$ Active plasma renin concentrations were measured using an immunoradiometric assay. ${ }^{17}$ We calculated the renin secretion rate (RSR) as the product of the renal venous-arterial difference in APRC and the renal plasma flow [MRBF*(1-hematocrit)]. We used SPSS software (SPSS Inc., version 17.0, Chicago, Illinois, USA) and Graphpad (Graphpad Software Inc., version 5.01, San Diego, California, USA) for the statistical analyses. For between-group comparisons we used one-way ANOVA or Student's t-test in case of normally distributed data (expressed as mean \pm S.D. or S.E.M) and Kruskal-Wallis test in case of non-normally distributed data (expressed as medians with interquartile ranges). Within-group comparisons were evaluated using paired t-test or one-way repeatedmeasures ANOVA with Dunnett's post-hoc test (all these data were distributed 
normally). The chi square test was used in case of categorical data. Next to the pergroup analyses we evaluated the effect of sodium intake as a continuous variable by using $24 \mathrm{~h}$ urinary sodium excretion as a proxy for dietary sodium intake. ${ }^{18}$ We tested this and other correlations (to find determinants of the eprosartan effect) using Pearson's R (only in the data of patients without Ang II infusion to avoid distortion of the results by Ang II co-infusion). A p-value of $<0.05$ was considered statistically significant.

\section{Results}

\section{Patient characteristics}

One-hundred-and-one patients were studied, of whom 21 were excluded because of renovascular abnormalities ( 14 had ARAS, 5 had FMD, and 2 had total occlusion of the renal artery). Moreover, we excluded four patients who could not discontinue their antihypertensive medication as requested, one patient who appeared to have had a renal artery balloon angioplasty before, one patient who was diagnosed with primary hyperaldosteronism, and one patient who had a stress-induced neurocardiogenic syncope during the procedure (before infusion of eprosartan). Thus 73 patients (all Caucasian) were available for analysis. Characteristics of the patients are shown in Table 5.1. As expected 24 hour urinary sodium excretion was higher in the high sodium groups, as compared to the low sodium groups $(p<0.001)$. This difference, however, was less than expected according to the prescribed sodium diet. No statistically significant differences were found between the study groups for any of the other patient characteristics.

Table 5.1 Patient characteristics

\begin{tabular}{lcccc}
\hline Characteristics & High sodium & Low sodium & High sodium - & Low sodium - Ang \\
& & & Ang II & II \\
\hline $\mathrm{n}$ & 27 & 24 & 8 & 14 \\
Gender (male/female) & $14 / 13$ & $15 / 9$ & $5 / 3$ & $10 / 4$ \\
Age (years) & $57.7 \pm 11.5$ & $52.3 \pm 15.5$ & $56.3 \pm 10.5$ & $55.1 \pm 11.9$ \\
Body mass index (kg/m ${ }^{2}$ ) & $27.0 \pm 4.5$ & $28.6 \pm 4.8$ & $27.0 \pm 5.4$ & $27.7 \pm 4.0$ \\
Current smoking (yes/no) & $9 / 18$ & $3 / 21$ & $3 / 5$ & $2 / 12$ \\
24h systolic blood pressure (mmHg) & $164 \pm 22$ & $163 \pm 23$ & $174 \pm 12$ & $169 \pm 27$ \\
24h diastolic blood pressure (mmHg) & $97 \pm 12$ & $99 \pm 15$ & $104 \pm 5$ & $97 \pm 18$ \\
eGFR (ml/min/1.73m ${ }^{2}$ ) & $86 \pm 21$ & $83 \pm 22$ & $94 \pm 9$ & $85 \pm 23$ \\
Urinary sodium excretion (mmol/24h) & $162 \pm 49$ & $78 \pm 31 *$ & $171 \pm 62$ & $74 \pm 53^{*}$ \\
Active plasma renin concentration (mU/l) & $15.2(9.0-24.7)$ & $18.6(12.1-41.3)$ & $13.8(10.3-19.6)$ & $12.2(10.8-24.4)$ \\
Baseline MRBF (ml/100g kidney/min) & $224 \pm 63$ & $217 \pm 68$ & $240 \pm 38$ & $245 \pm 68$ \\
Baseline RSR (mU/100g kidney/min) & $0.24(0.00-0.80)$ & $0.60(0.00-2.27)$ & $0.38(0.11-0.63)$ & $0.32(0.00-0.82)$ \\
\hline
\end{tabular}

Patient characteristics of the included patients. Values expressed as \pm S.D. or median (interquartile range). eGFR indicates estimated glomerular filtration rate using CKD-EPI formula. ${ }^{16}$ Ang II indicates angiotensin II co-infusion; $\mathrm{RSR}$, renin secretion rate of the right kidney; MRBF mean renal blood flow of the right kidney. 24h blood pressure data represent ambulatory blood pressure measurement on the day preceding the angiography. No statistically significant differences were found between the study groups, except for urinary sodium excretion which was higher in the high sodium groups as compared to the low sodium groups. ${ }^{*} p<0.001$ vs. high sodium and high sodium-Ang II. 


\section{Flow studies}

The results of the flow studies are shown in Figures 5.1 and 5.2. Infusion of incremental doses of eprosartan resulted in a significant increase in MRBF in all groups ( $p<0.05$ vs. baseline) for both doses, with the exception of the low sodium-Ang II group in whom the dose-response curve was not significant $(p=0.155$, repeated measures ANOVA, Figure 5.1). However, when performing separate comparisons per dose, the increase in MRBF vs. baseline was significant in this group as well $(p<0.001$ for both doses eprosartan vs. baseline). No differences in increase in MRBF were found between low ( $3 \mu \mathrm{g} / \mathrm{kg} / \mathrm{min})$ and high dose eprosartan $(10 \mu \mathrm{g} / \mathrm{kg} / \mathrm{min})$ ( $\mathrm{p}=\mathrm{NS}$ in all groups). Area under the curve (AUC) was not different between the groups. With regard to the maximal effect of eprosartan, we found a significant increase in MRBF in all groups (including the low sodium-Ang II group; $p<0.001$ vs. baseline). Although there was small trend towards less effect in the low-sodium groups, there were no statistically significant differences between the groups (Figure 5.2). No differences were found between the groups with Ang II co-infusion and the groups without Ang II co-infusion.

Figure 5.1 Renal blood flow

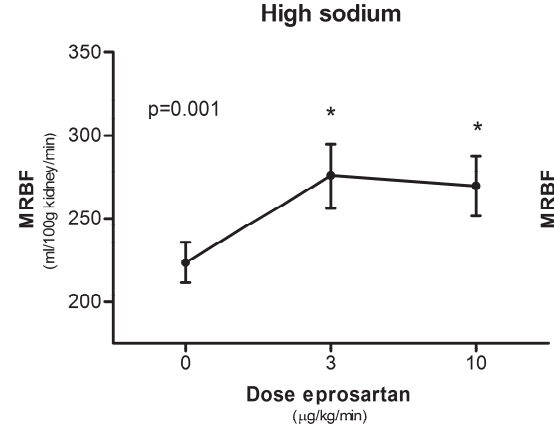

High sodium - Ang II

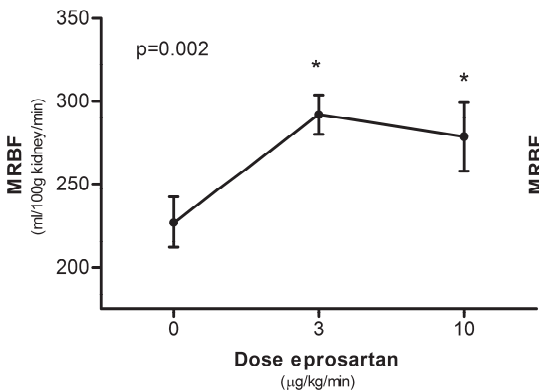

$(\mu \mathrm{g} / \mathrm{kg} / \mathrm{min})$

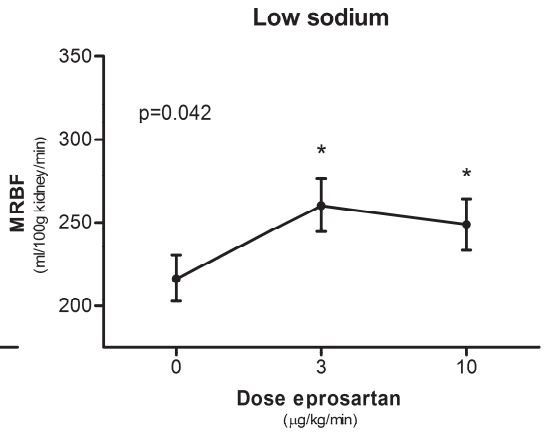

Low sodium - Ang II

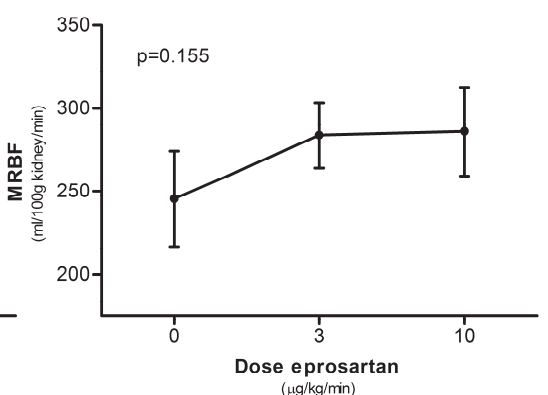

MRBF for incremental doses of intrarenal eprosartan infusion. Data presented as mean and S.E.M. and divided according to sodium intake and presence or absence of continuous Ang II infusion. MRBF indicates mean renal blood flow; Ang II, angiotensin II co-infusion. p-value represents repeated-measures ANOVA. ${ }^{*} p<0.05$ vs. baseline (repeated-measures ANOVA with Dunnett's post hoc test). 
As previously mentioned, the difference in sodium intake between the groups was smaller than expected according to the prescribed diet. In order to evaluate larger differences in sodium intake, we divided the group into quartiles according to 24 hour urinary sodium excretion. No differences in the maximal MRBF response to eprosartan were found between the lowest (mean $24 \mathrm{~h}$ urinary sodium excretion $54 \pm 16 \mathrm{mmol} / 24 \mathrm{~h}$ ) and the highest quartile (mean $24 \mathrm{~h}$ urinary sodium excretion $200 \pm 41 \mathrm{mmol} / 24 \mathrm{~h}$ ) either (data not shown).

Figure 5.2 Maximal increase in renal blood flow.

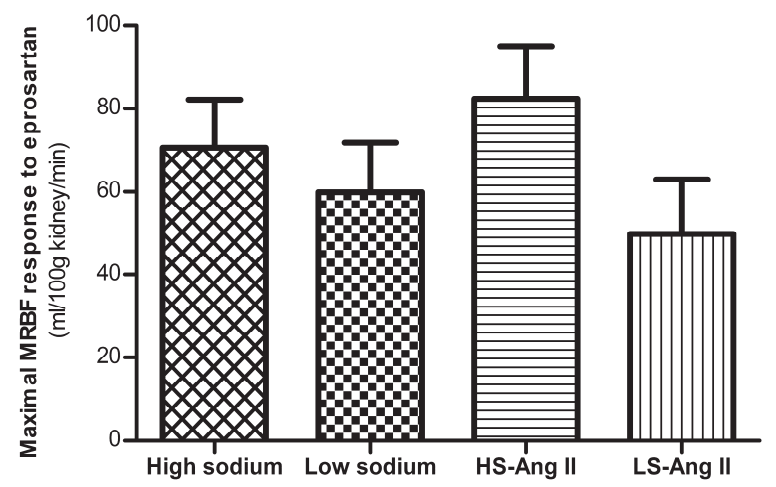

Maximal increase in MRBF in response to eprosartan infusion. Data presented as mean and S.E.M. and divided according to sodium intake and presence or absence of continuous Ang II infusion. MRBF indicates mean renal blood flow; HS, high sodium; LS, low sodium; Ang II, angiotensin II co-infusion. A significant increase in MRBF versus baseline was found in all groups ( $p<0.001$ vs. baseline). No statistically significant differences were found between the groups.

\section{Associations with eprosartan effect}

As shown in Figure 5.3 we found no association between the maximal MRBF response to eprosartan and 24 hour urinary sodium excretion. No association was found with renin, RSR (Supplemental Figure S5.1), blood pressure, body mass index, or eGFR (not shown) either. A small association was found with age (Pearsons $R-0.292 ; p=0.038$ ). During the infusion studies no significant changes in blood pressure or heart rate were found (data not shown), indicating that eprosartan had no systemic effects. During the study period no acute cardiovascular events were reported. 
Figure 5.3 Association with 24 hour urinary sodium excretion.
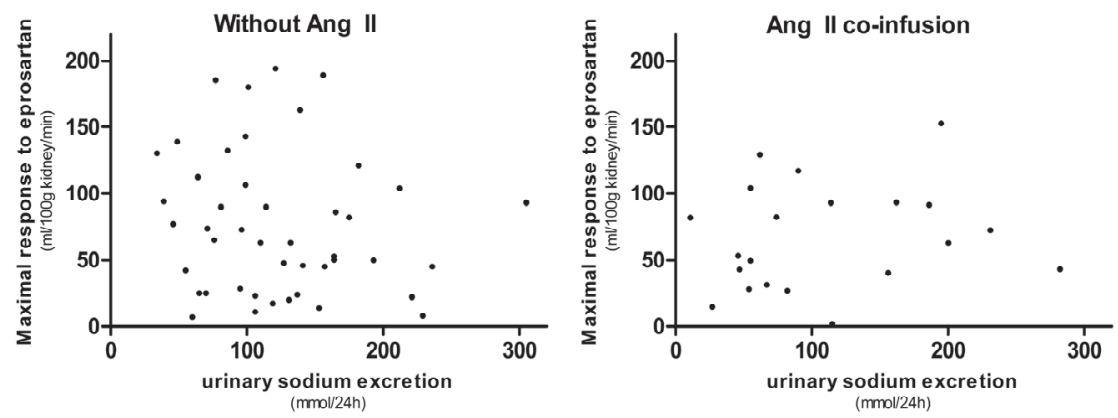

Correlation between 24h urinary sodium excretion and the increase in MRBF in response to eprosartan infusion (the highest increase in MRBF for one of both doses is shown). No statistically significant correlation between eprosartan effect and $24 \mathrm{~h}$ urinary sodium excretion was found. MRBF indicates mean renal blood flow.

\section{Discussion}

In the present study we demonstrated that intrarenal infusion of eprosartan induces renal vasodilation in hypertensive humans and that this effect is not influenced by dietary sodium intake and/or co-infusion of Ang II. We studied this in a cohort of humans with essential hypertension (thus without renovascular abnormalities) who had discontinued all antihypertensive medication.

\section{Ang II co-infusion}

In the present study we found no influence of Ang II co-infusion on the effect of eprosartan. Although the dose-response curve in the low sodium - Ang II group was not statistically significant (vs. baseline), this is probably the result of a lack of power and not a true difference from the other groups as the trend in increase in MRBF was similar to that in the other groups and the maximal effect of eprosartan (Figure 5.2) was statistically significant as compared to baseline and also not different from that in the other groups. We chose to infuse a relatively high dose of Ang II (without systemic effects) in order to provide sufficient $A T_{1} R$ stimulation $(1 \mathrm{ng} / \mathrm{kg} / \mathrm{min}$ ). Although not measured in this study because it would extent the duration of the measurements for the patients too much, infusion of Ang II alone results in substantial vasoconstriction in the kidneys of hypertensive humans: we previously demonstrated that low dose Ang II $(0.3 \mathrm{ng} / \mathrm{kg} / \mathrm{min})$ resulted in a decrease in renal blood flow of $92 \pm 13$ (high sodium diet) and $87 \pm 5$ (low sodium diet) $\mathrm{ml} / 100 \mathrm{~g}$ kidney/min, respectively. ${ }^{12}$ Despite infusion of a 
higher dose of Ang II (presumably inducing more vasoconstriction), eprosartan induced vasodilation in a magnitude similar to the groups without Ang II co-infusion. Thus, as previously demonstrated in animals, ${ }^{13}$ acute infusion of an $A T_{1} R$ blocker counterbalances the effects of Ang II, even during additional infusion of Ang II.

\section{Sodium}

Although we hypothesized that the vasodilatory effect of eprosartan would be greater in the low sodium group, no differences were found between high or low sodium intake, without any influence of Ang II co-infusion. Moreover, if any effect of sodium intake occurred, low sodium intake seems to reduce rather than increase eprosartaninduced vasodilation (non- statistically significant trend in Figure 5.2). The lack of difference between the groups could have been caused by a too small difference in sodium intake between the groups. Although statistically significant (as monitored by 24 hour urinary sodium excretion), these differences were less than expected, probably due to suboptimal adherence to the prescribed diet. In order to evaluate larger differences in sodium intake we changed the analyses from two sodium-diet groups into four groups by using $24 \mathrm{~h}$ urinary sodium excretion as a proxy for sodium intake. Furthermore, we evaluated sodium intake as a continuous variable, again using $24 \mathrm{~h}$ urinary sodium as a proxy for sodium intake. In these additional analyses, allowing evaluation of larger differences in sodium intake, we found no relationship between sodium and the effect of eprosartan either. Thus, despite the relatively small differences in sodium intake between the groups, we can still conclude that sodium intake does not influence the effect of acute eprosartan infusion on renal blood flow in this population of patients with essential hypertension. Thus far, the influence of sodium intake on the effects of $A T_{1} R$-blockade in humans has only been studied in normotensive subjects taking oral $\mathrm{AT}_{1} \mathrm{R}$-blockers. ${ }^{3,9}$ The results of these studies are difficult to compare with ours as the effects of oral administration differ fundamentally from those of acute intrarenal infusion. Oral medication not only produces systemic rather than local effects, but it also allows for several adaptation mechanisms to occur, such as changes in renin secretion, blood pressure, and sodium excretion. ${ }^{19}$ Notwithstanding this, one of the studies found no effect of oral $\mathrm{AT}_{1} \mathrm{R}$-blockade on renal blood flow, irrespective of a low or high sodium diet (50 vs. $200 \mathrm{mmol}$ sodium/day). ${ }^{9}$ Another study, however, found that the magnitude of oral eprosartan-induced vasodilation was greater in patients on a low sodium diet as compared to a high sodium diet (as we hypothesized). ${ }^{3}$ In that study, larger differences in sodium intake were achieved (16 vs. $306 \mathrm{mmol} / \mathrm{day}$ ), resulting in suppressed plasma renin activity in the high sodium group. Despite the suppressed RAS, however, eprosartan still induced an increase in renal blood flow. Apparently, $A T_{1} R$ stimulation still plays a role in renal blood flow homeostasis in a state of suppressed RAS.

Only one previous study (in animals) evaluated the influence of sodium intake on acute intrarenal infusion of an $\mathrm{AT}_{1} \mathrm{R}$-blocker. ${ }^{13}$ In that study, acute Ang II infusion resulted in 
a greater decrease in renal blood flow (56 vs. 16\%) in animals on a high sodium diet as compared to a low sodium diet. Infusion of losartan on top of Ang II counteracted the vasoconstrictory effects of Ang II and blunted the differences in Ang II induced vasoconstriction between the high and low sodium group. Thus, the present study and the abovementioned animal study demonstrate that sodium intake does not influence the effect of acute intrarenal $A T_{1} R$-blockade.

\section{Pathophysiological mechanisms}

Our observation that eprosartan-induced vasodilation is not influenced by Ang II coinfusion or low sodium intake is in contrast to our hypothesis and in contrast to our previous findings with Ang-(1-7). ${ }^{12}$ These unexpected findings could be explained by various mechanisms:

First, the differences in sodium intake between the groups might have been too small. However, as previously mentioned, additional analyses evaluating sodium intake as a continuous variable by using $24 \mathrm{~h}$ urinary sodium intake as a proxy and dividing the group into quartiles (thus increasing the differences in sodium intake between the groups), showed no differences either. Moreover, we found no association between renin or RSR and the effects of eprosartan. Based on these data we cannot rule out that very low or very high sodium intake (less than 3 or more than 14 grams salt per day) could influence the response to eprosartan. However, such low or high sodium intake is very unusual in the general population. ${ }^{20}$ Therefore, we conclude that differences in sodium intake as observed in clinical practice do not influence eprosartan-induced vasodilation.

Second, differences between circulating and tissue levels of Ang II and eprosartan could play a role. Intrarenal RAS activity only partly depends on systemic RAS activity, as more than $90 \%$ of intrarenal Ang II is synthesized locally or released from storage in lysozomes and not taken up from plasma. ${ }^{21}$ Higher levels of circulating Ang II (due to Ang II co-infusion or low sodium intake), ${ }^{22}$ only diffuse in small amounts into the renal tissue where the $A T_{1} R$ is localized ${ }^{21}$ and where they are easily antagonized by these doses of eprosartan. It is imaginable that eprosartan diffuses more easily into the renal tissue than Ang II does. This would result in occupation of the free $\mathrm{AT}_{1}$ Rs before Ang II reaches them, which could explain the lack of effect of Ang II co-infusion. Moreover, it has been suggested that high sodium intake could lead to a paradoxically increase in intrarenal Ang II levels in the hypertensive kidney. ${ }^{23}$ This pathophysiological phenomenon remains to be elucidated further but could explain the absence of an effect of variations in sodium intake as we observed in this cohort of hypertensive patients.

Third, stimulation of the angiotensin II type-2-receptor $\left(A T_{2} R\right)$ or the Mas-receptor [Ang-(1-7)s target receptor] could play a role. Blockade of the $A T_{1} R$ leads to a surplus of available Ang II, which finds an 'escape route' by binding to the $\mathrm{AT}_{2} \mathrm{R}$ or by being converted into Ang-(1-7), both inducing a counteracting vasodilatory effect. ${ }^{24,25}$ Hence, 
Ang II co-infusion in the presence of eprosartan will lead to vasodilation to some extent, counteracting its vasoconstrictor effects. As we previously demonstrated, low sodium intake attenuates the effects of Ang-(1-7), ${ }^{12}$ thus blunting the expected increase in effect of eprosartan during low sodium intake.

Fourth, $A T_{1} R$ expression could play a role. During high sodium intake, endogenous Ang II synthesis is low, resulting in increased $A T_{1} R$ expression. ${ }^{13}$ Despite high $A T_{1} R$ expression, eprosartan has little Ang II to compete with, thus inducing sufficient vasodilation. Conversely, during low sodium intake Ang II production is chronically increased, resulting in reduced $A_{1} \mathrm{R}_{1}$ expression. ${ }^{13}$ Therefore, even when eprosartan occupies only a small number of $\mathrm{AT}_{1} \mathrm{Rs}$, it will still lead to substantial vasodilation.

Fifth, infusion of the doses of eprosartan which we used could result in complete blockade of the $A T_{1} R$, inducing a vasodilatory effect regardless of Ang II levels. However, as $\mathrm{AT}_{1} \mathrm{R}$-blockade by eprosartan is not insurmountable (i.e. it is a pure competitive antagonist as high doses of Ang II could still yield a full vasoconstrictor response, despite the presence of eprosartan $)^{26}$ and the fact that we infused relatively high doses of Ang II, this is unlikely.

Sixth, eprosartan could induce a sympatholytic effect, as $\mathrm{AT}_{1} \mathrm{R}$-stimulation by Ang II induces release of norepinephrine from the sympathetic synapses. Some studies suggested that eprosartan exerts this effect to a greater degree than other $A T_{1} R$ blockers, ${ }^{27,}{ }^{28}$ but others found no differences between eprosartan and other $A T_{1} R$ blockers. ${ }^{29}$ Although eprosartan-induced vasodilation may be mediated by sympathetic inhibition to some extent, it is questionable whether this pathway is relevant with respect to sodium intake or Ang II co-infusion.

\section{Limitations}

This study is limited by its parallel design instead of a cross-over design. Therefore, small differences in patient characteristics could have influenced the outcome. A crossover study (with each patient being studied during a low and during a high sodium diet) would be unethical as this requires a second invasive procedure with additional risks. Furthermore, the chosen doses of eprosartan did not result in a clear dose response in the final study population, even though this was suggested in a pilot study in 6 patients. The chosen doses could have been too high (i.e. resulting in almost complete $A T_{1} R$ saturation already at the lowest dose) or the increment between both doses could be too small. Hence, we cannot comment on the effect of sodium intake or Ang II co-infusion with other doses of eprosartan. Furthermore, it remains unknown whether our results can be generalized to other $\mathrm{AT}_{1} \mathrm{R}$-blockers as eprosartan lacks the biphenyl-tetrazole group that is present in other $A_{1} T_{1}$-blockers. ${ }^{30}$ In addition, our population mainly consists of patients with difficult-to-treat hypertension, limiting the translation to the general hypertensive population. 


\section{Conclusion}

We found that acute intrarenal infusion of eprosartan induces renal vasodilation in essential hypertensive humans (off medication) and that, in contrast to Ang-(1-7), this effect is not influenced by dietary sodium intake or co-infusion of Ang II. These rather unexpected findings could be explained by several mechanisms, such as differences between circulating and tissue Ang II levels, variations in $A T_{1} R$ expression, and/or stimulation of other vasodilatory pathways such as Ang-(1-7) or $A T_{2} R$ stimulation. 


\section{References}

1. Fenoy FJ, Milicic I, Smith RD, Wong PC, Timmermans PB, Roman R. Effects of dup 753 on renal function of normotensive and spontaneously hypertensive rats. Am J Hypertens. 1991;4:321S-326S

2. Bovee KC, Wong PC, Timmermans PB, Thoolen MJ. Effects of the nonpeptide angiotensin ii receptor antagonist dup 753 on blood pressure and renal functions in spontaneously hypertensive ph dogs. $\mathrm{Am}$ J Hypertens. 1991;4:327S-333S

3. Price DA, De'Oliveira JM, Fisher ND, Hollenberg NK. Renal hemodynamic response to an angiotensin ii antagonist, eprosartan, in healthy men. Hypertension. 1997;30:240-246

4. Wuerzner G, Burnier M. Effects of selective angiotensin ii and beta(1)-receptor blockade on renal haemodynamics, and sodium handling during orthostatic stress in healthy individuals. $J$ Hypertens. 2006;24:S89-S93

5. Paterna S, Parrinello G, Scaglione R, Costa R, Bova A, Palumbo VA, Pinto A, Amato P, Licata G. Effect of long-term losartan administration on renal haemodynamics and function in hypertensive patients. Cardiovasc Drugs Ther. 2000;14:529-532

6. Gansevoort RT, de Zeeuw D, Shahinfar S, Redfield A, de Jong PE. Effects of the angiotensin ii antagonist losartan in hypertensive patients with renal disease. J Hypertens Suppl. 1994;12:S37-42

7. Burnier M, Hagman M, Nussberger J, Biollaz J, Armagnac C, Brouard R, Weber B, Brunner HR. Shortterm and sustained renal effects of angiotensin ii receptor blockade in healthy subjects. Hypertension. 1995;25:602-609

8. Gandhi SK, Ryder DH, Brown NJ. Losartan blocks aldosterone and renal vascular responses to angiotensin ii in humans. Hypertension. 1996;28:961-966

9. Burnier M, Rutschmann B, Nussberger J, Versaggi J, Shahinfar S, Waeber B, Brunner HR. Saltdependent renal effects of an angiotensin ii antagonist in healthy subjects. Hypertension. 1993;22: 339-347

10. Delles C, Klingbeil AU, Schneider MP, Handrock R, Weidinger G, Schmieder RE. Direct comparison of the effects of valsartan and amlodipine on renal hemodynamics in human essential hypertension. Am $\mathrm{J}$ Hypertens. 2003;16:1030-1035

11. Delles C, Jacobi J, John S, Fleischmann I, Schmieder RE. Effects of enalapril and eprosartan on the renal vascular nitric oxide system in human essential hypertension. Kidney Int. 2002;61:1462-1468

12. van Twist DJ, Houben AJ, de Haan MW, Mostard GJ, Kroon AA, de Leeuw PW. Angiotensin-(1-7)induced renal vasodilation in hypertensive humans is attenuated by low sodium intake and angiotensin ii co-infusion. Hypertension. 2013;62:789-793

13. Ruan X, Wagner C, Chatziantoniou C, Kurtz A, Arendshorst WJ. Regulation of angiotensin ii receptor at1 subtypes in renal afferent arterioles during chronic changes in sodium diet. J Clin Invest. 1997;99: 1072-1081

14. Wierema TK, Houben AJ, Kroon AA, Koster D, van der Zander K, van Engelshoven JM, de Leeuw PW. Nitric oxide dependence of renal blood flow in patients with renal artery stenosis. J Am Soc Nephrol. 2001;12:1836-1843

15. Dielis AW, Smid M, Spronk HM, Houben AJ, Hamulyak K, Kroon AA, Ten Cate H, de Leeuw PW. Changes in fibrinolytic activity after angiotensin ii receptor blockade in therapy-resistant hypertensive patients. J Thromb Haemost. 2007;5:1509-1515

16. Levey AS, Stevens LA, Schmid CH, Zhang YL, Castro AF, 3rd, Feldman HI, Kusek JW, Eggers P, Van Lente F, Greene T, Coresh J. A new equation to estimate glomerular filtration rate. Ann Intern Med. 2009; 150:604-612

17. Deinum J, Derkx FH, Schalekamp MA. Improved immunoradiometric assay for plasma renin. Clin Chem. 1999;45:847-854

18. Kesteloot $\mathrm{H}$, Joossens JV. The relationship between dietary intake and urinary excretion of sodium, potassium, calcium and magnesium: Belgian interuniversity research on nutrition and health. $J$ Hum Hypertens. 1990;4:527-533

19. Peng Y, Knox FG. Comparison of systemic and direct intrarenal angiotensin ii blockade on sodium excretion in rats. Am J Physiol. 1995;269:F40-46

20. Brown IJ, Tzoulaki I, Candeias V, Elliott P. Salt intakes around the world: Implications for public health. Int J Epidemiol. 2009;38:791-813 
21. Te Riet L, van Esch JH, Roks AJ, van den Meiracker AH, Danser AH. Hypertension: Renin-angiotensinaldosterone system alterations. Circ Res. 2015;116:960-975

22. Ingert C, Grima M, Coquard C, Barthelmebs M, Imbs JL. Effects of dietary salt changes on renal reninangiotensin system in rats. Am J Physiol Renal Physiol. 2002;283:F995-1002

23. Navar LG. Intrarenal renin-angiotensin system in regulation of glomerular function. Curr Opin Nephrol Hypertens. 2014;23:38-45

24. Singh RR, Lankadeva YR, Denton KM, Moritz KM. Improvement in renal hemodynamics following combined angiotensin ii infusion and at $1 \mathrm{r}$ blockade in aged female sheep following fetal unilateral nephrectomy. PLoS One. 2013;8:e68036

25. van Twist DJ, Kroon AA, de Leeuw PW. Angiotensin-(1-7) as a strategy in the treatment of hypertension? Curr Opin Nephrol Hypertens. 2014;23:480-486

26. Smith $\mathrm{DH}$. Comparison of angiotensin ii type 1 receptor antagonists in the treatment of essential hypertension. Drugs. 2008;68:1207-1225

27. Balt JC, Mathy MJ, Pfaffendorf M, van Zwieten PA. Sympatho-inhibitory properties of various at1 receptor antagonists. J Hypertens Suppl. 2002;20:S3-11

28. Ohlstein EH, Brooks DP, Feuerstein GZ, Ruffolo RR, Jr. Inhibition of sympathetic outflow by the angiotensin ii receptor antagonist, eprosartan, but not by losartan, valsartan or irbesartan: Relationship to differences in prejunctional angiotensin ii receptor blockade. Pharmacology. 1997;55: 244-251

29. Dendorfer A, Dominiak P, Tempel K, Raasch W. Peripheral sympatholytic actions of four at1 antagonists: Are they relevant for long-term antihypertensive efficacy? J Hypertens. 2005;23: 1861-1867

30. Michel MC, Foster C, Brunner HR, Liu L. A systematic comparison of the properties of clinically used angiotensin ii type 1 receptor antagonists. Pharmacol Rev. 2013;65:809-848 


\section{Supplemental figure}

Figure S5.1 Renin and the response to eprosartan.
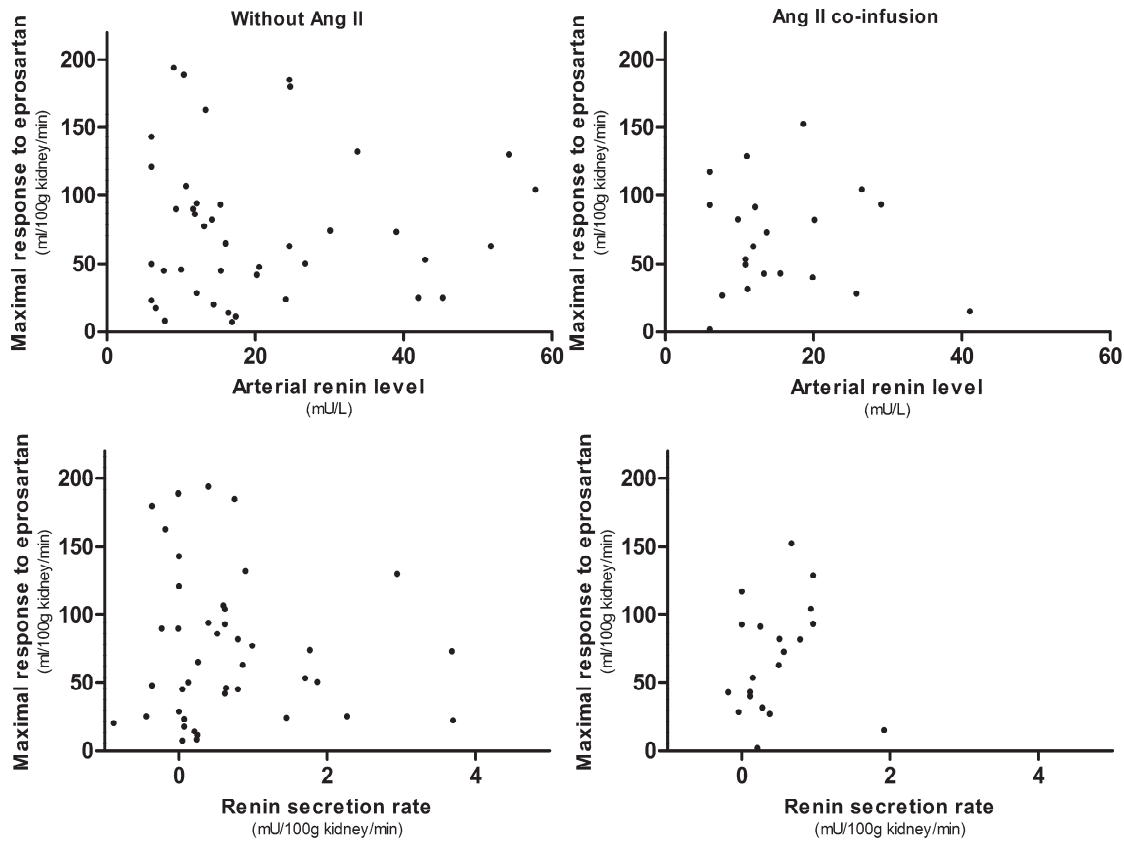

Correlation between renin level (upper panel), renin secretion rate (bottom panel) and the increase in renal blood flow in response to eprosartan infusion (the largest increase in renal blood flow during infusion of eprosartan is shown for each patient) for patients without (left) or with Ang II co-infusion (right). No statistically significant correlation was found. 


\section{Chapter 6}

Renal hemodynamics and renin-angiotensin system activity in humans with multifocal renal artery fibromuscular dysplasia

Daan J.L. van Twist, Alfons J.H.M. Houben, Michiel W. de Haan, Peter W. de Leeuw, Abraham A. Kroon

J Hypertension 2016;34:1160-1169 


\section{Abstract}

Fibromuscular dysplasia (FMD) is the second most common cause of renovascular hypertension. Nonetheless, knowledge on the renal microvasculature and renin-angiotensin-system activity in kidneys with FMD is scarce. Given the fairly good results of revascularization, we hypothesized that the renal microvasculature and renin-angiotensin-system are relatively spared in kidneys with FMD.

In 58 hypertensive patients with multifocal renal artery FMD (off medication) and 116 matched controls with essential hypertension we measured renal blood flow $\left({ }^{133}\right.$ Xenon-washout-method) per kidney and drew blood samples from the aorta and both renal veins to determine renin secretion and glomerular filtration rate per kidney. We found that renal blood flow and glomerular filtration rate in FMD were comparable to those in controls. Although systemic renin levels were somewhat higher in FMD, renal renin secretion was not elevated. Moreover, in patients with unilateral FMD, no differences between the affected and unaffected kidney were observed with regard to renal blood flow, glomerular filtration rate, or renin secretion. In males, renin levels and renin secretion were higher as compared to females. The renal blood flow response to renin-angiotensin-system modulation (by intrarenal infusion of angiotensin II, angiotensin-(1-7), an angiotensin-II-type-1-receptor-blocker, or a nitric-oxide-synthase blocker) was also comparable between FMD and controls. In conclusion, renal blood flow, glomerular filtration, and the response to vasoactive substances in kidneys with multifocal FMD is comparable to patients with essential hypertension, suggesting that microvascular function is relatively spared. Renin secretion was not increased and the response to renin-angiotensinsystem modulation was not affected in kidneys with FMD. 


\section{Introduction}

Fibromuscular dysplasia (FMD) is a non-atherosclerotic, non-inflammatory vascular disease that is the second most common cause of renovascular hypertension. ${ }^{1}$ Recently, both the European Society of Hypertension and the American Heart Association published a scientific statement on FMD, stating that essential parts of knowledge about this condition are missing, particularly with regard to etiology and pathophysiological mechanisms. ${ }^{1,2}$ From studies in patients with atherosclerotic renal artery stenosis it is known that the quality of the kidney tissue is diminished and that the intrarenal renin-angiotensin system (RAS) is disturbed. ${ }^{3-5}$ On kidneys with FMD however, such data on renal microvasculature and RAS activity is lacking. Considering the relatively good effects of revascularization on blood pressure, ${ }^{1}$ we hypothesized that the renal microvasculature is more or less preserved and that RAS activity is not disturbed in patients with FMD. Therefore, we studied renal blood flow, renin secretion, and glomerular filtration in a cohort of patients with untreated multifocal renovascular FMD and compared them to matched patients with essential hypertension (EH) without renovascular abnormalities. As previous research demonstrated major gender differences in the clinical presentation of $\mathrm{FMD}{ }^{6}$ we also assessed whether the abovementioned variables differ between men and women with FMD. In a subgroup of these patients we evaluated intrarenal RAS-activity and the ability of the renal vasculature to respond to vasoactive agents that stimulate or block the vasodilatory or the vasoconstrictory axis of the RAS. If our hypotheses that microvascular function is intact and that intrarenal RAS activity is not disturbed would be true, we expect that the response to RAS-modulation in kidneys with FMD is comparable to that in $\mathrm{EH}$.

\section{Methods}

\section{Patients}

Over the past two decades, we prospectively collected data from hypertensive patients who were angiographically evaluated for the presence of renovascular abnormalities in our hospital according to a standard protocol. Patients had been referred for suspicion of renovascular abnormalities because of difficult-to-treat hypertension (e.g. blood pressure remaining above goal despite the use of three full-dose antihypertensive drugs) and/or clinical suspicion of renovascular abnormalities [e.g. presence of peripheral vascular disease or an abdominal bruit, or a decrease in renal function following treatment with an angiotensin-converting-enzyme (ACE) inhibitor or angiotensin II type-1 receptor $\left(\mathrm{AT}_{1} \mathrm{R}\right)$ blocker]. The study complies with the Declaration of Helsinki and was approved by the Medical Ethics Committee of the Maastricht University Medical Centre. All patients gave written informed consent. 


\section{Protocol}

All patients underwent renal angiography according to the following standard study protocol. In order to avoid interference with the experiments, patients had to discontinue all antihypertensive medication three weeks before the angiographic evaluation. Therefore, we excluded patients with high risk for acute cardiovascular events (a cardiovascular event within 6 months prior to the study or expected rise in ambulatory blood pressure above $180 / 110 \mathrm{mmHg}$ after discontinuation of the antihypertensive medication) from the study. The day before the angiographic evaluation, patients were admitted to our ward, where they collected a 24 hour urine specimen for sodium excretion measurements (as a marker of dietary sodium intake) ${ }^{7}$ and underwent a 24 hour blood pressure measurement (using Spacelabs ambulatory blood pressure monitor type 90207 or $90217-b)$.

After an overnight fast, we selectively catheterized the aorta and both renal veins via the femoral route and drew blood samples from the aorta and both renal veins. Then we measured mean renal blood flow (MRBF, expressed as $\mathrm{ml} / 100 \mathrm{~g}$ kidney/min) in each kidney using the ${ }^{133}$ Xenon washout technique as we previously described. ${ }^{8}$ In summary, ${ }^{133}$ Xenon is infused directly into the renal artery and the washout of ${ }^{133}$ Xenon is recorded with an extracorporeal scintillation counter positioned at the kidney level. After subtraction of the background radiation the washout of ${ }^{133}$ Xenon from the kidney is analysed mathematically with an exponential decay model. With that model we calculated MRBF. In the majority of patients MRBF was measured twice in each kidney. The mean of these two measurements was used for the present analyses. In our hospital, the ${ }^{133}$ Xenon washout technique has a variation coefficient of $8 \%$ for repeated measurements and infusion of placebo $(0.9 \%$ saline) has no measurable effects on MRBF. ${ }^{8}$ Baseline MRBF measurements were obtained, first in the left and then in the right kidney. Subsequently we performed infusion studies as described below in a subgroup of the patients. During the procedure, heart rate and blood pressure (intra-arterially) were monitored continuously. Following the flow measurements, we performed diagnostic subtraction angiography of the renal arteries. No contrast material was administered prior to completion of the flow studies.

Angiographic images of the abdominal aorta and renal arteries were obtained in anterior-posterior and two oblique views with injection of $25 \mathrm{ml}$ of iopromide (Ultravist 300, Bayer HealthCare, Berlin, Germany) through a 4 French Universal Flush catheter (Cordis Europe, Johnson \& Johnson, Waterloo, Belgium) positioned at the level of the renal arteries. Selective renal angiography was performed as well with injection of $12 \mathrm{ml}$ iopromide through a 5 French end-hole Cobra-2 or Simmons-2 catheter (Cordis Europe, Johnson \& Johnson, Waterloo, Belgium). Balloon angioplasty was performed if considered necessary. After the procedure, angiographic films were analysed by two independent, experienced radiologists who were unaware of the results of the MRBF measurements. The patients were classified as having either no renal artery abnormalities, atherosclerotic renal artery stenosis, or FMD (uni- or bilateral), depending upon the presence or absence of visible abnormalities in the 
renal artery. In case of disagreement on renal artery abnormalities, a third radiologists' opinion was decisive.

\section{Inclusion criteria}

Only patients who were diagnosed with FMD of the multifocal type, defined as the presence of multiple non-atherosclerotic stenoses in at least one renal artery, with a typical 'string-of-beads' appearance, ${ }^{9}$ were included in the present analyses. Patients who were diagnosed with unifocal FMD of the renal artery were excluded, as recent data show that its characteristics substantially differ from those with multifocal FMD, ${ }^{9}$ suggesting that this may be a different disease. ${ }^{10}$ Additionally, it is difficult to distinguish unifocal FMD from atherosclerosis, which could result in incorrect inclusion. Patients with atherosclerotic renovascular abnormalities were also excluded, even if there was a combination of both FMD and atherosclerotic renal artery abnormalities. Finally, we excluded patients with a tumour of the kidney, a contracted kidney, syndromal disease such as Ehlers-Danlos syndrome or Marfan syndrome, inflammatory vascular diseases (e.g. Takayasu or giant-cell arteritis), other secondary causes of hypertension, patients in whom renovascular abnormalities had been previously treated, and patients who had only one kidney (congenital or acquired). We took patients with essential hypertension (EH) without renovascular abnormalities as controls in a case-control ratio of 1:2, matched with patients with FMD for gender, age, the presence of diabetes mellitus, current smoking, and body mass index. Patients were only included in the present analysis if both a successful renal angiography and data on MRBF measurements and/or renin sampling were available.

\section{Infusion studies}

In a subpopulation we intrarenally infused agents that interfere with either the $\mathrm{ACE} / \mathrm{Ang}$ II/AT ${ }_{1} \mathrm{R}$-axis or the ACE2/Ang-(1-7)/Mas-axis in the RAS. ${ }^{11}$ As schematically shown in Figure 1, stimulation of these axes was performed with Ang II or Ang-(1-7) respectively. Blockade of the $A C E / A n g ~ I I / A T_{1} R$-axis was performed by $A T_{1} R$ blocker eprosartan and L-NMMA ( $\mathrm{N}^{\mathrm{g}}$-monomethyl L-arginine) was used to block the nitric oxide synthesis in the final pathway of the ACE2/Ang-(1-7)/Mas-axis. We used the following doses (numbers refer to point of interference in Figure 6.1):

1. Ang II at a rate of $0.3 \mathrm{ng} / \mathrm{kg} / \mathrm{min}$ for 5 minutes.

2. Ang-(1-7) at a rate of $0.9 \mathrm{ng} / \mathrm{kg} / \mathrm{min}$ for 5 minutes.

3. $\mathrm{AT}_{1} \mathrm{R}$-blocker eprosartan at a rate of $3 \mu \mathrm{g} / \mathrm{kg} / \mathrm{min}$ for 15 minutes.

4. NO-synthase-blocker L-NMMA in a bolus of $0.03 \mu \mathrm{g} / \mathrm{kg}$.

MRBF was measured during infusion at the end of the abovementioned time period. After infusion of a bolus of L-NMMA, MRBF was measured after 1, 5, 10, and 20 minutes of which the lowest MRBF-value (i.e. the maximal vasoconstrictory effect of L-NMMA) was used in these analyses. Doses and study protocols were derived from 
studies that we performed in hypertensive patients previously. ${ }^{8,12,13}$ For reasons of standardization these studies were always performed in the right kidney only. Therefore, only patients with multifocal FMD of the right kidney (thus unilateral FMD of the right renal artery or bilateral FMD) were included in the analyses regarding the infusion studies. As the diagnosis of multifocal FMD could only be made after the renal angiography (and thus after performing the infusion studies), study groups are of unequal size. Again, we took EH patients as controls in a case-control ratio of 1:2. Since dietary sodium intake can influence the effects of Ang-(1-7) and Ang II on MRBF, ${ }^{13,14} \mathrm{EH}$ control patients were matched for dietary sodium intake based on their $24 \mathrm{~h}$ urinary sodium excretion. ${ }^{7}$

Figure 6.1 Points of interference of the infused agents within the renin-angiotensin system.

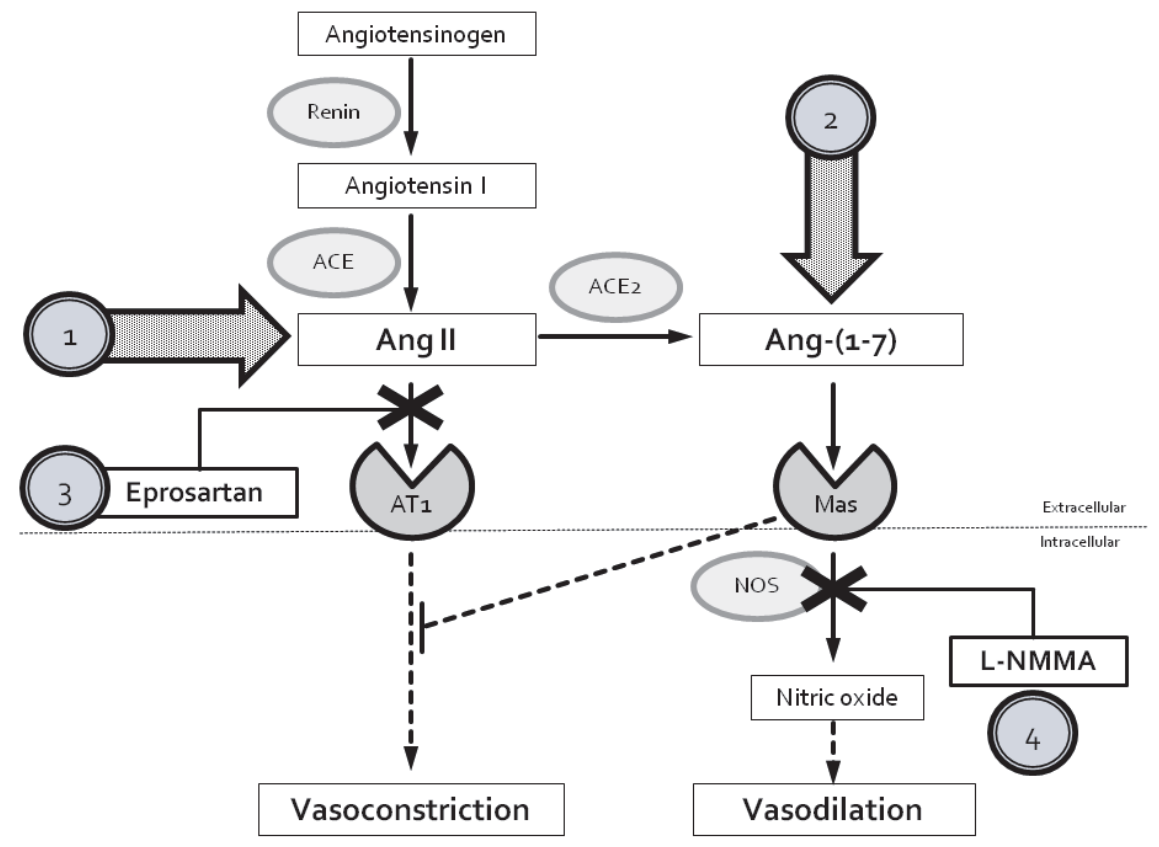

Points of interference within the RAS of stimulating and blocking agents used in this study: 1: Ang II; 2; Ang(1-7); 3: $\mathrm{AT}_{1} \mathrm{R}$ blocker eprosartan; 4: NOS blocker L-NMMA. RAS indicates renin-angiotensin-system; ACE, angiotensin converting enzyme; Ang II, angiotensin II; Ang-(1-7), angiotensin-(1-7); ACE2, angiotensin converting enzyme 2; $A T_{1} R$, angiotensin II type-1 receptor; NOS, nitric oxide synthase; L-NMMA, $\mathrm{N}^{\mathrm{g}}$-monomethyl L-arginine.

\section{Calculations and analyses}

We measured active plasma renin concentration (APRC) in blood samples obtained from the renal artery and both renal veins using an immunoradiometric assay. ${ }^{15}$ We 
assessed renin secretion in three different ways, all in accordance with previous literature: 1) We calculated renin (V-A)/A as the venous-arterial difference in APRC divided by the arterial APRC. ${ }^{16}$ 2) We calculated the renal vein renin ratio (renal vein APRC of the affected kidney divided by renal vein APRC of the unaffected kidney) in patients with unilateral FMD. ${ }^{17} 3$ ) We calculated the renin secretion rate (RSR) as the product of the venous-arterial difference in APRC and the renal plasma flow [MRBF*(1hematocrit)]. ${ }^{18}$ With this method it is possible to calculate the net renin-production per $100 \mathrm{~g}$ of kidney tissue for each kidney. Glomerular filtration rate (eGFR) was estimated using the Chronic Kidney Disease Epidemiology Collaboration (CKD-EPI) formula. ${ }^{19}$ As a proxy for glomerular filtration rate per individual kidney we calculated $G_{F R} R_{\text {proxy }}$ by multiplying the filtration fraction (estimated by means of creatinine extraction) by the renal plasma flow ((renal artery creatinine level minus renal vein creatinine level divided by the renal artery creatinine level) * [MRBF*(1-hematocrit)]). In a post hoc analysis we evaluated differences in FMD patients between patients with high and patients with low renin levels (high renin level was defined as the upper quartile $(>75 \%)$ of renin levels of the patients with $\mathrm{EH}$ in the present study) and between responders and non-responders to balloon angioplasty. According to previous literature, ${ }^{20}$ response was defined as a reduction in diastolic blood pressure $\geq 15 \mathrm{mmHg}$, a systolic blood pressure $\leq 140 \mathrm{mmHg}$, and/or a diastolic blood pressure $\leq 90 \mathrm{mmHg}$ (mean of the second and last measurement of three office blood pressure measurements with 1 minute intervals) one year after balloon angioplasty, without an increase in the number of antihypertensive drugs (evaluated using WHO's Defined Daily Doses classification). ${ }^{21}$

We used Graphpad (Graphpad Software Inc., version 5.01, San Diego, California, USA) and SPSS (SPSS Inc., version 17.0, Chicago, Illinois, USA) for the statistical analyses. We used one-way ANOVA or T-tests (paired and unpaired) for normally distributed data (expressed as mean \pm S.D.). In case of non-normally distributed data (expressed as medians and interquartile range) we used Wilcoxon signed rank test for within-group comparisons and Mann-Whitney $U$ test for between-group comparisons. Chi square test was used to assess categorical data. Correlation was tested using Pearsons R. For comparisons between males and females, high and low renin levels, and responders and non-responders to balloon angioplasty as well as for analyses of correlations, we pooled the data from patients with unilateral FMD and patients with bilateral FMD by selecting the affected kidney in case of unilateral FMD and the right kidney in case of bilateral FMD. ANCOVA was used to adjust for pre-existing differences in patient characteristics. A p-value of $<0.05$ was considered statistically significant. 


\section{Results}

\section{Patient characteristics}

Altogether, 58 patients with multifocal FMD were included in this study (all Caucasian), of whom 25 with bilateral FMD. The majority of patients with FMD were female (44 out of 58). These patients were matched for age, gender, diabetes, smoking, and body mass index in a 1:2 ratio with 116 hypertensive patients without renovascular abnormalities (EH, patients with essential hypertension). As shown in Table 6.1, both groups were comparable with regard to the matching variables and $24 \mathrm{~h}$ urinary sodium excretion. Diastolic blood pressure was significantly lower in patients with FMD $(p=0.044$ vs. EH). Renal function did not significantly differ between both groups, although a trend towards higher eGFR was observed in FMD. None of the study participants had to be excluded from the study because of unacceptable high blood pressure and no acute cardiovascular events were reported during the study period.

Table 6.1 Characteristics of the patients.

\begin{tabular}{lcc}
\hline Characteristic & FMD & EH \\
\hline $\mathrm{n}$ & 58 & 116 \\
Gender (male/female) & $14 / 44$ & $28 / 88$ \\
Age (years) & $53.5 \pm 10.7$ & $53.5 \pm 11.0$ \\
Body mass index $\left(\mathrm{kg} / \mathrm{m}^{2}\right)$ & $26.8 \pm 4.7$ & $26.8 \pm 4.1$ \\
Diabetes mellitus (yes/no) & $1 / 57$ & $2 / 114$ \\
Current smoking (yes/no) & $12 / 46$ & $25 / 91$ \\
24h systolic blood pressure (mmHg) & $157 \pm 26$ & $164 \pm 20$ \\
24h diastolic blood pressure $(\mathrm{mmHg})$ & $92 \pm 16$ & $98 \pm 11^{*}$ \\
eGFR (ml/min/1.73m ${ }^{2}$ ) & $79 \pm 24$ & $73 \pm 27$ \\
Urinary sodium excretion (mmol/24h) & $94 \pm 57$ & $104 \pm 76$ \\
\hline
\end{tabular}

Characteristics of the study patients. Values expressed as mean \pm S.D. or absolute number. eGFR indicates estimated glomerular filtration rate using CKD-EPI formula; ${ }^{19} \mathrm{FMD}$, fibromuscular dysplasia; $\mathrm{EH}$, patients with essential hypertension. ${ }^{*} p=0.044$ vs. FMD. No significant differences for the other patient characteristics were found between both groups.

\section{Renal blood flow}

As shown in Figure 6.2, no significant differences in MRBF were found between FMD and $\mathrm{EH}$. In patients with unilateral FMD (MRBF $240 \pm 77 \mathrm{ml} / 100 \mathrm{~g}$ kidney/min in the affected kidney and $232 \pm 67 \mathrm{ml} / 100 \mathrm{~g}$ kidney/min in the non-affected kidney) and bilateral FMD (MRBF $201 \pm 70$ and $203 \pm 81 \mathrm{ml} / 100 \mathrm{~g}$ kidney/min in the left and right kidney, respectively) no significant differences in MRBF were found between both kidneys. In $\mathrm{EH}$, however, MRBF was higher in the right kidney as compared to the left (218 \pm 74 vs. $196 \pm 64 \mathrm{ml} / 100 \mathrm{~g}$ kidney/min; $p<0.001$ ). 


\section{Renin and creatinine}

Although still within normal range, arterial renin levels were significantly higher in patients with unilateral and bilateral FMD as compared to $\mathrm{EH}$ (both $\mathrm{p}=0.004 \mathrm{vs}$. EH, Figure 6.3). In patients with unilateral FMD, no differences were found between the

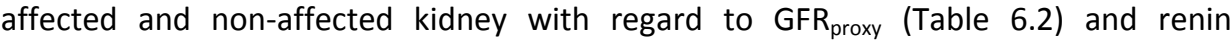
secretion, which was assessed by renal vein renin ratio (the ratio in renal vein renin level between the affected and unaffected kidney; mean 0.98, range 0.72-1.22), renin (V-A)/A (Table 6.2), and RSR (thus calculating the net renin-production per $100 \mathrm{~g}$ of kidney tissue, Figure 6.4). The cut-off for lateralization of renin secretion, based on previous literature ( $>1.5$ for renal vein renin ratio and $>0.48$ in the affected kidney for renin $(V-A) / A)^{16,17}$ was reached in any of the patients with unilateral FMD. No differences in renin (V-A)/A (Table 6.2) or RSR (Figure 6.4) were observed between unior bilateral FMD and $\mathrm{EH}$. In $\mathrm{EH}, \mathrm{GFR}_{\text {proxy }}$ was higher in the right kidney as compared to the left $(p=0.026)$. A similar trend was observed in bilateral FMD, but this was not statistically significant. No statistically significant differences were found for other between or within-group comparisons.

Figure 6.2 Renal blood flow.

Unilateral FMD

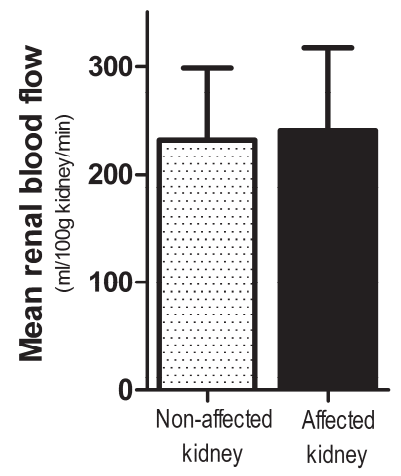

Bilateral FMD

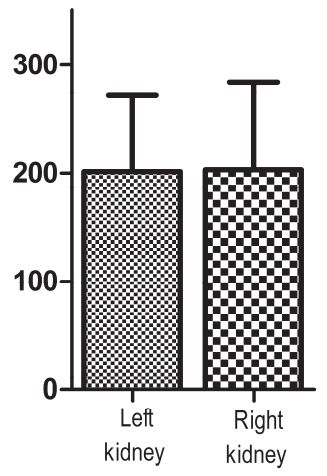

EH

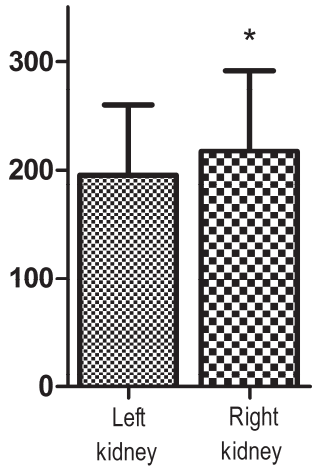

Mean renal blood flow measurements of both kidneys in patients with unilateral FMD, bilateral FMD, and EH. Values expressed as mean and S.D.. FMD indicates fibromuscular dysplasia; EH, patients with essential hypertension. ${ }^{*} p<0.001$ vs. left kidney. No statistically significant differences were found between or in any of the other groups.

\section{Gender differences}

In both men and women, FMD was found more often unilaterally ( 9 out of 14 in males and 24 out of 44 in females). Male patients were older $(p=0.035)$ and had a higher body mass index ( $p=0.006)$ as compared to female patients, but blood pressure, MRBF, 
and GFR $_{\text {proxy }}$ did not significantly differ between both genders (Supplemental Table S6.1). Renin levels [34.7 (14.0-67.8) vs. $17.9(14.2-27.6) \mathrm{mU} / \mathrm{I}]$ and RSR [0.70 (0.27-3.07) vs. $0.33(0.00-0.76) \mathrm{mU} / 100 \mathrm{~g}$ kidney/min], however, were slgnificantly higher in males as compared to females ( $p=0.026$ and $p=0.015$, respectively). A similar pattern was observed after adjustment for differences in patient characteristics (age, body mass index, diabetes, smoking, and urinary sodium excretion) using an ANCOVA model (data not shown). No differences in renin levels or RSR between both genders were observed in patients with $\mathrm{EH}$.

Figure 6.3 Arterial renin levels.

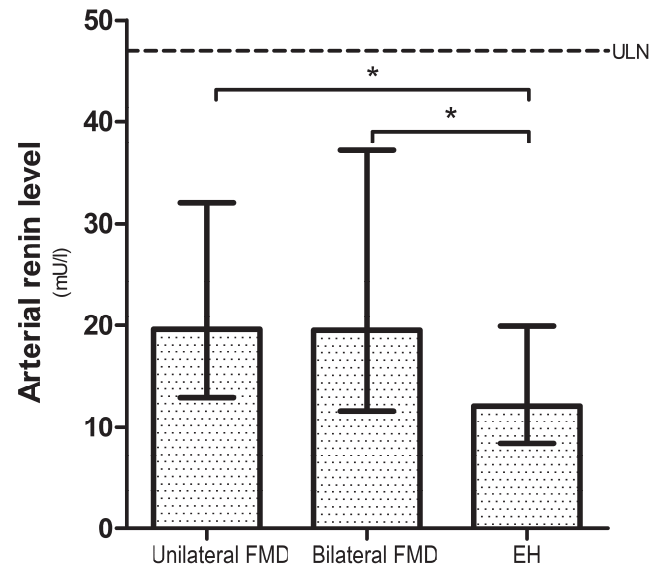

Arterial renin levels, split up for unilateral or bilateral FMD and EH. Values expressed as median and interquartile range. Dotted line indicates upper limit of normal (ULN) for arterial renin level (47 mU/I). FMD indicates fibromuscular dysplasia; $\mathrm{EH}$, patients with essential hypertension. ${ }^{*} \mathrm{p}=0.004$ vs. EH (for both comparisons).

Table 6.2 Renin (V-A)/A and GFR proxy.

\begin{tabular}{lcccc}
\hline Group & $\begin{array}{c}\text { Renin }(\mathrm{V}-\mathrm{A}) / \mathrm{A} \\
\text { left or } \\
\text { unaffected }\end{array}$ & $\begin{array}{c}\text { Renin }(\mathrm{V}-\mathrm{A}) / \mathrm{A} \\
\text { right or } \\
\text { affected }\end{array}$ & $\begin{array}{c}\mathrm{GFR}_{\text {proxy }} \text { left or } \\
\text { unaffected (ml/100g } \\
\text { kidney/min) }\end{array}$ & $\begin{array}{c}\text { GFR } \\
\text { affected } \text { right or } \\
\text { kidney/min) }\end{array}$ \\
\hline Unilateral FMD $(\mathrm{n}=33)$ & $0.18(0.00-0.32)$ & $0.14(0.00-0.32)$ & $39.3 \pm 23.4$ & $38.3 \pm 30.8$ \\
Bilateral FMD $(\mathrm{n}=25)$ & $0.12(0.07-0.19)$ & $0.15(0.02-0.36)$ & $36.0 \pm 22.3$ & $40.0 \pm 24.6$ \\
EH $(\mathrm{n}=116)$ & $0.13(0.01-0.25)$ & $0.15(0.03-0.29)$ & $30.7 \pm 24.9$ & $37.6 \pm 24.8^{*}$ \\
\hline
\end{tabular}

Renin (V-A)/A and GFR proxy for the right and left kidney in patients with bilateral FMD or EH and the affected and unaffected kidney in patients with unilateral FMD. Values expressed as medians and interquartile ranges or mean \pm S.D.. FMD indicates fibromuscular dysplasia; $E H$, patients with essential hypertension; $G_{F R} R_{\text {proxy }}$ a proxy for glomerular filtration rate per kidney. ${ }^{*} p=0.026$ vs. left kidney. No statistically significant differences were found other for within- or between-group comparisons. 


\section{Associations}

As shown in Figure 6.5, an inverse association between MRBF and age was found in EH $(p<0.001)$, but no association was found in FMD. MRBF was positively associated with $24 \mathrm{~h}$ urinary sodium excretion in FMD $(p=0.015)$, but no significant correlation was observed in $\mathrm{EH}$. No significant correlations were found between renin levels and $24 \mathrm{~h}$ urinary sodium excretion, MRBF, or $\mathrm{GFR}_{\text {proxy }}$ in any of the groups (data not shown). $48 \%$ of the patients with FMD had a blood pressure response to balloon angioplasty (Supplemental Table S6.2). In the responder group $(n=25)$, mean drop in blood pressure after 1 year was $23( \pm 19) / 13( \pm 7) \mathrm{mmHg}$, with a decrease in number of antihypertensive drugs of $-1.2( \pm 1.2)$ DDD. In the non-responder group $(n=27)$ no significant changes in blood pressure $[-6( \pm 29) /-2( \pm 14) \mathrm{mmHg} ; \mathrm{p}=0.022$ and $0.001 \mathrm{vs}$. responders for systolic and diastolic blood pressure respectively], with a stable number of antihypertensive drugs [0.0 ( \pm 2.2$)$ DDD; $p=0.017$ vs. responders]. No differences in MRBF, renin secretion, or GFRproxy were found between responders and nonresponders. Moreover, no differences in MRBF and GFR $\mathrm{R}_{\text {proxy }}$ were found between FMD patients with high renin levels (APRC $>19.9 \mathrm{mU} / \mathrm{l}$ ) and those with low renin levels (APRC $<19.9 \mathrm{mU} / \mathrm{l}$; Supplemental Table S6.3).

Figure 6.4 Renin secretion rates

Unilateral FMD

Bilateral FMD

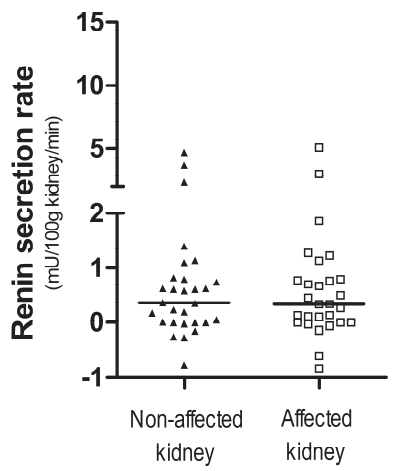

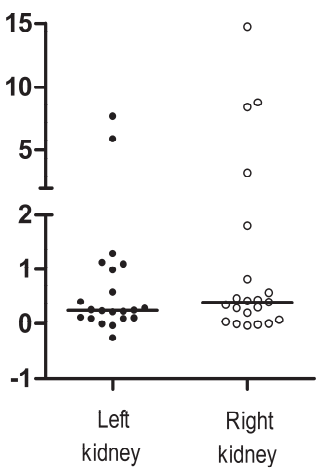

EH

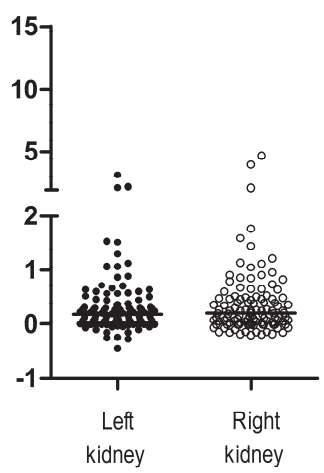

Renin secretion rate of each kidney in patients with unilateral FMD, bilateral FMD, and EH. Horizontal line indicates median. FMD indicates fibromuscular dysplasia; EH, patients with essential hypertension. No statistically significant differences were found between the affected and non-affected kidney, left and right kidney, or between the groups 
Figure 6.5 Correlations of age and urinary sodium excretion with MRBF in FMD and EH.

FMD

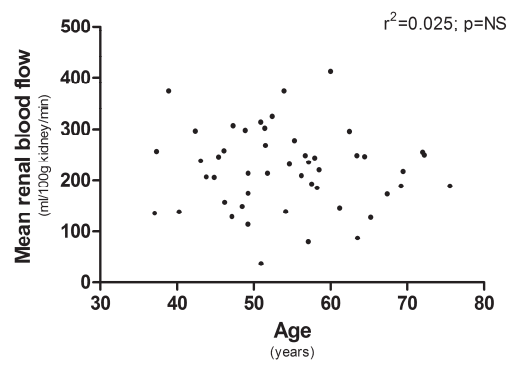

FMD

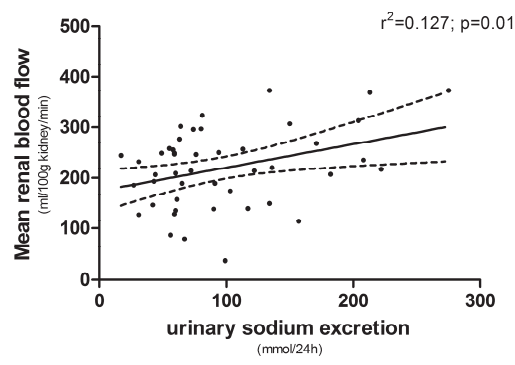

EH

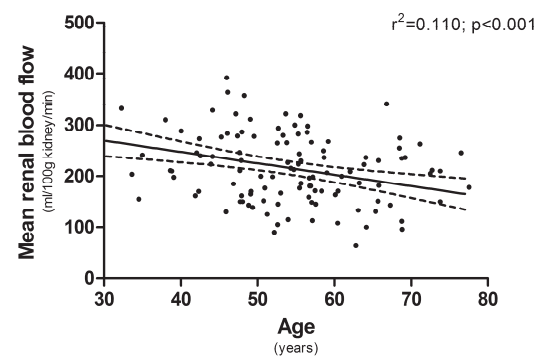

EH

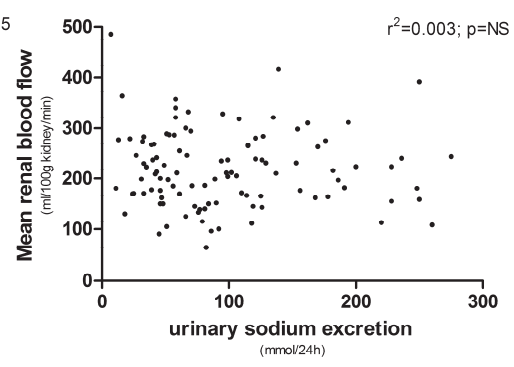

Correlation between MRBF and age (upper panel), and MRBF and 24h urinary sodium excretion (lower panel) for FMD and EH. MRBF was inversely associated with age in EH but not in FMD, whereas MRBF was associated positively with $24 \mathrm{~h}$ urinary sodium excretion in FMD but not in EH. MRBF indicates mean renal blood flow; FMD, fibromuscular dysplasia; EH, patients with essential hypertension.

\section{Infusion studies}

Thirty-three patients with multifocal FMD participated in one of the infusion protocols: 7 underwent infusion with Ang II, 8 with Ang-(1-7), 5 with AT $_{1}$ R-blocker eprosartan, and 13 with NO-synthase-blocker L-NMMA. The results were compared with EH controls in a case-control ratio of 1:2 who were comparable with regard to patient characteristics, baseline MRBF, renin levels, and 24h sodium excretion (Supplemental Table 6.4). As shown in Figure 6.6, intrarenal infusion of Ang-(1-7) or eprosartan resulted in a significant increase in MRBF in patients with FMD and $E H$ ( $p<0.05$ vs. baseline). L-NMMA or Ang II infusion resulted in a significant decrease in renal blood flow in both groups as compared to baseline $(p<0.05)$. The magnitude of these effects did not differ between FMD and EH. Flow results of patients with bilateral FMD did not significantly differ from patients with unilateral FMD (data not shown). During the procedure no significant variations in blood pressure or heart rate were noticed, indicating that no systemic effects of the infused substances occurred. 
Figure 6.6 Effects of vasoactive agents in kidneys with FMD and controls.

Ang II

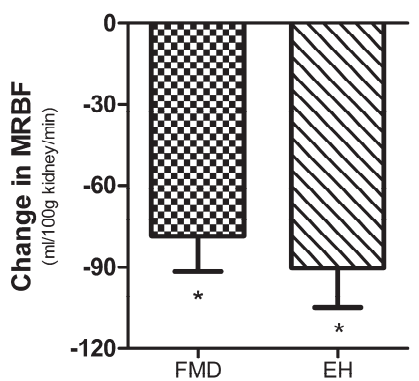

Eprosartan

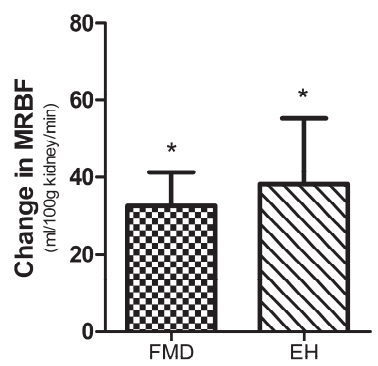

Ang-(1-7)

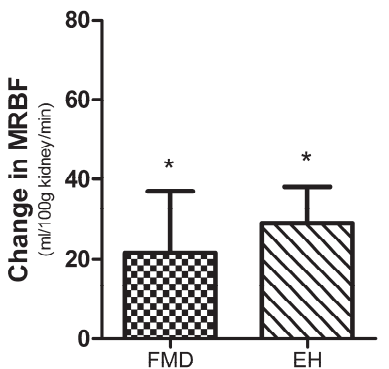

L-NMMA

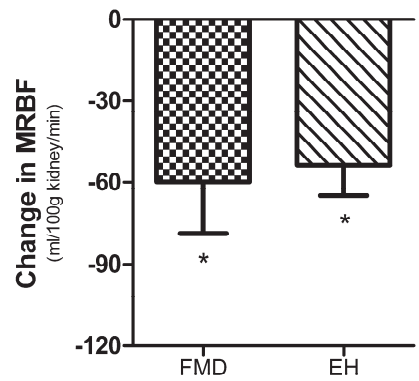

Change in MRBF in response to intrarenal infusion of Ang II, Ang-(1-7), $\mathrm{AT}_{1} \mathrm{R}$-blocker eprosartan, or L-NMMA infusion in kidneys with renal artery FMD and matched controls. Data expressed as mean and S.E.M.. MRBF indicates mean renal blood flow; FMD, fibromuscular dysplasia; $E H$, patients with essential hypertension; Ang-(1-7), angiotensin-(1-7); Ang II, angiotensin II; $\mathrm{AT}_{1} \mathrm{R}$-blocker, angiotensin II type-1 receptor blocker; L-NMMA, $\mathrm{N}^{\mathrm{g}}$-monomethyl L-arginine. ${ }^{*} \mathrm{p}<0.05$ change in MRBF vs. baseline. No differences in magnitude of effects were observed between the groups ( $p=N S$ ).

\section{Discussion}

The major finding of our study is that renal blood flow is not decreased in kidneys with multifocal FMD, but that it is comparable to that in EH. Moreover, renal blood flow is comparable between the affected and unaffected kidney in patients with unilateral FMD. Finally, renin secretion and the response to RAS modulation in FMD are also comparable to those in $\mathrm{EH}$. We studied this in a cohort of patients with untreated multifocal renovascular FMD (off medication) who were, as expected, predominantly female and of relatively young age. ${ }^{22-24}$ We compared them with matched patients with $\mathrm{EH}$, who were comparable with regard to several characteristics including age, gender, dietary sodium intake (all factors influencing renal blood flow and renin secretion), ${ }^{25,26}$ and smoking (a known risk factor for renovascular FMD). ${ }^{27}$ The only observed difference was a marginally higher diastolic blood pressure in the EH group. 


\section{Renal microvasculature}

In the present study, we found several arguments that support our hypothesis that renal microvasculature is relatively intact in patients with FMD:

The first and most important finding is that renal blood flow in FMD is comparable to that in EH. Moreover, we found no differences in MRBF between the affected and unaffected kidney in patients with unilateral FMD. Thus despite the presence of a 'string-of-beads' in the renal artery, MRBF is comparable to that in the unaffected kidney, suggesting that the 'string-of-beads' does not seriously affect local renal blood flow. Previous research on this topic, limited to a study that measured renal blood flow using electron beam computed tomography in ten patients with FMD, also found that renal blood flow in FMD is comparable to that in $\mathrm{EH}^{28}$

Second, glomerular filtration rate, assessed by using GFR $_{\text {proxy }}$ as a proxy, was comparable between FMD and EH. Similar to renal blood flow, GFR proxy was not different between the affected and non-affected kidney in patients with unilateral FMD, suggesting that the local presence of the 'string-of-beads' does not affect glomerular filtration.

Third, in contrast to patients with EH, MRBF is associated with 24h urinary sodium excretion, a marker for dietary sodium intake. ${ }^{7}$ Although we do not have intraindividual data on the effects of variations in sodium intake and thus have to be cautious with drawing conclusions, this suggests that kidneys with FMD are able to modulate renal blood flow in response to sodium intake (as occurs in healthy individuals but not in a large subset of $\mathrm{EH}$ patients), ${ }^{29}$ further supporting our hypothesis.

Fourth, infusion of vasoactive substances in kidneys with FMD resulted in vasodilation or vasoconstriction in a magnitude similar to that in $\mathrm{EH}$. This indicates that renal blood flow can be modulated in individual FMD patients, which confirms our hypothesis that microvascular function is more or less intact in FMD, as this is a prerequisite for the action of vasoactive substances. Unfortunately, other studies on the renal response to vasoactive substances in patients with renovascular FMD are lacking. These findings are in sharp contrast to patients with atherosclerotic renal artery stenosis in whom we previously demonstrated that the vasoactive effects of Ang-(1-7) and L-NMMA are substantially reduced. ${ }^{5,8}$

Additionally, no differences in renal blood flow were found between both kidneys in patients with unilateral or bilateral FMD. This in contrast to patients with $\mathrm{EH}$, in whom asymmetry in renal blood flow (as previously described) ${ }^{31}$ and GFR $_{\text {proxy }}$ was observed between both kidneys. Although the nature of this asymmetry in patients with $\mathrm{EH}$ is unknown, ${ }^{31}$ the absence of this phenomenon in FMD could indicate that some change in the flow balance between both kidneys has occurred. The pathophysiological implications of this phenomenon remain to be elucidated. 


\section{Renin-angiotensin system}

This study also provides several interesting insights into renin-angiotensin system activity in kidneys with multifocal FMD:

First, renin secretion is not increased in kidneys with FMD. Although a wide variation in RSR was observed (Figure 6.4), no statistically significant differences were found between FMD and EH. In addition, we found that renin secretion does not differ between the affected and non-affected kidneys in patients with unilateral FMD: RSR was comparable between both kidneys and renal vein renin ratio and renin (V-A)/A were negative in all patients. Thus, despite the presence of the 'string-of-beads', renin secretion is not increased in the affected kidney as one would expect. Systemic renin levels were somewhat higher in patients with FMD as compared to $\mathrm{EH}$, but still within normal range. Moreover, no differences in the outcome parameters were found between FMD patients with high renin levels and those with low renin levels. Unfortunately, previous research on this topic is limited. Some older studies also found that renal vein levels are not elevated in patients with unilateral FMD. ${ }^{16,17,32}$ In contrast to our study however, those studies found elevated renal vein renin levels in a subset of the patients with FMD. Possibly, patients with unifocal FMD were also included in those studies (the type of FMD was not reported). As unifocal FMD presumably is a different disease than multifocal FMD, ${ }^{9,10}$ renin secretion might be different in those patients. Furthermore, a bias in most of these studies could have occurred by using inferior vena caval renin levels in calculating renin (V-A)/A as a replacement for the arterial renin level, and, probably even more important, by using renal vein renin levels and/or renin ( $\mathrm{V}-\mathrm{A}) / \mathrm{A}$ without taking differences in renal blood flow between both kidneys into account by calculation of the RSR.

The results of the infusion studies also point to a normally functioning RAS in FMD as blocking of the Ang II/ACE/AT $R$ axis by $A T_{1} R$ blocker eprosartan resulted in vasodilation and blocking of the Ang-(1-7)/ACE2/Mas axis (by infusing NO-synthaseblocker L-NMMA) in vasoconstriction, both in a magnitude similar to $\mathrm{EH}$. Stimulation of the Ang II/ACE/AT ${ }_{1} \mathrm{R}$ axis by Ang II induced vasoconstriction, whereas stimulation of the Ang-(1-7)/ACE2/Mas axis by Ang-(1-7) induced vasodilation, again without differences between FMD and EH. Thus, these axes do not appear to exert their effect at full strength yet, as renal blood flow can still be modulated by infusion of Ang-(1-7) or Ang II. As previously mentioned these findings clearly differ from kidneys with atherosclerotic renal artery stenosis, where intrarenal RAS is clearly disturbed given the almost absent effects of Ang-(1-7) and L-NMMA.,

In addition, we found marked differences in renin levels and RSR between male and female FMD patients, even after adjustment for observed differences in age and body mass index. Although it is known that renin levels decrease under influence of estrogens and increase under influence of testosterone to some extent, ${ }^{25}$ it is questionable whether this completely explains the large elevation in renin levels and renin secretion in male FMD patients as we found. Possibly, these differences in renin 
levels play a role in the difference in clinical presentation between men and women as previously reported. ${ }^{6}$

\section{Clinical perspective}

The finding that microvascular function and intrarenal RAS are largely preserved in renovascular FMD could explain the fairly good results of revascularization in kidneys with $\mathrm{FMD}^{30}$ as there is sufficient and qualitatively good kidney tissue available 'behind the string-of-beads' which is able to provide 'normal' blood pressure homeostasis and renal function after revascularization. This in contrast to kidneys with atherosclerotic renal artery stenosis, in which microvascular function and intrarenal RAS are clearly disturbed (as we previously demonstrated), ${ }^{5,8}$ probably playing a role in the considerably lower success-rate of revascularization. ${ }^{33}$ The question that arises, however, is the one how FMD induces hypertension and why revascularization reduces blood pressure. It is questionable whether renin secretion plays a large role, as no differences in renin secretion were found between kidneys with FMD and EH or the unaffected kidney in unilateral FMD. differences in renin secretion with $\mathrm{EH}$ or with the unaffected kidney in unilateral FMD. Moreover, no differences in renin secretion were found between patients who did have a blood pressure response to balloon angioplasty and those who did not. Together with several smaller previous studies that also demonstrated that revascularization can cure or reduce high blood pressure in patients with renovascular FMD without increased RAS-activity, ${ }^{16,17,32,34}$ this indicates that other mechanisms next to renin secretion (e.g. nervous system activity or other humoral factors) contribute to hypertension induced by renovascular FMD. The intact response to RAS-modulation furthermore suggests that antihypertensive drugs targeting the RAS are quite effective in patients with FMD. Consequently, blood pressure in multifocal FMD is, as recently demonstrated, ${ }^{24}$ relatively easily controlled with drug therapy only. This probably also explains why renovascular FMD is underdiagnosed, which is very likely given the relatively high prevalence in screening studies among potential kidney donors ${ }^{22,35}$ compared to the low number of FMD diagnosis made in a hypertension outpatient clinic.

\section{Limitations}

Our study has limited statistical power due to the relatively small number of patients. Hence, we cannot rule out that the outcomes were influenced by small differences in patient characteristics that remained unnoticed. However, as the population was adequately matched with a control group, we consider the risk of such bias to be low. Additionally, these measurements, requiring an invasive procedure in untreated patients with FMD, have not been performed in such a large population so far. In the present study we did not routinely measure trans-stenotic pressure gradients to define the hemodynamic severity of the string-of-beads. Although this could have been of interest, this was not part of our protocol as the value of trans-stenotic pressure 
gradients as a guidance for revascularization has not been established in patients with FMD yet. Therefore, trans-stenotic pressure gradient measurements could not have ruled out that a subset of the population had essential hypertension with the string-ofbeads as an 'innocent bystander'. However, as $48 \%$ of the patients had a blood pressure response to balloon angioplasty, it appears that the string-of-beads played a role in maintaining high blood pressure in at least a subset of our cohort. A relatively large number of non-responders is expected in a population of this age, ${ }^{30}$ presumably caused by irreversible structural changes in the vascular system due to long-term exposure to high blood pressure. Moreover, no differences in renin secretion, MRBF, or GFRproxy were found between responders and non-responders, which strengthens our conclusion that those parameters do not differ between patients with FMD and $\mathrm{EH}$. Another limitation is that the control group consisted of selected patients with $\mathrm{EH}$, mostly with difficult-to-treat hypertension. However, as catheterization of the renal arteries and veins is an invasive procedure with several risks it would be unethical to perform such procedure in healthy individuals as controls. Nevertheless, as intraindividual comparisons between the affected and non-affected kidneys in patients with unilateral FMD demonstrated similar results as compared to $\mathrm{EH}$, we believe that our study provides valuable information that contributes to unravelling the pathophysiological mechanisms in FMD.

\section{Conclusion}

We found that renal blood flow, glomerular filtration rate, and the response to vasoactive substances are preserved in kidneys with multifocal FMD, suggesting that the microvascular function of these kidneys is intact. Although gender differences in renin secretion were observed, renin secretion was not increased in kidneys with FMD. Moreover, the response to renin-angiotensin system modulation is not affected in kidneys with FMD, indicating that intrarenal renin-angiotensin system activity is not disturbed. These findings could explain the fairly good response to revascularization and drug therapies in patients with FMD. 


\section{References}

1. Persu A, Giavarini A, Touze E, Januszewicz A, Sapoval M, Azizi M, Barral X, Jeunemaitre X, Morganti A, Plouin PF, de Leeuw P, Hypertension ESHWG, the K. European consensus on the diagnosis and management of fibromuscular dysplasia. J Hypertens. 2014;32:1367-1378

2. Olin JW, Gornik HL, Bacharach JM, Biller J, Fine L, Gray BH, Gray WA, Gupta R, Hamburg NM, Katzen BT, Lookstein RA, Lumsden AB, Newburger JW, Rundek T, Sperati CJ, Stanley JC. Fibromuscular dysplasia: State of the science and critical unanswered questions: A scientific statement from the american heart association. Circulation. 2014;129:1048-1078

3. Textor SC, Lerman L. Renovascular hypertension and ischemic nephropathy. Am J Hypertens. 2010;23:1159-1169

4. Lerman LO, Textor SC, Grande JP. Mechanisms of tissue injury in renal artery stenosis: Ischemia and beyond. Prog Cardiovasc Dis. 2009;52:196-203

5. Van Twist DJ, Houben AJ, De Haan MW, Mostard GJ, De Leeuw PW, Kroon AA. Angiotensin-(1-7)induced renal vasodilation is reduced in human kidneys with renal artery stenosis. J Hypertens. 2014;32:2428-2432; discussion 2432

6. Kim ES, Olin JW, Froehlich JB, Gu X, Bacharach JM, Gray BH, Jaff MR, Katzen BT, Kline-Rogers E, Mace PD, Matsumoto AH, McBane RD, White CJ, Gornik HL. Clinical manifestations of fibromuscular dysplasia vary by patient sex: A report of the united states registry for fibromuscular dysplasia. $J \mathrm{Am}$ Coll Cardiol. 2013;62:2026-2028

7. Kesteloot $\mathrm{H}$, Joossens JV. The relationship between dietary intake and urinary excretion of sodium, potassium, calcium and magnesium: Belgian interuniversity research on nutrition and health. $J$ Hum Hypertens. 1990;4:527-533

8. Wierema TK, Houben AJ, Kroon AA, Koster D, van der Zander K, van Engelshoven JM, de Leeuw PW. Nitric oxide dependence of renal blood flow in patients with renal artery stenosis. J Am Soc Nephrol. 2001;12:1836-1843

9. Savard S, Steichen O, Azarine A, Azizi M, Jeunemaitre X, Plouin PF. Association between 2 angiographic subtypes of renal artery fibromuscular dysplasia and clinical characteristics. Circulation. 2012;126: 3062-3069

10. Olin JW. Is fibromuscular dysplasia a single disease? Circulation. 2012;126:2925-2927

11. van Twist DJ, Kroon AA, de Leeuw PW. Angiotensin-(1-7) as a strategy in the treatment of hypertension? Curr Opin Nephrol Hypertens. 2014;23:480-486

12. Dielis AW, Smid M, Spronk HM, Houben AJ, Hamulyak K, Kroon AA, Ten Cate H, de Leeuw PW. Changes in fibrinolytic activity after angiotensin ii receptor blockade in therapy-resistant hypertensive patients. J Thromb Haemost. 2007;5:1509-1515

13. van Twist DJ, Houben AJ, de Haan MW, Mostard GJ, Kroon AA, de Leeuw PW. Angiotensin-(1-7)induced renal vasodilation in hypertensive humans is attenuated by low sodium intake and angiotensin ii co-infusion. Hypertension. 2013;62:789-793

14. Visser FW, Boonstra AH, Titia Lely A, Boomsma F, Navis G. Renal response to angiotensin ii is blunted in sodium-sensitive normotensive men. Am J Hypertens. 2008;21:323-328

15. Deinum J, Derkx FH, Schalekamp MA. Improved immunoradiometric assay for plasma renin. Clin Chem. 1999;45:847-854

16. Luscher TF, Greminger P, Kuhlmann U, Siegenthaler W, Largiader F, Vetter W. Renal venous renin determinations in renovascular hypertension. Diagnostic and prognostic value in unilateral renal artery stenosis treated by surgery or percutaneous transluminal angioplasty. Nephron. 1986;44 Suppl 1:17-24

17. Luscher TF, Vetter H, Studer A, Pouliadis G, Kuhlmann U, Glanzer K, Largiader F, Hauri D, Greminger P, Siegenthaler $\mathrm{W}$, Vetter $\mathrm{W}$. Renal venous renin activity in various forms of curable renal hypertension. Clin Nephrol. 1981;15:314-320

18. Blaufox MD, Fromowitz A, Lee $\mathrm{HB}$, Mend $\mathrm{CH}$, Elkin M. Renal blood flow and renin activity in renal venous blood in essential hypertension. Circ Res. 1970;27:913-920

19. Levey AS, Stevens LA, Schmid CH, Zhang YL, Castro AF, 3rd, Feldman HI, Kusek JW, Eggers P, Van Lente $\mathrm{F}$, Greene T, Coresh J, Ckd EPI. A new equation to estimate glomerular filtration rate. Ann Intern Med. 2009;150:604-612 
20. Rundback JH, Sacks D, Kent KC, Cooper C, Jones D, Murphy T, Rosenfield K, White C, Bettmann M, Cortell S, Puschett J, Clair D, Cole P. Guidelines for the reporting of renal artery revascularization in clinical trials. American heart association. Circulation. 2002;106:1572-1585

21. Who collaborating centre for drug statistics methodology. Guidelines for atc classification and ddd assignment, 2015. 2014

22. Hendricks NJ, Matsumoto AH, Angle JF, Baheti A, Sabri SS, Park AW, Stone JR, Patrie JT, Dworkin L, Cooper CJ, Murphy TP, Cutlip DE. Is fibromuscular dysplasia underdiagnosed? A comparison of the prevalence of fmd seen in coral trial participants versus a single institution population of renal donor candidates. Vasc Med. 2014;19:363-367

23. Olin JW, Froehlich J, Gu X, Bacharach JM, Eagle K, Gray BH, Jaff MR, Kim ES, Mace P, Matsumoto AH, McBane RD, Kline-Rogers E, White CJ, Gornik HL. The united states registry for fibromuscular dysplasia: Results in the first 447 patients. Circulation. 2012;125:3182-3190

24. Giavarini A, Savard S, Sapoval M, Plouin PF, Steichen O. Clinical management of renal artery fibromuscular dysplasia: Temporal trends and outcomes. J Hypertens. 2014;32:2433-2438; discussion 2438

25. Hilliard LM, Sampson AK, Brown RD, Denton KM. The "His and hers" Of the renin-angiotensin system. Curr Hypertens Rep. 2013;15:71-79

26. Weidmann P, De Myttenaere-Bursztein S, Maxwell MH, de Lima J. Effect on aging on plasma renin and aldosterone in normal man. Kidney Int. 1975;8:325-333

27. Savard S, Azarine A, Jeunemaitre X, Azizi M, Plouin PF, Steichen O. Association of smoking with phenotype at diagnosis and vascular interventions in patients with renal artery fibromuscular dysplasia. Hypertension. 2013;61:1227-1232

28. Lerman LO, Taler SJ, Textor SC, Sheedy PF, 2nd, Stanson AW, Romero JC. Computed tomographyderived intrarenal blood flow in renovascular and essential hypertension. Kidney Int. 1996;49:846-854

29. Williams GH, Hollenberg NK. Are non-modulating patients with essential hypertension a distinct subgroup? Implications for therapy. Am J Med. 1985;79:3-9

30. Trinquart L, Mounier-Vehier C, Sapoval M, Gagnon N, Plouin PF. Efficacy of revascularization for renal artery stenosis caused by fibromuscular dysplasia: A systematic review and meta-analysis. Hypertension. 2010;56:525-532

31. van Onna M, Houben AJ, Kroon AA, Wierema TK, Koster D, van Engelshoven JM, de Leeuw PW. Asymmetry of renal blood flow in patients with moderate to severe hypertension. Hypertension. 2003;41:108-113

32. Vetter W, Vetter H, Tenschert W, Kuhlmann U, Studer A, Glanzer K, Pouliadis G, Largiader F, Furrer J, Siegenthaler W. [renovascular hypertension. Prognostic value of renal venous renin determinations (author's transI)]. Klin Wochenschr. 1979;57:863-873

33. Cooper CJ, Murphy TP, Cutlip DE, Jamerson K, Henrich W, Reid DM, Cohen DJ, Matsumoto AH, Steffes M, Jaff MR, Prince MR, Lewis EF, Tuttle KR, Shapiro JI, Rundback JH, Massaro JM, D'Agostino RB, Sr., Dworkin LD, Investigators $C$. Stenting and medical therapy for atherosclerotic renal-artery stenosis. $N$ Engl J Med. 2014;370:13-22

34. Marks LS, Maxwell MH, Kaufman JJ. Non-renin-mediated renovascular hypertension: A new syndrome? Lancet. 1977;1:615-617

35. McKenzie GA, Oderich GS, Kawashima A, Misra S. Renal artery fibromuscular dysplasia in 2,640 renal donor subjects: A ct angiography analysis. J Vasc Interv Radiol. 2013;24:1477-1480 


\section{Supplemental tables}

Table S6.1 Gender differences in fibromuscular dysplasia.

\begin{tabular}{lcc}
\hline Parameter & Male & Female \\
\hline $\mathrm{n}$ & 14 & 44 \\
Bilateral FMD $(\mathrm{n})$ & 5 & 20 \\
Age (years) & $58.5 \pm 8.7^{*}$ & $51.9 \pm 10.8$ \\
Body mass index $\left(\mathrm{kg} / \mathrm{m}^{2}\right)$ & $29.7 \pm 4.8^{*}$ & $25.9 \pm 4.3$ \\
24h urinary sodium excretion $(\mathrm{mmol} / 24 \mathrm{~h})$ & $93 \pm 60$ & $95 \pm 58$ \\
24h systolic blood pressure $(\mathrm{mmHg})$ & $155 \pm 35$ & $158 \pm 22$ \\
24h diastolic blood pressure $(\mathrm{mmHg})$ & $96 \pm 21$ & $91 \pm 15$ \\
MRBF (ml/100g kidney/min) & $238 \pm 77$ & $210 \pm 82$ \\
Arterial renin level (mU/l) & $34.7(14.0-67.8)^{*}$ & $17.9(14.2-27.6)$ \\
RSR (mU/100g kidney/min) & $0.70(0.27-3.07)^{*}$ & $0.33(0.00-0.76)$ \\
GFR $_{\text {proxy }}(\mathrm{ml} / 100 \mathrm{~g}$ kidney/min) & $50.5 \pm 17.2$ & $34.0 \pm 30.9$ \\
\hline
\end{tabular}

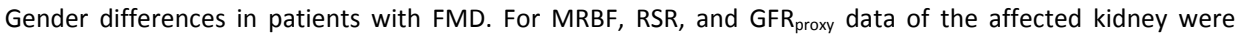
selected in case of unilateral FMD ( 9 males and 24 females). In case of bilateral FMD the right kidney was selected. Values expressed as medians and interquartile range or mean \pm S.D.. RSR indicates renin secretion rate; FMD, fibromuscular dysplasia; EH, patients with essential hypertension; $G_{F R}$ proxy, a proxy for glomerular filtration rate per individual kidney. ${ }^{*} p<0.05$ vs. females.

Table S6.2 Differences between responders and non-responders.

\begin{tabular}{lcc}
\hline Parameter & Responders & Non-responders \\
\hline $\mathrm{n}$ & 25 & 27 \\
Change in systolic blood pressure $(\mathrm{mmHg})$ & $-23 \pm 19 *$ & $-6 \pm 29$ \\
Change in diastolic blood pressure (mmHg) & $-13 \pm 7^{*}$ & $-2 \pm 14$ \\
Change in number of antihypertensive drugs (DDD) & $-1.2 \pm 1.2^{*}$ & $0.0 \pm 2.2$ \\
Gender (male/female) & $4 / 21$ & $6 / 21$ \\
Age (years) & $50.6 \pm 9.3$ & $55.7 \pm 10.9$ \\
Body mass index $\left(\mathrm{kg} / \mathrm{m}^{2}\right)$ & $25.5 \pm 3.6$ & $27.8 \pm 4.8$ \\
MRBF (ml/100g kidney/min) & $212 \pm 93$ & $232 \pm 76$ \\
Arterial renin level (mU/l) & $18.9(14.7-36.1)$ & $20.6(11.5-32.3)$ \\
RSR (mU/100g kidney/min) & $0.35(0.03-0.72)$ & $0.33(0.00-1.20)$ \\
GFR $_{\text {proxy }}(\mathrm{ml} / 100 \mathrm{~g}$ kidney/min) & $44.1 \pm 24.4$ & $34.5 \pm 31.6$ \\
\hline
\end{tabular}

Differences in MRBF, renin secretion, and GFRproxy between FMD patients with and without blood pressure response to balloon angioplasty. Response was defined as a reduction in diastolic blood pressure $\geq 15 \mathrm{mmHg}$, a systolic blood pressure $\leq 140 \mathrm{mmHg}$, and/or a diastolic blood pressure $\leq 90 \mathrm{mmHg}$ one year after balloon angioplasty. No follow-up data were available for four patients (due to follow-up in another hospital) and in two patients no balloon angioplasty was performed. For MRBF, RSR, and GFRproxy data of the affected kidney were selected in case of unilateral FMD. In case of bilateral FMD the right kidney was selected. Values expressed as medians and interquartile range or mean \pm S.D.. RSR indicates renin secretion rate; FMD, fibromuscular dysplasia; GFRproxy, a proxy for glomerular filtration rate per individual kidney; DDD, daily defined dose according to WHO Defined Daily Dose classification. ${ }^{21} * p<0.05$ vs. non-responders. 
Table S6.3 Differences between FMD patients with high and low renin levels.

\begin{tabular}{lcc}
\hline Parameter & High renin level & Low renin level \\
\hline $\mathrm{n}$ & 27 & 31 \\
Gender (male/female) & $10 / 17$ & $4 / 27$ \\
Arterial renin level $(\mathrm{mU} / \mathrm{l})$ & $35.2(25.6-55.3)^{*}$ & $12.2(8.9-16.6)$ \\
$\mathrm{RSR}(\mathrm{mU} / 100 \mathrm{~g}$ kidney/min) & $0.77(0.33-2.98)^{*}$ & $0.13(0.00-0.41)$ \\
Age (years) & $50.5 \pm 8.7^{*}$ & $56.1 \pm 11.6$ \\
Body mass index $\left(\mathrm{kg} / \mathrm{m}^{2}\right)$ & $27.6 \pm 4.8$ & $26.1 \pm 4.5$ \\
MRBF (ml/100g kidney/min) & $232 \pm 87$ & $217 \pm 75$ \\
Responders to balloon angioplasty $(\mathrm{n})$ & 10 & 15 \\
GFR $_{\text {proxy }}(\mathrm{ml} / 100 \mathrm{~g}$ kidney/min) & $38.7 \pm 28.2$ & $39.2 \pm 29.3$ \\
\hline
\end{tabular}

Differences between FMD patients with high and low renin levels. High renin level was defined as arterial renin level $>19.9 \mathrm{mU} / \mathrm{I}$ (corresponding to the upper quartile of renin levels found in patients with $\mathrm{EH}$ in the present study). For MRBF, RSR, and GFR $_{\text {proxy }}$ data of the affected kidney were selected in case of unilateral FMD ( 9 males and 24 females). In case of bilateral FMD the right kidney was selected. Values expressed as medians and interquartile range or mean \pm S.D.. RSR indicates renin secretion rate; FMD, fibromuscular dysplasia; $\mathrm{EH}$, patients with essential hypertension; $\mathrm{GFR}_{\text {proxy }}$, a proxy for glomerular filtration rate per individual kidney. ${ }^{*} \mathrm{p}<0.05$ vs. low renin level

Table S6.4 Baseline characteristics of patients participating in infusion studies.

\begin{tabular}{lcc}
\hline Baseline characteristic & FMD & EH \\
\hline $\mathrm{n}$ & 33 & 66 \\
Gender (male/female) & $4 / 29$ & $19 / 47$ \\
Age (years) & $52.5 \pm 8.5$ & $52.3 \pm 4.0$ \\
Body mass index (kg/m ${ }^{2}$ ) & $26.4 \pm 4.7$ & $26.8 \pm 4.0$ \\
24h ambulatory systolic blood pressure $(\mathrm{mmHg})$ & $157 \pm 24$ & $162 \pm 25$ \\
24h ambulatory diastolic blood pressure $(\mathrm{mmHg})$ & $93 \pm 16$ & $98 \pm 15$ \\
eGFR (ml/min/1.73m ${ }^{2}$ ) & $85 \pm 16$ & $78 \pm 23$ \\
Urinary sodium excretion (mmol/24h) & $99 \pm 61$ & $104 \pm 61$ \\
Arterial renin level (mU/l) & $18.1(12.3-28.9)$ & $15.6(9.0-28.8)$ \\
Baseline MRBF right (ml/100g kidney/min) & $237 \pm 79$ & $231 \pm 84$ \\
RSR right (mU/100g kidney/min) & $0.31(0.02-0.65)$ & $0.30(0.01-0.71)$ \\
\hline
\end{tabular}

Baseline characteristics of the patients included in the infusion studies. Values expressed as mean \pm S.D. or median (interquartile range). eGFR indicates estimated glomerular filtration rate using CKD-EPI formula; ${ }^{19}$ FMD, fibromuscular dysplasia. No statistically significant differences were found between the groups. 
Chapter 7

Pathophysiological differences between multifocal fibromuscular dysplasia and atherosclerotic renal artery stenosis

Daan J.L. van Twist, Alfons J.H.M. Houben, Peter W. de Leeuw, Abraham A. Kroon Submitted 


\section{Abstract}

Fibromuscular dysplasia (FMD) and atherosclerotic renal artery stenosis (ARAS) are the most common causes of renovascular hypertension. Thus far, FMD is believed to cause hypertension via similar mechanisms as ARAS, i.e. due to a decrease in renal blood flow which subsequently leads to increased renin secretion. However, given the differences in the blood pressure response to revascularization between patients with ARAS and FMD we questioned whether this is true. Therefore, we measured renal blood flow $\left({ }^{133}\right.$ Xenon washout method), renin secretion, and glomerular filtration rate per kidney in a cohort of 58 patients with multifocal FMD and 111 patients with ARAS (off medication, prior to revascularization). We found that renal blood flow is significantly higher in FMD as compared to ARAS. In patients with unilateral ARAS, renin secretion was increased in the affected kidney as compared to the unaffected kidney. This lateralization in renin secretion, however, was not found in unilateral FMD. After correction for differences in baseline characteristics we found that renin secretion was lower and glomerular filtration was higher in FMD as compared to ARAS. Moreover, the relationship between blood pressure and renin secretion in FMD was inverse to that in ARAS. In conclusion, these findings contradict with the hypothesis that FMD induces hypertension via the similar pathophysiological mechanism as in ARAS. Furthermore, microvasculature appears to be better preserved in FMD, which might explain the relatively good results of revascularization (as compared to ARAS) in these patients. 


\section{Introduction}

Fibromuscular dysplasia (FMD) is after atherosclerosis the second most common cause of renovascular hypertension. ${ }^{1}$ In contrast to atherosclerotic renal artery stenosis (ARAS), little is known about the pathophysiological mechanisms causing hypertension in these patients, which was recently highlighted in scientific statements of the European Society of Hypertension and the American Heart Association. ${ }^{1,2}$ Thus far, it was assumed that renal artery FMD causes hypertension due to a decrease in renal blood flow which subsequently leads to increased renin secretion, ${ }^{3}$ similar to (and based on experiments in) two-kidney-one-clip (2K1C) animal models and patients with renovascular hypertension caused by ARAS. In Chapter 6, we challenged this hypothesis by demonstrating that renal blood flow is not reduced and renin secretion is not increased in kidneys with FMD, but comparable to patients with essential hypertension. Hence, we hypothesized that the pathophysiological mechanisms in hypertension due to renovascular FMD differ from those in ARAS. As several characteristics, such as age, gender, and especially the response to revascularization substantially differ between patients with FMD and patients with ARAS, ${ }^{1}$ we furthermore hypothesized that the renal microvasculature is more preserved in FMD as compared to ARAS. Therefore, we studied renal blood flow, renal function, renin secretion, and its relationship to blood pressure in a cohort of patients with untreated multifocal renovascular FMD and compared them to patients with ARAS.

\section{Methods}

\section{Patients}

We prospectively collected data from all hypertensive patients who were angiographically evaluated for the presence of renovascular abnormalities in our hospital during the past two decades. These patients had been referred because of difficult-to-treat hypertension (i.e. blood pressure remaining above goal despite the use of three full-dose antihypertensive drugs) and/or clinical suspicion of renovascular abnormalities (e.g. presence of an abdominal bruit, peripheral vascular disease, or a decrease in renal function following treatment with an angiotensin-converting enzyme inhibitor or angiotensin II type-1-receptor blocker).

\section{Protocol}

To avoid interference with the measurements, the patients discontinued all antihypertensive medication three weeks before the angiographic evaluation. Patients with high risk for acute cardiovascular events [i.e. a recent cardiovascular event ( $<6$ months) or an expected rise in ambulatory blood pressure above 180/110 $\mathrm{mmHg}$ after discontinuation of antihypertensive drugs], were excluded from the study. The 
day preceding the angiographic evaluation patients underwent 24 hour blood pressure measurement (24h ABPM, using SpaceLabs ambulatory blood pressure monitor type 90207 or $90217-b)$ and collected a 24 hour urine specimen for sodium excretion measurements as a marker for dietary sodium intake. ${ }^{4}$

Patients were admitted to our ward and were fasted overnight. Under continuous monitoring of heart rate and blood pressure (intra-arterially) we selectively catheterized the aorta and both renal veins via the femoral route and drew blood samples from the aorta and both renal veins. After this, we measured mean renal blood flow (MRBF, expressed as $\mathrm{ml} / 100 \mathrm{~g}$ kidney/min) using the ${ }^{133}$ Xenon washout technique as previously described. ${ }^{5}$ In short, ${ }^{133}$ Xenon is infused directly into the renal artery and the washout of ${ }^{133}$ Xenon is recorded with a scintillation counter positioned extracorporeally at the kidney level. During the measurements the patients are required to wear a tight mask to prevent spreading of exhaled ${ }^{133}$ Xenon into the room. After subtraction of background radiation the washout of ${ }^{133}$ Xenon from the kidney is analyzed mathematically using an exponential decay model. From this model MRBF is calculated. In the majority of patients, MRBF was measured twice in each kidney, of which the mean was used in the analyses. In our hospital, ${ }^{133}$ Xenon washout technique has a variation coefficient of $8 \%$ for repeated measurements. ${ }^{5}$ Following the ${ }^{133}$ Xenon washout procedure, we performed diagnostic subtraction angiography of the renal arteries. No contrast material was administered prior to completion of the blood sampling and ${ }^{133}$ Xenon washout studies.

Selective renal angiography was performed with injection of $12 \mathrm{ml}$ iopromide (Ultravist 300, Bayer HealthCare, Berlin, Germany) through a 5 French end-hole Cobra-2 or Simmons-2 catheter (Cordis Europe, Johnson \& Johnson, Waterloo, Belgium). Angiographic images of the abdominal aorta and renal arteries were obtained in anterior-posterior and two oblique views using a 4 French Universal Flush catheter (Cordis Europe, Johnson \& Johnson, Waterloo, Belgium) positioned at the level of the renal arteries and injection of $25 \mathrm{ml}$ of iopromide.

The angiographic films were analyzed by two independent, experienced radiologists who were unaware of the results of the MRBF measurements. The patients were classified as having either no renal artery abnormalities, ARAS (uni- or bilateral), or FMD (uni- or bilateral), depending upon the presence or absence of visible abnormalities in the renal artery. In case of ARAS, the radiologists noted the grade of the stenosis (low grade less than $50 \%$ reduction in luminal diameter, high grade more than $50 \%$ ), which was measured using an electronic caliper. As obtaining an objective measure of stenosis is difficult in case of FMD, the degree of stenosis was not calculated in these patients. In case of disagreement on renal artery abnormalities, a third radiologists' opinion was decisive. This protocol was approved by the Medical Ethics Committee of the Maastricht University Medical Centre and all patients gave written informed consent. 


\section{Inclusion criteria}

Patients were only included in the present analysis if both a successful renal angiography and data on MRBF measurements and/or selective blood sampling were available. We included all patients who were diagnosed with FMD of the multifocal type, which is defined as the presence of more than 2 non-atherosclerotic stenoses with a typical string-of-beads appearance in at least one renal artery. ${ }^{6}$ Furthermore, we included patients with high grade ARAS, which was defined as a reduction in luminal diameter of $50 \%$ or more. Patients with unifocal FMD of the renal artery were excluded, as previous data suggest this is probably a different disease entity ${ }^{6,7}$ and difficulties could arise in distinguishing it from ARAS. Patients with low grade ARAS (a reduction in luminal diameter of less than $50 \%$ ) were also excluded, as the many uncertainties that exist among low grade $\mathrm{ARAS}^{8}$ might obscure the results. Moreover, we excluded patients without renovascular abnormalities (i.e. patients with essential hypertension), patients in whom renovascular abnormalities had been previously treated, patients with a combination of ARAS and FMD, patients with other secondary causes of hypertension, and patients who had only one kidney (congenital or acquired), a contracted kidney, a tumor of the kidney, syndromal disease (such as Ehlers-Danlos syndrome or Marfan syndrome), or inflammatory vascular diseases (e.g. Takayasu or giant-cell arteritis).

\section{Calculations and analyses}

We measured active plasma renin concentration (APRC) and creatinine levels in blood samples obtained from the renal artery and both renal veins. APRC was measured using an immunoradiometric assay. ${ }^{9}$ We assessed renin secretion in three different ways according to previous literature: 1 ) Renin (V-A)/A, calculated as the venousarterial difference in APRC divided by the arterial APRC; ${ }^{10}$ 2) renal vein renin ratio (renal vein renin level of the affected kidney divided by renal vein renin level of the non-affected kidney) ${ }^{11} 3$ ) renin secretion rate (RSR), ${ }^{12}$ calculated as the product of the venous-arterial difference in APRC and the renal plasma flow [MRBF*(1-hematocrit)], a method that makes it possible to calculate the net renin-production per $100 \mathrm{~g}$ of kidney tissue for each individual kidney.

Estimated glomerular filtration rate (eGFR) was calculated using the Chronic Kidney Disease Epidemiology Collaboration (CKD-EPI) formula. ${ }^{13}$ GFR $_{\text {proxy }}$ was calculated as a proxy for glomerular filtration rate per individual kidney by multiplying the filtration fraction (estimated by means of creatinine extraction) by the renal plasma flow ((renal artery creatinine level minus renal vein creatinine level divided by the renal artery creatinine level) * [MRBF*(1-hematocrit)]). Renovascular resistance (RVR) was calculated as mean arterial blood pressure divided by MRBF and is expressed as arbitrary units (AU).

SPSS (SPSS Inc., version 17.0, Chicago, Illinois, USA) and Graphpad (Graphpad Software Inc., version 5.01, San Diego, California, USA) were used for the statistical analyses. 
T-tests (paired and unpaired) were used for normally distributed data (expressed as mean \pm S.D. unless otherwise stated). We used Wilcoxon signed rank test and MannWhitney $U$ test for non-normally distributed data (expressed as medians and interquartile range). Chi square test was used to assess categorical data and correlation was tested using Pearsons R. For statistical analyses of correlations of the outcome measures, we pooled the data obtained from the affected kidney of patients with unilateral ARAS or FMD with the data obtained from the right kidney of patients with bilateral ARAS or FMD. We used mean arterial blood pressure instead of systolic and diastolic blood pressure to simplify analyses of correlation. An ANCOVA model was used to adjust for pre-existing differences in patient characteristics. A p-value of $<0.05$ was considered statistically significant.

\section{Results}

\section{Patient characteristics}

In total, 58 patients with multifocal FMD and 111 patients with high grade ARAS (reduction in luminal diameter of at least 50\%) were included (all Caucasian). As shown in Table 7.1, several differences in patient characteristics were found between ARAS and FMD: patients with FMD were more often female ( $p<0.001$ vs. ARAS), were younger $(p<0.001)$, had a lower prevalence of smoking and diabetes mellitus $(p=0.041$ and $p=0.007$ respectively), and had a higher eGFR $(p<0.001)$. Systolic blood pressure (24h ambulatory blood pressure, data were available for 29 patients with FMD and 63 with ARAS) was significantly higher in ARAS ( $p=0.022$ ). No differences in $24 \mathrm{~h}$ urinary sodium excretion were found between both groups. During the study period no acute cardiovascular events were reported and any of the study participants had to be excluded from the study because of unacceptable high blood pressure.

Table 7.1 Characteristics of the patients.

\begin{tabular}{lcc}
\hline Patient characteristic & FMD & ARAS \\
\hline $\mathrm{n}$ & 58 & 111 \\
Gender (male/female) & $14 / 44$ & $64 / 47^{*}$ \\
Age (years) & $53.5 \pm 10.7$ & $63.4 \pm 8.1^{*}$ \\
Body mass index $\left(\mathrm{kg} / \mathrm{m}^{2}\right)$ & $26.8 \pm 4.7$ & $26.5 \pm 4.0$ \\
Diabetes mellitus $(\mathrm{n}(\%))$ & $1(2 \%)$ & $17(15 \%)^{\dagger}$ \\
Current smoking ( $\mathrm{n}(\%))$ & $12(21 \%)$ & $41(38 \%)^{\dagger}$ \\
24h systolic blood pressure (mmHg) & $157 \pm 26$ & $170 \pm 23^{\dagger}$ \\
24 diastolic blood pressure (mmH) & $92 \pm 16$ & $92 \pm 12$ \\
eGFR (ml/min/1.73m ${ }^{2}$ ) & $79 \pm 23$ & $54 \pm 23^{*}$ \\
Urinary sodium excretion (mmol/24h) & $94 \pm 57$ & $94 \pm 60$ \\
\hline
\end{tabular}

Characteristics of the study patients. Values expressed as mean \pm S.D.. eGFR indicates estimated glomerular filtration rate using the CKD-EPI formula; ${ }^{13}$ FMD, fibromuscular dysplasia; ARAS, atherosclerotic renal artery stenosis. ${ }^{*} p<0.001$ vs. FMD, ${ }^{\dagger} p<0.05$ vs. FMD. 


\section{Renal blood flow}

As shown in Figure 7.1, MRBF of both kidneys was significantly higher in FMD as compared to ARAS, in patients with unilateral abnormalities as well as in patients with bilateral abnormalities $(p<0.001)$. No significant differences in MRBF were found between the affected and non-affected kidney in unilateral FMD or ARAS, but in patients with bilateral ARAS, MRBF of the left kidney was significantly lower as compared to the right kidney $(p=0.003)$. In FMD, however, no such difference was observed. As shown in Table 7.2, RVR was significantly higher in kidneys with ARAS as compared to FMD. From 5 patients with FMD and 20 patients with ARAS, MRBF data could not be obtained from any of the kidneys and in 22 patients only from one kidney. Reasons for this were difficulties in advancing the catheter into the renal artery (without the use of iodinated contrast agents), unreliable measurement of the scintillation counter, or patient's intolerance of wearing the tight mask that is necessary to prevent spreading of exhaled ${ }^{133}$ Xenon into the room.

Figure 7.1 Mean renal blood flow.

Unilateral

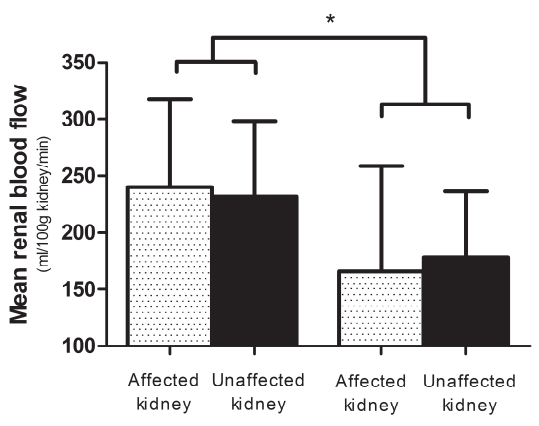

FMD

ARAS
Bilateral

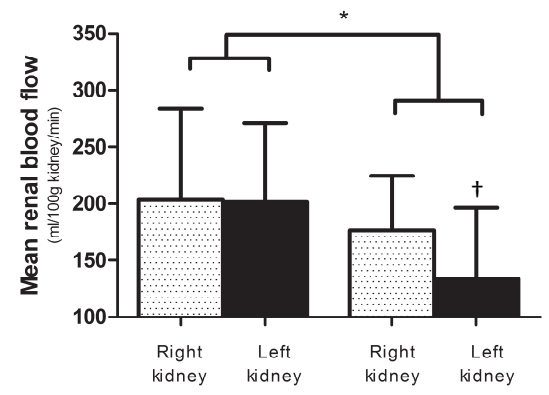

FMD
ARAS

Mean renal blood flow according to the presence of renovascular abnormalities, split up for unilateral (left panel) or bilateral (right panel) renovascular abnormalities. Values expressed as mean \pm S.D.. FMD indicates fibromuscular dysplasia; ARAS, atherosclerotic renal artery stenosis. ${ }^{*} p<0.001$ vs. FMD, $+p=0.003$ vs. right kidney.

\section{Renin}

We found a wide variation in systemic renin levels, but without significant differences between the groups (Table 7.2). Renin (V-A)/A (Table 7.2) and RSR (Figure 7.2) were comparable between bilateral FMD and bilateral ARAS, without differences between the left and right kidney. In the 64 patients with unilateral ARAS, renal vein renin ratio (cut-off $\geq 1.5$ based on previous literature) ${ }^{11}$ was positive in 20 patients (mean of all patients with unilateral ARAS 1.55, range 0.70-6.00) and renin (V-A)/A (cut-off $\geq 0.48$ based on previous literature) ${ }^{10}$ was positive in 19 patients (Table 7.2) with unilateral 
ARAS. In unilateral FMD, however, renal vein renin ratio (mean 0.98, range 0.72-1.22; $p=0.002$ vs. ARAS) and renin (V-A)/A were negative in all 33 patients. RSR and renin (V$A) / A$ were significantly higher in the affected kidney as compared to the non-affected kidney in unilateral ARAS ( $p=0.014$ and $p<0.001$, respectively), but not in unilateral FMD (Table 7.2 and Figure 7.2). Renin (V-A)/A in the affected kidney was significantly higher in unilateral ARAS as compared to unilateral FMD ( $p=0.011)$. However, after correction for renal blood flow by calculating the RSR, this difference is no longer statistically significant (Figure 7.2).

Table 7.2 Renin levels and renovascular resistance.

\begin{tabular}{llcccccc}
\hline Group & & $\mathrm{n}$ & $\begin{array}{c}\text { Arterial renin } \\
\text { level }(\mathrm{mU} / \mathrm{l})\end{array}$ & $\begin{array}{c}\text { Renin (V-A)/A } \\
\text { non-affected or } \\
\text { left kidney }\end{array}$ & $\begin{array}{c}\text { Renin (V-A)/A } \\
\text { affected or right } \\
\text { kidney }\end{array}$ & $\begin{array}{c}\text { RVR (AU) non- } \\
\text { affected or left } \\
\text { kidney }\end{array}$ & $\begin{array}{c}\text { RVR (AU) affected } \\
\text { or right kidney }\end{array}$ \\
\hline Unilateral & FMD & 33 & $19.6(12.9-32.1)$ & $0.18(0.00-0.32)$ & $0.14(0.00-0.32)$ & $0.48(0.40-0.61)$ & $0.43(0.36-0.57)$ \\
& ARAS & 64 & $20.8(11.7-47.7)$ & $0.08(-0.02-0.20)$ & $0.31(0.08-0.93)^{* \dagger}$ & $0.61(0.48-0.77) \ddagger$ & $0.58(0.45-1.01) \neq$ \\
\hline Bilateral & FMD & 25 & $19.5(11.6-37.2)$ & $0.12(0.06-0.19)$ & $0.16(0.03-0.36)$ & $0.50(0.41-0.60)$ & $0.45(0.33-0.54)$ \\
& ARAS & 47 & $28.5(14.5-43.5)$ & $0.15(0.02-0.35)$ & $0.20(0.02-0.37)$ & $0.82(0.62-1.20) \dagger$ & $0.68(0.56-1.07) \ddagger$ \\
\hline
\end{tabular}

Systemic renin levels (arterial level), renin (V-A)/A, and RVR for each kidney in patients with uni- or bilateral FMD or ARAS. Data expressed as median (interquartile range). FMD indicates fibromuscular dysplasia; ARAS, atherosclerotic renal artery stenosis; RVR, renovascular resistance; $A U$, arbitrary units. ${ }^{*} p=0.011$ vs. unilateral FMD; $\dagger p<0.001$ vs. contralateral kidney, $\ddagger p<0.028$ vs. FMD. No statistically significant differences were found for other between- and within-group comparisons.

Figure 7.2 Renin secretion rate.

Unilateral

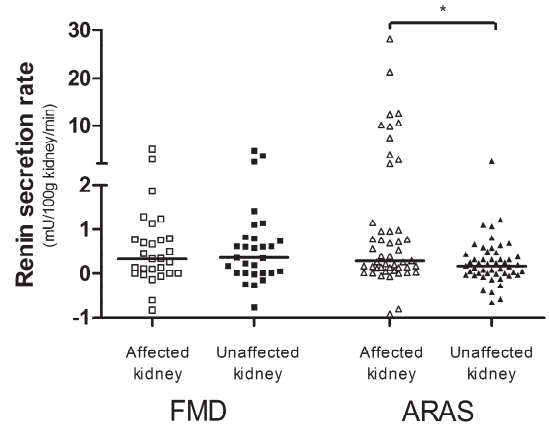

Bilateral

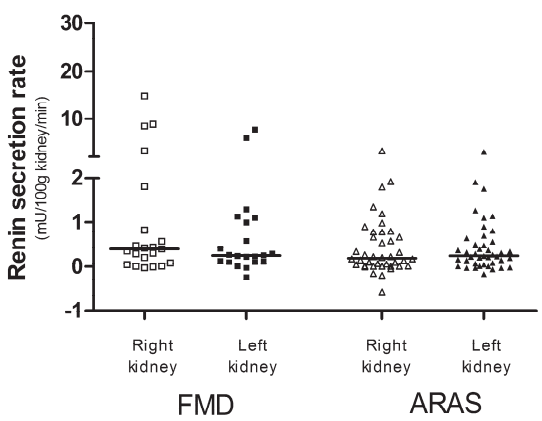

Renin secretion rates of patients with uni- or bilateral FMD or ARAS. Horizontal line indicates median. ${ }^{*} p=0.014$ for comparison between affected and non-affected kidney in unilateral ARAS. FMD indicates fibromuscular dysplasia; ARAS, atherosclerotic renal artery stenosis. No statistically significant differences were found for within- or between-group comparisons

\section{GFR proxy}

Although not statistically significant, a trend towards higher $\mathrm{GFR}_{\text {proxy }}$ was observed in FMD as compared to ARAS (Figure 7.3). In unilateral ARAS, GFR proxy $_{\text {was }}$ reduced in the 
affected kidney as compared to non-affected kidney $(p=0.042)$. In bilateral ARAS, $G_{\text {proxy }}$ was lower in the left kidney as compared to the right kidney $(p=0.022)$. In patients with FMD (uni- or bilateral), however, no differences in $\mathrm{GFR}_{\text {proxy }}$ between both kidneys were observed.

Figure 7.3 GFR $_{\text {proxy }}$.
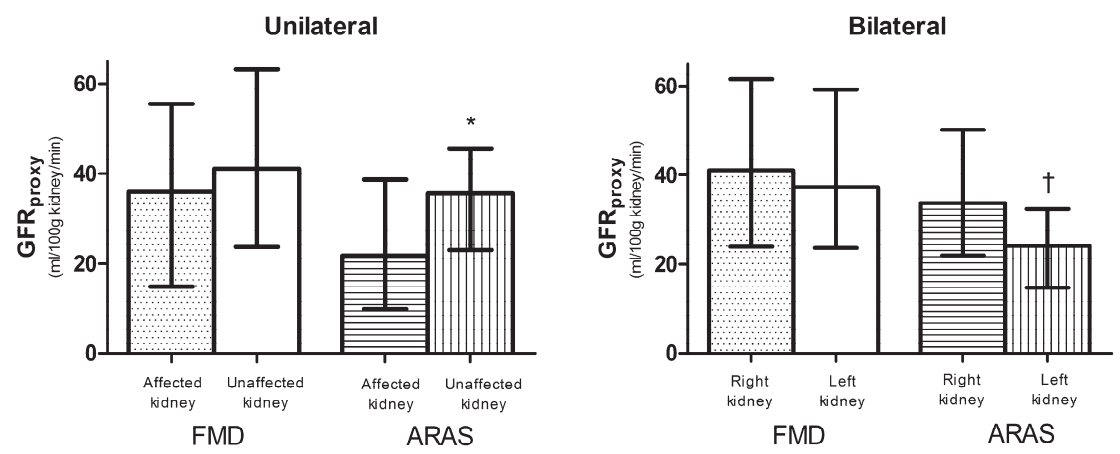

$\mathrm{GFR}_{\text {proxy }}$ of patients with uni- or bilateral FMD or ARAS. Data expressed as median and interquartile range. FMD indicates fibromuscular dysplasia; ARAS, atherosclerotic renal artery stenosis; GFR proxy, a proxy for glomerular filtration rate per kidney. ${ }^{*} p=0.042$ vs. affected kidney, $+p=0.022$ vs. right kidney. No statistically significant differences were found for other within- or between-group comparisons.

\section{Adjusted outcomes}

As several differences in patient characteristics existed between the groups, we adjusted the outcome measures for gender, body mass index, age, and $24 \mathrm{~h}$ urinary sodium excretion using an ANCOVA model. As shown in Table 7.3, the difference in MRBF between FMD and ARAS is still statistically significant. As compared to FMD, arterial renin levels, RSR, and systolic blood pressure were after adjustment significantly higher in ARAS. Adjusted GFR proxy was significantly lower in ARAS as compared to FMD $(\mathrm{p}<0.001)$.

Table 7.3 Adjusted outcome parameters.

\begin{tabular}{lcc}
\hline Parameter & FMD & ARAS \\
\hline Adjusted standardized MRBF (ml/100g kidney/min) & $219 \pm 20$ & $172 \pm 26^{*}$ \\
Adjusted arterial renin (mU/l) & $27.0(14.7-56.0)$ & $42.4(24.8-52.4)^{\dagger}$ \\
Adjusted RSR (mU/100g kidney/min) & $0.73(0.25-1.69)$ & $2.91(0.26-4.34)^{*}$ \\
Adjusted 24h systolic blood pressure (mmHg) & $161 \pm 12$ & $169 \pm 11 \dagger$ \\
Adjusted 24h diastolic blood pressure (mmHg) & $96 \pm 5$ & $94 \pm 5$ \\
Adjusted GFR $_{\text {proxy }}(\mathrm{ml} / 100 \mathrm{~g}$ kidney/min) & $39.1(30.0-47.6)$ & $29.2(25.3-32.8)^{*}$ \\
\hline
\end{tabular}

Outcome parameters adjusted for gender, body mass index, age, and $24 \mathrm{~h}$ urinary sodium excretion. Values expressed as mean \pm S.D. or median (interquartile range). MRBF indicates mean renal blood flow; FMD, fibromuscular dysplasia; ARAS,

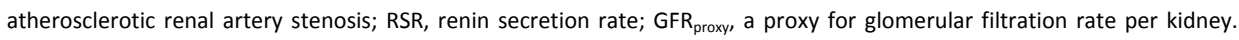
${ }^{*} \mathrm{p}<0.001$ vs. FMD, $+p<0.05$ vs. FMD. 


\section{Associations with blood pressure and renal blood flow}

As shown in Figure 7.4, a positive correlation between renin levels and mean arterial blood pressure was observed in ARAS $(\beta$ 0.388; $p=0.002)$. Interestingly, this relationship was inverse in the FMD group $(\beta-0.472 ; p=0.011)$. As shown in Supplemental Figure S7.1, 24h urinary sodium excretion, a proxy for dietary sodium intake, was associated with MRBF in FMD ( $\beta$ 0.357; $p=0.015)$, but not in ARAS ( $\beta$-0.084; $p=N S$ ). No significant correlation was found between renin levels and MRBF. As demonstrated in Supplemental Figure S7.2, no significant correlation between urinary sodium excretion and renin levels was found in either ARAS or FMD. A strong correlation was found between urinary sodium excretion and mean arterial blood pressure in the FMD group ( $\beta$ 0.483; $p=0.012$ ), but not in ARAS.

Figure 7.4 Associations between blood pressure and renin level.
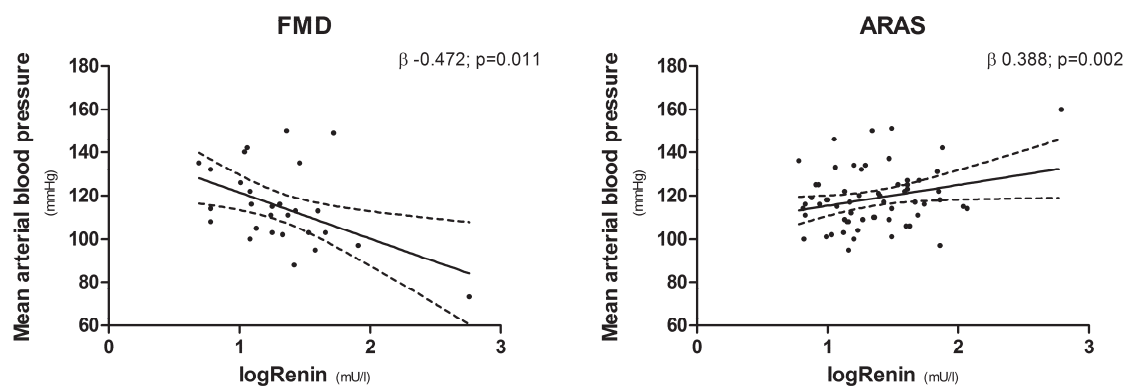

Correlation between mean arterial blood pressure (during $24 \mathrm{~h}$ ambulatory blood pressure measurement) and renin level for FMD (left column) and ARAS (right column). FMD indicates fibromuscular dysplasia; ARAS, atherosclerotic renal artery stenosis.

\section{Discussion}

In this study we evaluated renal blood flow, renin secretion, and its relation to blood pressure in order to elucidate differences in pathophysiological mechanisms between patients with multifocal renovascular FMD and patients with ARAS, both without use of antihypertensive drugs or previous revascularization. In the present study we found several differences between FMD and ARAS:

First, renal blood flow was substantially higher in patients with FMD as compared to those with ARAS, even after adjustment for several pre-existing differences in patient characteristics. Furthermore, renovascular resistance was higher in kidneys with ARAS as compared to kidneys with FMD. Renal blood flow did not differ between the affected and non-affected kidney in unilateral FMD, but that was not the case in ARAS 
either. In bilateral ARAS, renal blood flow was lower in the left kidney (and presumably as a result also $\mathrm{GFR}_{\text {proxy }}$ ) as compared to the right, a phenomenon that was previously also found in patients with essential hypertension. ${ }^{14}$ In bilateral FMD this was not the case, suggesting that the flow balance between both kidneys has changed. The nature of this phenomenon, however, remains unknown. Only one small study evaluated renal blood flow in FMD and ARAS before. ${ }^{15}$ That study yielded similar results, supporting our finding that renal blood flow is higher in kidneys with FMD as compared to that in kidneys with ARAS.

Second, renin secretion was higher in kidneys with ARAS as compared to kidneys with FMD. Although we initially found that systemic renin levels were comparable between FMD and ARAS, adjustment for differences in patient characteristics such as age and gender (both known factors that influence renin levels) ${ }^{16,17}$ revealed that renin levels and renin secretion are substantially higher in ARAS as compared to FMD. Previously, we demonstrated that renin secretion in FMD is comparable to matched patients with essential hypertension (Chapter 6). Furthermore, in the present study we found (as expected) that renin secretion in patients with unilateral ARAS was increased in the affected kidney as compared to the contralateral, non-affected kidney (assessed in three different ways using renal vein renin ratio, renin (V-A)/A, and RSR). This in contrast to patients with unilateral FMD, in whom no differences in renin secretion were found between both kidneys. These findings suggest that the presence of a 'string-of-beads' does not increase local renin secretion. One could argue that this indicates that the FMD patients in our cohort would probably not respond to revascularization. This is, however, not the case, as balloon angioplasty reduced blood pressure in $48 \%$ of the included patients with multifocal FMD (Chapter 6). In a population of this age, a relatively large number of non-responders can be expected, ${ }^{18}$ presumably due to irreversible changes in the systemic circulation caused by longlasting hypertension. Similar to our results, other small studies also demonstrated that FMD patients without increased renin secretion can be cured from hypertension by revascularization. ${ }^{10,11,19,20}$ Taken together, our finding that local renin secretion is not increased in kidneys with FMD (in contrast to kidneys with ARAS) combined with those previous observations, argue against the hypothesis that it is increased local renin secretion that induces hypertension in patients with renovascular FMD.

Third, the correlation between renin levels and blood pressure is inverse in patients with FMD as compared to patients with ARAS. In ARAS higher renin levels were associated with higher blood pressure, which is in line with the generally accepted view that hypertension in these patients is caused by increased renin secretion. ${ }^{3}$ In FMD, however, the correlation between renin levels and blood pressure is inverse. In other words, the lower the blood pressure, the higher the renin level, similar to the normal physiological response that one would expect in healthy subjects without renovascular abnormalities. Although we have to be cautious with drawing conclusions as these data are only cross-sectional (without information on the effects of intraindividual variation in renin secretion or blood pressure), this suggests that systemic 
blood pressure is still able to reach the juxtaglomerular apparatus in kidneys with FMD, resulting in a decrease in renin secretion. In ARAS, renovascular resistance is presumably so high, that the juxtaglomerular apparatus is less able to detect and to respond to changes in systemic blood pressure, resulting in excessive renin secretion. In summary, renal blood flow, renin secretion, and the relation between renin and blood pressure differed substantially between FMD and ARAS. Moreover, in the affected kidney in unilateral FMD, renal blood flow and renin secretion are similar to the contralateral kidney and, as we showed in Chapter 6, not different from patients with essential hypertension. Therefore, we cannot but conclude that it is not likely that the commonly held (but unproved) hypothesis, stating that renovascular FMD causes hypertension due to a reduction in renal perfusion and subsequently an increase in renin production, is true. The question which pathophysiological mechanisms are responsible for the increase in blood pressure remains unknown. Regrettably, without further research into the contribution of other mechanisms next to renin secretion (e.g. nervous system activity or other humoral factors) we can only hypothesize on this subject.

Furthermore, several findings in our study support our hypothesis that microvasculature is more preserved in kidneys with FMD compared to those with ARAS. As previously mentioned, MRBF was higher in FMD, whereas renovascular

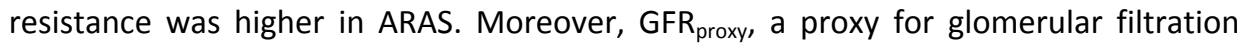
rate, is higher in FMD as compared to ARAS. Whereas GFR proxy is lower in the affected kidney as compared to the contralateral non-affected kidney in patients with unilateral ARAS, this is not the case in unilateral FMD, indicating that the string-of-beads does not reduce local glomerular filtration rate. Additionally, in patients with FMD but not in patients with ARAS, urinary sodium excretion is associated with blood pressure and $M R B F$, indicating that kidneys with FMD are able to modulate renal blood flow in response to sodium intake. Although these latter findings are also only cross-sectional, we previously demonstrated that the response to vasoactive substances or reninangiotensin system modulation is preserved in kidneys with FMD (Chapter 6), but disturbed in those with ARAS, ${ }^{5,21}$ supporting our hypothesis that microvascular function in kidneys with FMD is less affected by high blood pressure and/or atherosclerotic burden as occurs in ARAS. $^{22}$ As sufficient kidney tissue with qualitatively good microvasculature is preserved, this could explain the better results of revascularization in these patients as compared to patients with ARAS. ${ }^{18,23}$

The present study is limited by its small power. However, given the low incidence of diagnosed FMD in the hypertensive population this study is relatively large. Furthermore, the inevitable differences in patient characteristics between newly diagnosed FMD and ARAS result in difficulties in comparing both groups. As expected, patients with FMD were younger and more often female, ${ }^{24,25}$ and had lower blood pressure. Although smoking is also considered a risk factor for FMD, ${ }^{26}$ the FMD 
patients in this study were less often exposed to classical cardiovascular risk factors such as smoking and diabetes. Although we attempted to adjust for these betweengroup differences using an ANCOVA model, these differences are also a reflection of normal clinical practice. Importantly, no differences in $24 \mathrm{~h}$ urinary sodium excretion (a proxy for dietary sodium intake) were found between the groups, as this could influence several outcome parameters such as MRBF, renin secretion, and blood pressure. In the present study we did not routinely measure trans-stenotic pressure gradients to define the hemodynamic severity of the string-of-beads as the value of trans-stenotic pressure gradients as a guidance for revascularization has not been established in patients with FMD yet. Although FMD could be an 'innocent bystander' without contribution of the string-of-beads to high blood pressure (i.e. the patients had essential hypertension) it is not yet possible to differentiate between symptomatic and asymptomatic FMD before revascularization. As previously mentioned, balloon angioplasty reduced blood pressure in $48 \%$ of the patients in this cohort (Chapter 6), indicating that the string-of-beads contributed to maintaining high blood pressure in those patients. Furthermore, selection bias might have occurred, as we only included patients who had been referred for difficult-to-treat hypertension or clinical suspicion for renovascular abnormalities. Patients with undiagnosed FMD that respond well to antihypertensive drugs (which is probably a large number of cases given the relatively high prevalence of renovascular FMD among kidney donor candidates) ${ }^{2}$ therefore probably remained unrecognized and were not included in this study.

In conclusion, we found several arguments against the hypothesis that the pathophysiological mechanisms leading to hypertension in patients with FMD are similar to those in patients with ARAS. Especially the findings that renal blood flow is more preserved, that local renin secretion is not increased, and that the association between renin levels and blood pressure is inverse in patients with FMD, contradict with the commonly held but unproved hypothesis that states that hypertension in renovascular FMD is caused by a reduction in renal perfusion and, subsequently, increased renin secretion. Moreover, renal microvasculature appears to be better preserved in FMD, which might explain the relatively good results of revascularization (as compared to ARAS) in these patients. Further research however, is required to further elucidate the pathophysiological mechanisms in renovascular FMD. 


\section{References}

1. Persu A, Giavarini A, Touze E, Januszewicz A, Sapoval M, Azizi M, Barral X, Jeunemaitre X, Morganti A, Plouin PF, de Leeuw P, Hypertension ESHWG, the K. European consensus on the diagnosis and management of fibromuscular dysplasia. J Hypertens. 2014;32:1367-1378

2. Olin JW, Gornik HL, Bacharach JM, Biller J, Fine L, Gray BH, Gray WA, Gupta R, Hamburg NM, Katzen BT, Lookstein RA, Lumsden AB, Newburger JW, Rundek T, Sperati CJ, Stanley JC. Fibromuscular dysplasia: State of the science and critical unanswered questions: A scientific statement from the american heart association. Circulation. 2014;129:1048-1078

3. Textor SC, Lerman L. Renovascular hypertension and ischemic nephropathy. Am J Hypertens. 2010;23:1159-1169

4. Kesteloot $\mathrm{H}$, Joossens JV. The relationship between dietary intake and urinary excretion of sodium, potassium, calcium and magnesium: Belgian interuniversity research on nutrition and health. Journal of human hypertension. 1990;4:527-533

5. Wierema TK, Houben AJ, Kroon AA, Koster D, van der Zander K, van Engelshoven JM, de Leeuw PW. Nitric oxide dependence of renal blood flow in patients with renal artery stenosis. J Am Soc Nephrol. 2001;12:1836-1843

6. Savard S, Steichen O, Azarine A, Azizi M, Jeunemaitre X, Plouin PF. Association between 2 angiographic subtypes of renal artery fibromuscular dysplasia and clinical characteristics. Circulation. 2012;126:3062-3069

7. Olin JW. Is fibromuscular dysplasia a single disease? Circulation. 2012;126:2925-2927

8. Dechering DG, Kruis HM, Adiyaman A, Thien T, Postma CT. Clinical significance of low-grade renal artery stenosis. Journal of internal medicine. 2010;267:305-315

9. Deinum J, Derkx FH, Schalekamp MA. Improved immunoradiometric assay for plasma renin. Clin Chem. 1999;45:847-854

10. Luscher TF, Greminger P, Kuhlmann U, Siegenthaler W, Largiader F, Vetter W. Renal venous renin determinations in renovascular hypertension. Diagnostic and prognostic value in unilateral renal artery stenosis treated by surgery or percutaneous transluminal angioplasty. Nephron. 1986;44 Suppl 1:17-24

11. Luscher TF, Vetter H, Studer A, Pouliadis G, Kuhlmann U, Glanzer K, Largiader F, Hauri D, Greminger P, Siegenthaler $\mathrm{W}$, Vetter W. Renal venous renin activity in various forms of curable renal hypertension. Clin Nephrol. 1981;15:314-320

12. Blaufox $M D$, Fromowitz $A$, Lee $H B$, Mend $C H$, Elkin $M$. Renal blood flow and renin activity in renal venous blood in essential hypertension. Circ Res. 1970;27:913-920

13. Levey AS, Stevens LA, Schmid CH, Zhang YL, Castro AF, 3rd, Feldman HI, Kusek JW, Eggers P, Van Lente $\mathrm{F}$, Greene T, Coresh J, Ckd EPI. A new equation to estimate glomerular filtration rate. Ann Intern Med. 2009;150:604-612

14. van Onna M, Houben AJ, Kroon AA, Wierema TK, Koster D, van Engelshoven JM, de Leeuw PW. Asymmetry of renal blood flow in patients with moderate to severe hypertension. Hypertension. 2003;41:108-113

15. Lerman LO, Taler SJ, Textor SC, Sheedy PF, 2nd, Stanson AW, Romero JC. Computed tomographyderived intrarenal blood flow in renovascular and essential hypertension. Kidney Int. 1996;49:846-854

16. Hilliard LM, Sampson AK, Brown RD, Denton KM. The "His and hers" Of the renin-angiotensin system. Curr Hypertens Rep. 2013;15:71-79

17. Weidmann P, De Myttenaere-Bursztein S, Maxwell MH, de Lima J. Effect on aging on plasma renin and aldosterone in normal man. Kidney Int. 1975;8:325-333

18. Trinquart L, Mounier-Vehier C, Sapoval M, Gagnon N, Plouin PF. Efficacy of revascularization for renal artery stenosis caused by fibromuscular dysplasia: A systematic review and meta-analysis. Hypertension. 2010;56:525-532

19. Vetter W, Vetter H, Tenschert W, Kuhlmann U, Studer A, Glanzer K, Pouliadis G, Largiader F, Furrer J, Siegenthaler W. [renovascular hypertension. Prognostic value of renal venous renin determinations (author's transI)]. Klin Wochenschr. 1979;57:863-873

20. Marks LS, Maxwell MH, Kaufman JJ. Non-renin-mediated renovascular hypertension: A new syndrome? Lancet. 1977;1:615-617 
21. Van Twist DJ, Houben AJ, De Haan MW, Mostard GJ, De Leeuw PW, Kroon AA. Angiotensin-(1-7)induced renal vasodilation is reduced in human kidneys with renal artery stenosis. $J$ Hypertens. 2014;32:2428-2432; discussion 2432

22. Eirin A, Lerman LO. Darkness at the end of the tunnel: Poststenotic kidney injury. Physiology (Bethesda). 2013;28:245-253

23. Cooper CJ, Murphy TP, Cutlip DE, Jamerson K, Henrich W, Reid DM, Cohen DJ, Matsumoto AH, Steffes M, Jaff MR, Prince MR, Lewis EF, Tuttle KR, Shapiro JI, Rundback JH, Massaro JM, D'Agostino RB, Sr., Dworkin LD, Investigators C. Stenting and medical therapy for atherosclerotic renal-artery stenosis. $N$ Engl J Med. 2014;370:13-22

24. Giavarini A, Savard S, Sapoval M, Plouin PF, Steichen O. Clinical management of renal artery fibromuscular dysplasia: Temporal trends and outcomes. J Hypertens. 2014;32:2433-2438; discussion 2438

25. Olin JW, Froehlich J, Gu X, Bacharach JM, Eagle K, Gray BH, Jaff MR, Kim ES, Mace P, Matsumoto AH, McBane RD, Kline-Rogers E, White CJ, Gornik HL. The united states registry for fibromuscular dysplasia: Results in the first 447 patients. Circulation. 2012;125:3182-3190

26. Savard S, Azarine A, Jeunemaitre X, Azizi M, Plouin PF, Steichen O. Association of smoking with phenotype at diagnosis and vascular interventions in patients with renal artery fibromuscular dysplasia. Hypertension. 2013;61:1227-1232 


\section{Supplemental figures}

Figure S7.1 Associations with MRBF in FMD and ARAS.

FMD

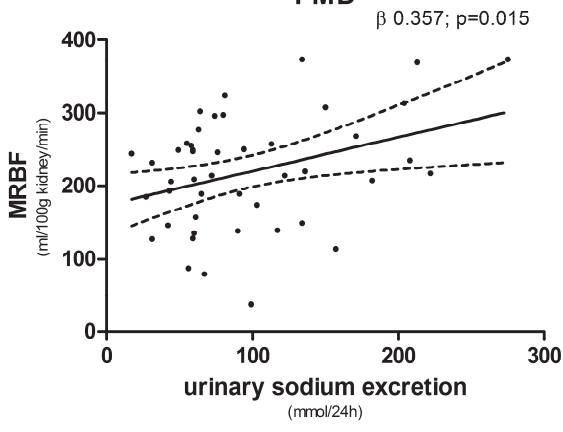

FMD

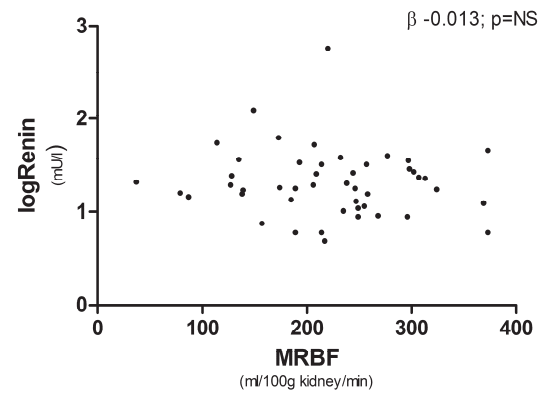

ARAS

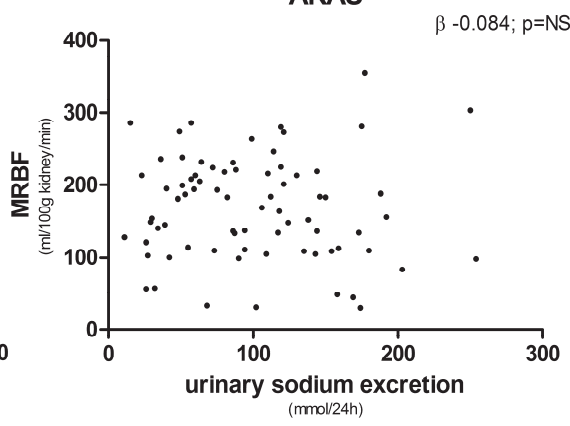

ARAS

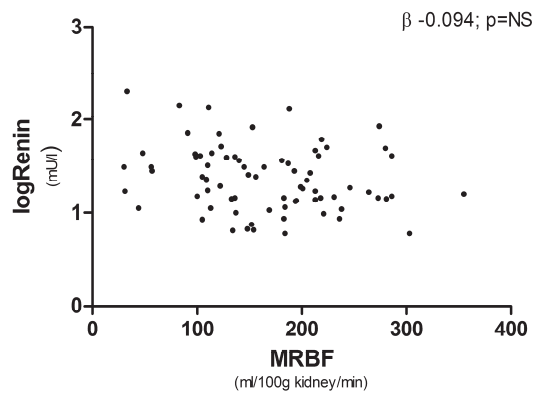

Correlation between MRBF and urinary sodium excretion (upper panel), and MRBF and renin level (lower panel) split up for FMD (left column) and ARAS (right column). MRBF indicates mean renal blood flow; FMD, fibromuscular dysplasia; ARAS, atherosclerotic renal artery stenosis. 
Figure S7.2 Associations between sodium, renin, and blood pressure

\section{FMD}

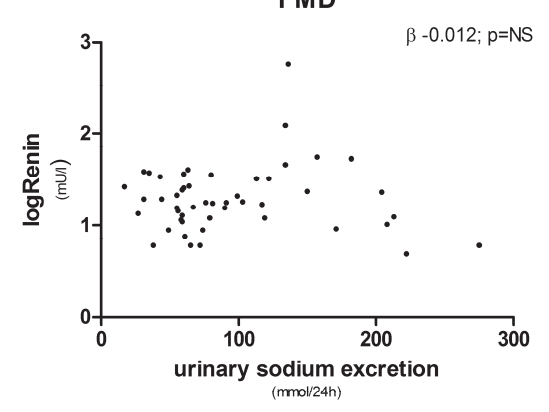

FMD

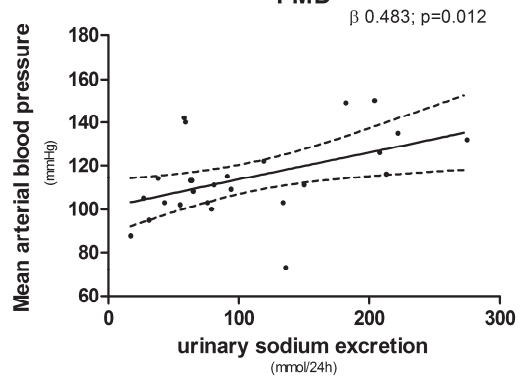

ARAS

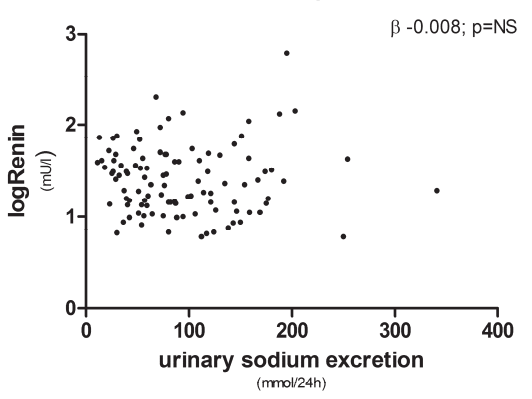

ARAS

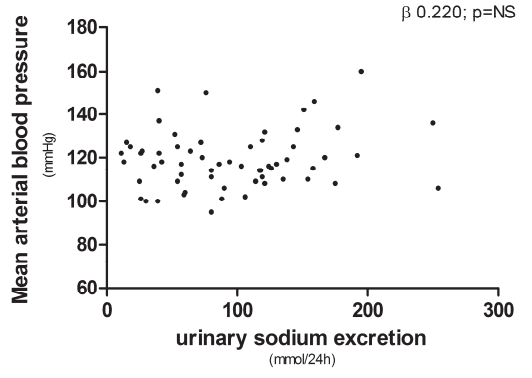

Correlation between urinary sodium excretion and renin (upper panel) and blood pressure (during 24h ambulatory blood pressure measurement; lower panel). Data split up for FMD (left column) and ARAS (right column). MRBF indicates mean renal blood flow; FMD, fibromuscular dysplasia; ARAS, atherosclerotic renal artery stenosis. 


\section{Chapter 8}

General discussion 


\section{Introduction}

The renin-angiotensin system plays an important role in the regulation of tissue blood flow and blood pressure. The kidney is essential for this system: it is the sensor (detection blood pressure and distal tubular sodium delivery by the macula densa), the regulator (secretion of renin, the rate-limiting activator), and the main target organ (regulation of renal blood flow and water and sodium balance). ${ }^{1}$ The renin-angiotensin system allows the kidney to maintain intraglomerular pressure at a stable level, despite changes in systemic blood pressure and/or circulating volume. This process is vital for the preservation of renal function during situations with volume loss such as dehydration or bleeding. However, next to these 'protective' effects during episodes of hypovolemia, the renin-angiotensin system is also one of the most important contributing factors in the development and persistence of hypertension, eventually leading to cardiovascular diseases and chronic kidney failure. Hence, drugs targeting the renin-angiotensin system are nowadays considered the cornerstone in the treatment of hypertension. ${ }^{2}$

\section{The renin-angiotensin system: more than ACE and Ang II}

Although the renin-angiotensin system has been extensively studied since its discovery in $1898,{ }^{3}$ our current understanding of this system remains limited. Continuously, new pathways with new peptides, new enzymes, new receptors, and new signalling transduction mechanisms are being discovered. Whereas for decades the ACE/Ang II/AT ${ }_{1} \mathrm{R}$ (angiotensin converting enzyme / angiotensin II / angiotensin II type-1 receptor) axis was considered to be the exclusive pathway, it is nowadays known that several angiotensins other than Ang II are involved. In this thesis we predominately focussed on angiotensin-(1-7) [Ang-(1-7)] with its Mas-receptor, but many other angiotensins (such as angiotensin $\mathrm{III}^{4}{ }^{4}$ angiotensin $\mathrm{IV},{ }^{5}$ angiotensin $\mathrm{A},{ }^{6}$ and alamandine ${ }^{7}$ ) and several other receptors next to the $\mathrm{AT}_{1} \mathrm{R}$ [e.g. the angiotensin II type2 and type- 4 receptors, ${ }^{8,9}$ pro-renin receptor, ${ }^{10}$ and more recently the $\mathrm{MrgD}^{7}$ (Masrelated G-protein coupled receptor, member $D$ )] have been discovered. An overview of these complex pathways is shown in Figure 8.1. Although these discoveries have greatly increased our understanding of the renin-angiotensin system, they presumably are only a tip of the iceberg given the large number of remaining uncertainties. Future discoveries will be of great interest, as a lot of the abovementioned pathways have the potential to become a target for new therapeutic strategies in hypertension, renal, and cardiovascular diseases.

Current understanding of these 'new' pathways is predominately based on studies in animals and in vitro studies. Only little is known on their role in humans, especially during pathologic conditions such as hypertension or chronic kidney disease. This knowledge, however, is indispensable to develop new therapeutic strategies that cure, 
prevent, or arrest such diseases' progress. Therefore, we focused in this thesis on the renin-angiotensin system in the kidneys of humans with hypertension. Several aspects of the microvasculature differ between the kidneys of healthy patients and those with hypertension: in almost all patients with essential hypertension thickening and narrowing of the renal arterioles occurs. This induces changes in the glomerular membrane, tubular injury, and an inflammatory response, eventually resulting in glomerular and tubulointerstitial scarring with loss of renal function. ${ }^{11}$ In kidneys with atherosclerotic renal artery stenosis these changes are often even more pronounced. ${ }^{12}$ To improve our knowledge on the renin-angiotensin system in renovascular hypertension we did not limit our research to patients with essential hypertension, but also studied patients with renal artery stenosis due to atherosclerosis or fibromuscular dysplasia.

Figure 8.1 Simplified overview of the currently known angiotensins, their target receptors, and the involved enzymes of the renin-angiotensin system.

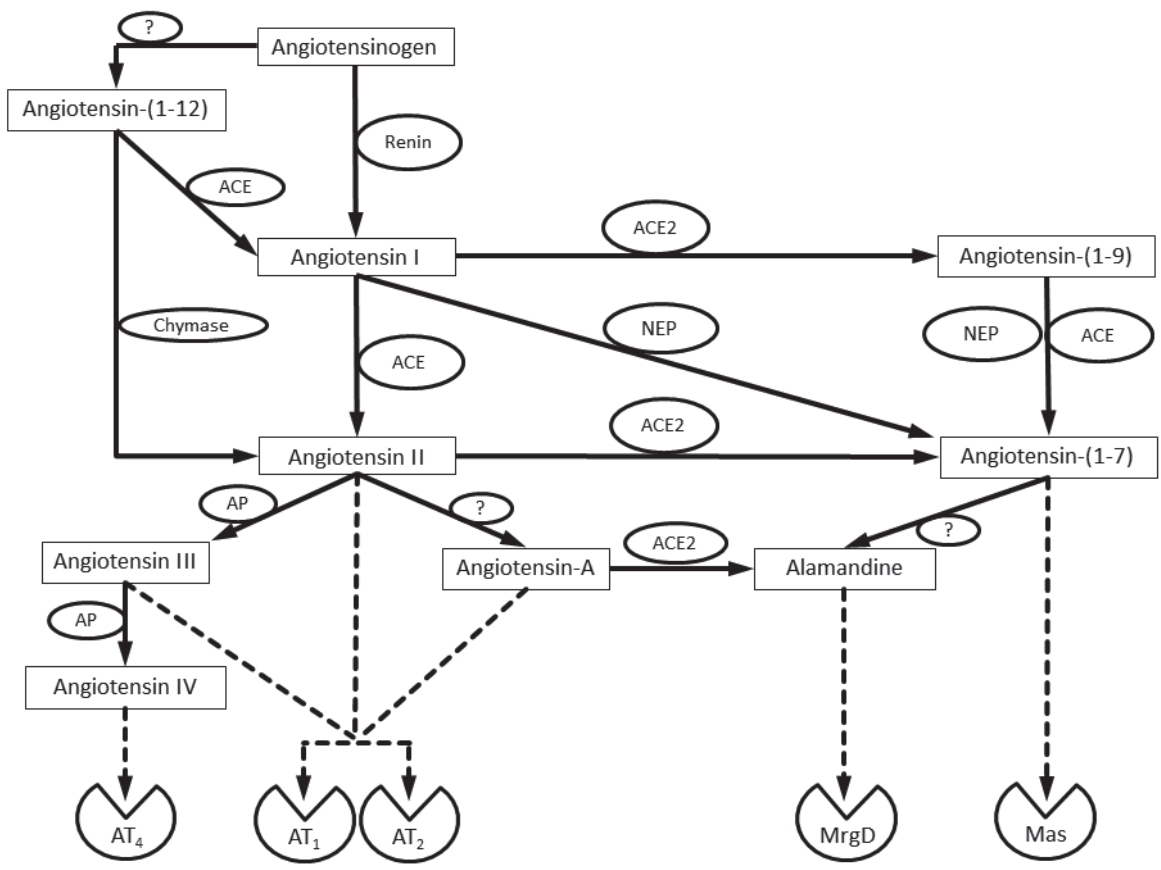

ACE indicates angiotensin-converting-enzyme; ACE2 angiotensin-converting-enzyme 2; AP, aminopeptidase; NEP, neutral endopeptidase and neprilysin; ? indicates unknown enzymes; MrgD, Mas-related G-protein coupled receptor $\mathrm{D} ; A \mathrm{~T}_{1}$, angiotensin II type-1 receptor; $A T_{2}$, angiotensin II type- 2 receptor; $\mathrm{AT}_{4}$, angiotensin II type-4 receptor. 


\section{ACE/Ang II/AT 1 R versus ACE2/Ang-(1-7)/Mas: a delicate balance}

From animal studies it is known that the ACE/Ang II/AT ${ }_{1} \mathrm{R}$ axis and the ACE2/Ang-(1-7)/ Mas axis are closely related: ACE2 uses Ang II as its substrate to produce Ang-(1-7) and Mas-receptor induced vasodilation is, next to the release of nitric oxide, partially the result of inhibition of the vasoconstrictory effects of the $A T_{1} R$ via inhibition of intracellular signalling pathways such as ERK $1 / 2$ (extracellular signal-regulated kinases 1/2) and C-Src. In this thesis, we demonstrated that Ang-(1-7) counteracts the vasoconstrictory effects of Ang II in kidneys of patients with hypertension as well. Ang II, in turn, attenuates the vasodilatory effects of Ang-(1-7). These findings indicate that in the human hypertensive kidney a balance exists between Ang II-induced vasoconstriction and Ang-(1-7)-induced vasodilation (Figure 8.2). This balance appears to be rather delicate, given that relatively small doses of Ang II (too low to induce systemic effects) are able to reduce the maximal vasodilatory effect of Ang-(1-7) up to $42 \%$ (Chapter 2). In order to understand this balance better, we evaluated the influence of renin-angiotensin system activity on the intrarenal vasodilatory effects of Ang-(1-7) and $A T_{1} R$ blockade. We studied this in hypertensive kidneys under three different conditions inducing intrarenal renin-angiotensin system activation: 1) endogenous activation by using a low sodium diet, 2) exogenous activation of the $A C E / A n g ~ I I / A T_{1} R$ axis by infusion of Ang $\mathrm{I}$, and 3 ) endogenous activation due to the presence of a high-grade renal artery stenosis.

Figure 8.2 A delicate balance between angiotensin II induced vasoconstriction and angiotensin-(1-7) induced vasodilation.

$$
\text { Vasoconstriction }
$$

Vasodilation

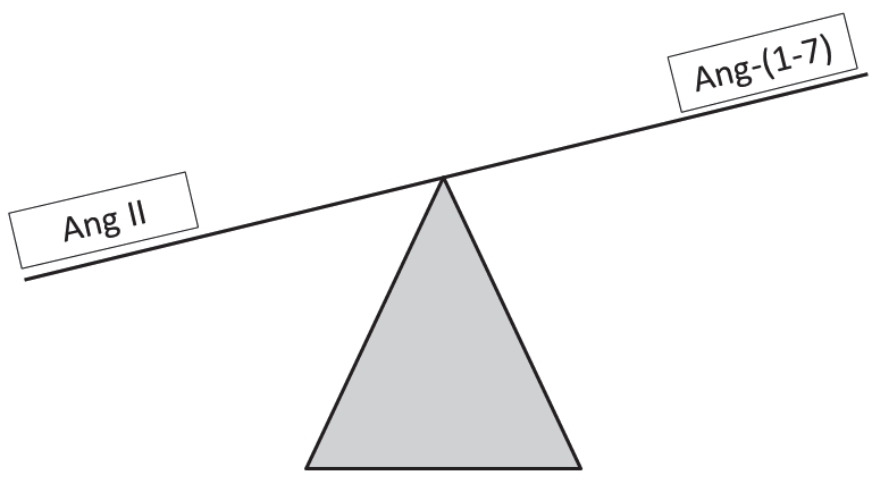




\section{The intrarenal renin-angiotensin system and sodium intake}

Endogenous renin-angiotensin system stimulation by low sodium intake induces activation of both the ACE/Ang II/AT $R$ axis and the ACE2/Ang-(1-7)/Mas axis, eventually leading to high intrarenal levels of Ang II and Ang-(1-7). ${ }^{13-15}$ As shown in Chapter 2, low sodium intake attenuated the effects of Ang-(1-7). The finding that the prevailing renin concentration was the only independent predictor for the effect of Ang-(1-7), confirms that it is renin-angiotensin system activation that is involved. Vasodilation induced by blockade of the $A T_{1} R$ with eprosartan, however, was not influenced by sodium restriction (Chapter 5 ). Thus, whereas low sodium intake reduces the effect of Ang-(1-7)-induced vasodilation, it does not influence $A T_{1} R$ blockerinduced vasodilation. This again illustrates the complexity of the intrarenal reninangiotensin system.

Attenuation of the vasodilatory effect of Ang-(1-7) by low sodium intake could be caused by an already maximal stimulation of the Mas-receptor, as endogenously produced Ang-(1-7) levels increase during low sodium intake. ${ }^{13,14}$ The addition of exogenous Ang-(1-7) therefore mainly creates a surplus on top of the already elevated Ang-(1-7) levels. As continuous stimulation of the Mas receptor results in desensitization of this receptor, ${ }^{16}$ this surplus of Ang-(1-7) only results in a small vasodilatory effect. Furthermore, elevated Ang II levels induced by low sodium intake $^{17,18}$ presumably turn the balance between Ang-(1-7) and Ang II so far towards Ang II-induced vasoconstriction, that infusion of a low dose of Ang-(1-7) is not sufficient to counteract this.

The finding that $\mathrm{AT}_{1} \mathrm{R}$ blocker-induced vasodilation was not influenced by reduced sodium intake was rather surprising, as we expected a greater vasodilatory response due to higher prevailing Ang II levels. ${ }^{15}$ This differential effect of sodium intake on Ang(1-7)- and $\mathrm{AT}_{1} \mathrm{R}$ blocker-induced vasodilation could be explained by the fact that Ang II has several 'escape-routes' that Ang-(1-7) has not: high circulating levels of Ang II can stimulate the $\mathrm{AT}_{2} \mathrm{R}^{19}$ and they can also be converted to Ang-(1-7). ${ }^{20-25}$ These 'escaperoutes' presumably contribute to the vasodilatory and blood pressure lowering effect of $A T_{1} R$ blockers. However, the part of the vasodilatory effect of $A T_{1} R$ blockade that is mediated via Ang-(1-7), is probably diminished during low sodium intake, as the vasodilatory effect of Ang-(1-7) is attenuated by a low sodium intake (Chapter 2). This could diminish the increased vasodilatory effect $A T_{1} R$ blockade during low sodium intake that we expected from antagonizing higher levels of Ang II. Another factor which could contribute to the lack of effect of sodium intake could be downregulation of the $\mathrm{AT}_{1} \mathrm{R}$ during low sodium intake, ${ }^{26}$ similarly as occurs with the Mas-receptor. ${ }^{16}$ Most likely, however, appears to be a disconnection between systemic reninangiotensin system activity and the activity in the kidney, a concept that is referred to as 'local renin-angiotensin system' ${ }^{27,28}$ Although it was thought for a long time that there was only one (systemic) renin-angiotensin system, more and more evidence has made it clear that the renin-angiotensin system within the kidney acts relatively 
independent from the systemic renin-angiotensin system. Levels of angiotensins differ substantially between the kidney and the systemic circulation and almost all precursors, enzymes, and receptors from the renin-angiotensin system are present in the kidney, suggesting that local formation of angiotensins occurs in the renal vasculature. ${ }^{27,29}$ It appears that more than $90 \%$ of tissue Ang II is synthesized locally or released from storage in lysozomes and not taken up from plasma. ${ }^{30}$ Therefore, systemic activation of the renin-angiotensin system does not necessarily lead to increased renin-angiotensin system activity in the kidney.

Interestingly, some studies indicate that the response of the intrarenal reninangiotensin system to sodium intake is different in the hypertensive kidney than that it is in the healthy kidney: those studies suggest that high sodium intake paradoxically leads to an increase in intrarenal Ang II levels in the hypertensive kidney. ${ }^{27,31}$ If this indeed occurs in the hypertensive kidney, this would truly change our view on the relationship between sodium intake and intrarenal renin-angiotensin system activity. According to this new concept, low sodium intake would decrease instead of increase intrarenal Ang II levels, resulting in less rather than more vasodilation during infusion of an $\mathrm{AT}_{1} \mathrm{R}$ blocker. Our findings would fit very well in this concept, as we indeed observed a non-statistically significant trend towards less effect on renal blood flow during low sodium intake (Figure 5.2, Chapter 5). Moreover, previous observations that the antiproteinuric effect of ACE-inhibition is diminished during high sodium intake $^{32,33}$ can be explained by this phenomenon: the paradoxical elevation in intrarenal Ang II would require more ACE-inhibition to achieve sufficient reduction of intrarenal Ang II levels. The question remains, however, which pathophysiological mechanism is responsible for this abnormal response to sodium intake in the hypertensive kidney. Furthermore, it is not known whether sodium intake influences the intrarenal renin-angiotensin system as a whole, or whether differences occur in the balance between Ang II and Ang-(1-7), for example due to changes in ACE2 expression. One way or another, this again emphasizes that the intrarenal renin-angiotensin system in the hypertensive kidney is very complex and still not completely understood.

\section{The ACE2/Ang-(1-7)/Mas axis: a future therapeutic target?}

As previously mentioned, we demonstrated in Chapter 2 that Ang-(1-7) is able to induce vasodilation in the kidney of patients with essential hypertension. Hitherto, these vasodilatory effects of Ang-(1-7) had only been evaluated in studies using animal models or the human forearm. ${ }^{34-36}$ Our finding that Ang-(1-7) is able to exert these vasodilatory effects in the hypertensive kidney as well provides interesting opportunities for new pharmacological interventions in hypertension and chronic kidney disease. As described in Chapter 4, several drugs targeting the ACE2/Ang-(1-7)/ Mas axis are currently under development. Although not evaluated in humans yet, our findings on the effects of Ang-(1-7) in the hypertensive kidney suggest that similar 
effects could be achieved with drugs that have an agonistic effect on the Mas-receptor

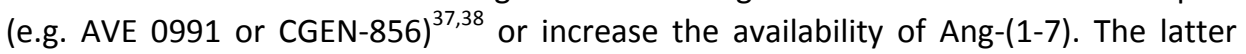
could be achieved either by drugs that increase endogenous production via stimulation of ACE2 or via oral supplementation of Ang-(1-7), administrated in a formulation that protects it from degradation by bacteria in the digestive tract. ${ }^{39,40}$ Animal studies with such experimental drugs already demonstrated beneficial effects on blood pressure, atherosclerosis, endothelial function, diabetic nephropathy, and cardiac function. ${ }^{39-44}$ However, life style factors, such as low sodium intake (Chapter 2), or the presence of an atherosclerotic renal artery stenosis (Chapter 3 ) could attenuate these beneficial effects. Therefore, there is still a long road to be travelled requiring clinical studies in patients with hypertension, chronic kidney disease, and/or cardiovascular disease instead of animal models or healthy subjects before this promising research can be applied in clinical practice.

\section{Atherosclerotic renal artery stenosis}

Renovascular hypertension caused by high grade atherosclerotic renal artery stenosis is known for its activated renin-angiotensin system. ${ }^{12}$ Given that renin-angiotensin system activation by low sodium intake or Ang II co-infusion attenuated the intrarenal vasodilatory response to Ang-(1-7), we hypothesized that this effect would also be reduced in kidneys with atherosclerotic renal artery stenosis. Indeed, we found that intrarenal infusion of Ang-(1-7) hardly increases renal blood flow in kidneys with high grade atherosclerotic renal artery stenosis (Chapter 3 ). Interestingly, the effect of Ang-(1-7) was preserved in the contralateral, non-stenotic kidney in patients with unilateral atherosclerotic renal artery stenosis. Thus, the diminished effect of Ang-(1-7) in the stenotic kidney is apparently the result of local changes in the stenotic kidney and not the result of generalized atherosclerotic burden or systemic renin-angiotensin system activation. Several pathophysiological changes could contribute to this difference. More intense activation of the local, intrarenal renin-angiotensin system in the stenotic kidney results in activation of both the ACE/Ang II/AT ${ }_{1}$-axis and ACE2/Ang-(1-7)/Mas-axis, ${ }^{45,46}$ leading to more powerful vasoconstriction by Ang II and saturation/desensitization of the Mas-receptor by higher levels of Ang-(1-7). ${ }^{16}$ Structural changes in the stenotic kidney also play a role in the decreased response to Ang-(1-7). In kidneys with atherosclerotic lesions, intrarenal microvascular changes are generally more pronounced as compared to those in patients with essential hypertension. The longstanding atherosclerotic burden, activation of the reninangiotensin system, inflammation, oxidative stress, and fibrosis, ${ }^{47,48}$ decreases the density of microvessels in the renal cortex, ${ }^{49}$ eventually resulting in tubulointerstitial atrophy and glomerulosclerosis. ${ }^{50,51}$ These changes are generally irreversible, ${ }^{52,53}$ resulting in a rather disappointing effect of revascularization in such patients. ${ }^{54,55}$ Structural changes lead to diminished renal blood flow, reduced kidney function, and 
an increase in renovascular resistance. Moreover, the vasodilatory response to vasoactive agents (e.g. acetylcholine, nitroprusside, and the nitric oxide synthase blocker L-NMMA) is also reduced. ${ }^{52,56,57}$ Although this suggests that the blunted response to Ang-(1-7) which we observed is entirely the result of structural changes, the fact that adenosine-induced vasodilation is not diminished (but even prolonged) in kidneys with atherosclerotic renal artery stenosis argues against that possibility as the sole explanation. ${ }^{58}$ Therefore, it appears that next to structural changes (i.e. atrophy and glomerular sclerosis) also functional changes occur in the microvasculature of kidneys with atherosclerotic renal artery stenosis. As previously demonstrated in animal models and in patients with atherosclerotic renal artery stenosis, bioavailability of nitric oxide is reduced in kidneys with atherosclerotic renal artery stenosis. ${ }^{57,59}$ Since Mas-receptor-induced vasodilation is mainly exerted via nitric oxide release, it is likely that this plays a role in the diminished effect of Ang-(1-7) in the stenotic kidney. The decrease in bioavailability of nitric oxide is presumably caused by alterations in the renin-angiotensin system, inflammation, and oxidative stress. ${ }^{48}$ Not surprisingly, modulation of the renin-angiotensin system with ACE-inhibitors or $\mathrm{AT}_{1} \mathrm{R}$ blockers, apart from its blood pressure lowering effect, improves and protects microvascular density, renal blood flow, and tubular function in kidneys with renal artery stenosis. ${ }^{49,60}$

\section{Renovascular hypertension due to fibromuscular dysplasia}

Although fibromuscular dysplasia is the second most common cause of renovascular hypertension (after atherosclerotic renal artery stenosis), pathophysiological mechanisms/changes in kidneys of patients with this disease have hardly been studied. Thus far, it was assumed that renal artery fibromuscular dysplasia causes hypertension due to a decrease in renal blood flow, followed by increased renin secretion, which on its turn increases blood pressure. ${ }^{12}$ This view, however, was predominately based on experiments in two-kidney-one-clip (2K1C) animal models and studies in patients with renovascular hypertension caused by atherosclerotic renal artery stenosis and not in patients with fibromuscular dysplasia. In this thesis we found several arguments against this prevailing concept:

First, we found that renal blood flow is not decreased in kidneys with fibromuscular dysplasia, but significantly higher as compared to kidneys with high grade atherosclerotic renal artery stenosis (Chapter 7). Moreover, renal blood flow in kidneys with fibromuscular dysplasia was comparable to that in patients with essential hypertension and to the flow in the non-affected kidney of patients with unilateral fibromuscular dysplasia (Chapter 6). One small earlier study yielded similar results. ${ }^{61}$ Thus, despite the presence of a string-of-beads, renal blood flow appears not to be reduced in kidneys with fibromuscular dysplasia.

Second, renin secretion was not increased in kidneys with fibromuscular dysplasia: renin secretion was comparable to that in patients with essential hypertension 
(Chapter 6) and substantially lower as compared to that in kidneys with atherosclerotic renal artery stenosis (Chapter 7). Moreover, no differences in renin-secretion were observed between the affected kidney and the non-affected kidney in patients with unilateral fibromuscular dysplasia (Chapter 6). This in contrast to unilateral atherosclerotic renal artery stenosis, in which lateralization of renin secretion is observed in a large subset of the patients (Chapter 7). Altogether, these findings suggest that the presence of a string-of-beads does not result in an increase in renin secretion.

Third, the relationship between renin levels and blood pressure in patients with fibromuscular dysplasia is inverse as compared to that in patients with atherosclerotic renal artery stenosis (Chapter 7). Although these data are only cross-sectional, without information on the intra-individual effect of changes in renin levels or blood pressure, these findings suggest that kidneys with fibromuscular dysplasia are still able to exert a normal physiological response towards changes in blood pressure: a rise in blood pressure is associated with more suppression of renin levels. This is in sharp contrast to kidneys with atherosclerotic renal artery stenosis in which higher renin levels are, in line with the abovementioned hypothesis on renovascular hypertension, associated with higher blood pressure (Chapter 7). Presumably, renovascular resistance eventually becomes so high in kidneys with atherosclerotic renal artery stenosis that the juxtaglomerular apparatus is less able to detect and to respond to changes in systemic blood pressure, resulting in excessive renin secretion. This appears not to be the case in fibromuscular dysplasia where the kidney is still able to respond well to changes in systemic blood pressure.

Taken together, these findings all contradict with the generally accepted view that fibromuscular dysplasia induces hypertension via decreased renal blood flow and increased renin secretion. Several small studies which reported that revascularization can reduce or cure hypertension in patients with fibromuscular dysplasia without increased renin secretion ${ }^{62-65}$ and the lack of differences in renin secretion between responders and non-responders to balloon angioplasty in our study (Chapter 6) also argue against this view.

The question remains which pathophysiological mechanism is responsible for the development of hypertension in patients with fibromuscular dysplasia. As fibromuscular dysplasia is also found in non-hypertensive humans, ${ }^{66}$ it is very well possible that a subset of the patients with fibromuscular dysplasia have, in fact, essential hypertension, with the string-of-beads as an 'innocent bystander' that does not contribute to high blood pressure. This, however, would not explain the success of revascularization strategies in these patients. ${ }^{67}$ Another possibility is that the reninangiotensin system is only activated in an early stage of the disease. Longstanding exposure to an activated renin-angiotensin system and high blood pressure could have led to severe parenchymal damage, increasing blood pressure due to increased peripheral resistance and volume overload due to excess water and sodium retention. $^{68}$ On the long term parenchymal damage and volume overload could 
decrease renin-angiotensin system activity again, resulting in normal renin secretion as we observed. However, we would have expected that lateralization of renin-secretion occurred in at least some patients with unilateral fibromuscular dysplasia in our cohort (i.e. those still in an early stage of the disease), which was not the case. Neither would this theory fit into our findings that the renal microvasculature and the response to renin-angiotensin system modulation is relatively preserved in fibromuscular dysplasia (see below and Chapter 6). Furthermore, it would not explain the success of revascularization as that would only increase renal blood flow and not reverse parenchymal damage already done. Therefore it is likely that other, still unknown mechanisms are involved. It could be that other humoral factors are involved, but no studies have evaluated other vasoactive substances in fibromuscular dysplasia yet. Another possibility could be increased sympathetic nervous system activity, for example due to local turbulence of blood flow caused by the string-of-beads. A recent report of successful renal denervation in a patient with renal artery fibromuscular dysplasia would be consistent with that hypothesis. ${ }^{69}$ Unfortunately, without further research we can only hypothesize on those mechanisms.

\section{Renal microvasculature in fibromuscular dysplasia versus atherosclerotic renal artery stenosis}

In Chapter 6, we demonstrated that the renal microvasculature in kidneys with multifocal fibromuscular dysplasia is relatively intact: renal perfusion, glomerular filtration rate, and the response to vasoactive agents appears to be preserved, as no differences were observed with such response in matched patients with essential hypertension. Moreover, renal blood flow and glomerular filtration rate were substantially higher in kidneys with fibromuscular dysplasia as compared to kidneys with atherosclerotic renal artery stenosis (Chapter 7). Furthermore, the reninangiotensin system is still functioning in kidneys with fibromuscular dysplasia, as blockade of both axes [with either the $\mathrm{AT}_{1} \mathrm{R}$ blocker eprosartan or with L-NMMA as a blocker of the final common pathway of Ang-(1-7)] results in substantial changes in renal blood flow (Chapter 6). Also, neither of the axes is fully operative, as infusion of more Ang II or Ang-(1-7) still results in a hemodynamic effect. These findings are in sharp contrast to kidneys with atherosclerotic renal artery stenosis, in whom the effect of Ang-(1-7) (Chapter 3) and L-NMMA ${ }^{57}$ is markedly reduced.

These findings indicate that, in contrast to kidneys with atherosclerotic renal artery stenosis, intrarenal microvascular function is relatively preserved in kidneys with fibromuscular dysplasia. This could play a role in the differences in blood pressure lowering effect of revascularization between atherosclerotic renal artery stenosis and fibromuscular dysplasia. As previously mentioned, several studies showed that the effect of balloon angioplasty in atherosclerotic renal artery stenosis is rather disappointing and not superior to medical treatment only. ${ }^{54,55}$ Although all of these 
studies can be criticized, these results are in sharp contrast to the available literature in fibromuscular dysplasia: according to a large meta-analysis $(n=1616)$, hypertension cure can be achieved by balloon angioplasty in 40 to $52 \%$ of the patients with fibromuscular dysplasia. ${ }^{67}$ Our finding that the kidney tissue behind the 'string-ofbeads' is qualitatively good (as far as blood flow and renal function is concerned) and still able to respond to external stimuli (i.e. vasoactive agents) suggests that the kidney will be able to function relatively well after revascularization. This could explain the difference in blood pressure response to revascularization between fibromuscular dysplasia and atherosclerotic renal artery stenosis.

The intact response to renin-angiotensin modulation (Chapter 6) furthermore suggests that antihypertensive drugs (in particular ACE-inhibitors or $\mathrm{AT}_{1} \mathrm{R}$ blockers) may be quite effective in patients with fibromuscular dysplasia. This could explain why renovascular fibromuscular dysplasia remains undiagnosed in the majority of patients: screening studies reported a prevalence of $2.6-4.4 \%$ in the healthy population (in studies among potential kidney donors) ${ }^{66,70,71}$ and $1.7-5.8 \%$ in the hypertensive population, ${ }^{72,73}$ while fibromuscular dysplasia is still only occasionally diagnosed in hypertension outpatient clinics. As most hypertensive patients with fibromuscular dysplasia respond to antihypertensive drug treatment fairly well, $^{74}$ no diagnostic studies to detect secondary causes of hypertension (such as fibromuscular dysplasia) will be initiated. Although blood pressure is often adequately treated, missing the diagnosis of renovascular fibromuscular dysplasia still could have several disadvantages for the patients. First, they will need antihypertensive treatment for the long-term (with possible adverse effects, costs, and inconvenience for the patients) while, possibly, cure could have been achieved with balloon angioplasty. Furthermore, it is conceivable that the risk of renal failure and cardiovascular events is increased in this population if left undetected, especially with regard to ischemic and haemorrhagic stroke in case of concomitant cerebrovascular fibromuscular dysplasia. Although data on the effectiveness are not available yet, some experts suggest to screen patients with renal artery fibromuscular dysplasia for the presence of intracranial aneurysms. Treatment could then be initiated to prevent haemorrhagic stroke. Therefore, it could be of value to diagnose renal artery fibromuscular dysplasia, even if blood pressure is well controlled with antihypertensive drugs.

\section{Future perspectives}

The findings in this thesis provide interesting data on the renin-angiotensin system in kidneys of patients with essential hypertension, atherosclerotic renal artery stenosis, and fibromuscular dysplasia. Many questions, however, remain unresolved.

As previously mentioned, knowledge on the cause and pathophysiological mechanisms in fibromuscular dysplasia is still lacking. Moreover, optimal screening strategies for renal fibromuscular dysplasia and how to manage extrarenal fibromuscular dysplasia 
(e.g. prevention of stroke due to cervicocephalic fibromuscular dysplasia or intracranial aneurysms) remains unclear. Further research on this disease is difficult, as (on this moment) only a small number of patients is diagnosed each year. Therefore, international collaboration will be necessary to perform large interventional studies that could answer these pivotal questions. These studies would presumably provide valuable information that improves diagnostic and therapeutic strategies, not only in patients with fibromuscular dysplasia, but also in hypertensive patients without fibromuscular dysplasia. In atherosclerotic renal artery stenosis for example, large studies demonstrated that revascularization has no benefit over medical treatment, ${ }^{54,}$ 55 which is in sharp contrast to the fairly good effects achieved in patients with fibromuscular dysplasia. ${ }^{67}$ In clinical practice, however, many clinicians notice that revascularization of atherosclerotic renal artery stenosis had beneficial effects in some patients. Thus, it appears that within the large population of patients with atherosclerotic renal artery stenosis some patients do benefit from revascularization. The question is how we could identify these responders before revascularization is performed. In this thesis we hypothesized that the difference in treatment efficacy between fibromuscular dysplasia and atherosclerotic renal artery stenosis could be related to differences in microvascular function of the kidney behind the renovascular abnormalities. If true, this suggests that the quality of renal microvascular function could predict whether patients will benefit from revascularization or not. In that case, it possibly does not matter whether renovascular hypertension is caused by atherosclerosis or fibromuscular dysplasia, as long as renal microvascular function is preserved. Those patients could be selected for revascularization (e.g. by measuring the response to vasoactive substances), while those with severe microvascular dysfunction and loss of kidney tissue who would probably not respond to revascularization can be managed with antihypertensive drugs or device-based antihypertensive strategies.

With regard to the treatment of essential hypertension, the progress that has been made in the development of new therapeutic strategies that target the reninangiotensin system is promising (Chapter 4). Several new pathways, predominately with beneficial effects, have been discovered. Nevertheless, it is more than 20 years since the last real 'game-changing' breakthrough in renin-angiotensin modulation (the introduction of $\mathrm{AT}_{1} \mathrm{R}$ blockers) took place. Still too many questions on this topic remain. In this thesis, for example, we demonstrated that the effects of Ang-(1-7) are attenuated in patients on a low sodium diet and in patients with atherosclerotic renal artery stenosis (Chapter 2 and 3 ) and that the influence of renin-angiotensin system activity on $\mathrm{AT}_{1} \mathrm{R}$-blockade in hypertensive humans is different from that in animal models (Chapter 5). Therefore, future studies should not only focus on the discovery of new angiotensins, enzymes, receptors, and intracellular signalling pathways, but also on the role of these different axes within the renin-angiotensin system in real patients (e.g. with hypertension, renal failure, or other cardiovascular diseases) and the influence of other factors such as lifestyle and co-morbidities. 


\section{References}

1. Castrop H, Hocherl K, Kurtz A, Schweda F, Todorov V, Wagner C. Physiology of kidney renin. Physiol Rev. 2010;90:607-673

2. Mancia G, Fagard R, Narkiewicz K, Redon J, Zanchetti A, Bohm M, Christiaens T, Cifkova R, De Backer G, Dominiczak A, Galderisi M, Grobbee DE, Jaarsma T, Kirchhof P, Kjeldsen SE, Laurent S, Manolis AJ, Nilsson PM, Ruilope LM, Schmieder RE, Sirnes PA, Sleight P, Viigimaa M, Waeber B, Zannad F. 2013 esh/esc guidelines for the management of arterial hypertension: The task force for the management of arterial hypertension of the european society of hypertension (esh) and of the european society of cardiology (esc). J Hypertens. 2013;31:1281-1357

3. Tigerstedt R, Bergman P. Niere und kreislauf. Skand Arch Physiol. 1898;8:223-271

4. Nussberger J, Buhler K, Waeber B, Brunner HR. Identification and quantitation of angiotensins. J Cardiovasc Pharmacol. 1986;8 Suppl 10:S23-28

5. Naveri L, Stromberg C, Saavedra JM. Angiotensin iv reverses the acute cerebral blood flow reduction after experimental subarachnoid hemorrhage in the rat. J Cereb Blood Flow Metab. 1994;14:10961099

6. Jankowski V, Vanholder R, van der Giet M, Tolle M, Karadogan S, Gobom J, Furkert J, Oksche A, Krause E, Tran TN, Tepel M, Schuchardt M, Schluter H, Wiedon A, Beyermann M, Bader M, Todiras M, Zidek W, Jankowski J. Mass-spectrometric identification of a novel angiotensin peptide in human plasma. Arterioscler Thromb Vasc Biol. 2007;27:297-302

7. Lautner RQ, Villela DC, Fraga-Silva RA, Silva N, Verano-Braga T, Costa-Fraga F, Jankowski J, Jankowski V, Sousa F, Alzamora A, Soares E, Barbosa C, Kjeldsen F, Oliveira A, Braga J, Savergnini S, Maia G, Peluso $A B$, Passos-Silva D, Ferreira A, Alves F, Martins A, Raizada M, Paula R, Motta-Santos D, Klempin F, Pimenta A, Alenina N, Sinisterra R, Bader M, Campagnole-Santos MJ, Santos RA. Discovery and characterization of alamandine: A novel component of the renin-angiotensin system. Circ Res. 2013;112:1104-1111

8. Martin MM, Su B, Elton TS. Molecular cloning of the human angiotensin ii type 2 receptor cdna. Biochem Biophys Res Commun. 1994;205:645-651

9. Zulli A, Burrell LM, Buxton BF, Hare DL. Ace2 and at4r are present in diseased human blood vessels. Eur $J$ Histochem. 2008;52:39-44

10. Nguyen G, Delarue F, Burckle C, Bouzhir L, Giller T, Sraer JD. Pivotal role of the renin/prorenin receptor in angiotensin ii production and cellular responses to renin. J Clin Invest. 2002;109:1417-1427

11. Johnson RJ, Lanaspa MA, Gabriela Sanchez-Lozada L, Rodriguez-Iturbe B. The discovery of hypertension: Evolving views on the role of the kidneys, and current hot topics. Am J Physiol Renal Physiol. 2015;308:F167-178

12. Textor SC, Lerman L. Renovascular hypertension and ischemic nephropathy. Am J Hypertens. 2010;23:1159-1169

13. Burgelova M, Kramer HJ, Teplan V, Thumova M, Cervenka L. Effects of angiotensin-(1-7) blockade on renal function in rats with enhanced intrarenal ang ii activity. Kidney Int. 2005;67:1453-1461

14. Iyer SN, Averill DB, Chappell MC, Yamada K, Allred AJ, Ferrario CM. Contribution of angiotensin-(1-7) to blood pressure regulation in salt-depleted hypertensive rats. Hypertension. 2000;36:417-422

15. Ingert C, Grima M, Coquard C, Barthelmebs M, Imbs JL. Effects of dietary salt changes on renal reninangiotensin system in rats. Am J Physiol Renal Physiol. 2002;283:F995-1002

16. Gironacci MM, Adamo HP, Corradi G, Santos RA, Ortiz P, Carretero OA. Angiotensin (1-7) induces mas receptor internalization. Hypertension. 2011;58:176-181

17. Kocks MJ, Lely AT, Boomsma F, de Jong PE, Navis G. Sodium status and angiotensin-converting enzyme inhibition: Effects on plasma angiotensin-(1-7) in healthy man. J Hypertens. 2005;23:597-602

18. Nakamura S, Averill DB, Chappell MC, Diz DI, Brosnihan KB, Ferrario CM. Angiotensin receptors contribute to blood pressure homeostasis in salt-depleted shr. Am J Physiol Regul Integr Comp Physiol. 2003;284:R164-173

19. Schalekamp MA, Danser AH. How does the angiotensin ii type 1 receptor 'trump' the type 2 receptor in blood pressure control? J Hypertens. 2013;31:705-712 
20. Vickers C, Hales P, Kaushik V, Dick L, Gavin J, Tang J, Godbout K, Parsons T, Baronas E, Hsieh F, Acton S, Patane $M$, Nichols A, Tummino P. Hydrolysis of biological peptides by human angiotensin-converting enzyme-related carboxypeptidase. J Biol Chem. 2002;277:14838-14843

21. Schindler C, Brosnihan KB, Ferrario CM, Bramlage P, Maywald U, Koch R, Oertel R, Kirch W. Comparison of inhibitory effects of irbesartan and atorvastatin treatment on the renin angiotensin system (ras) in veins: A randomized double-blind crossover trial in healthy subjects. J Clin Pharmacol. 2007;47:112-120

22. Iyer SN, Chappell MC, Averill DB, Diz DI, Ferrario CM. Vasodepressor actions of angiotensin-(1-7) unmasked during combined treatment with lisinopril and losartan. Hypertension. 1998;31:699-705

23. Iyer SN, Ferrario CM, Chappell MC. Angiotensin-(1-7) contributes to the antihypertensive effects of blockade of the renin-angiotensin system. Hypertension. 1998;31:356-361

24. Zimmerman MA, Harris RA, Sullivan JC. Female spontaneously hypertensive rats are more dependent on ang (1-7) to mediate effects of low-dose at1 receptor blockade than males. Am J Physiol Renal Physiol. 2014;306:F1136-1142

25. Ohshima K, Mogi M, Nakaoka H, Iwanami J, Min LJ, Kanno H, Tsukuda K, Chisaka T, Bai HY, Wang XL, Ogimoto A, Higaki J, Horiuchi M. Possible role of angiotensin-converting enzyme 2 and activation of angiotensin ii type 2 receptor by angiotensin-(1-7) in improvement of vascular remodeling by angiotensin ii type 1 receptor blockade. Hypertension. 2014;63:e53-59

26. Ruan X, Wagner C, Chatziantoniou C, Kurtz A, Arendshorst WJ. Regulation of angiotensin ii receptor at1 subtypes in renal afferent arterioles during chronic changes in sodium diet. J Clin Invest. 1997;99:10721081

27. Navar LG. Intrarenal renin-angiotensin system in regulation of glomerular function. Curr Opin Nephrol Hypertens. 2014;23:38-45

28. Zhuo JL, Ferrao FM, Zheng Y, Li XC. New frontiers in the intrarenal renin-angiotensin system: A critical review of classical and new paradigms. Front Endocrinol (Lausanne). 2013;4:166

29. Bernstein KE, Giani JF, Shen XZ, Gonzalez-Villalobos RA. Renal angiotensin-converting enzyme and blood pressure control. Curr Opin Nephrol Hypertens. 2014;23:106-112

30. Te Riet L, van Esch JH, Roks AJ, van den Meiracker AH, Danser AH. Hypertension: Renin-angiotensinaldosterone system alterations. Circ Res. 2015;116:960-975

31. Susic D, Frohlich ED, Kobori H, Shao W, Seth D, Navar LG. Salt-induced renal injury in shrs is mediated by at1 receptor activation. J Hypertens. 2011;29:716-723

32. Slagman MC, Waanders F, Hemmelder MH, Woittiez AJ, Janssen WM, Lambers Heerspink HJ, Navis G, Laverman GD, Group HONS. Moderate dietary sodium restriction added to angiotensin converting enzyme inhibition compared with dual blockade in lowering proteinuria and blood pressure: Randomised controlled trial. BMJ. 2011;343:d4366

33. Vegter S, Perna A, Postma MJ, Navis G, Remuzzi G, Ruggenenti P. Sodium intake, ace inhibition, and progression to esrd. J Am Soc Nephrol. 2012;23:165-173

34. Sasaki S, Higashi Y, Nakagawa K, Matsuura H, Kajiyama G, Oshima T. Effects of angiotensin-(1-7) on forearm circulation in normotensive subjects and patients with essential hypertension. Hypertension. 2001;38:90-94

35. Sampaio WO, Nascimento AA, Santos RA. Systemic and regional hemodynamic effects of angiotensin(1-7) in rats. Am J Physiol Heart Circ Physiol. 2003;284:H1985-1994

36. Ren Y, Garvin JL, Carretero OA. Vasodilator action of angiotensin-(1-7) on isolated rabbit afferent arterioles. Hypertension. 2002;39:799-802

37. Silveira KD, Barroso LC, Vieira AT, Cisalpino D, Lima CX, Bader M, Arantes RM, Dos Santos RA, Simoes ESAC, Teixeira MM. Beneficial effects of the activation of the angiotensin-(1-7) mas receptor in a murine model of adriamycin-induced nephropathy. PLoS One. 2013;8:e66082

38. Savergnini SQ, lanzer D, Carvalho MB, Ferreira AJ, Silva GA, Marques FD, Peluso AA, Beiman M, Cojocaru G, Cohen Y, Almeida AP, Rotman G, Santos RA. The novel mas agonist, cgen-856s, attenuates isoproterenol-induced cardiac remodeling and myocardial infarction injury in rats. PLoS One. 2013;8:e57757

39. Fraga-Silva RA, Savergnini SQ, Montecucco F, Nencioni A, Caffa I, Soncini D, Costa-Fraga FP, De Sousa FB, Sinisterra RD, Capettini LA, Lenglet S, Galan K, Pelli G, Bertolotto M, Pende A, Spinella G, Pane B, Dallegri F, Palombo D, Mach F, Stergiopulos N, Santos RA, da Silva RF. Treatment with angiotensin-(17) reduces inflammation in carotid atherosclerotic plaques. Thromb Haemost. 2014;111 
40. Haber PK, Ye M, Wysocki J, Maier C, Haque SK, Batlle D. Angiotensin-converting enzyme 2independent action of presumed angiotensin-converting enzyme 2 activators: Studies in vivo, ex vivo, and in vitro. Hypertension. 2014

41. Bertagnolli M, Casali KR, De Sousa FB, Rigatto K, Becker L, Santos SH, Dias LD, Pinto G, Dartora DR, Schaan BD, Milan RD, Irigoyen MC, Santos RA. An orally active angiotensin-(1-7) inclusion compound and exercise training produce similar cardiovascular effects in spontaneously hypertensive rats. Peptides. 2013;51C:65-73

42. Qi Y, Zhang J, Cole-Jeffrey CT, Shenoy V, Espejo A, Hanna M, Song C, Pepine CJ, Katovich MJ, Raizada MK. Diminazene aceturate enhances angiotensin-converting enzyme 2 activity and attenuates ischemia-induced cardiac pathophysiology. Hypertension. 2013;62:746-752

43. Fraga-Silva RA, Costa-Fraga FP, Murca TM, Moraes PL, Martins Lima A, Lautner RQ, Castro CH, Soares CM, Borges CL, Nadu AP, Oliveira ML, Shenoy V, Katovich MJ, Santos RA, Raizada MK, Ferreira AJ. Angiotensin-converting enzyme 2 activation improves endothelial function. Hypertension. 2013;61: 1233-1238

44. Yang JM, Dong M, Meng X, Zhao YX, Yang XY, Liu XL, Hao PP, Li JJ, Wang XP, Zhang K, Gao F, Zhao XQ, Zhang $M X$, Zhang $Y$, Zhang $C$. Angiotensin-(1-7) dose-dependently inhibits atherosclerotic lesion formation and enhances plaque stability by targeting vascular cells. Arterioscler Thromb Vasc Biol. 2013;33:1978-1985

45. Rakusan D, Burgelova M, Vaneckova I, Vanourkova Z, Huskova Z, Skaroupkova P, Mrazova I, Opocensky M, Kramer HJ, Netuka I, Maly J, Alenina N, Bader M, Santos RA, Cervenka L. Knockout of angiotensin 17 receptor mas worsens the course of two-kidney, one-clip goldblatt hypertension: Roles of nitric oxide deficiency and enhanced vascular responsiveness to angiotensin ii. Kidney Blood Press Res. 2010;33:476-488

46. Webb DJ, Cumming AM, Adams FC, Hodsman GP, Leckie BJ, Lever AF, Morton JJ, Murray GD, Robertson $\mathrm{Jl}$. Changes in active and inactive renin and in angiotensin ii across the kidney in essential hypertension and renal artery stenosis. J Hypertens. 1984;2:605-614

47. Chade AR, Rodriguez-Porcel M, Grande JP, Zhu X, Sica V, Napoli C, Sawamura T, Textor SC, Lerman A, Lerman LO. Mechanisms of renal structural alterations in combined hypercholesterolemia and renal artery stenosis. Arterioscler Thromb Vasc Biol. 2003;23:1295-1301

48. Lerman LO, Textor SC, Grande JP. Mechanisms of tissue injury in renal artery stenosis: Ischemia and beyond. Prog Cardiovasc Dis. 2009;52:196-203

49. Zhang X, Eirin A, Li ZL, Crane JA, Krier JD, Ebrahimi B, Pawar AS, Zhu XY, Tang H, Jordan KL, Lerman A, Textor SC, Lerman LO. Angiotensin receptor blockade has protective effects on the poststenotic porcine kidney. Kidney Int. 2013;84:767-775

50. Keddis MT, Garovic VD, Bailey KR, Wood CM, Raissian Y, Grande JP. Ischaemic nephropathy secondary to atherosclerotic renal artery stenosis: Clinical and histopathological correlates. Nephrol Dial Transplant. 2010;25:3615-3622

51. Eirin A, Lerman LO. Mesenchymal stem cell treatment for chronic renal failure. Stem Cell Res Ther. 2014;5:83

52. Favreau F, Zhu XY, Krier JD, Lin J, Warner L, Textor SC, Lerman LO. Revascularization of swine renal artery stenosis improves renal function but not the changes in vascular structure. Kidney Int. 2010;78:1110-1118

53. Eirin A, Zhu XY, Urbieta-Caceres VH, Grande JP, Lerman A, Textor SC, Lerman LO. Persistent kidney dysfunction in swine renal artery stenosis correlates with outer cortical microvascular remodeling. $\mathrm{Am}$ J Physiol Renal Physiol. 2011;300:F1394-1401

54. Wheatley K, Ives N, Gray R, Kalra PA, Moss JG, Baigent C, Carr S, Chalmers N, Eadington D, Hamilton G, Lipkin G, Nicholson A, Scoble J. Revascularization versus medical therapy for renal-artery stenosis. $N$ Engl J Med. 2009;361:1953-1962

55. Cooper CJ, Murphy TP, Cutlip DE, Jamerson K, Henrich W, Reid DM, Cohen DJ, Matsumoto AH, Steffes $M$, Jaff MR, Prince MR, Lewis EF, Tuttle KR, Shapiro JI, Rundback JH, Massaro JM, D'Agostino RB, Sr., Dworkin LD, Investigators C. Stenting and medical therapy for atherosclerotic renal-artery stenosis. $N$ Engl J Med. 2014;370:13-22

56. Chade AR, Rodriguez-Porcel M, Grande JP, Krier JD, Lerman A, Romero JC, Napoli C, Lerman LO. Distinct renal injury in early atherosclerosis and renovascular disease. Circulation. 2002;106:1165-1171 
57. Wierema TK, Houben AJ, Kroon AA, Koster D, van der Zander K, van Engelshoven JM, de Leeuw PW. Nitric oxide dependence of renal blood flow in patients with renal artery stenosis. J Am Soc Nephrol: JASN. 2001;12:1836-1843

58. Wierema TK, Postma CT, Houben AJ, Kroon AA, Thien T, Smits P, de Leeuw PW. Adenosine-induced renal vasodilatation is prolonged in renal artery stenosis. J Hypertens. 1998;16:2109-2112

59. Bosse HM, Bachmann S. Immunohistochemically detected protein nitration indicates sites of renal nitric oxide release in goldblatt hypertension. Hypertension. 1997;30:948-952

60. Jarraya F, Pruijm M, Wuerzner G, Burnier M. Blockade of the renin-angiotensin system in hypertensive patients with atherosclerotic renal artery stenosis. Curr Hypertens Rep. 2013;15:497-505

61. Lerman LO, Taler SJ, Textor SC, Sheedy PF, 2nd, Stanson AW, Romero JC. Computed tomographyderived intrarenal blood flow in renovascular and essential hypertension. Kidney Int. 1996;49:846-854

62. Vetter W, Vetter H, Tenschert W, Kuhlmann U, Studer A, Glanzer K, Pouliadis G, Largiader F, Furrer J, Siegenthaler W. [renovascular hypertension. Prognostic value of renal venous renin determinations (author's transl)]. Klin Wochenschr. 1979;57:863-873

63. Marks LS, Maxwell MH, Kaufman JJ. Non-renin-mediated renovascular hypertension: A new syndrome? Lancet. 1977;1:615-617

64. Luscher TF, Greminger P, Kuhlmann U, Siegenthaler W, Largiader F, Vetter W. Renal venous renin determinations in renovascular hypertension. Diagnostic and prognostic value in unilateral renal artery stenosis treated by surgery or percutaneous transluminal angioplasty. Nephron. 1986;44 Suppl 1:17-24

65. Luscher TF, Vetter H, Studer A, Pouliadis G, Kuhlmann U, Glanzer K, Largiader F, Hauri D, Greminger P, Siegenthaler $W$, Vetter $W$. Renal venous renin activity in various forms of curable renal hypertension. Clin Nephrol. 1981;15:314-320

66. McKenzie GA, Oderich GS, Kawashima A, Misra S. Renal artery fibromuscular dysplasia in 2,640 renal donor subjects: A ct angiography analysis. J Vasc Interv Radiol. 2013;24:1477-1480

67. Trinquart L, Mounier-Vehier C, Sapoval M, Gagnon N, Plouin PF. Efficacy of revascularization for renal artery stenosis caused by fibromuscular dysplasia: A systematic review and meta-analysis. Hypertension. 2010;56:525-532

68. Salem MM. Pathophysiology of hypertension in renal failure. Semin Nephrol. 2002;22:17-26

69. Kelle S, Teller DC, Fleck E, Stawowy P. Renal denervation in fibromuscular dysplasia. BMJ case reports. 2013;2013

70. Andreoni KA, Weeks SM, Gerber DA, Fair JH, Mauro MA, McCoy L, Scott L, Johnson MW. Incidence of donor renal fibromuscular dysplasia: Does it justify routine angiography? Transplantation. 2002;73:1112-1116

71. Cragg AH, Smith TP, Thompson BH, Maroney TP, Stanson AW, Shaw GT, Hunter DW, Cochran ST. Incidental fibromuscular dysplasia in potential renal donors: Long-term clinical follow-up. Radiology. 1989;172:145-147

72. Hendricks NJ, Matsumoto AH, Angle JF, Baheti A, Sabri SS, Park AW, Stone JR, Patrie JT, Dworkin L, Cooper CJ, Murphy TP, Cutlip DE. Is fibromuscular dysplasia underdiagnosed? A comparison of the prevalence of fmd seen in coral trial participants versus a single institution population of renal donor candidates. Vascular medicine. 2014;19:363-367

73. Kuczera P, Wloszczynska E, Adamczak M, Pencak P, Chudek J, Wiecek A. Frequency of renal artery stenosis and variants of renal vascularization in hypertensive patients: Analysis of 1550 angiographies in one centre. J Hum Hypertens. 2009;23:396-401

74. Giavarini A, Savard S, Sapoval M, Plouin PF, Steichen O. Clinical management of renal artery fibromuscular dysplasia: Temporal trends and outcomes. J Hypertens. 2014;32:2433-2438; discussion 2438 
Summary 


\section{Introduction}

Hypertension is still the most important individual risk factor for death and burden of disease worldwide. Although mortality and burden of disease due to hypertension can be reduced by reducing blood pressure with antihypertensive drugs, blood pressure remains above goal despite treatment in more than $50 \%$ of the hypertensive patients. Therefore, these patients continue to be at risk for kidney failure, cardiovascular diseases, and premature death. Hence, it is important to find new and better treatment strategies to reduce blood pressure in these patients. In order to develop new strategies it is necessary to understand the pathophysiological mechanisms that contribute to the development and persistence of hypertension. In this thesis we therefore evaluated several questions regarding one of the most important systems in the regulation of blood pressure: the renin-angiotensin system.

The renin-angiotensin system is a complex endocrine cascade leading to the production of angiotensins that exert several effects on the on the cardiovascular system. The kidneys play an essential role in the renin-angiotensin system: they are the sensor (detection of blood pressure and distal tubular sodium delivery), the regulator (secretion of renin, the rate-limiting activator), and the main target organ for the angiotensins (regulation of renal blood flow and water and sodium balance). The reninangiotensin system enables the kidneys to maintain intraglomerular pressure at a stable level in case of changes in systemic blood pressure and/or circulating volume, for example due to dehydration or severe bleeding. However, next to these protective effects it is also one of the most important contributing factors in the development and persistence of hypertension. Hence, drugs targeting the renin-angiotensin system are nowadays considered the cornerstone in the treatment of hypertension.

\section{Angiotensin-(1-7)}

Activation of the renin-angiotensin system leads to the production of different angiotensins that eventually determine the effect of the renin-angiotensin system on the cardiovascular system. For a long time, it was thought that angiotensin II (Ang II), a potent vasoconstrictor, was the only clinically important angiotensin. However, over the past decades more and more studies demonstrated that other angiotensins also play an important role. One of these angiotensins is angiotensin-(1-7) [Ang-(1-7)], a peptide that is present in the plasma in levels comparable to those of Ang II. It is closely related to Ang II as the enzymes producing Ang-(1-7) use Ang II as its substrate (Figure 9.1).Thus far, only little was known on the role of Ang-(1-7) in humans, particularly in patients with pathologic conditions such as hypertension or chronic kidney disease. This knowledge, however, is indispensable to develop new therapeutic strategies that cure, prevent, or arrest such diseases' progress. Therefore, we focused 
in this thesis on the renin-angiotensin system in the kidneys of humans with hypertension.

Figure 9.1 The renin-angiotensin system.

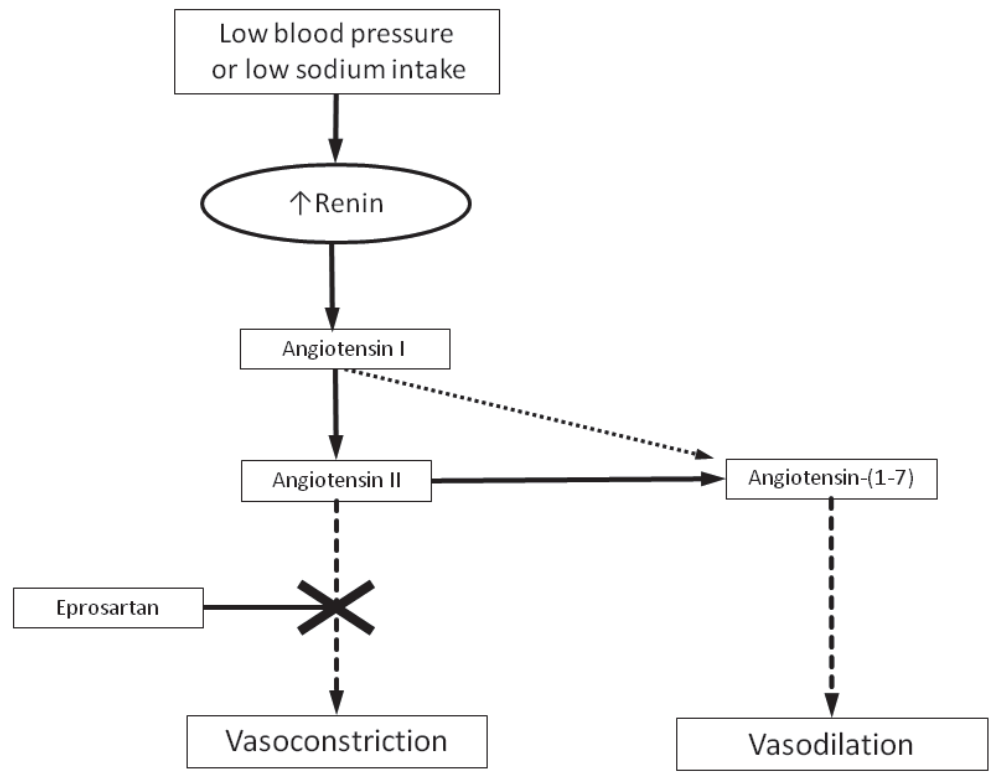

Simplified overview of the renin-angiotensin system. On the left side angiotensin II which induces vasoconstriction and on the right side angiotensin-(1-7) which induces vasodilation. The enzymes producing angiotensin-(1-7) use angiotensin II as its substrate, but can also form it directly out of angiotensin I. Eprosartan, used in Chapter 5, blocks the vasoconstrictory effects of angiotensin II.

In Chapter 2 we evaluated the effects of intrarenal infusion of Ang-(1-7) on renal blood flow. We found that Ang-(1-7) is able to induce vasodilation in the kidneys of humans with essential hypertension. Furthermore, Ang-(1-7) partially counteracts the vasoconstrictory effects of Ang II, while Ang II, on its turn, attenuates the vasodilatory effects of Ang-(1-7). This indicates that in the human hypertensive kidneys a balance exists between Ang II-induced vasoconstriction and Ang-(1-7)-induced vasodilation. Our finding that Ang-(1-7) is able to induce vasodilation in patients with hypertension as well provides a strong basis for further development of drugs targeting Ang-(1-7), for example by increasing the plasma concentration of Ang-(1-7) or by developing agonists that stimulate the Mas-receptor [Ang-(1-7)s target receptor]. Recent animal studies about Ang-(1-7) as a potential therapeutic target were summarized in Chapter 4 and demonstrated promising results, which could on the long term lead to the introduction of new pharmacotherapeutic strategies for patients with hypertension. 


\section{Influence of renin-angiotensin activity}

In this thesis we also questioned whether renin-angiotensin system activity has any influence on the effect of angiotensins. We studied this kidneys from hypertensive patients (off medication) under three different conditions that induce reninangiotensin system activation: 1 ) endogenous activation by using a low sodium diet, 2) exogenous activation of the $A C E / A n g ~ I I / A T_{1} R$ axis by infusion of Ang II, and 3 ) endogenous activation due to the presence of a high-grade atherosclerotic renal artery stenosis.

As previously mentioned, we found in Chapter 2 that intrarenal infusion of Ang-(1-7) induces vasodilation. Low sodium intake and/or co-infusion of Ang II, however, attenuated the vasodilatory effects of Ang-(1-7). We furthermore found that the prevailing renin level is the only independent predictor of Ang-(1-7)-induced intrarenal vasodilation. This indicates that Ang-(1-7)-induced vasodilation is reduced during activation of the renin-angiotensin system, which could have implications for the effectiveness of future drugs using Ang-(1-7) as a target.

As the renin-angiotensin activation is also activated in the presence of a high grade atherosclerotic renal artery stenosis we hypothesized that this would also attenuate the intrarenal effects of Ang-(1-7). We studied this in Chapter 3 and found that Ang-(1-7)-induced vasodilation is indeed reduced in kidneys with atherosclerotic renal artery stenosis. However, in patients with unilateral renal artery stenosis we found that the vasodilatory effect of Ang-(1-7) is preserved in the contralateral, non-affected kidney. This suggests that the reduced effect of Ang-(1-7) in kidneys with atherosclerotic renal artery stenosis is a local phenomenon and not related to systemic activation of the renin-angiotensin system or generalized atherosclerotic burden, as this would have attenuated the effect of Ang-(1-7) in the contralateral kidney as well. Thereafter, we questioned whether renin-angiotensin system activity would also affect other axes of the renin-angiotensin system. In Chapter $\mathbf{5}$ we performed a similar experiment with eprosartan (a blocker of the $\mathrm{AT}_{1}$-receptor, Ang II's target receptor) in patients with essential hypertension. We found that acute intrarenal infusion of eprosartan indeed induces renal vasodilation. However, in contrast to our findings on Ang-(1-7) the vasodilatory effect of eprosartan was not influenced by dietary sodium intake or Ang II co-infusion. This finding was rather unexpected and differed from our findings with Ang-(1-7), but can be explained by the presence of several 'escape routes' for Ang II (e.g. by conversion into Ang-(1-7) or vasodilation induced by stimulation of the $\mathrm{AT}_{2}$-receptor), differences in renin-angiotensin system activity between the kidneys and the systemic circulation, and differences in the effect of sodium intake on intrarenal renin-angiotensin system between hypertensive patients and healthy subjects. 


\section{Fibromuscular dysplasia versus atherosclerotic renal artery stenosis}

Fibromuscular dysplasia is a renovascular abnormality that is less often found than atherosclerotic renal artery stenosis. This non-atherosclerotic, non-inflammatory disease of the vascular wall is predominantly known for its typical string-of-beads appearance (Figure 9.2). Although it is the second most common renovascular abnormality, pathophysiological mechanisms and changes in kidneys of patients with this disease have hardly been studied. It is generally assumed that renal artery fibromuscular dysplasia causes hypertension due to a decrease in renal blood flow, followed by increased renin secretion, which on its turn increases blood pressure. This view, however, is mainly based on experiments in animal models and studies in patients with atherosclerotic renal artery stenosis, but not on studies in patients with fibromuscular dysplasia. Therefore, we evaluated the pathophysiological mechanisms in fibromuscular dysplasia Chapters 6 and 7. We found that renal blood flow is higher in kidneys with fibromuscular dysplasia as compared to kidneys with atherosclerotic renal artery stenosis and that it is comparable to renal blood flow in patients with essential hypertension (without renovascular abnormalities). Moreover, renin secretion was not increased in kidneys with fibromuscular dysplasia, this in contrast to patients with atherosclerotic renal artery stenosis. Most strikingly was our finding that the association between renin levels and blood pressure is inverted in fibromuscular dysplasia as compared to atherosclerotic renal artery stenosis: in patients with fibromuscular dysplasia high renin levels are associated with lower blood pressure, while in patients with atherosclerotic renal artery stenosis high renin levels are associated with higher blood pressure. Taken together, these findings all contradict the generally accepted view that fibromuscular dysplasia induces hypertension via decreased renal blood flow and increased renin secretion. Unfortunately, it remains unknown what mechanism is responsible for high blood pressure in these patients. Nevertheless, it appears to be related to the string-of-beads, given the relatively good effects of balloon angioplasty on blood pressure in these patients. 
Figure 9.2 Schematic overview of a normal renal artery, atherosclerotic renal artery stenosis, and multifocal fibromuscular dysplasia with a typical string-of-beads appearance.

Normal renal artery

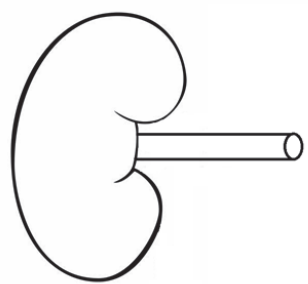

Atherosclerotic renal artery stenosis

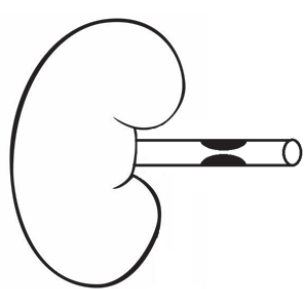

Fibromuscular dysplasia

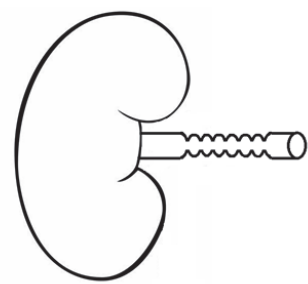

\section{Microvascular function in fibromuscular dysplasia}

Given the fairly good effects of balloon angioplasty (in contrast to patients with atherosclerotic renal artery stenosis) we hypothesized that renal microvascular function is preserved in kidneys with fibromuscular dysplasia. In Chapters 6 and $\mathbf{7}$ we found that renal blood flow, glomerular filtration rate, and the response to reninangiotensin system modulation [stimulation or blockade of Ang II and Ang-(1-7)] were higher as compared to kidneys with atherosclerotic renal artery stenosis and comparable to that in patients with essential hypertension. These findings indicate that in kidneys with fibromuscular dysplasia, the intrarenal renin-angiotensin system is not disturbed and microvascular function is relatively preserved, this in contrast to kidneys with atherosclerotic renal artery stenosis. This could explain the difference in effect of balloon angioplasty on blood pressure between atherosclerotic renal artery stenosis and fibromuscular dysplasia: as sufficient and qualitatively good renal tissue is preserved the kidney will be able to function relatively normal again after revascularization. Furthermore, our finding that the kidneys still respond normally to renin-angiotensin modulation suggests that patients with fibromuscular dysplasia would respond relatively well to antihypertensive drugs. This could explain why fibromuscular dysplasia is underdiagnosed, as often no diagnostic renovascular studies are performed in patients who reach blood pressure targets quite easily with antihypertensive drugs. 


\section{Main findings in this thesis}

In this thesis we evaluated several questions regarding new and older concepts on the renin-angiotensin system and the kidneys in patients with essential hypertension, atherosclerotic renal artery stenosis, and fibromuscular dysplasia. Our main findings in this thesis were:

- $\quad$ Ang-(1-7) induces vasodilation in the kidneys of patients with essential hypertension.

- The vasodilatory effect of Ang-(1-7) in the human hypertensive kidney is attenuated by renin-angiotensin system activation due to low sodium intake or Ang II co-infusion.

- $\quad$ The vasodilatory effect of Ang-(1-7) is reduced in kidneys with atherosclerotic renal artery stenosis, but not in the contralateral, non-affected kidney.

- In patients with essential hypertension, eprosartan-induced vasodilation is not influenced by sodium intake or Ang II co-infusion.

- Microvascular function and intrarenal renin-angiotensin system are relatively preserved in kidneys with fibromuscular dysplasia.

- Renin secretion is not increased in kidneys with fibromuscular dysplasia.

- Pathophysiological mechanisms in hypertension due to atherosclerotic renal artery stenosis differ from hypertension due to fibromuscular dysplasia. 
Nederlandstalige samenvatting 


\section{Introductie}

Hoge bloeddruk (hypertensie) is nog altijd de belangrijkste individuele risicofactor voor ziektelast en sterfte. Wereldwijd lijden op dit moment meer dan 1 miljard mensen aan hoge bloeddruk. Langdurige blootstelling aan hoge bloeddruk kan leiden tot nierfunctieachteruitgang en hart- en vaatziekten, zoals hartinfarcten en beroertes. Samen zijn hartinfarcten en beroertes verantwoordelijk voor bijna 1 op de 4 sterfgevallen wereldwijd. Gelukkig kan een deel van de sterfte en ziektelast als gevolg van hart- vaatziekten voorkomen worden door verlaging van de bloeddruk, bijvoorbeeld met bloeddrukverlagende medicatie. Echter, bij meer dan $50 \%$ van de patiënten blijft de bloeddruk verhoogd, ondanks het gebruik van medicatie. Deze patiënten blijven daardoor het risico lopen op nierfunctieachteruitgang en hart- en vaatziekten. Daarom is het belangrijk nieuwe en betere behandelingen te vinden voor het verlagen van hoge bloeddruk. Om dit te kunnen doen is het echter noodzakelijk om eerst beter inzicht te krijgen in de mechanismen die bijdragen aan het ontstaan en in stand houden van hoge bloeddruk.

\section{Het renine-angiotensine systeem}

In dit proefschrift hebben we onderzoek gedaan naar één van de belangrijkste systemen die het lichaam ter beschikking heeft voor de regulatie van bloeddruk: het renine-angiotensine systeem (RAS). Om de resultaten van ons onderzoek goed te kunnen begrijpen is enige uitleg over het RAS vereist. Het RAS vormt een keten van signaalstoffen die uiteindelijk tot een effect leiden in nieren en bloedvaten. Dit zorgt er voor dat de bloeddruk hoger of lager wordt. De nieren spelen bij het RAS een centrale rol die onder te verdelen valt in een aantal functies:

1) De sensor: de nieren detecteren of de bloeddruk hoog of laag is en of er sprake is van een verminderd zoutaanbod.

2) De activator: indien de nieren een te lage bloeddruk of een verminderd zoutaanbod detecteren geven ze het eiwit renine af. Renine zet op zijn beurt een keten in gang die leidt tot de productie van signaalstoffen: de angiotensines.

3) Het doelorgaan: de angiotensines hebben allerlei effecten in de nier. De meest belangrijke effecten zijn het verminderen van de uitscheiding van water en zout en het vernauwen van de bloedvaten in de nier. Dit laatste doen de angiotensines ook in de rest van het lichaam. Het vernauwen van de bloedvaten en het beter vasthouden van zout en water leidt uiteindelijk tot een toename van de bloeddruk.

Het RAS is van levensbelang bij gezonde mensen. In geval van weinig drinken, weinig zoutinname en vochtverlies (bijvoorbeeld als gevolg van braken, diarree of een ernstige bloeding) zorgt het er namelijk voor dat de bloeddruk, het zoutgehalte en de hoeveelheid vocht in het lichaam hoog genoeg blijven om de organen goed te laten 
functioneren. Zonder het RAS zou een eenvoudige buikgriep er al toe kunnen leiden dat de nieren onvoldoende doorbloed worden en daardoor niet meer goed kunnen functioneren. Echter, naast het beschermende effect van het RAS schuilt er ook een gevaar in dit systeem. Het RAS blijkt namelijk een belangrijke rol te spelen in het ontstaan en in stand houden van hoge bloeddruk. Daarom vormen medicijnen die het RAS beïnvloeden (zogenaamde ACE-remmers, zoals perindopril, lisinopril en quinapril, en angiotensine II receptor-blokkeerders, zoals losartan, eprosartan, en irbesartan) tegenwoordig een essentieel onderdeel van de behandeling van hoge bloeddruk.

\section{Onderzoeksmethode}

Veel van de kennis over het RAS is opgedaan uit onderzoek met proefdieren. Het is echter maar de vraag of het RAS in een proefdier hetzelfde werkt als in een menselijke patiënt met hoge bloeddruk. Daarom onderzochten wij het RAS bij patiënten met hoge bloeddruk die een onderzoek van de niervaten ondergingen om te zien of sprake was van een vernauwing van de nierslagader (zie verderop). Dit deden we door de bloedstroom door de nier en de afgifte van renine te meten. De patiënten ondergingen hierbij een katheterisatie, een procedure waarbij een slangetje vanuit een bloedvat in de lies naar een ander bloedvat in het lichaam wordt opgevoerd. We plaatsten hierbij zowel slangetjes in de nierslagaders (de aanvoerende bloedvaten) alsook in de nieraders (de afvoerende bloedvaten). Uit deze bloedvaten namen we bloed af, waarmee we de afgifte (verschil in concentratie tussen het afvoerende en aanvoerende bloedvat) van onder andere renine konden bepalen. Vervolgens werd de bloeddoorstroming in de nier gemeten door een radioactief gas ( ${ }^{133}$ Xenon) rechtstreeks in de nierslagader te spuiten. Door de verandering van de radioactiviteit in de nier te meten (met een gammacamera) konden we bepalen hoeveel bloed er per minuut door de nier stroomt.

\section{Angiotensine II en angiotensine-(1-7)}

Zoals reeds aangegeven zorgt het RAS voor de productie van angiotensines die het uiteindelijke effect van het systeem bepalen. Een vereenvoudigd overzicht van de vorming van angiotensines is weergegeven in Figuur 10.1. Lange tijd werd gedacht dat slechts één angiotensine belangrijk was: angiotensine II. Als gevolg van toegenomen renine-activiteit (door een lage bloeddruk of weinig zoutinname) wordt eerst angiotensine I gevormd. Hieruit wordt vervolgens angiotensine II gemaakt, dat ervoor zorgt dat de bloeddruk wordt verhoogd door bloedvatvernauwing en het vasthouden van water en zout door de nier. Echter, de laatste jaren is steeds duidelijker geworden dat ook andere angiotensines een rol spelen. Een andere angiotensine met een 
belangrijke rol is angiotensine-(1-7). Angiotensine-(1-7) wordt met name gevormd door afbraak van angiotensine II, maar een klein deel wordt rechtstreeks gevormd uit angiotensine I. In tegenstelling tot angiotensine II zorgt angiotensine-(1-7) juist voor bloedvatverwijding en daardoor afname van de bloeddruk.

Figur 10.1 Het renine-angiotenisine systeem.

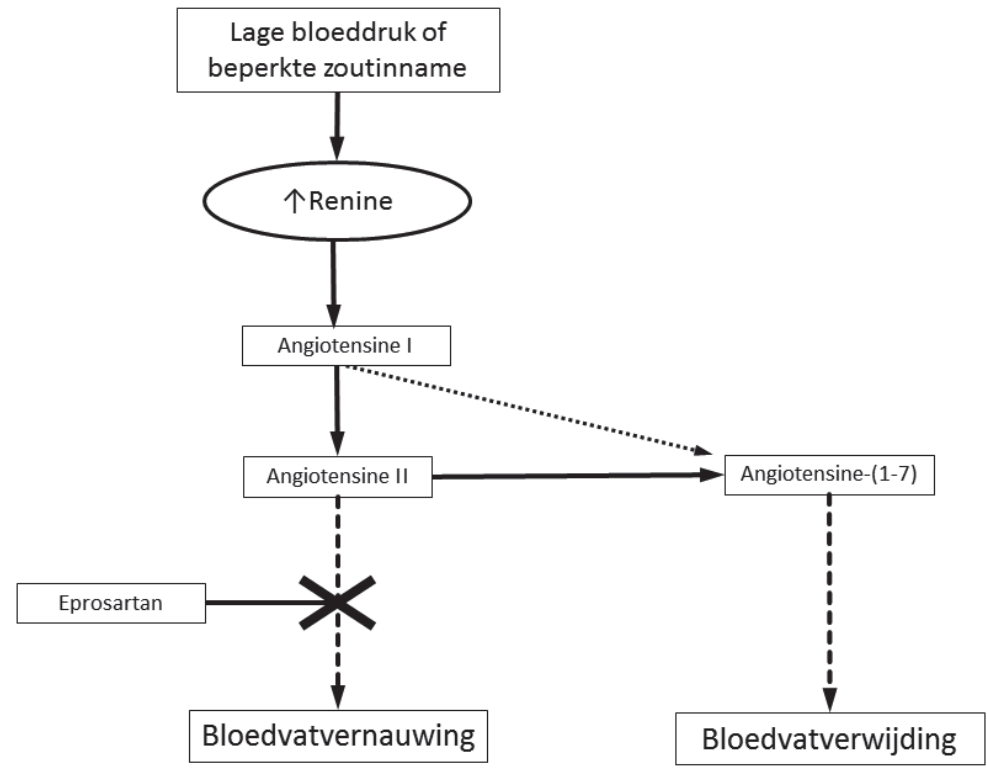

Vereenvoudigde weergave van het renine-angiotensine systeem met aan de linkerkant angiotensine II welk leidt tot bloedvatvernauwing (en dus stijging van de bloeddruk) en aan de rechterkant angiotensine-(1-7), welk leidt tot bloedvatverwijding. Angiotensine-(1-7) wordt met name gevormd uit angiotensine II, maar voor een klein deel ook direct uit angiotensine I. Eprosartan, een bloeddrukverlagend medicijn gebruikt in hoofdstuk 5, blokkeert het bloedvatvernauwend effect van angiotensine II.

Althans in proefdiermodellen, want over de effecten bij patiënten met hoge bloeddruk is hierover weinig bekend. In hoofdstuk $\mathbf{2}$ onderzochten we daarom wat er bij patiënten met hoge bloeddruk gebeurt met de bloeddoorstroming door de nier op het moment dat de concentratie angiotensine-(1-7) toeneemt. Dit deden we door verschillende concentraties angiotensine-(1-7) rechtstreeks in de nierslagader te spuiten en vervolgens de bloeddoorstroming door de nier te meten. We vonden dat hogere concentraties angiotensine-(1-7) ook bij patiënten met hoge bloeddruk voor een behoorlijke toename van de bloeddoorstroming door de nieren zorgen. Dit is een interessante bevinding, omdat het aannemelijk is dat angiotensine-(1-7) dan ook in de rest van het lichaam kan zorgen voor gegeneraliseerde bloedvatverwijding. Een hoge concentratie angiotensine-(1-7) kan zo via de nieren en de bloedvaten in de rest van 
het lichaam waarschijnlijk zorgen voor een afname van de bloeddruk, waardoor angiotensine-(1-7) een interessante optie zou kunnen zijn voor de behandeling van hoge bloeddruk. Dit zou bijvoorbeeld kunnen door medicijnen die de concentratie van de angiotensine-(1-7) in het bloed verhogen of door medicijnen die het effect van angiotensine-(1-7) nabootsten (zogeheten agonisten). De ontwikkeling van zulke medicijnen vindt momenteel plaats en de eerste, veelbelovende resultaten van zulke onderzoeken werden samengevat in hoofdstuk 4.

Wij vroegen ons echter af wat er zou gebeuren met het effect van angiotensine-(1-7) als het we het eigen RAS van de patiënt zouden activeren. Hiervoor gaven we sommige patiënten een dieet met weinig zout (circa 4 gram keukenzout per dag, hetgeen voldoende bleek om een toename van renine-afgifte uit te lokken) en bij anderen gaven we een infuus met angiotensine II [dat dus bloedvatvernauwing geeft, omgekeerd aan het effect van angiotensine-(1-7)]. Het bleek dat zowel activatie van het RAS door een laag-zout dieet als een infuus met angiotensine II de effecten van angiotensine-(1-7) fors verminderden.

Hierop vroegen wij ons af of dit verminderde effect tijdens laag-zout dieet en/of een infuus met angiotensine II ook op zou treden bij andere bloedvatverwijde substanties. Daarom herhaalden we in hoofdstuk 5 het experiment, alleen spoten we dit keer geen angiotensine-(1-7) in, maar eprosartan, een angiotensine II type-1 receptorblokkeerder. Een angiotensine II type-1 receptor-blokkeerder is in staat het bloedvatvernauwende effect van angiotensine II tegen te gaan. Inderdaad bleek dat eprosartan leidde tot een toename van de bloeddoorstroming in de nier, dit als gevolg van bloedvatverwijding. Echter, bij patiënten die weinig zout innamen en patiënten die een infuus kregen met angiotensine II was dit effect even groot als bij de patiënten die een hoog zout dieet volgden en geen infuus met angiotensine II kregen. In tegenstelling tot het effect van angiotensine-(1-7) is het effect van angiotensine II type1 receptor-blokkeerders dus niet afhankelijk van activatie van het RAS.

\section{Angiotensine-(1-7) en vernauwing van de nierslagader}

Een bijzondere vorm van hoge bloeddruk is hoge bloeddruk als gevolg van een vernauwing van de nierslagader: een nierarteriestenose. De meest voorkomende oorzaak van een nierarteriestenose is aderverkalking (atherosclerose). Bij aderverkalking ontstaan ophopingen van cholesterol en kalk aan de binnenkant van de slagaders. Dit neemt over de jaren langzaam toe waardoor de slagader steeds nauwer wordt. Het orgaan dat bloed ontvangt via deze slagader krijgt op een bepaald moment een tekort aan bloed waardoor het niet meer goed kan functioneren. Hierdoor kunnen bijvoorbeeld een hartinfarct, een beroerte of etalagebenen ontstaan.

Zoals gezegd kan een nierarteriestenose leiden tot hoge bloeddruk. Dit komt doordat de bloedtoevoer naar de nier verminderd is. De nier detecteert dit alsof sprake is van 
een lage bloeddruk en start met de afgifte van renine en activeert zo (eigenlijk onterecht) het RAS, waarbij uiteindelijk angiotensine II ervoor zorgt dat de bloeddruk toeneemt. Het opheffen van een nierarteriestenose (bijvoorbeeld door deze op te rekken met een ballonnetje, het zogenaamde 'dotteren') kan ervoor zorgen dat de bloeddruk weer daalt. Dit is dan ook de reden dat de patiënten die meededen aan de wetenschappelijke onderzoeken in dit proefschrift een onderzoek van hun niervaten ondergingen: hun arts wilde weten of sprake was van een nierarteriestenose om deze eventueel te kunnen opheffen. Tijdens zulke onderzoeken hebben wij uit wetenschappelijke interesse extra metingen verricht.

Aangezien in hoofdstuk $\mathbf{2}$ bleek dat de bloedvatverwijdende effecten van angiotensine-(1-7) verminderd waren tijdens activatie van het eigen RAS (door een laag-zout dieet en/of een infuus met angiotensine II) vroegen wij ons af hoe dit zit bij activatie van het RAS als gevolg van een nierarteriestenose. Daarom herhaalden wij in hoofdstuk 3 het experiment met angiotensine-(1-7), maar nu in patiënten met een nierarteriestenose. Het bleek dat in nieren met een nierarteriestenose inderdaad nauwelijks bloedvatverwijding optrad bij het verhogen van de concentratie angiotensine-(1-7). Echter, bij patiënten met een eenzijdige nierarteriestenose (dus één nier met een nierarteriestenose en één nier zonder vaatafwijkingen) bleek dat angiotensine-(1-7) in de niet-aangedane nier nog altijd bloedvatverwijding gaf. Dit duidt er dan ook op dat het verminderde effect van angiotensine-(1-7) het gevolg is van lokale veranderingen in de nier met de nierarteriestenose en niet het gevolg is van generaliseerde nierschade door langdurige hoge bloeddruk of gegeneraliseerde veranderingen in het RAS, want dan zou ook angiotensine-(1-7) ook geen effect meer hebben in de niet-aangedane nier.

\section{Fibromusculaire dysplasie}

Een minder vaak geziene vorm van vernauwing van de nierslagader is fibromusculaire dysplasie (afgekort als FMD). Meestal is een langgerekt deel van de nierslagader aangedaan, waarbij de afwijkingen typisch lijken op een kralensnoer (Figuur 10.2). De oorzaak van deze afwijking is niet duidelijk, maar in elk geval is dit niet het gevolg van aderverkalking of ontsteking. In tegenstelling tot een nierarteriestenose door aderverkalking is slechts weinig bekend over fibromusculaire dysplasie. Aangenomen werd dat hoge bloeddruk bij patiënten met fibromusculaire dysplasie ook het gevolg is van een verminderde bloeddoorstroming en, als gevolg daarvan, activatie van het RAS. In hoofdstukken $\mathbf{6}$ en $\mathbf{7}$ onderzochten we of dit inderdaad zo is. Hierbij ontdekten we dat de bloeddoorstroming door nieren met fibromusculaire dysplasie beter is dan bij nieren met een nierarteriestenose als gevolg van aderverkalking en dat deze zelfs vergelijkbaar is met de bloeddoorstroming van nieren bij patiënten met hoge bloeddruk zonder afwijkingen aan de niervaten. Verder blijkt de afgifte van renine niet verhoogd in nieren met fibromusculaire dysplasie. Ook ontdekten we dat patiënten 
met fibromusculaire dysplasie juist bij een lagere bloeddruk een hoger renine hebben, dit in tegenstelling tot nierarteriestenose als gevolg van aderverkalking, waarbij juist een hoger renine samengaat met een hogere bloeddruk. Deze drie bevindingen passen niet bij het idee dat de verhoogde bloeddruk bij patiënten met fibromusculaire dysplasie wordt veroorzaakt door een verminderde bloeddoorstroming en verhoogde renine-afgifte zoals dit bij nierarteriestenose door aderverkalking het geval is. Hoe fibromusculaire dysplasie dan wel hoge bloeddruk veroorzaakt is helaas nog niet geheel duidelijk en vereist verder onderzoek. In elk geval lijkt de vernauwing wel een rol te spelen, aangezien een dotterbehandeling vaak een bloeddrukverlagend effect heeft bij deze patiënten.

Figuur 10.2 Schematische weergave van een normale nierslagader, een nierarteriestenose door aderverkalking en fibromusculaire dysplasie met een typisch kralensnoer patroon.

Normale nierslagader

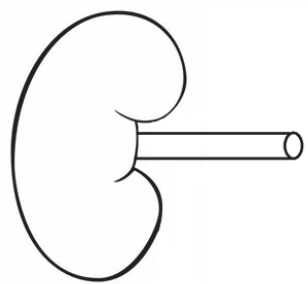

Nierarteriestenose door aderverkalking

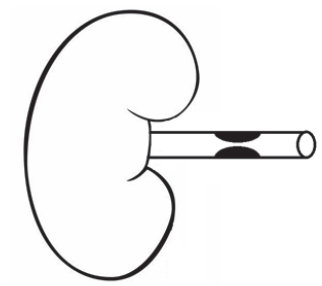

Fibromusculaire dysplasie

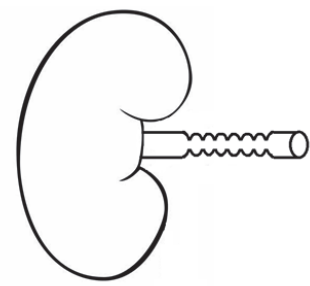

Verder ontdekten we in de hoofdstukken 6 en $\mathbf{7}$ dat de kwaliteit van het nierweefsel bij patiënten met fibromusculaire dysplasie relatief behouden is gebleven. De bloeddoorstroming en de nierfunctie (mate waarin de nier afvalstoffen kan uitscheiden) was namelijk vergelijkbaar met nieren van patiënten met hoge bloeddruk zonder vaatafwijkingen en een stuk beter dan bij nieren met een nierarteriestenose door aderverkalking. Daarnaast bleek dat de effecten van angiotensine II en angiotensine-(1-7) en van blokkeerders van deze angiotensines vergelijkbaar waren met de effecten bij patiënten zonder vaatafwijkingen. Dit in tegenstelling dus tot nieren van patiënten met een nierarteriestenose door aderverkalking, waarin het effect van angiotensine-(1-7) en een blokkeerder hiervan sterk verminderd is (zoals we in hoofdstuk 4 en in een eerdere studie ontdekten). Dit duidt erop dat het nierweefsel van patiënten met fibromusculaire dysplasie van betere kwaliteit is dan dat in nieren met een nierarteriestenose door aderverkalking. Bovendien functioneert het RAS (nog) normaal in deze nieren. Deze bevinding is wel interessant, met name omdat het effect van een dotterbehandeling op de bloeddruk bij patiënten met fibromusculaire dysplasie aanmerkelijk beter is dan bij patiënten met een nierarteriestenose door aderverkalking. Wij vermoeden dan ook dat de kwaliteit van het nierweefsel bepalend is voor de uitkomst van een dotterbehandeling. Immers, een kwalitatief goede nier is uiteindelijk na de dotterbehandeling weer in staat normaal te functioneren. 


\section{Belangrijkste conclusies uit dit proefschrift}

- Angiotensine-(1-7) induceert bloedvatverwijding in de nieren van patiënten met hoge bloeddruk.

- Het bloedvatverwijdende effect van angiotensine-(1-7) in de nieren van patiënten met hoge bloeddruk is verminderd bij activatie van het renine-angiotensine systeem als gevolg van een zoutarm dieet of toediening van angiotensine II.

- Het bloedvatverwijdende effect van eprosartan is niet afhankelijk van zoutinname en/of toediening van angiotensine II.

- Het bloedvatverwijdende effect van angiotensine-(1-7) is verminderd in nieren met een nierarteriestenose door aderverkalking.

- In nieren met fibromusculaire dysplasie is de nierfunctie en de werkzaamheid van het renine-angiotensine systeem relatief intact.

- Renine afgifte is niet verhoogd in nieren met fibromusculaire dysplasie.

- De mechanismen die tot hoge bloeddruk leiden verschillen tussen fibromusculaire dysplasie en nierarteriestenose door aderverkalking. 
Valorization addendum 


\section{Valorization addendum}

Research should not only be focused on gaining knowledge per se, but should in some way create value for the society. In this valorization addendum we describe how the findings presented in this thesis could provide relevant benefit for the general public.

\section{Cardiovascular disease is a socio-economic issue}

The focus in this thesis is on patients with high blood pressure (hypertension). As already discussed in Chapter 1, hypertension is a major threat for human society as it is the most important individual risk factor for death and affects more than 1 billion people worldwide. ${ }^{1-3}$ At least $7 \%$ of the disability-adjusted life years (the cumulative number of life years lost due to illness, disability, or early death) can be attributed to hypertension in the global population, thereby even beating tobacco smoking $(6.3 \%)$ and air pollution (4.3\%) in the top three of most important individual risk factors for disease burden. ${ }^{4}$ This disease burden consists predominately of cardiovascular diseases such as myocardial infarction and stroke. In Europe, the costs related to cardiovascular diseases were estimated on $€ 169$ billion annually in 2003 . $^{3} \mathrm{~A}$ recent report from Canada revealed that the average individual with hypertension had annual health care costs of $\$ 5768$, of which $\$ 2341$ were directly attributable to hypertension. ${ }^{5}$ Although health care costs (in- and outpatient care, costs of medications) account for most of the costs involved (62\%), a substantial part of these costs is not directly health care related: loss of productivity due to the inability to work represents $21 \%$ of these costs (i.e. more than $€ 35$ billion annually) and costs for informal care (e.g. by family members that care for the patient and therefore cannot contribute to society otherwise) represent $17 \%$ of these costs. ${ }^{3}$ As the global incidence of hypertension is still rising, ${ }^{6}$ one can expect that more and more people will suffer from hypertension related diseases in the upcoming decades. ${ }^{7,8}$ This will increase the already gigantic social and economic burden for the society even further. Fortunately, blood pressure reduction is able to decrease the incidence of cardiovascular disease (and subsequently reductions in death and disease burden). ${ }^{9,10}$ However, blood pressure remains above target despite treatment in more than $50 \%$ of patients with hypertension. ${ }^{11,12}$ These difficult-to-control patients therefore continue to be at risk for death and cardiovascular diseases.

\section{Understanding pathophysiological mechanisms}

The ultimate goal of cardiovascular research is the development of new, better therapeutic strategies and finding ways to select or diagnose those people who will 
benefit (in terms of prevention of death or morbidity) from these new strategies. To develop new diagnostic and therapeutic strategies, the first and most important step is to understand the pathophysiological mechanisms involved in a disease. From this knowledge, hypotheses can be formulated on how a disease could be cured or controlled. As the kidney and the renin-angiotensin system both play an important role in the regulation of blood pressure and thus in the development and maintenance of high blood pressure that is what we focused on in this thesis. Several findings in this thesis (for example the influence of sodium intake on the effects of angiotensin-(1-7) and on the effects $\mathrm{AT}_{1}$-receptor blocker eprosartan, the renin-angiotensin system in fibromuscular dysplasia, and the differences in pathophysiological mechanisms between fibromuscular dysplasia and atherosclerotic renal artery stenosis) provided us with more insight into the pathophysiological mechanisms involved in high blood pressure. Although the research in this thesis did not lead to a change in the treatment of difficult-to-treat hypertension yet, the increased understanding of pathophysiological mechanisms brings us a step closer to this ultimate goal. The implications of our findings are summarized in the paragraphs below.

\section{New pharmacotherapeutic strategies}

In the present thesis we demonstrated that angiotensin-(1-7), a peptide within the renin-angiotensin system, is able to increase renal blood flow (Chapter 2). Even in patients with difficult-to-control hypertension, angiotensin-(1-7) can induce vasodilation in the organ that plays a key role in blood pressure regulation: the kidney. This finding opens up opportunities for using the angiotensin-(1-7)-pathway as a therapeutic target in the treatment of difficult-to-control hypertension. As described in Chapter 4, promising progress has been made regarding the development of such drugs. One way to use angiotensin-(1-7) as a target could be to increase the levels of angiotensin-(1-7) in the circulation, for example by enhancing the activity of the enzyme ACE2 [which produces angiotensin-(1-7)] or by supplementation of angiotensin-(1-7) via an oral formula that releases angiotensin-(1-7) slowly to the circulation. Furthermore, drugs with similar actions as angiotensin-(1-7), i.e. so-called agonists which stimulate the same processes in the human body as angiotensin-(1-7), are currently under development. In animal models the abovementioned experimental drugs have already been evaluated. Interestingly, they did not only reduce blood pressure, ${ }^{13-15}$ but also had beneficial effects on atherosclerosis, kidney disease, and cardiac function, ${ }^{15-20}$ indicating that such drugs could also become a new treatment option for patients with other cardiovascular and/or kidney diseases besides high blood pressure. Our finding that angiotensin-(1-7) is able to exert these effects in patients with difficult-to-control hypertension as well (in spite of several changes that occur in the kidneys of such patients due to long term exposure to high blood pressure) indicates that these experimental drugs could be beneficial in humans. 
However, we also found that the effects of angiotensin-(1-7) (and not the effects of $\mathrm{AT}_{1}$-receptor blocker eprosartan; Chapter 5) are attenuated by low sodium intake, presence of high levels of angiotensin II (Chapter 2), and/or the presence of an atherosclerotic renal artery stenosis (Chapter 3 ). This suggests that the effectiveness of new drugs targeting the angiotensin-(1-7) pathway might be reduced under those conditions, which should be taken account during the further development of such drugs.

\section{The right treatment to the right patient at the right time}

Although renal artery fibromuscular dysplasia is quite prevalent among patients with high blood pressure (studies estimate a prevalence between 1.7 and 5.8\%), ${ }^{21,22}$ research on this disease is very scarce. Up till now, most knowledge on this disease is based on case-series and theoretical assumptions derived from other renovascular diseases. In this thesis we aimed to improve our understanding of the pathophysiological mechanisms in this relatively frequently occurring disease. Although the research in this thesis is only a first step towards further understanding the pathophysiological mechanisms involved, it does contribute already. For example, we demonstrated that renin secretion is not increased in kidneys with multifocal fibromuscular dysplasia (Chapters 6 and 7). Until recently, the clinical decision to perform balloon angioplasty in kidneys with fibromuscular dysplasia was often guided by the presence or absence of increased renin secretion: e.g. balloon angioplasty was only performed in kidneys with increased renin secretion. This practice was based on previous studies in patients with atherosclerotic renal artery stenosis and animal models, but not on research in patients with fibromuscular dysplasia. In our study, however, systemic renin levels were below the upper limit of normal in all 58 patients, while $48 \%$ of the patients had a decrease in blood pressure in response to balloon angioplasty. Moreover, no differences in renin secretion were found between responders and non-responders. This indicates that using renin secretion as a predictor for the effectiveness of balloon angioplasty is not a good strategy.

We furthermore demonstrated that the microvascular function in kidneys with fibromuscular dysplasia is better preserved as compared to kidneys with atherosclerotic renal artery stenosis. We hypothesized that this difference in microvascular function may be responsible for the difference in response to revascularization between patients with fibromuscular dysplasia and atherosclerotic renal artery stenosis. If this is indeed the case, this opens up opportunities for improving the selection of patients who will benefit from revascularization. If we will be able to develop a test that identifies the patients with sufficiently preserved renal microvascular function, we can select those patients for balloon angioplasty. The patients with too much loss of kidney tissue and/or severe microvascular dysfunction (e.g. due to too long exposure to high blood pressure) would probably not respond 
anymore and should be withheld from balloon angioplasty and, consequently, treated in a different way.

\section{Improving cost-effectiveness}

The abovementioned change in patient selection could improve cost-effectiveness in two ways:

First, rejecting patients with fibromuscular dysplasia for balloon angioplasty because of low renin levels leads to undertreatment. Based on the incorrect assumption that patients would only respond in case of increase renin secretion, balloon angioplasty was withheld in many patients. Since those patients did not receive a possibly curative intervention (based on unjustified grounds) they continue to be at risk for cardiovascular and kidney disease on the long term. Moreover, undertreatment leads to substantial economic burden due to additional costs for antihypertensive drugs and hospital visits.

Second, better selection of the patients improves the success rate of revascularization and reduces the number of unnecessary procedure-related complications and, probably even more importantly, the costs: Currently, the estimated costs for a balloon angioplasty without complications are $€ 3233$ : $€ 2154$ procedure-related costs, $€ 946$ for hospital admission, and $€ 133$ for other costs such as laboratory tests, travel costs, and productivity losses [costs were derived from a previous study ${ }^{23}$ and adjusted for annual inflation in the Netherlands (Statline, Statistics Netherlands)]. Given that $52 \%$ of the patients with fibromuscular dysplasia did not respond to balloon angioplasty (Chapter 6), a test that is able to identify the responders before balloon angioplasty is performed could already have saved almost $€ 100,000$ in our cohort of 58 patients only. If such test is not too expensive, it is very likely that cost-effectiveness will improve, especially when this can be applied on a larger scale, for example in patients with atherosclerotic renal artery stenosis as well.

\section{Conclusion}

In this thesis we performed research on the renin-angiotensin system in kidneys from hypertensive patients. In this way, we improved our knowledge in pathophysiological changes that occur in these kidneys. Although further research is required, the increased knowledge of the kidneys from patients with hypertension could lead to changes in diagnostic and therapeutic strategies. This research contributes to society as it eventually could lead to improved cost-effectiveness of current treatment strategies and to new strategies that potentially reduce death and morbidity in patients with hypertension, cardiovascular diseases, and kidney failure. 


\section{References}

1. Ezzati M, Riboli E. Behavioral and dietary risk factors for noncommunicable diseases. $N$ Engl J Med. 2013;369:954-964

2. Go AS, Mozaffarian D, Roger VL, Benjamin EJ, Berry JD, Blaha MJ, Dai S, Ford ES, Fox CS, Franco S, Fullerton HJ, Gillespie C, Hailpern SM, Heit JA, Howard VJ, Huffman MD, Judd SE, Kissela BM, Kittner SJ, Lackland DT, Lichtman JH, Lisabeth LD, Mackey RH, Magid DJ, Marcus GM, Marelli A, Matchar DB, McGuire DK, Mohler ER, 3rd, Moy CS, Mussolino ME, Neumar RW, Nichol G, Pandey DK, Paynter NP, Reeves MJ, Sorlie PD, Stein J, Towfighi A, Turan TN, Virani SS, Wong ND, Woo D, Turner MB. Heart disease and stroke statistics--2014 update: A report from the american heart association. Circulation. 2014;129:e28-e292

3. Leal J, Luengo-Fernandez R, Gray A, Petersen S, Rayner M. Economic burden of cardiovascular diseases in the enlarged european union. Eur Heart J. 2006;27:1610-1619

4. Lim SS, Vos T, Flaxman AD, Danaei G, Shibuya K, et al. A comparative risk assessment of burden of disease and injury attributable to 67 risk factors and risk factor clusters in 21 regions, 1990-2010: A systematic analysis for the global burden of disease study 2010. Lancet. 2012;380:2224-2260

5. Weaver CG, Clement FM, Campbell NR, James MT, Klarenbach SW, Hemmelgarn BR, Tonelli M, McBrien KA, Alberta Kidney Disease N, the Interdisciplinary Chronic Disease C. Healthcare costs attributable to hypertension: Canadian population-based cohort study. Hypertension. 2015;66:502-508

6. Kearney PM, Whelton M, Reynolds K, Muntner P, Whelton PK, He J. Global burden of hypertension: Analysis of worldwide data. Lancet. 2005;365:217-223

7. Allen N, Berry JD, Ning H, Van Horn L, Dyer A, Lloyd-Jones DM. Impact of blood pressure and blood pressure change during middle age on the remaining lifetime risk for cardiovascular disease: The cardiovascular lifetime risk pooling project. Circulation. 2012;125:37-44

8. Lozano R, Naghavi M, Foreman K, Lim S, Shibuya K, et al. Global and regional mortality from 235 causes of death for 20 age groups in 1990 and 2010: A systematic analysis for the global burden of disease study 2010. Lancet. 2012;380:2095-2128

9. Effects of treatment on morbidity in hypertension. Results in patients with diastolic blood pressures averaging 115 through $129 \mathrm{~mm}$ hg. JAMA. 1967;202:1028-1034

10. van Vark LC, Bertrand M, Akkerhuis KM, Brugts JJ, Fox K, Mourad JJ, Boersma E. Angiotensinconverting enzyme inhibitors reduce mortality in hypertension: A meta-analysis of randomized clinical trials of renin-angiotensin-aldosterone system inhibitors involving 158,998 patients. Eur Heart J. 2012;33:2088-2097

11. Banegas JR, Lopez-Garcia E, Dallongeville J, Guallar E, Halcox JP, Borghi C, Masso-Gonzalez EL, Jimenez FJ, Perk J, Steg PG, De Backer G, Rodriguez-Artalejo F. Achievement of treatment goals for primary prevention of cardiovascular disease in clinical practice across europe: The eurika study. Eur Heart $J$. 2011;32:2143-2152

12. Prugger C, Keil U, Wellmann J, de Bacquer D, de Backer G, Ambrosio GB, Reiner Z, Gaita D, Wood D, Kotseva K, Heidrich J, Group EIS. Blood pressure control and knowledge of target blood pressure in coronary patients across europe: Results from the euroaspire iii survey. J Hypertens. 2011;29:16411648

13. Singh Y, Singh K, Sharma PL. Effect of combination of renin inhibitor and mas-receptor agonist in docasalt-induced hypertension in rats. Mol Cell Biochem. 2013;373:189-194

14. Cunha TM, Lima WG, Silva ME, Souza Santos RA, Campagnole-Santos MJ, Alzamora AC. The nonpeptide ang-(1-7) mimic ave 0991 attenuates cardiac remodeling and improves baroreflex sensitivity in renovascular hypertensive rats. Life Sci. 2013;92:266-275

15. Bertagnolli M, Casali KR, De Sousa FB, Rigatto K, Becker L, Santos SH, Dias LD, Pinto G, Dartora DR, Schaan BD, Milan RD, Irigoyen MC, Santos RA. An orally active angiotensin-(1-7) inclusion compound and exercise training produce similar cardiovascular effects in spontaneously hypertensive rats. Peptides. 2013;51C:65-73

16. Fraga-Silva RA, Savergnini SQ, Montecucco F, Nencioni A, Caffa I, Soncini D, Costa-Fraga FP, De Sousa FB, Sinisterra RD, Capettini LA, Lenglet S, Galan K, Pelli G, Bertolotto M, Pende A, Spinella G, Pane B, Dallegri F, Palombo D, Mach F, Stergiopulos N, Santos RA, da Silva RF. Treatment with angiotensin-(17) reduces inflammation in carotid atherosclerotic plaques. Thromb Haemost. 2014;111 
17. Yang JM, Dong $M$, Meng $X$, Zhao YX, Yang XY, Liu XL, Hao PP, Li JJ, Wang XP, Zhang K, Gao F, Zhao XQ, Zhang MX, Zhang $Y$, Zhang C. Angiotensin-(1-7) dose-dependently inhibits atherosclerotic lesion formation and enhances plaque stability by targeting vascular cells. Arterioscler Thromb Vasc Biol. 2013;33:1978-1985

18. Qi Y, Zhang J, Cole-Jeffrey CT, Shenoy V, Espejo A, Hanna M, Song C, Pepine CJ, Katovich MJ, Raizada MK. Diminazene aceturate enhances angiotensin-converting enzyme 2 activity and attenuates ischemia-induced cardiac pathophysiology. Hypertension. 2013;62:746-752

19. Haber PK, Ye M, Wysocki J, Maier C, Haque SK, Batlle D. Angiotensin-converting enzyme 2independent action of presumed angiotensin-converting enzyme 2 activators: Studies in vivo, ex vivo, and in vitro. Hypertension. 2014

20. Fraga-Silva RA, Costa-Fraga FP, Murca TM, Moraes PL, Martins Lima A, Lautner RQ, Castro CH, Soares CM, Borges CL, Nadu AP, Oliveira ML, Shenoy V, Katovich MJ, Santos RA, Raizada MK, Ferreira AJ. Angiotensin-converting enzyme 2 activation improves endothelial function. Hypertension. 2013;61:1233-1238

21. Hendricks NJ, Matsumoto AH, Angle JF, Baheti A, Sabri SS, Park AW, Stone JR, Patrie JT, Dworkin L, Cooper CJ, Murphy TP, Cutlip DE. Is fibromuscular dysplasia underdiagnosed? A comparison of the prevalence of fmd seen in coral trial participants versus a single institution population of renal donor candidates. Vasc Med. 2014;19:363-367

22. Kuczera P, Wloszczynska E, Adamczak M, Pencak P, Chudek J, Wiecek A. Frequency of renal artery stenosis and variants of renal vascularization in hypertensive patients: Analysis of 1550 angiographies in one centre. J Hum Hypertens. 2009;23:396-401

23. van Helvoort-Postulart D, Dirksen CD, Nelemans PJ, Kroon AA, Kessels AG, de Leeuw PW, Vasbinder GB, van Engelshoven JM, Hunink MG. Renal artery stenosis: Cost-effectiveness of diagnosis and treatment. Radiology. 2007;244:505-513 
Dankwoord 


\section{Dankwoord}

Een proefschrift schrijven doe je nooit alleen. Ook dit proefschrift is tot stand gekomen dankzij de inzet en steun van heel veel verschillende mensen. Zonder anderen tekort te doen wil ik een aantal van hen hierbij in het bijzonder bedanken.

Prof. dr. A.A. Kroon, beste Bram. Toen ik in 2009 als geneeskundestudent bij jou op gesprek kwam voor een wetenschapsstage had ik nooit kunnen vermoeden dat dit zou leiden tot zo'n intensieve en langdurige samenwerking. Naast een onderzoeksstage kreeg ik een rol (-letje) in de patiëntenzorg, een combinatie die ik uiteindelijk tot op heden heb mogen voortzetten. Je deed een goed woordje voor me toen ik graag internist wilde worden en eenmaal bezig met mijn opleiding tot internist motiveerde jij me om het wetenschappelijk onderzoek weer op te pakken. Uiteindelijk heeft dit er toe geleid dat ik dit jaar niet alleen mijn promotieonderzoek afrond, maar ook internist-vasculair geneeskundige zal worden. De afgelopen jaren had ik al zeer plezierig met je samengewerkt in het onderzoek, maar de laatste twee jaar is onze samenwerking nog intensiever nu ik mij, met jou als opleider, verder specialiseer tot vasculair-geneeskundige. Hierbij krijg ik, behalve een uitstekende opleiding, veel vrijheid en ruimte om nieuwe dingen te proberen en verschillende zaken efficiënter te organiseren. Je deur staat hierbij letterlijk altijd open voor overleg, hetgeen ik zeer waardeer. Je recente benoeming tot hoogleraar heb je als uitstekende onderzoeker en opleider meer dan verdiend en het is een eer om de eerste te zijn die onder jouw leiding als hoogleraar promoveert. Ik hoop dan ook dat we onze samenwerking in de toekomst nog verder kunnen voortzetten.

Prof. dr. P.W. de Leeuw, beste Peter. Onze eerste kennismaking moet ergens in het voorjaar van 2008 zijn geweest. Ik moest na mijn coschap Interne Geneeskunde mondeling examen doen bij professor De Leeuw. Met een goede voorbereiding en een uitstekend oordeel van mijn coschapbegeleider zag ik dit met het volste vertrouwen tegemoet. Maar, na een kruisverhoor waarbij alle oorzaken van vitamine B12 deficiëntie de revue passeerden en 16 differentiaal diagnoses van een syncope werden benoemd (inclusief vertebrobasilaire insufficiëntie en conversiestoornis) was het oordeel twijfelachtig: "Met de hakken over de sloot, maar net voldoende". Mij enigszins verbaasd afvragend of ik het dan echt zo matig had gedaan luidde het antwoord "Syncope heeft wel meer differentiaal diagnoses en een coassistent mag best weten wélke worm een vitamine B12 deficiëntie veroorzaakt..." Enkele jaren later ontmoetten wij elkaar opnieuw toen ik bezig was met mijn wetenschapsstage. Behoorlijk bevreesd voor opnieuw veel (te) moeilijke vragen mocht ik toen mijn onderzoeksresultaten presenteren. Het oordeel was deze keer gelukkig veel positiever en leidde uiteindelijk tot een uitnodiging om ook na het behalen van mijn Masterdiploma (welk ik toevallig uit jouw handen mocht ontvangen) onderzoek te blijven doen binnen jouw groep. Hierbij heb ik veel geleerd van je enorme ervaring, 
zowel inhoudelijk wanneer het gaat over hypertensie, alsook op het wetenschappelijke vlak. Maar je vermogen om na een paar seconden nadenken een figuur te tekenen die 10 keer beter is dan die figuur waar ik avonden lang aan gepuzzeld heb, heeft volgens mij meer met kunst te maken. Ik hoop dat ik in de toekomst nog eens af en toe gebruik van mag maken van deze kunst. Bedankt voor de samenwerking in de afgelopen periode! En oh ja, die vitamine B12 consumerende worm...is het een diphyllobothrium latum?

Dr. A.J.H.M. Houben, beste Boy. Ook jou ken ik toch al wat langer. Het moet ergens in 2008 zijn geweest dat ik als coassistent voor het eerst bij een nierangiografie mocht meekijken. Ik, gehuld in operatiemuts en mondkapje, zag je druk bezig met allerlei interessante metingen. Desgevraagd kreeg ik uitvoerige uitleg over deze voor mij toen nog onbekende Xenon-metingen. Een maand of twee later keek ik opnieuw met een nierangiografie mee (opnieuw vermomd met muts en mondkapje) en vroeg je of ik niet iets wilde leren over de Xenon-meting. Je verbazing was groot toen ik 'zomaar' kon uitleggen hoe de Xenon-meting werkte. Twee jaar later, toen ik tijdens mijn wetenschapsstage mocht meehelpen met diezelfde Xenon-metingen, was je nog meer verbaasd dat ik, zonder dat je me ooit had 'gezien', precies wist waar alle apparatuur voor diende. Onmiddellijk wilde je weten van wie ik dat toch allemaal geleerd had... Uiteindelijk bleek dit het begin van een prettige samenwerking waarbij de Xenonmetingen nog steeds centraal staan. Als echte doctór tussen de soms wat eigenwijze dokters lever je hierbij vanuit een ander perspectief een belangrijke bijdrage aan dit onderzoek. Maar ook als het gaat om het sociale aspect ben je altijd beschikbaar. Hartelijk dank hiervoor!

Verder wil ik graag de co-auteurs uit dit proefschrift bedanken. Guy Mostard, al voor ik bij dit project betrokken werd heb je veel werk verricht voor de studies in hoofdstukken 2 en 3. Hierdoor kon ik een vliegende start maken die uiteindelijk leidde tot publicaties in fraaie tijdschriften. Prof. dr. M.W. de Haan en de gehele afdeling interventieradiologie wil ik bedanken voor de gelegenheid die wij elke keer weer krijgen om onze metingen te doen.

Daarnaast wil ik graag alle anderen die een rol hadden bij de studies in dit proefschrift bedanken. Op de eerste plaats natuurlijk de patiënten, die zich belangeloos beschikbaar hebben gesteld om verschillende extra metingen te ondergaan. Maar ook de medewerkers van het Circulatielab Interne Geneeskunde, die telkens maar weer ervoor zorgen dat iedereen op het juiste moment op de juiste plaats is wanneer weer metingen plaatsvinden en ervoor zorgen dat de patiënten worden geïnformeerd, zij zich aan het dieet houden, hun bloeddruk gemeten wordt en zij hun urine goed verzamelen. Bijzonder woord van dank aan Monique Fuss voor het verzamelen en opslaan van de vele bloedmonsters, maar ook zeker aan Claudia de Haan met wie ik 
met name de afgelopen twee jaar veel heb mogen samenwerken in het organiseren van nierangiografieën en andere klinische onderzoeken.

Ook wil ik graag de leden van de beoordelingscommissie Prof. dr. T. Unger, Prof. dr. A.H.J. Danser, dr. L.J. Schurgers en en prof. dr. J.E. Wildberger bedanken voor de beoordeling van mijn proefschrift. I would also like to thank Prof. dr. A. Persu for the assessment of my thesis.

Bijna vanzelfsprekend wil ik (net als vele van mijn voorgangers) Tiny Wouters bedanken voor de vele hulp bij opmaken van dit proefschrift.

Het onderzoek uit dit proefschrift heb ik altijd verricht naast mijn werk in de kliniek als internist in opleiding. Deze combinatie was nooit mogelijk geweest zonder een gedegen organisatie binnen de kliniek en een optimaal opleidingsklimaat. Graag wil ik dan ook iedereen bedanken die hieraan een bijdrage heeft geleverd. Natuurlijk mijn opleiders van de afdeling Interne Geneeskunde in het Maastrichts Universitair Medisch Centrum, prof. dr. C.D.A. Stehouwer en prof. dr. R.P. Koopmans, maar zeker ook alle Maastrichtse internisten en AIOS met wie ik de afgelopen jaren heb mogen samenwerken. Ook de internisten en AIOS uit het VieCuri Medisch Centrum wil ik bedanken voor de prettige tijd in Venlo, in het bijzonder mijn opleiders dr. A.J. Luik en dr. M.M.H. Hermans.

Graag wil ik ook mijn collega's van de afdeling Vasculaire Geneeskunde in Maastricht bedanken: vasculair-geneeskundigen Roger, Floris, Renske, Esther en Esther, mijn collega fellows Marion, Roel en Arne en natuurlijk ook Mariet en Angéle: Bedankt voor de zeer prettige samenwerking de afgelopen periode! Bijzonder woord van dank aan prof. dr. Hugo ten Cate, degene die niet alleen verreweg de meeste van mijn poli's superviseerde, maar bij wie ik lang geleden ook eens solliciteerde voor een onderzoeksstage. Na een uitgebreid gesprek verwees Hugo mij door naar Bram Kroon, want 'zijn onderzoek sluit veel beter aan bij jouw interesses'... Het resultaat hiervan ligt voor $u$.

Naast al het harde werken bleef er gelukkig ook tijd over om leuke te dingen te doen met mijn vrienden en familie. Dit bleek enorm belangrijk om de motivatie te behouden.

Allereerst de slagwerkers van Koninklijke Harmonie St. Caecilia uit Echt. Ooit begonnen als kleine mennekes die toevallig allemaal op trommel-les gingen zijn we uiteindelijk uitgegroeid tot een vriendengroep die niet alleen wekelijks de repetities onveilig maakt, maar daarbuiten inmiddels ook graag met de vrouwen en kinderen op stap gaat. Nu dit proefschrift is afgerond zal ik in elke geval proberen me tijdens de repetities wat minder bezig te houden met het lezen van wetenschappelijke artikelen. Jeroen en Wiro wil ik graag bedanken voor hun ondersteuning als paranimf. 
Verder dank aan de POL-ers voor alle gezellige (soms eindeloze) avonden op de bank, bij een kampvuur of bij 'de snor'. Hoewel het door drukte steeds moeilijker wordt om iedereen bij elkaar te krijgen hoop ik dat we dit nog vele jaren kunnen voortzetten.

Mijn ouders wil ik graag bedanken voor alle mogelijkheden en aanmoediging die ze mij hebben gegeven om mijn opleidingen en uiteindelijk ook deze promotie te voltooien. Mijn broers Stijn en Bas wil ik graag bedanken voor hun eindeloze pogingen mij af te leiden als ik weer teveel bezig ben met serieuze zaken.

Lieve Dex, mijn allerbeste vriend, jij wint zeker de eerste prijs als het gaat om wie het beste zijn pappa kan afleiden als ie weer van plan is aan zijn proefschrift te gaan werken. Je vrolijke lach en eindeloze zin om met pappa en mamma te spelen zijn zo aanstekelijk dat het vrijwel onmogelijk is om aan andere dingen toe te komen. Ga hier vooral mee door!

Lieve Stéphanie, de grootste steun die ik de afgelopen jaren heb gehad was zonder twijfel van jou. Als ik weer eens urenlang een database wilde verbouwen deed je voor hoe het ook in 5 minuten kon, als ik niet zoveel zin had in een buitenlands congres ging je gewoon met me mee en zelfs als ik als ik me weer op het meest onmogelijke project stortte stond jij altijd klaar om mee te helpen. Na eerst samen de wereld rond te hebben gereisd zijn we sinds kort aan een nieuwe reis begonnen als pappa en mamma. Ook die reis is weer fantastisch. Nu dit proefschrift af is hoop ik dat we nog vaker leuke dingen kunnen gaan doen met $z^{\prime} n$ drieën. 
Curriculum vitae 


\section{Curriculum vitae}

Daan van Twist was born on February 18, 1986 in Geleen, The Netherlands. He attended secondary school at Bisschoppelijk College in Echt and graduated in 2004. Thereafter he studied Medicine at Maastricht University, where he obtained his Bachelor's degree (cum laude) in 2007 and was awarded with the top 3\% student award several times. In 2009, the final year of his medical studies, he started doing scientific research into hypertension under supervision of dr. A.A. Kroon. After obtaining his Master's degree in 2010, he started his residency in Internal Medicine at Maastricht University Medical Centre (under supervision of prof. dr. C.D.A. Stehouwer and prof. dr. R.P. Koopmans) and Viecuri Medical Centre Venlo (supervisors dr. A.J. Luik and dr. M.M. Hermans). During his residency, he continued doing scientific research under supervision of prof. dr. A.A. Kroon, prof. dr. P.W. de Leeuw, and dr. A.J.H.M. Houben at the Department of Internal Medicine of Maastricht University Medical Centre. This work finally led to this PhD thesis. He will finish his residency in Internal Medicine as well as his subspecialization in Vascular Medicine (also under supervision of prof. dr. A.A. Kroon) in August 2016. Daan is married to Stéphanie Knoors and they have a son named Dex. 


\section{List of publications}




\section{List of publications}

Van Twist DJ, Houben AJ, De Leeuw PW, Kroon AA. Acute eprosartan-induced intrarenal vasodilation in hypertensive humans is not influenced by dietary sodium intake or angiotensin II co-infusion. J Hypertension 2016; in press.

Van Twist DJ, Houben AJ, De Haan MW, De Leeuw PW, Kroon AA. Renal hemodynamics and renin-angiotensin system activity in humans with multifocal renal artery fibromuscular dysplasia. J Hypertension 2016;34:1160-9.

Van Twist DJ, Dielis AW, Kroon AA. Hypertension at young age: beware of the unexpected. Neth J Med 2015;73(8):388-0.

Van Twist DJ, Kroon AA. Hypertension in the young patient - when to consider a secondary cause? (article in Dutch: Hypertensie bij de jonge patiënt - wanneer moet $u$ denken aan een secundaire oorzaak?). Huisarts en Wetenschap 2015; themanummer 2.

Van Twist DJ, Houben AJ, De Haan MW, Mostard GJ, De Leeuw PW, Kroon AA. Angiotensin-(1-7)-induced renal vasodilation is reduced in human kidneys with renal artery stenosis. J Hypertension 2014;32(12):2428-32.

Van Twist DJ, Kroon AA, De Leeuw PW. Angiotensin-(1-7) as a strategy in the treatment of hypertension. Curr Opin Nephrol Hypertens 2014;23(5):480-6.

Van Twist DJ, Houben AJ, De Haan MW, Mostard GJ, Kroon AA, De Leeuw PW. Angiotensin-(1-7) induced renal vasodilation in hypertensive humans is attenuated by low sodium intake and angiotensin II co-infusion. Hypertension 2013;62:789-93.

De Wolf MWP, Van Twist DJL, Marcus MAE. Perioperative hypertension (article in Dutch: Hypertensie rondom een operatie). A\&l nascholingstijdschrift voor operatieve geneeskunde 2013;5(2);33-39.

Van Twist DJ, Lobbes MB, Vanwetswinkel S, Stassen PM. An unexpected cause of chest pain. Penetrating aortic ulcer. Neth J Med 2012;70(4):192-6.

\section{Oral presentations}

Dutch Cardiovascular Conference 2016, Ede: Pathophysiological differences between multifocal fibromuscular dysplasia and atherosclerotic renal artery stenosis.

European Society of Hypertension (ESH) 2016, Paris (France): Pathophysiological differences between multifocal fibromuscular dysplasia and atherosclerotic renal artery stenosis. 
Joint Meeting of the Dutch, Belgian and Swiss Hypertension Societies 2015, Antwerp (Belgium): Renal hemodynamics and renin-angiotensin system activity in humans with renal artery fibromuscular dysplasia.

European Society of Hypertension (ESH) 2015, Milan (Italy): Renal microvasculature and renin secretion in humans with multifocal renal artery fibromuscular dysplasia.

Summer School European Society of Hypertension (ESH) 2015, Vienna (Austria): Renal hemodynamics and renin-angiotensin system activity in humans with renal artery fibromuscular dysplasia.

Vascular Rounds 2015, Thorn: Subclavian steal syndrome and fibromuscular dysplasia (case-report).

Dutch Hypertension Society (Nederlandse Hypertensie Vereniging) 2015, Zeist: Angiotensin-(1-7)-induced renal vasodilation is reduced in human kidneys with renal artery stenosis.

Dutch Cardiovascular Conference 2014, Ermelo: Intrarenal renin-angiotensin system activity in fibromuscular dysplasia.

Dutch Society of Internal Medicine (Internistendagen) 2014, Maastricht: Multi-organ toxicity due to chronic occupational heavy metal exposure (case-report).

European Society of Hypertension (ESH) 2013, Milan (Italy): Effects of Angiotensin(1-7) on renal blood flow in patients with renal artery stenosis.

Dutch Society of Internal Medicine (Internistendagen) 2012, Maastricht: An unexpected cause of chest pain (case-report)

European Society of Hypertension (ESH) 2012, London (United-Kingdom): Angiotensin(1-7) induced renal vasodilation in hypertensive humans is attenuated by low sodium intake and angiotensin II co-infusion.

European Society of Hypertension (ESH) 2010, Oslo (Norway): Influence of dietary sodium on renal nitric oxide inhibition and renal blood flow in hypertensive Caucasians 